\title{
Post thrombotic syndrome, exploring aspects of pathophysiology and personalized management
}

Citation for published version (APA):

Bouman, A. C. (2016). Post thrombotic syndrome, exploring aspects of pathophysiology and personalized management. [Doctoral Thesis, Maastricht University]. Uitgeverij BOXPress. https://doi.org/10.26481/dis.20160218ab

Document status and date:

Published: 01/01/2016

DOI:

10.26481/dis.20160218ab

Document Version:

Publisher's PDF, also known as Version of record

\section{Please check the document version of this publication:}

- A submitted manuscript is the version of the article upon submission and before peer-review. There can be important differences between the submitted version and the official published version of record.

People interested in the research are advised to contact the author for the final version of the publication, or visit the DOI to the publisher's website.

- The final author version and the galley proof are versions of the publication after peer review.

- The final published version features the final layout of the paper including the volume, issue and page numbers.

Link to publication

\footnotetext{
General rights rights.

- You may freely distribute the URL identifying the publication in the public portal. please follow below link for the End User Agreement:

www.umlib.nl/taverne-license

Take down policy

If you believe that this document breaches copyright please contact us at:

repository@maastrichtuniversity.nl

providing details and we will investigate your claim.
}

Copyright and moral rights for the publications made accessible in the public portal are retained by the authors and/or other copyright owners and it is a condition of accessing publications that users recognise and abide by the legal requirements associated with these

- Users may download and print one copy of any publication from the public portal for the purpose of private study or research.

- You may not further distribute the material or use it for any profit-making activity or commercial gain

If the publication is distributed under the terms of Article $25 \mathrm{fa}$ of the Dutch Copyright Act, indicated by the "Taverne" license above, 


\section{Post thrombotic syndrome,}

\section{exploring aspects of pathophysiology and personalized management}


The research presented in this thesis was funded by the Netherlands Organization for Health Research and Development (ZonMw), grant number 171102007.

Printing and dissemination of this thesis was financially supported by medi Nederland BV, firma Oldekamp, and Leo Pharma.
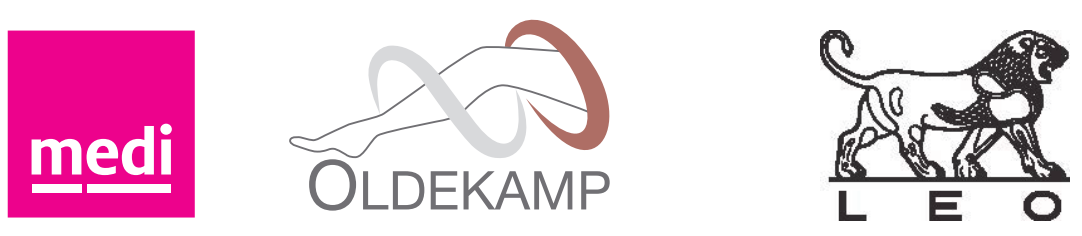

(C) Annemieke Bouman

No part of this book may be reproduced or transmitted in any form or by any means, without permission of the author. For all articles published or accepted the copyright has been transferred to the respective publisher.

Cover: Arie Bouman

Layout: Tiny Wouters

Printed by: Proefschriftmaken.nl || Uitgeverij BOXPress

ISBN: 9789462954359 


\title{
Post thrombotic syndrome, exploring aspects of pathophysiology and personalized management
}

\author{
PROEFSCHRIFT \\ ter verkrijging van de graad van doctor aan de Universiteit Maastricht, \\ op gezag van de Rector Magnificus, Prof. dr. L.L.G. Soete, \\ volgens het besluit van het College van Decanen, \\ in het openbaar te verdedigen \\ op donderdag 18 februari 2016 om 14.00 uur \\ door
}

Annemieke Clementine Bouman 
Promotor:

Prof. dr. H. ten Cate

\section{Copromotores:}

Dr. A.J. ten Cate-Hoek

Dr. M.A. Joore

Beoordelingscommissie:

Prof. dr. A.E. Boonen (voorzitter)

Dr. B.A. Essers

Prof. dr. M.V. Huisman (LUMC, Leiden)

Prof. dr. K. Meijer (UMCG, Groningen)

Prof. dr. P.M. Steijlen 
"A drop of love is more than an ocean of intellect." Blaise Pascal 



\section{Contents}

Chapter 1 General introduction 9

$\begin{array}{lll}\text { Part I } & \text { Pathophysiology of post thrombotic syndrome } & 17\end{array}$

Chapter 2 Markers of coagulation, fibrinolysis and inflammation in relation 19 to post thrombotic syndrome

Chapter $3 \quad$ Biomarkers for post thrombotic syndrome 33

Chapter 4 Biomarkers for post thrombotic syndrome: a case-control study 51

Chapter 5 Clot structure and fibrinolytic potential in patients with 67 post thrombotic syndrome

Part II Personalized management of post thrombotic syndrome $\quad 83$

Chapter 6 Timing and duration of compression therapy after deep 85 vein thrombosis

Chapter 7 The IDEAL DVT study, individualized duration elastic compression therapy against long-term duration of therapy for the prevention of post thrombotic syndrome: protocol of a randomized controlled trial

Chapter 8 Sample size estimation for non-inferiority trials: frequentist approach versus decision theory approach

Chapter 9 Eliciting patients' preferences for elastic compression stocking therapy in patients after deep vein thrombosis: a potential for improving compliance

Part III Discussion

Chapter 10 Summary and general discussion

Part IV Addendum

Samenvatting

Valorization

Curriculum Vitae

List of publications

Dankwoord 



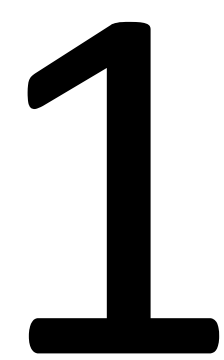

General introduction 
Deep vein thrombosis (DVT) of the leg is a prevalent disease with an incidence of 1-2 per 1000 persons per year. ${ }^{1-3}$ DVT is associated with complications, of which pulmonary embolism (PE) is probably the most well-known. Post thrombotic syndrome (PTS) is less familiar to the average clinician. PTS is a long-term complication of DVT. Twenty to fifty percent of patients develop PTS, usually within two years after DVT. $^{4-7}$ Patients with PTS experience complaints of heaviness, pain, cramps, itching, tingling, and/or swelling of the leg that was affected by the DVT. These complaints usually worsen with walking or standing and decrease with rest. Severity of complaints differs among patients, but also varies over time. ${ }^{4}$ About $5 \%$ of DVT patients develop severe PTS, with (chronic) ulceration of the leg. ${ }^{4-6}$

PTS is a syndrome, a compilation of clinical phenomena that usually occur together. There is no gold standard diagnostic test for PTS. Therefore, clinical scales are used for diagnosing PTS and rating of its severity. Several scoring systems for PTS have been described: the Widmer classification, CEAP classification, venous clinical severity (VCS), classification by Brandjes, and the Villalta scale. ${ }^{8}$ For reasons of standardization the scientific and standardization committee (SSC) of the international society on thrombosis and haemostatis (ISTH) recommended the use of the Villalta scale for diagnosing PTS, especially in clinical studies. ${ }^{9}$ The Villalta scale was developed by Prandoni and colleagues in the nineties of the previous century. ${ }^{10,11}$ It was first described in a cohort of 100 patients 6 to 36 months after venography confirmed DVT. Presence and severity of signs and symptoms of PTS were scored by two independent physicians. Another independent physician scored interference of PTS with daily life, using a standardized questionnaire. Apart from a good reproducibility $(\kappa=0.78)$, the scale appeared to correlate well with the interference of the leg complaints with daily life as perceived by the patients. After publication of these results in an abstract, the clinical scale became known as the Villalta scale. ${ }^{11}$ The Villalta scale consists of five patient-rated symptoms: pain; heaviness; cramps; paraesthesia; and pruritus, and six clinician-rated signs: pretibial edema; skin induration; hyperpigmentation; redness; venous ectasia; and pain on calf compression. The symptoms and signs are rated: none (zero points), mild (one point), moderate (two points), or severe (three points), and all points are summed up. ${ }^{5,10,11}$ Diagnosis of PTS according to the Villalta scale is originally defined as two consecutive Villalta scores of $\geq 5$ with a minimum interval of three months between the two assessments. ${ }^{10}$ The SSC recommended in 2008 to diagnose PTS on a single Villalta score of $\geq 5$ or the presence of a venous ulcer. ${ }^{9}$ The studies described in this thesis adhere to the original definition, thus PTS is defined as a Villalta score of $\geq 5$ on two consecutive visits that were at least three months apart.

\section{Etiology of post thrombotic syndrome}

The exact etiology of PTS is not yet clear. According to the leading theory, the signs and symptoms of PTS are the manifestations of chronic venous insufficiency due to 
venous hypertension. Venous hypertension is thought to be caused by a combination of (1) venous outflow obstruction, (2) valvular incompetence, and (3) stiffening of the vein walls.

(1) Poor recanalization after thrombosis causes blockage of the vein and subsequent venous outflow resistance. ${ }^{12}$

(2) Destruction of the venous valves occurs by entrapment of the valves within the thrombus or their approximation against the vein wall. ${ }^{13}$ The release of free radicals and proteolytic enzymes by leukocytes involved in thrombus resolution also damages the venous valves. Dysfunction of venous valves allows reflux of venous blood. $^{14}$

(3) Thrombus resolution is accompanied by an inflammatory process. Inflammation directs tissue remodelling and fibrosis, ultimately resulting in stiff and noncompliant vein walls. ${ }^{14}$

Venous outflow obstruction, reflux of blood, and stiff non-compliant vein walls increase venous pressure. Transmission of the increased venous pressure to the microcirculation causes extravasation of large molecules, leukocytes, and erythrocytes. The extravasated molecules and breakdown products of the extravasated erythrocytes induce chronic inflammation of the dermal interstitium, leading to skin changes. ${ }^{15}$ Increased filtration of plasma due to the increased hydrostatic pressure causes edema. ${ }^{16}$ Complaints of heaviness of the leg, especially after prolonged standing or walking, are thought to be the consequence of increased intracompartimental and subcutaneous volume and pressure, while pain during walking is thought to result from obstruction of the venous system. ${ }^{16}$ Via complex and largely unresolved mechanisms, these processes can ultimately result in chronic ulceration of the leg. ${ }^{17,18}$

It is not clear why only a subset of patients develop PTS after DVT. There are some established risk factors for PTS. High BMI, ${ }^{19-23}$ recurrent or previous ipsilateral DVT, ${ }^{4,5,7,23,24}$ iliofemoral or proximal DVT as opposed to distal DVT, ${ }^{4,25-27}$ subtherapeutic INRs, ${ }^{20,23,28,29}$ residual thrombosis, ${ }^{20,30-32}$ and pre-existent venous insufficiency ${ }^{6,20}$ all increase the risk of PTS. Increasing age was found to be a risk factor for PTS in some studies, ${ }^{4,6,7,23}$ although other studies did not confirm this association. ${ }^{21,27,33}$

There is no effective treatment for PTS. Although several surgical and endovascular techniques were found to have some positive effect in patients with moderate to severe PTS, these techniques have only been studied in small, non-randomized studies. $^{34}$ Furthermore, various veno-active drugs have been described to reduce complaints of venous insufficiency, which is closely related to PTS. However, the effectiveness of veno-active drugs have not been shown in large randomized studies. $^{35,36}$ 


\section{Management of post thrombotic syndrome}

Lacking an effective treatment, prevention of PTS in patients after DVT is crucial. Elastic compression stocking therapy (ECS) therapy is the cornerstone of PTS prevention. Besides ECS therapy, there might be a role for catheter-directed thrombolysis in selected groups of patients. A first randomized controlled trial on this subject showed that catheter-directed thrombolysis $(n=90)$ renders a $14.4 \%$ absolute risk reduction of PTS compared to standard treatment $(n=90)$, at the expense of 20 bleeding complications related to the thrombolysis. ${ }^{37}$ However, additional trials are needed to clearly establish the role of catheter-directed thrombolysis in the prevention of PTS.

This thesis focuses on ECS therapy in the management of PTS. Two randomized studies found a $23-39 \%$ absolute risk reduction of PTS when patients wore ECS for two years after DVT, in comparison to the control group that did not receive ECS therapy. ${ }^{7,38}$ The recommendation to use ECS for two years after DVT is mainly based on these two studies. ${ }^{39}$ Recently, a placebo-controlled trial found no difference in PTS incidence between active ECS for two years compared to placebo ECS for two years. ${ }^{40}$ This study stirs up the debate on the customary use of ECS after DVT, underlining the need for additional research. Probably, two years of ECS therapy is not necessary for every patient, and duration of therapy could be personalized or individually tailored, which could reduce costs and increase patients' well-being. The costs of ECS therapy after DVT are substantial. In the Netherlands, the yearly costs amount to about $€ 2.5$ million for stockings $(25,000$ patients $x € 100)$ and $€ 21$ million for homecare to apply and take off the stocking in a subset of patients $(7.5 \%$ of 25,000 patients $x 500$ visits $x$ $€ 20) .{ }^{41-43}$ In addition, most patients experience ECS therapy as very unpleasant, because the ECS is tight, warm, and considered unfashionable. Also, the ECS is difficult to apply and take off, and a subset of patients will need home care to assist in the use of the ECS. ${ }^{42}$ Such an unpleasant therapy might be easier to endure, when noticing a clear benefit to one's health. Only a subset of patients feels that the ECS supports the leg and decreases complaints. However, over $50 \%$ of patients after DVT do not experience any or only mild complaints of the leg. For those patients, the risk reduction of PTS is the only benefit of therapy. A personal feeling of being at risk is often related to physical signs or symptoms and not to population-derived probabilities. ${ }^{44}$ The way patients perceive their risk of developing PTS, will influence the risk-benefit trade-off they make when deciding to (continue to) use ECS therapy. This could affect compliance to ECS therapy.

Individually tailoring the duration of ECS therapy reduces therapy duration in those patients that do not experience complaints and do not have signs of PTS, because the risk of developing PTS is probably substantially lower in these patients. Individually tailored duration of ECS therapy could reduce costs substantially and might be a superior alternative to either abandoning ECS therapy after DVT altogether, or to two years ECS therapy for every patient. 
It is worthwhile to investigate whether the potential increase in PTS risk of individually tailored duration of ECS therapy does not outweighs its advantages. A randomized controlled non-inferiority trial is needed to compare individually tailored duration of ECS therapy with two years ECS therapy for the prevention of PTS. Costs, costeffectiveness, and (reasons for) compliance to ECS therapy should be measured additionally in this study. However, for such a trial the traditional frequentist approach of sample size calculation for non-inferiority trials may fall short, as it does not include aspects of costs or other health consequences, apart from the main clinical outcome.

\section{Outline of the thesis}

In this thesis aspects of pathophysiology and personalized management of post thrombotic syndrome are explored.

Part I - Pathophysiology of the post thrombotic syndrome summarizes some aspects regarding the etiology of PTS. Chapters $\mathbf{2}$ and $\mathbf{4}$ describe two studies in which levels of biomarkers are compared between patients with and without PTS. Chapter 3 is a systematic review on biomarkers and post thrombotic syndrome in humans. In chapter 5 fibrinolysis and clot structure in patients with and without PTS are investigated.

The prevention of PTS is discussed in part II - Personalized management of post thrombotic syndrome. In chapter 6 the literature on compression therapy for the prevention of PTS in the acute as well as the long-term phase after DVT is reviewed. Chapter $\mathbf{7}$ is a detailed description of the protocol of the IDEAL DVT study: a randomized controlled trial on individually tailored duration of ECS therapy, compared to standard duration of two years ECS therapy for the prevention of PTS after DVT. Chapter 8 questions the use of traditional frequentist methods to estimate sample size for non-inferiority trials, as this method ignores many relevant factors, like costs and health consequences besides the main clinical outcome. As an alternative, the decision analytical approach, which is able to incorporate all relevant factors, is proposed. Both methods are applied to the sample size estimation of the IDEAL DVT study. Little is known regarding patient preferences of ECS therapy in patients after DVT, and how this influences compliance to therapy. Chapter 9 describes the results of a discrete choice experiment that was performed to investigate what characteristics of ECS therapy in patients after DVT affect their preferences, in a subset of the study population of the IDEAL DVT study.

Finally chapter 10, Summary and general discussion, provides a discussion of the main findings of this thesis. Discrepancies between results of this thesis and other studies are described and discussed. Furthermore, implications for clinic and future research are given. 


\section{References}

1. Anderson FA Jr, Wheeler HB, Goldberg RJ, Hosmer DW, Patwardhan NA, Jovanovic B, Forcier A, Dalen JE. A population-based perspective of the hospital incidence and case-fatality rates of deep vein thrombosis and pulmonary embolism. The Worcester DVT Study. Arch Intern Med 1991;151:933-8.

2. Cogo A, Lensing AW, Prandoni $P$, Hirsh J. Distribution of thrombosis in patients with symptomatic deep vein thrombosis. Implications for simplifying the diagnostic process with compression ultrasound. Arch Intern Med 1993;153:2777-80.

3. Nordstrom M, Lindblad B, Bergqvist D, Kjellstrom T. A prospective study of the incidence of deep-vein thrombosis within a defined urban population. J Intern Med 1992;232:155-60.

4. Kahn SR, Shrier I, Julian JA, Ducruet T, Arsenault L, Miron MJ, Roussin A, Desmarais S, Joyal F, Kassis J, Solymoss S, Desjardins L, Lamping DL, Johri M, Ginsberg JS. Determinants and time course of the postthrombotic syndrome after acute deep venous thrombosis. Ann Intern Med 2008;149:698-707.

5. Prandoni P, Lensing AW, Cogo A, Cuppini S, Villalta S, Carta M, Cattelan AM, Polistena P, Bernardi E, Prins $\mathrm{MH}$. The long-term clinical course of acute deep venous thrombosis. Ann Intern Med 1996;125: 1-7.

6. Schulman S, Lindmarker $P$, Holmstrom M, Larfars $G$, Carlsson A, Nicol P, Svensson E, Ljungberg B, Viering S, Nordlander S, Leijd B, Jahed K, Hjorth M, Linder O, Beckman M. Post-thrombotic syndrome, recurrence, and death 10 years after the first episode of venous thromboembolism treated with warfarin for 6 weeks or 6 months. J Thromb Haemost 2006;4:734-42.

7. Prandoni $P$, Lensing AW, Prins MH, Frulla M, Marchiori A, Bernardi E, Tormene D, Mosena L, Pagnan A, Girolami A. Below-knee elastic compression stockings to prevent the post-thrombotic syndrome: a randomized, controlled trial. Ann Intern Med 2004;141:249-56.

8. Kolbach DN, Neumann HA, Prins MH. Definition of the post-thrombotic syndrome, differences between existing classifications. Eur J Vasc Endovasc Surg 2005;30:404-14.

9. Kahn SR, Partsch H, Vedantham S, Prandoni P, Kearon K. Definition of post-thrombotic syndrome of the leg for use in clinical investigations: a recommendation for standardization. J Thromb Haemost 2009; 7: 879-83.

10. Prandoni P. The Diagnostic and Therapeutic Management of Deep-Vein Thrombosis and its Sequelae, in Department of Internal medicine. 1992, University of Amsterdam: Amsterdam.

11. Villalta S, Bagatella P, Picolli A, Lensing A, Prins M, Prandoni P. Assessment of validity and reproducibility of a clinical scale for the post thrombotic syndrome (abstract). Haemostasis 1994: 158a.

12. Neglen P. Chronic deep venous obstruction: definition, prevalence, diagnosis, management. Phlebology 2008;23:149-57.

13. Phillips LJ 2nd, Sarkar R. Molecular characterization of post-thrombotic syndrome. J Vasc Surg 2007; 45 Suppl A: A116-22.

14. Henke PK, Comerota AJ. An update on etiology, prevention, and therapy of postthrombotic syndrome. J Vasc Surg 2011;53:500-9.

15. Pappas PJ, Lal BK, Cerveira JJ, Padberg FT Jr, Duran WN. Causes of severe chronic venous insufficiency. Semin Vasc Surg 2005;18:30-5.

16. Eberhardt RT, Raffetto JD. Chronic venous insufficiency. Circulation 2014;130:333-46.

17. Chen WY, Rogers AA. Recent insights into the causes of chronic leg ulceration in venous diseases and implications on other types of chronic wounds. Wound Repair Regen 2007;15:434-49.

18. Gemmati D, Tognazzo S, Serino ML, Fogato L, Carandina S, De Palma M, Izzo M, De Mattei M, Ongaro A, Scapoli GL, Caruso A, Liboni A, Zamboni P. Factor XIII V34L polymorphism modulates the risk of chronic venous leg ulcer progression and extension. Wound Repair Regen 2004;12:512-7.

19. Ageno W, Piantanida E, Dentali F, Steidl L, Mera V, Squizzato A, Marchesi C, Venco A. Body mass index is associated with the development of the post-thrombotic syndrome. Thromb Haemost 2003;89: 305-9.

20. Galanaud JP, Holcroft CA, Rodger MA, Kovacs MJ, Betancourt MT, Wells PS, Anderson DR, Chagnon I, Le Gal G, Solymoss S, Crowther MA, Perrier A, White RH, Vickars LM, Ramsay T, Kahn SR. Predictors of post-thrombotic syndrome in a population with a first deep vein thrombosis and no primary venous insufficiency. J Thromb Haemost 2013; 11(3): 474-80. 
21. Kahn SR, Kearon C, Julian JA, Mackinnon B, Kovacs MJ, Wells P, Crowther MA, Anderson DR, Van Nguyen P, Demers C, Solymoss S, Kassis J, Geerts W, Rodger M, Hambleton J, Ginsberg JS; Extended Low-intensity Anticoagulation for Thrombo-embolism (ELATE) Investigators. Predictors of the postthrombotic syndrome during long-term treatment of proximal deep vein thrombosis. J Thromb Haemost 2005;3:718-723.

22. Kahn SR, Shbaklo H, Lamping DL, Holcroft CA, Shrier I, Miron MJ, Roussin A, Desmarais S, Joyal F, Kassis J, Solymoss S, Desjardins L, Johri M, Ginsberg JS. Determinants of health-related quality of life during the 2 years following deep vein thrombosis. J Thromb Haemost 2008; 6(7): 1105-12.

23. van Dongen $\mathrm{CJ}$, Prandoni P, Frulla M, Marchiori A, Prins MH, Hutten BA. Relation between quality of anticoagulant treatment and the development of the postthrombotic syndrome. J Thromb Haemost 2005;3:939-42.

24. Beyth RJ, Cohen AM, Landefeld CS. Long-term outcomes of deep-vein thrombosis. Arch Intern Med 1995;155:1031-7.

25. Meissner MH, Caps MT, Zierler BK, Polissar N, Bergelin RO, Manzo RA, Strandness DE Jr. Determinants of chronic venous disease after acute deep venous thrombosis. J Vasc Surg 1998;28:826-33.

26. Mohr DN, Silverstein MD, Heit JA, Petterson TM, O'Fallon WM, Melton LJ. The venous stasis syndrome after deep venous thrombosis or pulmonary embolism: a population-based study. Mayo Clin Proc 2000; 75:1249-56.

27. Stain M, Schonauer V, Minar E, Bialonczyk C, Hirschl M, Weltermann A, Kyrle PA, Eichinger S. The post-thrombotic syndrome: risk factors and impact on the course of thrombotic disease. J Thromb Haemost 2005;3:2671-6.

28. Chitsike RS, Rodger MA, Kovacs MJ, Betancourt MT, Wells PS, Anderson DR, Chagnon I, LE Gal G, Solymoss S, Crowther MA, Perrier A, White RH, Vickars LM, Ramsay T, Kahn SR. Risk of postthrombotic syndrome after subtherapeutic warfarin anticoagulation for a first unprovoked deep vein thrombosis: results from the REVERSE study. J Thromb Haemost 2012;10:2039-44.

29. Ziegler S, Schillinger M, Maca TH, Minar E. Post-thrombotic syndrome after primary event of deep venous thrombosis 10 to 20 years ago. Thromb Res 2001;101:23-33.

30. Gonzalez-Fajardo JA, Martin-Pedrosa M, Castrodeza J, Tamames S, Vaquero-Puerta C. Effect of the anticoagulant therapy in the incidence of post-thrombotic syndrome and recurrent thromboembolism: Comparative study of enoxaparin versus coumarin. J Vasc Surg 2008;48:953-9.

31. Prandoni $P$, Lensing AW, Prins $M H$, Bernardi E, Marchiori A, Bagatella P, Frulla M, Mosena L, Tormene $D$, Piccioli A, Simioni $P$, Girolami A. Residual venous thrombosis as a predictive factor of recurrent venous thromboembolism. Ann Intern Med 2002;137:955-60.

32. Piovella F, Crippa L, Barone M, Viganò D'Angelo S, Serafini S, Galli L, Beltrametti C, D'Angelo A. Normalization rates of compression ultrasonography in patients with a first episode of deep vein thrombosis of the lower limbs: association with recurrence and new thrombosis. Haematologica 2002; 87:515-22.

33. Kahn SR, Hirsch A, Shrier I. Effect of postthrombotic syndrome on health-related quality of life after deep venous thrombosis. Arch Intern Med 2002;162:1144-8.

34. Bond RT, Cohen JM, Comerota A, Kahn SR. Surgical treatment of moderate-to-severe post-thrombotic syndrome. Ann Vasc Surg 2013;27:242-58.

35. Pittler $\mathrm{MH}$, Ernst E. Horse chestnut seed extract for chronic venous insufficiency. Cochrane Database Syst Rev 2006(1):CD003230.

36. Morling JR, Yeoh SE, Kolbach DN. Rutosides for prevention of post-thrombotic syndrome. Cochrane Database Syst Rev 2013;4:CD005626.

37. Watson L, Broderick C, Armon MP. Thrombolysis for acute deep vein thrombosis. Cochrane Database Syst Rev 2014; 1: CD002783.

38. Brandjes DP, Buller HR, Heijboer H, Huisman MV, de Rijk M, Jagt H, ten Cate JW. Randomised trial of effect of compression stockings in patients with symptomatic proximal-vein thrombosis. Lancet 1997; 349:759-62.

39. СВО. СВO Richtlijn Diagnostiek, preventie en behandeling van veneuze trombo-embolie en secundaire preventie van arteriele trombose, ed. K.v.d.G. CBO. 2008, Utrecht: Kwaliteitsinstituut voor de Gezondheidszorg СВO. 
40. Kahn SR, Shapiro S, Wells PS, Rodger MA, Kovacs MJ, Anderson DR, Tagalakis V, Houweling AH, Ducruet T, Holcroft C, Johri M, Solymoss S, Miron MJ, Yeo E, Smith R, Schulman S, Kassis J, Kearon C, Chagnon I, Wong T, Demers C, Hanmiah R, Kaatz S, Selby R, Rathbun S, Desmarais S, Opatrny L, Ortel $\mathrm{TL}$, Ginsberg JS. Compression stockings to prevent post-thrombotic syndrome: a randomised placebocontrolled trial. Lancet 2014;383:880-8.

41. Blattler W. Aspects of cost effectiveness in therapy of acute leg/pelvic vein thrombosis. Wien Med Wochenschr 1999;149:61-5.

42. Gelderblom GJ, Hagedoorn-Meuwissen eav. Kousen uittrekhulpmiddel Easy-Lever. Een onderzoek naar bruikbaarheid, effecten en belemmeringen, in opdracht van ZonMw. 2005(juni).

43. Raju S, Hollis K, Neglen P. Use of compression stockings in chronic venous disease: patient compliance and efficacy. Ann Vasc Surg 2007;21:790-5.

44. Salant T, Ganschow PS, Olopade OI, Lauderdale DS. "Why take it if you don't have anything?" breast cancer risk perceptions and prevention choices at a public hospital. J Gen Intern Med 2006;21:779-85 


\section{Part I}

Pathophysiology of post thrombotic syndrome 


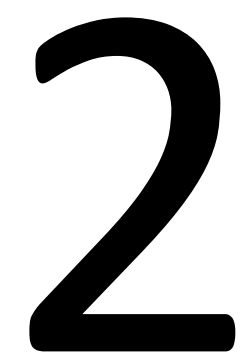

\section{Markers of coagulation, fibrinolysis and inflammation in relation to post thrombotic syndrome}

AC Bouman, JJM Smits, $\mathrm{H}$ ten Cate, AJ ten Cate-Hoek Journal of Thrombosis and Haemostasis 2012;10:1532-1538 


\section{Abstract}

\section{Background}

Post thrombotic syndrome (PTS) occurs in $20-50 \%$ of patients after deep vein thrombosis (DVT). It is difficult to accurately predict which patients will develop PTS. Biomarkers could be a valuable tool for PTS risk assessment.

\section{Objectives}

To investigate whether increased levels of factor (F)VIII, C-reactive protein (CRP), or D-dimer, over time, are associated with the development of PTS in patients after acute DVT.

\section{Methods}

PTS status was assessed using the Villalta scale. Blood sampling was performed at three points during follow-up.

\section{Results}

A cohort of 228 consecutive patients were included after an acute DVT. At T1 (twelve months after index DVT), both levels of D-dimer (median $725 \mathrm{ng} / \mathrm{ml}$ [interquartile range, IQR 400-1400] versus $378 \mathrm{ng} / \mathrm{ml}$ [IQR 251-652] $\mathrm{p}=0.004$ ) and CRP (median $3.9 \mathrm{mg} / \mathrm{I}$ [IQR 1.6-8.5] versus $2.4 \mathrm{mg} / \mathrm{I}$ [IQR 1.0-4.3] $\mathrm{p}=0.018$ ) were increased in patients with PTS, compared with patients without PTS. FVIII was not associated with PTS. In the multivariate logistic regression analysis, varicosities (odds ratio (OR) 13.4 [95\% confidence interval $(\mathrm{Cl}) 3.0-59.1] \mathrm{p}=0.001$ ), previous ipsilateral DVT (OR 6.3 [95\% Cl 1.5-26.9] $\mathrm{p}=0.012$ ), and CRP $>5 \mathrm{mg} / \mathrm{l}$ on T1 (OR $8.0[95 \% \mathrm{Cl}$ 2.4-26.4] $\mathrm{p}=0.001$ ) were significantly associated with PTS.

\section{Conclusions}

Besides previous ipsilateral DVT and varicosities, CRP $>5 \mathrm{mg} / \mathrm{l}$ at $\mathrm{T} 1$ was strongly and independently associated with PTS. Persistent inflammation rather than hypercoagulability might be the most important etiological factor in PTS, and may be a target for future therapy. The development of a risk score for PTS, including both clinical risk factors and biomarker levels, such as CRP, might be desirable. 


\section{Introduction}

Post thrombotic syndrome (PTS) is a common chronic complication of deep vein thrombosis (DVT) of the leg. PTS is a clinical syndrome characterized by symptoms of pain, itching, tingling, heaviness, or swelling of the leg affected by the DVT. The symptoms typically increase while standing or walking, and decrease with rest. ${ }^{1-3}$ As many as $20 \%$ to $50 \%$ of patients develop PTS after an event of DVT, in most cases within a period of two years. ${ }^{1,3-6}$ The use of elastic compression stockings following DVT has been associated with a $50 \%$ relative reduction of the incidence of PTS, if compression stockings are worn for at least two years. ${ }^{4,6}$ Apart from that, treatment options for PTS are still limited.

The pathophysiology of PTS is explained by the presence of venous hypertension, which is caused by a combination of inflammation leading to damaged venous valves and a stiff, fibrotic vein wall on the one hand, and impaired fibrinolysis leading to residual thrombosis on the other hand. It is postulated that these two processes give rise to the symptoms of PTS. ${ }^{5,7-9}$ However, not all patients who experience a DVT develop PTS. Several risk factors for the development of PTS have been recognized, including a high body mass index (BMI), ${ }^{10-13}$ increasing age, ${ }^{6,12,14,15}$ proximal DVT compared to distal DVT, ${ }^{12,13}$ recurrent ipsilateral DVT, ${ }^{6,15,16}$ and pre-existent varicosities. ${ }^{13,14}$ However, it still is difficult to predict which patients will, and which patients will not develop PTS. If it could be possible to identify patients at risk for the development of PTS at an early point in time, preventive measures could be applied timely and in the right patients. ${ }^{4,6}$ The identification of biomarkers associated with PTS could be valuable for the individual risk assessment of PTS. The objective of this study was therefore to investigate whether increased levels of factor (F)VIII, C-reactive protein (CRP), or D-dimer are associated with the development of PTS in patients after an acute DVT, over time. Our hypothesis is that these markers are associated with PTS, since enhanced coagulation together with inflammation are important in the pathogenesis of PTS.

\section{Materials and methods}

\section{Patients and study design}

Data for the present study are collected in the context of an ongoing prospective cohort study, which is performed at the outpatient thrombosis clinic of the Maastricht University Medical Centre. All patients, enrolled between July 2003 and August 2009, who had completed a two-year follow-up period, were included in the present analysis. The PTS status of each patient was assessed using Villalta scores, as determined at several moments during follow-up. This study has been described in detail elsewhere. ${ }^{17}$ In brief, patients with confirmed acute proximal DVT were 
followed for a period of two years after the acute event, as part of routine patient care. A proximal DVT was defined as thrombosis in the popliteal vein, including the trifurcation; the femoral vein; or the common femoral vein. All consecutive patients with an objectively confirmed acute proximal DVT were enrolled, and there were no exclusion criteria, as this was a management study. ${ }^{17}$ Patients with pre-existent venous insufficiency were categorized as having skin signs equal to C3-C6 on CEAP score or requiring elastic compression stocking therapy. All patients received oral anticoagulation $(A / C)$, according to the American College of Chest Physicians guidelines. ${ }^{18}$ All patients were initially bandaged for as long as it took for the acute edema to resorb; new bandages were applied three times a week for a median duration of four weeks. Consequently, class III (ankle pressure $30-40 \mathrm{mmHg}$ ) customfitted elastic compression stockings were prescribed to patients for a period of 6 to 24 months, individually tailored based on the Villalta scores and duplex ultrasound. Overall, about $50 \%$ of patients wore elastic compression stockings for two years. ${ }^{17}$

According to regular care, patients visited the outpatient clinic five times: within a month of the index DVT and at 3, 6, 12, and 24 months after diagnosis. During the first visit a complete medical history was taken, a physical examination was performed, and risk factors for venous thromboembolism (VTE) and PTS were recorded. At every follow-up visit the affected leg was clinically assessed and signs and symptoms were scored using the Villalta scale. All patients were scored by one physician, who was blinded for results of the duplex ultrasound. PTS was defined as having a Villalta score of $\geq 5$ on two consecutive visits that were at least three months apart.

A compression ultrasound was performed one week before planned cessation of $A / C$, to screen for residual thrombosis. If residual thrombosis was present, $A / C$ was prolonged.

Markers for coagulation and fibrinolysis (FVIII and D-dimer), and a marker for inflammation (CRP) were determined in this cohort of patients. Blood was drawn at three time points during follow-up in the context of a separate study on recurrent DVT. ${ }^{19}$ This study was approved by the local ethics committee and informed consent was signed by each participating patient. Blood was drawn at one month after discontinuation of A/C (TO: 4-7 months after index DVT), at 12 months (T1), and 24 months (T2) after the index DVT. Venous blood was collected in 3,2\% citrate (w/v) and centrifuged for five minutes at $2500 \mathrm{~g}$ and for ten minutes at $10000 \mathrm{~g}$. D-dimer and CRP measurements were performed immediately after centrifugation. FVIII was measured batch wise from plasma stored at $-80^{\circ} \mathrm{C}$.

CRP measurements were performed using a turbidimetric method (Synchron LX ${ }^{\circledR}$ Systems, Beckman Coulter Inc., Fullerton, CA, USA). D-dimer was measured by means of Vidas D-dimer assay (bioMérieux Clinical Diagnostics) until May 2008. From June 2008 onwards D-dimer measurements were performed with the Innovance D-dimer assay (Siemens, Sysmex CA7000). The test characteristics of these two D-dimer assays are comparable. ${ }^{20}$ FVIII was determined using a one stage clotting assay, actin FS (lupus insensitive aPTT reagent, Siemens) was used as an activator and the 
measurements were performed on a Sysmex CA7000. Laboratory analyses were performed by laboratory technicians who were blinded for the PTS status of the patients.

\section{Statistical analysis}

SPSS 18.0 statistical software (SPSS Inc., Chicago, IL, USA) was used for statistical analyses. Patients who died or were lost to follow-up before the diagnosis of PTS was made were not taken into account in the analysis. Non-parametric Mann-Whitney U-tests were performed to assess associations between PTS and each of the markers measured (D-dimer, FVIII, and CRP). Levels of the markers were described by medians and interquartile ranges (IQR, $25^{\text {th }}$ percentile $-75^{\text {th }}$ percentile). Associations between PTS and D-dimer were assessed both for patients on and off $A / C$ separately, since $D$-dimer levels are affected by the $A / C$ status. For all analyses, statistical significance was set as a two-sided $p$-value of $\leq 0.05$.

Differences in marker levels over time were analyzed using Friedman test. ${ }^{21}$ Post hoc Wilcoxon's signed-rank testing with Bonferroni's correction was performed on significant Friedman test results.

Univariate associations between PTS, the markers, and various patient characteristics were checked using the chi-square test. Cut-offs for D-dimer (at the $90^{\text {th }}$ percentile of controls), FVIII (at the $75^{\text {th }}$ percentile of controls), and CRP (at the $75^{\text {th }}$ percentile of controls) were used to create binomial $(1 / 0)$ variables. It was explored whether these binomial variables led to a clearer identification of relations between the markers and PTS than continuous values of D-dimer, FVIII, and CRP.

Consequently, logistic regression analysis was carried out to further analyze significant associations found in chi-square testing. To this end variables with a $p$ value of $\leq 0.1$ in chi-square tests were entered in the model. Estimates were reported as odds ratios (OR) with their respective 95\% confidence intervals $(\mathrm{Cl})$ and p-values. Pearson's test was used to check for correlation between variables included in the logistic regression model. When a correlation was present, its influence on the multivariate model was tested by building different models.

\section{Results}

\section{Characteristics of study subjects}

As described above, patients were drawn from the population of an ongoing management cohort study. The total cohort at the time of analysis consisted of 313 patients, 228 of whom were included for the analysis.(Figure 2.1) One patient had not yet completed the follow-up period of two years at time of analysis. Eighty-four patients were not included in the analyses due to loss to follow up in 14 cases (one 
patient died, one patient moved, and of twelve patients the reason remained unknown). Another 24 patients were partly lost from the study; they did not finish their thrombosis clinic follow-up of two years, however, they did attend the hospital for other reasons, during and after the two year follow-up.

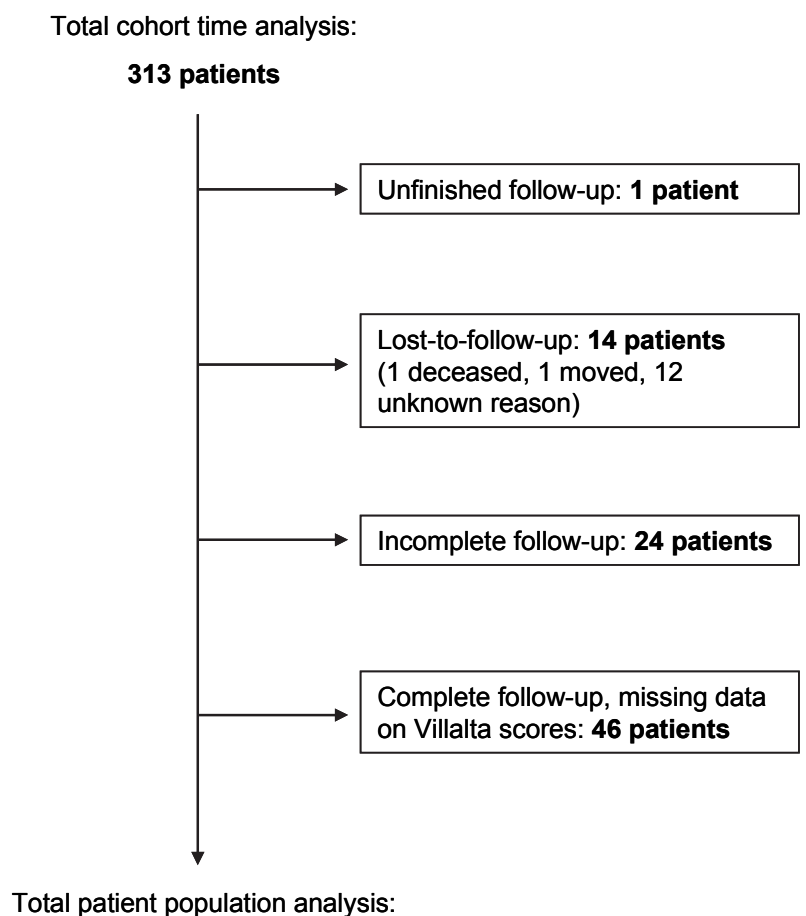

228 patients

Figure $2.1 \quad$ Flow diagram.

Forty-six patients were excluded because of missing data on Villalta scores (i.e. only one or no Villalta scores recorded), in spite of the fact that they had finished their follow-up at the thrombosis clinic. The study population consisted of 105 men (46\%) and 123 women (54\%) with an average age of 58 years at diagnosis. Forty-three patients (19\%) developed PTS during follow-up. PTS was mild in 28 patients (65\%), moderate in eleven patients (26\%), and severe in four patients (9\%), according to the highest Villalta score measured during follow-up. Of these 43 patients, the vast majority (40 patients) developed PTS within the first year after the DVT. In Table 2.1 the baseline characteristics of the 228 patients are shown. Overall, data on laboratory tests were available for approximately $75 \%$ of patients (D-dimer (78\%), CRP (67\%), and FVIII (76\%)). 
Table 2.1 Baseline characteristics of study patients.

\begin{tabular}{|c|c|c|c|c|}
\hline & $\begin{array}{c}\text { Total cohort } \\
\mathbf{n}=\mathbf{2 2 8} \\
\end{array}$ & $\begin{array}{c}\text { PTS } \\
n=43\end{array}$ & $\begin{array}{c}\text { No PTS } \\
n=185\end{array}$ & p-value \\
\hline \multicolumn{5}{|l|}{ Demographic characteristics } \\
\hline Gender Male & $105(46.1 \%)$ & $15(34.9 \%)$ & $90(48.6 \%)$ & 0.10 \\
\hline \multicolumn{5}{|l|}{ Age at diagnosis } \\
\hline Average (SD) & $58(15)$ & $61(14)$ & $56(15)$ & 0.11 \\
\hline Range & 17-87 & $17-82$ & $20-87$ & \\
\hline $\mathrm{BMI}\left(\mathrm{kg} / \mathrm{m}^{2}\right)(\mathrm{SD})$ & $27.7(5.3)$ & $29.3(6.1)$ & $27.3(5.1)$ & 0.08 \\
\hline \multicolumn{5}{|l|}{ Clinical characteristics } \\
\hline Smoking & $50(21.9 \%)$ & $10(23.3 \%)$ & $40(21.6 \%)$ & 0.83 \\
\hline Cardiovascular disease & $47(20.6 \%)$ & $13(30.2 \%)$ & $34(18.4 \%)$ & 0.09 \\
\hline Surgery or trauma within past 2 months & $46(20.2 \%)$ & $5(11.6 \%)$ & $41(22.2 \%)$ & 0.12 \\
\hline Traveling $>10$ consecutive hours in past 2 months & $23(10.1 \%)$ & $1(2.3 \%)$ & $22(11.9 \%)$ & 0.06 \\
\hline Immobilization $>2$ consecutive days in past 2 months & $46(20.2 \%)$ & $7(16.3 \%)$ & $39(21.1 \%)$ & 0.47 \\
\hline Use of estrogens* & $42(34.1 \%)$ & $2(7.1 \%)$ & $40(42.1 \%)$ & 0.00 \\
\hline Pregnancy, puerperium* & $4(3.3 \%)$ & $1(3.6 \%)$ & $3(3.2 \%)$ & 0.92 \\
\hline Active malignancy & $6(2.6 \%)$ & $0(0.0 \%)$ & $6(3.2 \%)$ & 0.23 \\
\hline Known thrombophilia & $9(3.9 \%)$ & $3(7.0 \%)$ & $6(3.2 \%)$ & 0.26 \\
\hline Inflammatory disease & $38(16.7 \%)$ & $11(25.6 \%)$ & $27(14.6 \%)$ & 0.09 \\
\hline Venous insufficiency & $6(2.6 \%)$ & $3(7.0 \%)$ & $3(1.6 \%)$ & 0.05 \\
\hline Varicosities & $22(9.6 \%)$ & $12(27.9 \%)$ & $10(5.4 \%)$ & 0.00 \\
\hline Residual thrombosis & $83(36.4 \%)$ & $17(39.5 \%)$ & $66(35.7 \%)$ & 0.65 \\
\hline Positive family history for VTE & $9(3.9 \%)$ & $3(7.0 \%)$ & $6(3.2 \%)$ & 0.79 \\
\hline \multicolumn{5}{|l|}{ Index DVT } \\
\hline Idiopathic & $127(55.7 \%)$ & $30(69.8 \%)$ & $97(52.4 \%)$ & 0.04 \\
\hline Previous VTE & $46(20.2 \%)$ & $15(34.9 \%)$ & $31(16.8 \%)$ & 0.01 \\
\hline Ipsilateral DVT & $17(7.5 \%)$ & $7(16.3 \%)$ & $10(5.4 \%)$ & \\
\hline Contralateral DVT & $13(5.7 \%)$ & $4(9.3 \%)$ & $9(4.9 \%)$ & \\
\hline Both ipsi- and contralateral DVT & $2(0.9 \%)$ & $1(2.3 \%)$ & $1(0.5 \%)$ & \\
\hline Pulmonary embolism & $5(2.2 \%)$ & $0(0.0 \%)$ & $5(2.7 \%)$ & \\
\hline Pulmonary embolism and ipsilateral DVT & $1(0.4 \%)$ & $1(2.3 \%)$ & $0(0.0 \%)$ & \\
\hline Unknown & $8(3.5 \%)$ & $2(4.7 \%)$ & $6(3.2 \%)$ & \\
\hline Recurrent VTE & $30(13.2 \%)$ & $10(23.3 \%)$ & $20(10.8 \%)$ & 0.03 \\
\hline Ipsilateral DVT & $14(6.1 \%)$ & $3(7.0 \%)$ & $11(5.9 \%)$ & \\
\hline Contralateral DVT & $4(1.8 \%)$ & $2(4.7 \%)$ & $2(1.1 \%)$ & \\
\hline Pulmonary embolism & $9(3.9 \%)$ & $4(9.3 \%)$ & $5(2.7 \%)$ & \\
\hline Pulmonary embolism and DVT & $2(0.9 \%)$ & $1(2.3 \%)$ & $1(0.5 \%)$ & \\
\hline Other (sinus thrombosis) & $1(0.4 \%)$ & $0(0.0 \%)$ & $1(0.5 \%)$ & \\
\hline Mortality & $10(4.4 \%)$ & $2(4.7 \%)$ & $8(4.3 \%)$ & 0.93 \\
\hline
\end{tabular}

BMI, body mass index; VTE, venous thromboembolism; DVT, deep vein thrombosis. Previous VTE was defined as having a history of objectively proven venous thromboembolism at study entry. Recurrent VTE was defined as having a new event of venous thromboembolism, objectively diagnosed, during follow up. *Analyzed in women only.

A total of 83 patients had residual thrombosis; the presence of residual thrombosis was not associated with PTS. Of those 83 patients, 35 did not use A/C anymore at the 4-7 month blood test. Forty-seven patients had prolonged $A / C$ : 18 because of residual thrombosis after a first event of DVT, 21 had residual thrombosis in combination with a history of DVT, and eight patients had a lifelong indication for $A / C$. A/C status of one 
patient was unknown. The D-dimer levels of these 48 patients were not included in the analysis, as $\mathrm{A} / \mathrm{C}$ use influences the D-dimer level.

\section{D-dimer, CRP, and FVIII in relation to PTS}

The data of D-dimer and CRP levels in relation to PTS for the three points in time during follow-up, are summarized in Tables 2 and 3, respectively. Twelve months (T1) after the acute event of DVT, D-dimer levels were significantly higher in patients with PTS, compared to patients without PTS, in patients off A/C.(Table 2.2, Figure 2.2)

Table 2. Levels of D-dimer by PTS status.

\begin{tabular}{lllll}
\hline $\begin{array}{l}\text { D-dimer (ng/ml) } \\
\text { Median (25-75 percentiles) }\end{array}$ & & \multicolumn{1}{c}{ PTS } & \multicolumn{1}{c}{ No PTS } & p-value \\
\hline PTS within 1 year* & T0 & $495(330-838) \mathrm{n}=18$ & $360(222-607) \mathrm{n}=117$ & 0.11 \\
& T1 & $725(400-1400) \mathrm{n}=16$ & $379(251-652) \mathrm{n}=124$ & 0.00 \\
& T2 & $550(330-1137) \mathrm{n}=18$ & $457(286-750) \mathrm{n}=95$ & 0.20 \\
\hline
\end{tabular}

Patients using oral anticoagulants are excluded. * PTS defined as Villalta score of $\geq 5$ on two consecutive visits, that were at least three months apart, within one year. Only results of patients who developed PTS within one year after DVT are shown; only three patients developed PTS within two years.

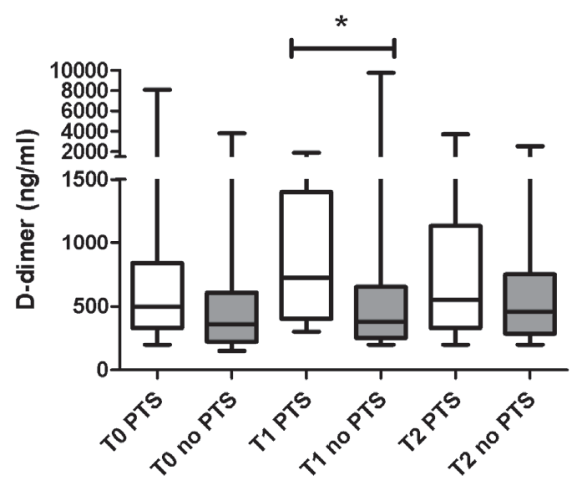

Figure 2.2 Distribution of the levels of D-dimer. The bars depict the median with interquartile ranges, whiskers depict the minimum and maximum values. Open bars represent patients with PTS and grey bars represent patients without PTS. Patients using oral anticoagulants were excluded. PTS is defined as a Villalta score of $\geq 5$ on two consecutive visits, that were at least three months apart, within one year. ${ }^{*} p<0.05$.

Also, CRP levels were found to be significantly higher in patients with PTS, compared to patients without PTS, twelve months (T1) after the index DVT. These findings were irrespective of A/C status.(Table 2.3, Figure 2.3)

No significant differences were found between patients with PTS and patients without PTS for FVIII in any of the analyses performed. Median FVIII levels were $168 \%$ [IQR 142-203] in patients without PTS compared to 163\% [IQR 141-198] in patients with PTS ( $p=0.721)$, one year after index DVT (T1). 
Table 2.3 Levels of CRP by PTS status.

\begin{tabular}{lcccc}
\hline $\begin{array}{l}\text { CRP (mg/l) } \\
\text { Median (25-75 percentiles) }\end{array}$ & & PTS & No PTS & p-value \\
\hline PTS within 1 year* & T0 & $3.7(2.2-8.2) n=29$ & $2.7(1.4-5.8) n=147$ & 0.06 \\
& T1 & $3.9(1.6-8.5) n=26$ & $2.4(1.0-4.3) n=137$ & 0.02 \\
& T2 & $2.8(1.8-6.6) n=19$ & $2.3(1.2-4.9) n=99$ & 0.31 \\
\hline
\end{tabular}

No patients are excluded. * PTS defined as Villalta score of $\geq 5$ on two consecutive visits, that were at least three months apart, within one year. Only results of patients who developed PTS within one year after DVT are shown; only three patients developed PTS within two years.

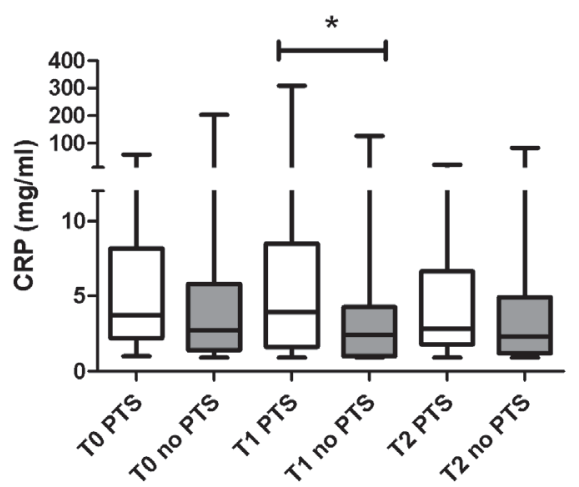

Figure 2.3 Distribution of the levels of CRP. The bars depict the median with interquartile ranges, whiskers depict the minimum and maximum values. Open bars represent patients with PTS and grey bars represent patients without PTS. No patients were excluded. PTS is defined as a Villalta score of $\geq 5$ on two consecutive visits, that were at least three months apart, within one year. ${ }^{*} p<0.05$.

\section{Levels of biomarkers over time}

D-dimer levels varied significantly over time in patients who did not develop PTS. In these patients, D-dimer levels were relatively low one month after cessation of $A / C$ and rose over time during follow-up; at T2, D-dimer was significantly higher than Ddimer at TO $(p=0.011)$. D-dimer levels in patients who did develop PTS were relatively high at TO and rose less markedly.(Table 2.2)

Levels of CRP did not vary significantly over time.(Table 2.3 )

\section{Characteristics associated with PTS}

In univariate analyses, recurrent VTE during follow-up (OR 2.5 [95\% Cl 1.1-5.8] $\mathrm{p}=0.030$ ); previous VTE (OR 2.6 [95\% Cl 1.3-5.5] $\mathrm{p}=0.008$ ); previous ipsilateral DVT (OR 4.2 [95\% Cl 1.6-10.9] $p=0.002$ ); varicosities (OR 6.7 [95\% $\mathrm{Cl} 2.7-16.9] \mathrm{p}=0.000$ ); venous insufficiency (without varicosities) (OR 4.5 [95\% $\mathrm{Cl} 0.9-23.2] \mathrm{p}=0.05$ ); and CRP above cut-off of $5 \mathrm{mg} / \mathrm{l}$ on T1 (cut-off based on the $75^{\text {th }}$ percentile of controls) (OR 3.0 [95\% 
Cl 1.3-7.3] $p=0.011$ ) were all associated with an increased risk of developing PTS. This is in contrast with provoked DVT (OR 0.5 [95\% $\mathrm{Cl} 0.2-1.0] \mathrm{p}=0.043$ ), which appeared to reduce the risk of developing PTS. That was also the case for use of estrogencontaining agents (OR 0.1 [95\% $\mathrm{Cl} 0.0-0.5] \mathrm{p}=0.001)$ in women.

Neither D-dimer above cut-off of $1000 \mathrm{ng} / \mathrm{ml}$ on T1 (cut-off based on the $90^{\text {th }}$ percentile of controls) in patients off $\mathrm{A} / \mathrm{C}$, nor inflammatory disease, were significantly associated with PTS: OR 3.1 [95\% Cl 0.92-10.3] $\mathrm{p}=0.058$ and OR 2.0 [95\% Cl 0.9-4.4] $\mathrm{p}=0.085$, respectively.

All described variables were entered into a logistic regression model. Pearson's tests demonstrated correlations between certain variables in the logistic regression model. The effect of these correlated variables on model fit and model outcomes were investigated by building different models. Model fit turned out to be optimal with previous VTE removed from the model. Testing for multicollinearity did not reveal significant interactions.

After adjustment, varicosities (OR 13.4 [95\% Cl 3.0-59.1] $\mathrm{p}=0.001$ ), previous ipsilateral DVT (OR 6.3 [95\% Cl 1.5-26.9] p=0.012), and CRP above cut-off of $5 \mathrm{mg} / \mathrm{l}$ on T1 (OR 8.0 [95\% $\mathrm{Cl}$ 2.4-26.4] $\mathrm{p}=0.001$ ) showed an independent and strong association with PTS. The other variables that were significantly associated with PTS in the univariate analysis did not retain significance in the multivariate logistic regression analysis.

\section{Discussion}

The aim of this study was to investigate whether there are, time dependent, associations between three biomarkers measured in the blood of patients at three discrete points in time after acute proximal DVT, and the occurrence of PTS. We hypothesized that both enhanced coagulation and inflammation would be contributors to the development of PTS. The biomarkers studied therefore were markers of coagulation (FVIII and D-dimer), fibrinolysis (D-dimer), and inflammation (CRP). D-dimer was chosen because of its established value in indicating recurrent thrombosis risk, and its potential value as a biomarker for PTS. ${ }^{12,22-26}$ As increased levels of FVIII were also associated with recurrent events, we selected this protein as well. ${ }^{27-30}$ CRP is an acute phase protein and a global marker for inflammation and as such a likely candidate biomarker for PTS. We performed laboratory measurements at different points in time because the development of PTS may have acute and chronic components. We observed that increased levels of both D-dimer and CRP, at twelve months after the index DVT, were associated with PTS. As the levels of these markers could be influenced by patient characteristics, adjustment for confounders was performed. Only CRP remained strongly and positively associated with PTS after adjustment, suggesting that inflammation is a dominant feature in the pathophysiology of PTS, as compared with hypercoagulability. This distinct association between CRP and PTS classified by Villalta scoring is a novel finding and strengthens 
the idea that inflammation is an important element in the etiology of PTS. While a similar link between CRP and PTS was observed previously, this was only existent when the CEAP classification was used, whereas this relation did not emerge when the Villalta score was used for PTS diagnosis. ${ }^{31}$

A link between elevated levels of D-dimer and PTS was also found in two previous studies, showing an association between increased levels of D-dimer and PTS, four months after index DVT and four weeks after cessation of $A / C .{ }^{12,25}$ The value of FVIII in relation to PTS seems to be limited. In adults, associations between FVIII and PTS are not established, consistent with our own findings. ${ }^{12}$ Elevated levels of FVIII have been associated with peripheral venous disease. ${ }^{32}$ In children, increased levels of FVIII were found to be related to PTS in one study, ${ }^{33}$ but this was not confirmed in another report. $^{34}$

In our study, for both D-dimer and CRP the differences in levels between patients with PTS and patients without PTS were most apparent twelve months after the index DVT. From literature it is known that PTS usually develops within two years after the index event. ${ }^{13}$ It is thought that the development of PTS is a sequence of processes: starting with thrombus resolution and inflammation, culminating in tissue remodeling and fibrosis. ${ }^{9,35}$ In the acute phase after DVT, thrombus resolution is associated with an acute inflammatory process. Leukocytes invade the thrombus and thereby contribute to thrombus resolution. ${ }^{36}$

Persistent elevation of CRP suggests that the inflammatory process persists in a proportion of patients, contributing to the occurrence of PTS. However, one can also argue that the presence of increased venous pressure in some patients (caused by decreased fibrinolysis and/or residual thrombosis) drives the inflammatory response, and therefore the inflammation is merely a consequence than a cause of increased venous pressure and PTS.

Yet, while in the sub acute phase inflammation and impaired thrombus resolution are key players in the pathogenesis of PTS, these processes tend to taper at later points in time; longer than twelve months after the index DVT. This would explain the loss of discriminating value for PTS of CRP and D-dimer at 24 months after the index DVT.

In the acute phase after DVT, all patients experience an inflammatory process, as a part of thrombus resolution. Therefore both patients that have (or will develop) PTS and patients that do not have (or will not develop) PTS, will show increased levels of inflammatory and fibrinolytic markers. This might explain why the difference in CRP and D-dimer levels, between patients with PTS and patients without PTS, did not reach significance at T0 (4-7 months after index DVT). However, at twelve months these differences are statistically significant, probably because at twelve months the inflammation and thrombus resolution is still ongoing in patients with PTS, while it is already subsided in patients without PTS.

A strength of this study is that the patient population is quite comparable with other patient populations in studies on DVT and PTS. Risk factors for PTS found in our patient cohort are similar to risk factors found in previous studies: recurrent 
DVT, ${ }^{6,15,16,37,38}$ venous insufficiency and varicosities. ${ }^{13,14}$ However, a high $\mathrm{BMI}^{10-13}$ and increasing age, ${ }^{6,12,14,15}$ two established risk factors for PTS, were not associated with PTS in our patient cohort, possibly because of a limited sample size.

Furthermore, in our cohort previous VTE and previous ipsilateral DVT appeared to be risk factors for PTS. This was not found in other studies, probably because previous DVT was an exclusion criterion in most studies.

Limitations of our study are the already mentioned limited sample size, partly because of loss-to-follow-up and missing data on Villalta scores. Furthermore, the cohort study design can cause bias of the results, through the lack of randomization non-equal distributions of (unobserved) confounding factors, which cannot be adjusted for, may have been introduced.

We found D-dimer and CRP to be associated with PTS at twelve months after diagnosis. As such CRP and D-dimer measurements can strengthen the clinical diagnosis of PTS made using the Villalta scale. CRP can be especially valuable in the diagnostic process, as its levels are not influenced by the use of A/C. In addition, the biomarkers can establish a possible treatment cut-in-point. The clinical judgement together with biomarker levels, can inform decisions to continue or discontinue elastic compression stocking therapy. Ultimately, a combination of biomarkers and clinical criteria could be translated into a risk prediction score, identifying those patients at risk of developing PTS.

Finally, our study supports interest in modifying inflammation as a target for prevention of PTS. Yet, more research in this field is necessary to optimize the diagnostic process making use of risk scores, to find additional biomarkers, and to obtain better therapies for PTS. 


\section{References}

1. Kahn SR. The post thrombotic syndrome. Thromb Res 2011;127 Suppl 3:S89-92.

2. Kahn SR, Shbaklo H, Shapiro S, Wells PS, Kovacs MJ, Rodger MA, Anderson DR, Ginsberg JS, Johri M, Tagalakis V; SOX Trial Investigators. Effectiveness of compression stockings to prevent the postthrombotic syndrome (the SOX Trial and Bio-SOX biomarker substudy): a randomized controlled trial. BMC Cardiovasc Disord 2007;7:21.

3. Pesavento R, Villalta S, Prandoni P. The postthrombotic syndrome. Intern Emerg Med 2010;5:185-92.

4. Brandjes DP, Büller HR, Heijboer $H$, Huisman MV, de Rijk M, Jagt $H$, ten Cate JW. Randomised trial of effect of compression stockings in patients with symptomatic proximal-vein thrombosis. Lancet 1997;349:759-62.

5. Henke PK, Comerota AJ. An update on etiology, prevention, and therapy of postthrombotic syndrome. J Vasc Surg 2011;53:500-9.

6. Prandoni $P$, Lensing AW, Prins $M H$, Frulla $M$, Marchiori A, Bernardi $E$, Tormene $D$, Mosena L, Pagnan A, Girolami A. Below-knee elastic compression stockings to prevent the post-thrombotic syndrome: a randomized, controlled trial. Ann Intern Med 2004;141:249-56.

7. Kahn SR. The post-thrombotic syndrome: progress and pitfalls. Br J Haematol 2006;134:357-65.

8. Kahn SR, Ginsberg JS. Relationship between deep venous thrombosis and the postthrombotic syndrome. Arch Intern Med 2004;164:17-26.

9. Phillips LJ 2nd, Sarkar R. Molecular characterization of post-thrombotic syndrome. J Vasc Surg 2007;45 Suppl A:A116-22.

10. Ageno W, Piantanida E, Dentali F, Steidl L, Mera V, Squizzato A, Marchesi C, Venco A. Body mass index is associated with the development of the post-thrombotic syndrome. Thromb Haemost 2003;89:3059.

11. Kahn SR, Kearon C, Julian JA, Mackinnon B, Kovacs MJ, Wells P, Crowther MA, Anderson DR, Van Nguyen P, Demers C, Solymoss S, Kassis J, Geerts W, Rodger M, Hambleton J, Ginsberg JS; Extended Low-intensity Anticoagulation for Thrombo-embolism (ELATE) Investigators. Predictors of the postthrombotic syndrome during long-term treatment of proximal deep vein thrombosis. J Thromb Haemost 2005;3:718-23.

12. Stain M, Schönauer V, Minar E, Bialonczyk C, Hirschl M, Weltermann A, Kyrle PA, Eichinger S. The post-thrombotic syndrome: risk factors and impact on the course of thrombotic disease. J Thromb Haemost 2005;3:2671-6.

13. Tick LW, Kramer MH, Rosendaal FR, Faber WR, Doggen CJ. Risk factors for post-thrombotic syndrome in patients with a first deep venous thrombosis. J Thromb Haemost 2008;6:2075-81.

14. Schulman $S$, Lindmarker $P$, Holmström $M$, Lärfars $G$, Carlsson A, Nicol $P$, Svensson $E$, Ljungberg $B$, Viering S, Nordlander S, Leijd B, Jahed K, Hjorth M, Linder O, Beckman M. Post-thrombotic syndrome, recurrence, and death 10 years after the first episode of venous thromboembolism treated with warfarin for 6 weeks or 6 months. J Thromb Haemost 2006;4:734-42.

15. van Dongen CJ, Prandoni P, Frulla M, Marchiori A, Prins MH, Hutten BA. Relation between quality of anticoagulant treatment and the development of the postthrombotic syndrome. J Thromb Haemost 2005;3:939-42.

16. Labropoulos N, Waggoner T, Sammis W, Samali S, Pappas PJ. The effect of venous thrombus location and extent on the development of post-thrombotic signs and symptoms. J Vasc Surg 2008;48:407-12.

17. Ten Cate-Hoek AJ, Ten Cate H, Tordoir J, Hamulyák K, Prins MH. Individually tailored duration of elastic compression therapy in relation to incidence of the postthrombotic syndrome. J Vasc Surg 2010;52:132-8

18. Hirsh J, Dalen J, Guyatt G; American College of Chest Physicians. The sixth (2000) ACCP guidelines for antithrombotic therapy for prevention and treatment of thrombosis. American College of Chest Physicians. Chest 2001;119(1 Suppl):1S-2S.

19. ten Cate-Hoek AJ, Dielis AW, Spronk HM, van Oerle R, Hamulyák K, Prins MH, ten Cate H. Thrombin generation in patients after acute deep-vein thrombosis. Thromb Haemost 2008;100:240-5.

20. Coen Herak D, Milos M, Zadro R. Evaluation of the Innovance D-DIMER analytical performance. Clin Chem Lab Med 2009;47:945-51. 
21. Friedman $\mathrm{M}$. The use of ranks to avoid the assumption of normality implicit in the analysis of variance. J Am Stat Assoc 1937;32:675-701.

22. Cushman M, Folsom AR, Wang L, Aleksic N, Rosamond WD, Tracy RP, Heckbert SR. Fibrin fragment Ddimer and the risk of future venous thrombosis. Blood 2003;101:1243-8.

23. Eichinger S, Minar E, Bialonczyk C, Hirschl M, Quehenberger P, Schneider B, Weltermann A, Wagner O, Kyrle PA. D-dimer levels and risk of recurrent venous thromboembolism. JAMA 2003;290: 1071-4.

24. Fattorini A, Crippa L, Vigano' D'Angelo S, Pattarini E, D'Angelo A. Risk of deep vein thrombosis recurrence: high negative predictive value of $D$-dimer performed during oral anticoagulation. Thromb Haemost 2002;88:162-3.

25. Latella J, Desmarais S, Miron MJ, Roussin A, Joyal F, Kassis J, Solymoss S, Desjardins L, Ginsberg JS, Kahn SR. Relation between D-dimer level, venous valvular reflux and the development of postthrombotic syndrome after deep vein thrombosis. J Thromb Haemost 2010;8:2169-75.

26. Palareti G, Legnani C, Cosmi B, Guazzaloca G, Pancani C, Coccheri S. Risk of venous thromboembolism recurrence: high negative predictive value of $\mathrm{D}$-dimer performed after oral anticoagulation is stopped. Thromb Haemost 2002;87:7-12.

27. Cosmi B, Legnani C, Cini M, Favaretto E, Palareti G. D-dimer and factor VIII are independent risk factors for recurrence after anticoagulation withdrawal for a first idiopathic deep vein thrombosis. Thromb Res 2008;122:610-7.

28. Cristina L, Benilde C, Michela C, Mirella F, Giuliana G, Gualtiero P. High plasma levels of factor VIII and risk of recurrence of venous thromboembolism. Br J Haematol 2004;124:504-10.

29. Eischer L, Gartner V, Schulman S, Kyrle PA, Eichinger S; AUREC-FVIII investigators. 6 versus 30 months anticoagulation for recurrent venous thrombosis in patients with high factor VIII. Ann Hematol 2009;88:485-90.

30. Kyrle PA, Minar E, Hirschl M, Bialonczyk C, Stain M, Schneider B, Weltermann A, Speiser W, Lechner K, Eichinger S. High plasma levels of factor VIII and the risk of recurrent venous thromboembolism. $\mathrm{N}$ Engl J Med 2000;343:457-62.

31. Roumen-Klappe EM, Janssen MC, Van Rossum J, Holewijn S, Van Bokhoven MM, Kaasjager K, Wollersheim H, Den Heijer M. Inflammation in deep vein thrombosis and the development of postthrombotic syndrome: a prospective study. J Thromb Haemost 2009;7:582-7.

32. Cushman M, Callas PW, Denenberg JO, Bovill EG, Criqui MH. Risk factors for peripheral venous disease resemble those for venous thrombosis: the San Diego Population Study. J Thromb Haemost 2010;8: 1730-5.

33. Goldenberg NA, Knapp-Clevenger R, Manco-Johnson MJ. Elevated plasma factor VIII and D-dimer levels as predictors of poor outcomes of thrombosis in children. N Engl J Med 2004;351:1081-8.

34. Kreuz W, Stoll M, Junker R, Heinecke A, Schobess R, Kurnik K, Kelsch R, Nowak-Göttl U. Familial elevated factor VIII in children with symptomatic venous thrombosis and post-thrombotic syndrome: results of a multicenter study. Arterioscler Thromb Vasc Biol 2006;26:1901-6.

35. Wojcik BM, Wrobleski SK, Hawley AE, Wakefield TW, Myers DD Jr, Diaz JA. Interleukin-6: a potential target for post-thrombotic syndrome. Ann Vasc Surg 2011;25:229-39.

36. Wakefield TW, Henke PK. The role of inflammation in early and late venous thrombosis: Are there clinical implications? Semin Vasc Surg 2005;18:118-29.

37. González-Fajardo JA, Martin-Pedrosa M, Castrodeza J, Tamames S, Vaquero-Puerta C. Effect of the anticoagulant therapy in the incidence of post-thrombotic syndrome and recurrent thromboembolism: Comparative study of enoxaparin versus coumarin. J Vasc Surg 2008;48:953-9.

38. Ziegler S, Schillinger M, Maca TH, Minar E. Post-thrombotic syndrome after primary event of deep venous thrombosis 10 to 20 years ago. Thromb Res 2001;101:23-33. 


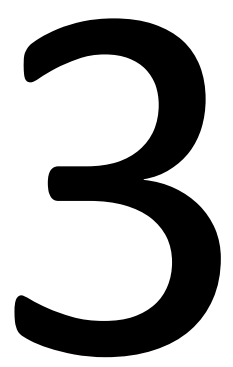

\section{Biomarkers for post thrombotic syndrome}

AC Bouman, S Atalay, $\mathrm{H}$ ten Cate, $\mathrm{M}$ ten Wolde, AJ ten Cate-Hoek Journal of Vascular Surgery: Venous and Lymphatic Disorders 2014;2:79-88 


\section{Abstract}

\section{Background}

Post thrombotic syndrome (PTS) is a serious condition that occurs in $20-50 \%$ of patients following deep vein thrombosis (DVT). Biomarkers can be of use in further exploring the etiology as well as in developing risk stratification tools for PTS. The relationship between PTS and specific biomarkers may help guide prevention and therapy based on a patient's individual risk profile. This review gives an overview of the current knowledge on biomarkers in relation to PTS.

\section{Methods}

A systematic search was executed in three databases (Pubmed, Embase/Medline, Cochrane) to identify all publications on biomarkers in relation to PTS. Where possible, results of studies were pooled and a meta-analysis was performed using Review Manager 5.1 (The Cochrane Collaboration).

\section{Results}

Twenty-four papers were included in this review. In patients after DVT, increased D-dimer appeared to be associated with the development of PTS (odds ratio (OR) 2.04 [95\% confidence interval (Cl) 1.02-4.08] $\mathrm{p}=0.04$ ). Neither prothrombin G20210A (OR 0.95 [95\% Cl 0.53-1.69] $\mathrm{p}=0.86)$, nor increased factor (F)VIII (OR $1.78[95 \% \mathrm{Cl} 0.88-3.57] \mathrm{p}=0.11$ ) were associated with PTS. For Factor V Leiden (FVL) conflicting results were found. FVL was not associated with PTS within a population of patients with a history of DVT (OR 0.98 [95\% Cl 0.74-1.29] p=0.88), but FVL was positively associated with post thrombotic ulceration in severe PTS, in patients compared with healthy individuals without a history of DVT (OR 11.42 [95\% Cl 6.37-20.48] $\mathrm{p}<0.00001)$. A meta-analysis could not be performed for markers of inflammation and tissue remodelling in relation to PTS.

\section{Conclusions}

Increased D-dimer levels are associated with a twofold increased risk for PTS. Inherited hypercoagulability, including FVL, is not associated with PTS in general. In contrast, FVL is strongly associated with post thrombotic ulceration in severe PTS. The role of inflammation in the etiology of PTS still has to be elucidated. 


\section{Introduction}

Post thrombotic syndrome (PTS) is a chronic complication of deep vein thrombosis (DVT) of the leg, which arises in $20-50 \%$ of patients, usually within one to two years after acute DVT. ${ }^{1,2}$ The symptoms and signs of PTS consist of heaviness, pain, cramps, itching, tingling, edema, venous ectasia, hyperpigmentation, and in severe cases even venous ulceration. These symptoms and signs are thought to be caused by venous hypertension. Since PTS is a syndrome, no gold standard diagnostic test exists. It is recommended to establish the diagnosis of PTS using the Villalta scale. ${ }^{3}$ The ruling theory is that venous hypertension, precipitated by venous thrombosis, leads to venous stasis and disturbs the microcirculation and blood supply to the muscles of the lower limb. Consequently, this chain of events gives rise to the signs and symptoms of PTS. $^{4-6}$

This review focuses on biomarkers in relation to PTS. The reason for studying biomarkers in PTS is twofold. (1) Identification of biomarkers is a clinically feasible start for unravelling the pathogenesis of PTS. Knowledge on the exact etiology of PTS is worthwhile to pursue, since it may contribute to the development of new therapeutic tools, which are most certainly needed for this burdensome and expensive condition. ${ }^{7-11}$ (2) Biomarkers might be helpful in risk stratification for PTS. A combination of biomarkers and risk factors could be used to assess the individual risk of PTS in a patient who experienced DVT. Potentially, this may increase the options for optimizing preventive or therapeutic measures according to the individual risk profile. The objective of this systematic review is to give an overview of current knowledge on biomarkers in relation to PTS. The primary endpoint was PTS in all its different manifestations, ranging from mild PTS to post thrombotic ulceration.

\section{Materials and methods}

\section{Identification of studies}

Our aim was to identify all relevant original studies on biomarkers in relation to PTS in human adults.

A systematic search of the literature was performed using the following academic search strategy: biomarkers OR fibrin fragment $D$ OR D-dimer OR biological markers OR inflammation mediators OR intercellular signaling peptides and proteins $\mathrm{OR}$ intracellular signaling peptides and proteins OR lipoproteins OR blood coagulation factors AND postthrombotic syndrome OR post thrombotic syndrome OR postthrombotic Syndrome OR postphlebitic syndrome OR post-phlebitic syndrome OR post phlebitic syndrome. This combination of search terms was entered in Pubmed central database (January 1, 1950 to October 2012), Embase/Medline database (January 1, 
1974 to October 2012), and Cochrane Central Register of Controlled Trials (January 1980 to August 2012). A manual search of references was also performed.

\section{Selection and data extraction}

Studies were considered eligible if: (1) it concerned an original study on biomarkers in relation to PTS, performed in human adults; (2) information on PTS incidence was available; (3) biomarkers were measured and related to the development of PTS, and results of these analyses could be extracted; and (4) articles were written in the English, Dutch, German, or French language.

Two authors performed selection of articles independently (A.B., S.A.). Disagreements were solved, by consulting 2 other authors (M.t.W., A.t.C.).

Two authors read full text of all eligible articles independently (A.B., S.A.). Relevant information was recorded in a predefined data extraction sheet, which included data on study design, recruitment of patients, treatment of patients, strategy of PTS diagnosis, biomarker assays, characteristics of study population, and results.

\section{Quality assessment of studies}

Methodological quality of studies was assessed using the Newcastle-Ottawa quality assessment scale for cohort studies and case-control studies. To achieve comparability, the Newcastle-Ottawa quality assessment scale for case-control studies was also used for a cross-sectional study and a family study. ${ }^{12,13}$

\section{Statistical analyses}

Associations between different biomarkers and PTS were examined by pooling the results of the separate studies. Odds ratios (ORs) of the variable PTS (yes/no) versus dichotomized biomarker levels (>cut-off value/<cut-off value) or thrombophilia factors (present/absent), were pooled using the generic inverse variance method. Since in the majority of studies results were reported as ORs only, it was inevitable to use the generic inverse variance method. Random-effects models were incorporated in the generic inverse variance method of data pooling in Review Manager 5.1 (The Cochrane Collaboration).

Heterogeneity was assessed using $\mathrm{I}^{2}$ statistics, $\mathrm{I}^{2} \geq 50 \%$ was defined as substantial heterogeneity. To determine sources of heterogeneity, sensitivity analyses were performed in case of substantial heterogeneity.

\section{Results}

The search of the three databases yielded a total of 354 publications; 321 of the 354 publications were excluded based on title and/or abstract for the following 
reasons: it concerned a review (132 articles), protocol (ten articles), or guideline (one article), it was written in a language other than English; Dutch; German; or French (six articles), the study was not performed in humans (eight articles), the study was performed in children (15 articles), it did not concern biomarkers (32 articles) or PTS (117 articles).

The full text of the remaining 33 articles was evaluated and a total amount of 16 articles were included. Through manual search of references another nine eligible articles were found. Two articles appeared to be identical (double publication), which led to a final number of 24 publications included in this review.(Figure 3.1)

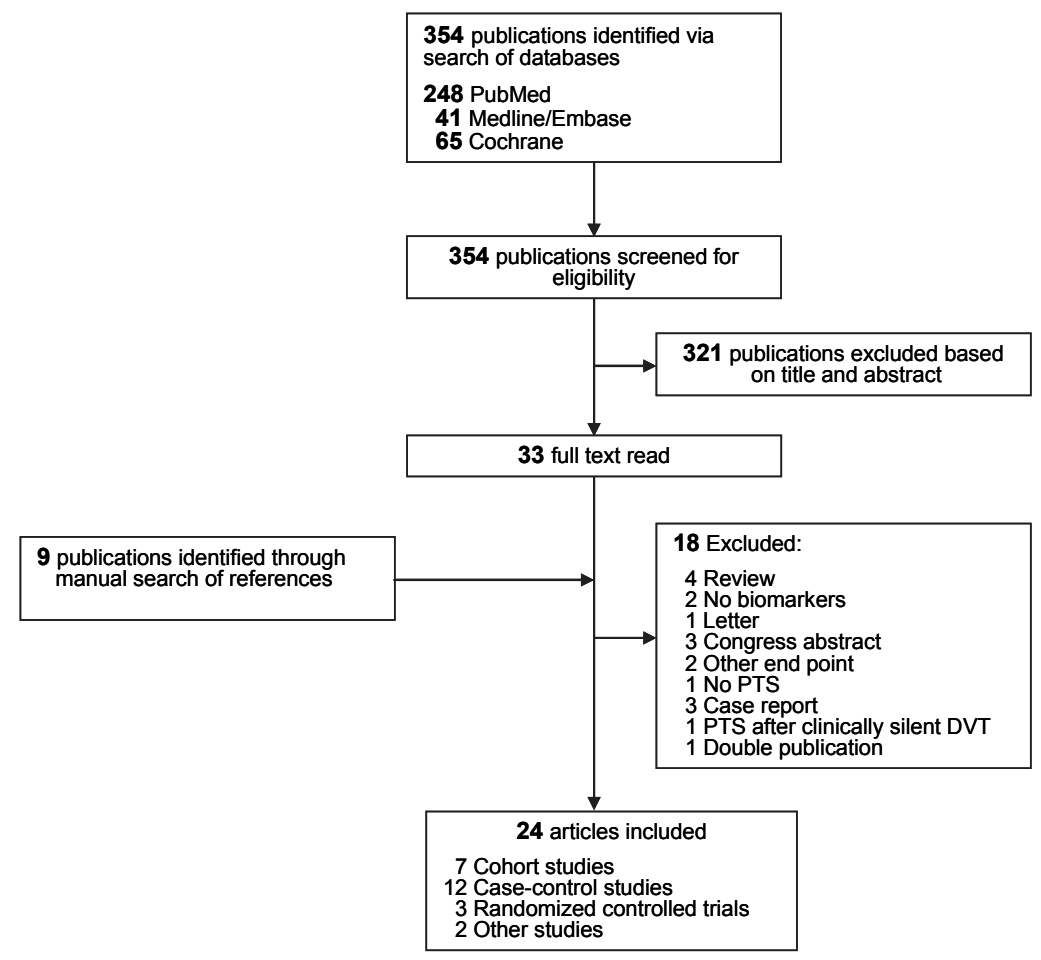

Figure 3.1 Literature search flow diagram. DVT, deep venous thrombosis; PTS, post thrombotic syndrome.

The methodological quality of the included studies on the Newcastle-Ottawa quality assessment scale is represented in Table 3.1 (methodological quality of cohort studies) and Table 3.2 (methodological quality of case-control studies). The cohort studies all scored fairly well. The average quality was $75 \%$ (5 out of 7 points); all studies but one had $\geq 5$ points on the 7-point scale.(Table 3.1) Methodological quality of the case-control studies was inferior, with an average quality of $57 \%$. Seven of the 17 studies had a quality of $\leq 50 \%$.(Table 3.2 ) 
Table 3.1 Methodological quality of studies. Newcastle - Ottawa quality assessment scale Cohort studies.

\begin{tabular}{|c|c|c|c|c|c|c|c|c|c|c|c|c|c|}
\hline & 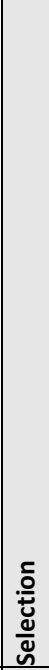 & 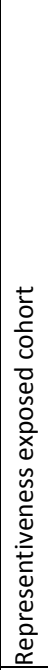 & 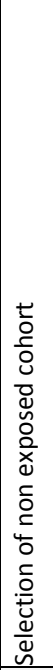 & 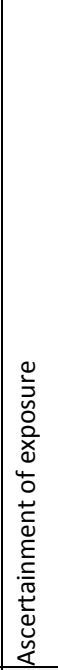 & 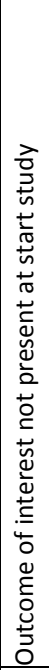 & 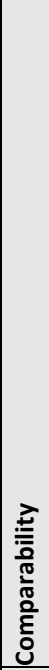 & 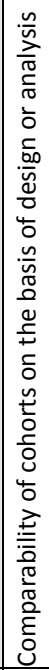 & 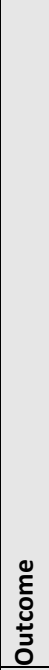 & 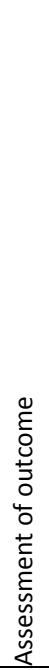 & 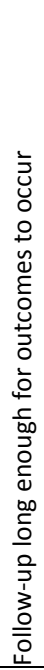 & 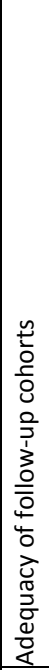 & 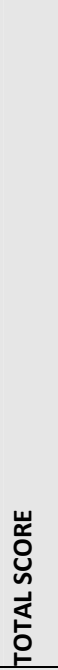 & 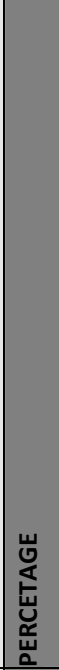 \\
\hline Stain 2005 (25) & 2 & $*$ & $n / a$ & $\mathrm{n} / \mathrm{a}$ & $*$ & 2 & $* *$ & 2 & I & $*$ & $*$ & $6 / 7$ & $86 \%$ \\
\hline Kahn 2008 (17) & 1 & $*$ & $n / a$ & $n / a$ & / & 2 & $* *$ & 3 & $*$ & $*$ & $*$ & $6 / 7$ & $86 \%$ \\
\hline Roumen-Klappe 2009 (21) & 2 & $*$ & $\mathrm{n} / \mathrm{a}$ & $n / a$ & $*$ & 2 & $* *$ & 2 & $*$ & 1 & $*$ & $6 / 7$ & $86 \%$ \\
\hline Shbaklo 2009 (23) & 1 & $*$ & n/a & $n / a$ & / & 2 & $* *$ & 2 & $*$ & * & / & $5 / 7$ & $71 \%$ \\
\hline Latella 2010 (18) & 1 & $*$ & n/a & $n / a$ & I & 2 & $* *$ & 2 & $*$ & $*$ & / & $5 / 7$ & $71 \%$ \\
\hline Spiezia 2010 (24) & 1 & $*$ & $\mathrm{n} / \mathrm{a}$ & $n / a$ & 1 & 2 & $* *$ & 1 & 1 & $*$ & I & $4 / 7$ & $57 \%$ \\
\hline Bouman 2012 (15) & 1 & $*$ & $\mathrm{n} / \mathrm{a}$ & $\mathrm{n} / \mathrm{a}$ & / & 2 & $* *$ & 2 & $*$ & $*$ & / & $5 / 7$ & $71 \%$ \\
\hline
\end{tabular}

n/a, not applicable. * 1 point; ${ }^{* *}, 2$ points; /, 0 points

The studies were performed in two distinctive patient populations, therefore we separated the description of the results in two parts: (1) studies that compare PTS patients to patients without PTS, within a population of patients who all experienced a DVT (twelve studies); and (2) studies that compare PTS patients to healthy individuals who never had a DVT (twelve studies).

\section{PTS versus no PTS, within a population after DVT}

In twelve of the 24 studies, biomarkers were measured in a cohort of patients who all experienced a DVT. ${ }^{14-25}$ Characteristics and results of these studies are summarized in Table 3.3. The mean incidence of PTS in these studies was 39.6\% (18.9-56.4\%). Except for three studies, the Villalta scale was used to diagnose PTS in all studies. ${ }^{15-21,23,24}$ The other three studies used the CEAP classification to make the diagnosis. ${ }^{14,22,25}$ Five studies defined PTS as a Villalta score of $\geq 5$ at two visits (either or not consecutive)..$^{15,18,20,23,24}$ In three studies one Villalta score of $\geq 5$ was sufficient to make the diagnosis PTS. ${ }^{16,17,21}$ In one study, it was not described whether one or two Villalta 
scores were used. $^{19}$ The studies that applied the CEAP classification considered a patient with signs and symptoms according to either class $1-6^{22,25}$ or class $3-6^{14}$ to have PTS.

We were able to pool data for a limited number of biomarkers only; data on D-dimer, Factor V Leiden (FVL), prothrombin G20210A, and factor (F)VIII were pooled. None of the analyses showed an $I^{2}$ of $\geq 50 \%$.

Table 3.2 Methodological quality of studies. Newcastle - Ottawa quality assessment scale Case-control studies.

\begin{tabular}{|c|c|c|c|c|c|c|c|c|c|c|c|c|c|}
\hline & 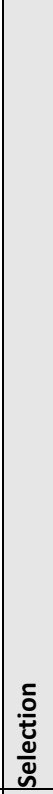 & 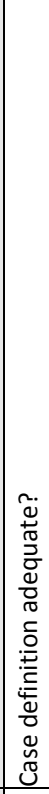 & 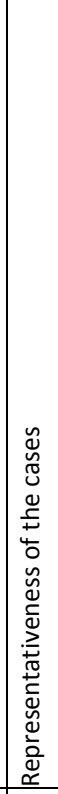 & 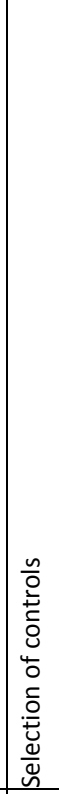 & 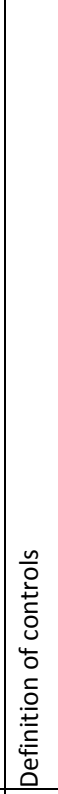 & 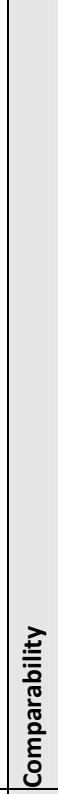 & 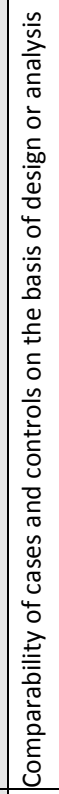 & 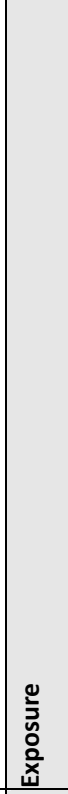 & 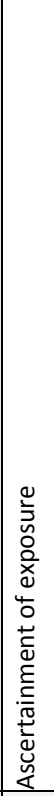 & 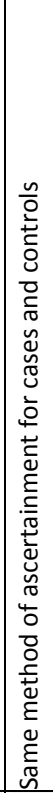 & 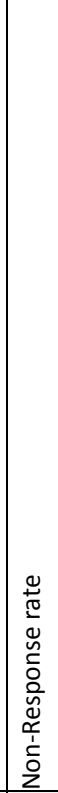 & 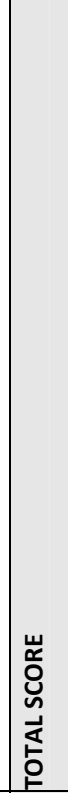 & $\begin{array}{l}\text { 岕 } \\
\text { 点 } \\
\text { 足 } \\
\text { 品 } \\
\end{array}$ \\
\hline Heintz 1989 (35) & 2 & $*$ & / & $*$ & / & 2 & $* *$ & $n / a$ & & & & $4 / 6$ & $67 \%$ \\
\hline Vanscheidt 1990 (32) & 1 & $*$ & I & 1 & I & 0 & / & $n / a$ & & & & $1 / 6$ & $17 \%$ \\
\hline Munkvad 1996 (30) & 2 & / & $*$ & * & / & 0 & / & n/a & & & & $2 / 6$ & $33 \%$ \\
\hline Caimi 1999 (34) & 0 & / & / & I & I & 0 & / & $n / a$ & & & & $0 / 6$ & $0 \%$ \\
\hline Maessen- Visch 1999 (29) & 0 & / & / & / & $/$ & 2 & $* *$ & $n / a$ & & & & $2 / 6$ & $33 \%$ \\
\hline Ribeaudeau 1999 (31) & 2 & / & $*$ & / & $*$ & 2 & $* *$ & $n / a$ & & & & $4 / 6$ & $67 \%$ \\
\hline Gaber 2001 (26) & 4 & $*$ & $*$ & $*$ & $*$ & 0 & / & $n / a$ & & & & $4 / 6$ & $67 \%$ \\
\hline Hafner 2001 (28) & 3 & $*$ & $*$ & I & $*$ & 2 & $* *$ & n/a & & & & $5 / 6$ & $83 \%$ \\
\hline Mackenzie 2002 (13) & 1 & I & $*$ & n/a & n/a & 0 & I & n/a & & & & $1 / 4$ & $25 \%$ \\
\hline Gemmati 2004 (27) & 3 & / & $*$ & $*$ & $*$ & 2 & $* *$ & n/a & & & & $5 / 6$ & $83 \%$ \\
\hline Prandoni 2004 (20) & 3 & $*$ & $*$ & I & $*$ & 2 & $* *$ & 3 & $*$ & * & * & $8 / 9$ & $89 \%$ \\
\hline Emmerich 2005 (12) & 1 & $*$ & I & n/a & $n / a$ & 2 & $* *$ & $n / a$ & & & & $3 / 4$ & $75 \%$ \\
\hline Kahn 2005 (16) & 3 & $*$ & $*$ & I & $*$ & 2 & $* *$ & 3 & $*$ & $*$ & $*$ & $8 / 9$ & $89 \%$ \\
\hline Schulman 2006 (22) & 3 & $*$ & $*$ & / & $*$ & 2 & $* *$ & 3 & $*$ & $*$ & * & $8 / 9$ & $89 \%$ \\
\hline Zutt 2011 (33) & 2 & $*$ & 1 & I & * & 2 & $* *$ & $n / a$ & & & & $4 / 6$ & $67 \%$ \\
\hline Bittar 2012 (14) & 2 & $*$ & I & $*$ & $/$ & 0 & / & $n / a$ & & & & $2 / 6$ & $33 \%$ \\
\hline Mazetto 2012 (19) & 3 & $*$ & * & / & * & 0 & / & $n / a$ & & & & $3 / 6$ & $50 \%$ \\
\hline
\end{tabular}

n/a, not applicable. *, 1 point; **, 2 points; /, 0 points 


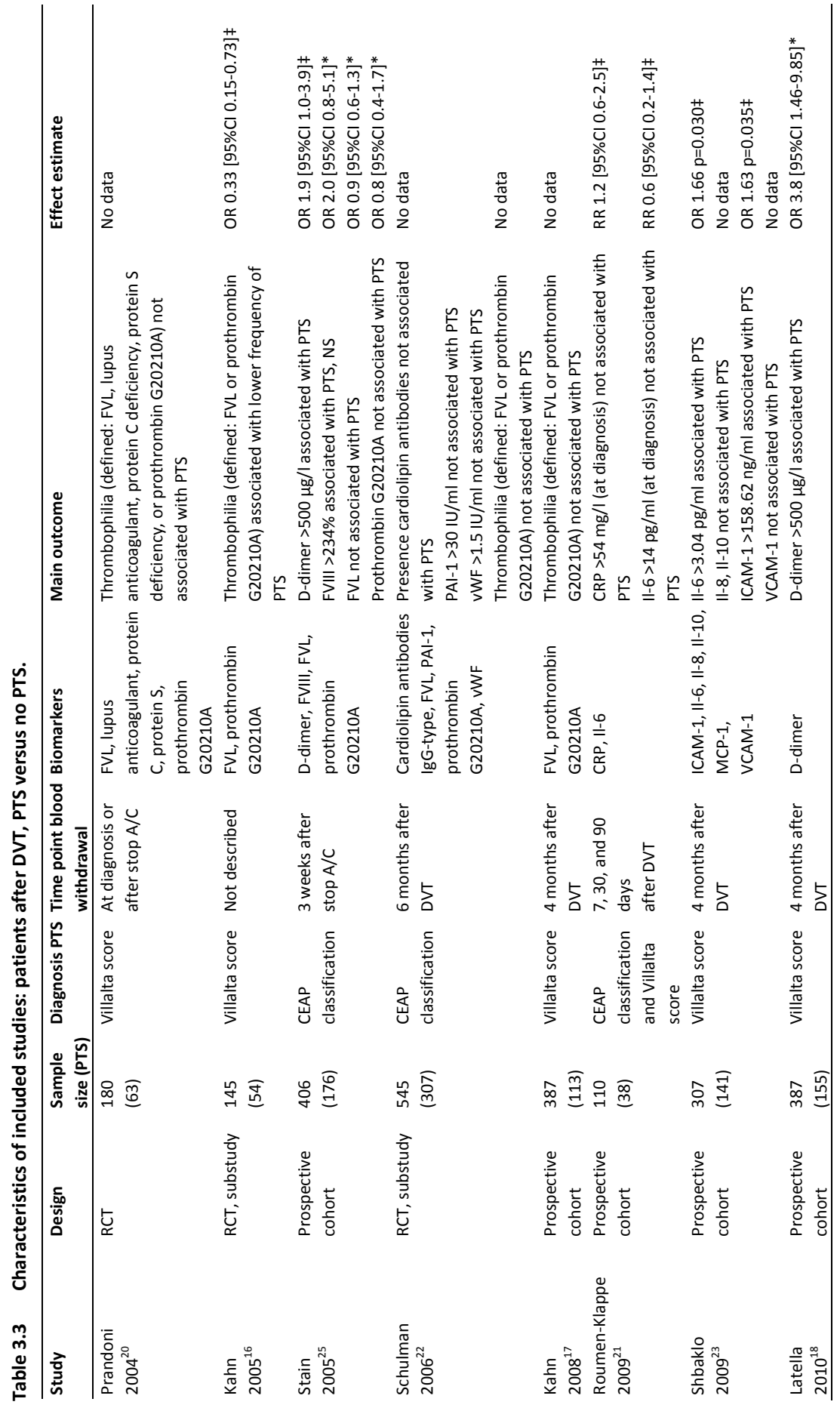




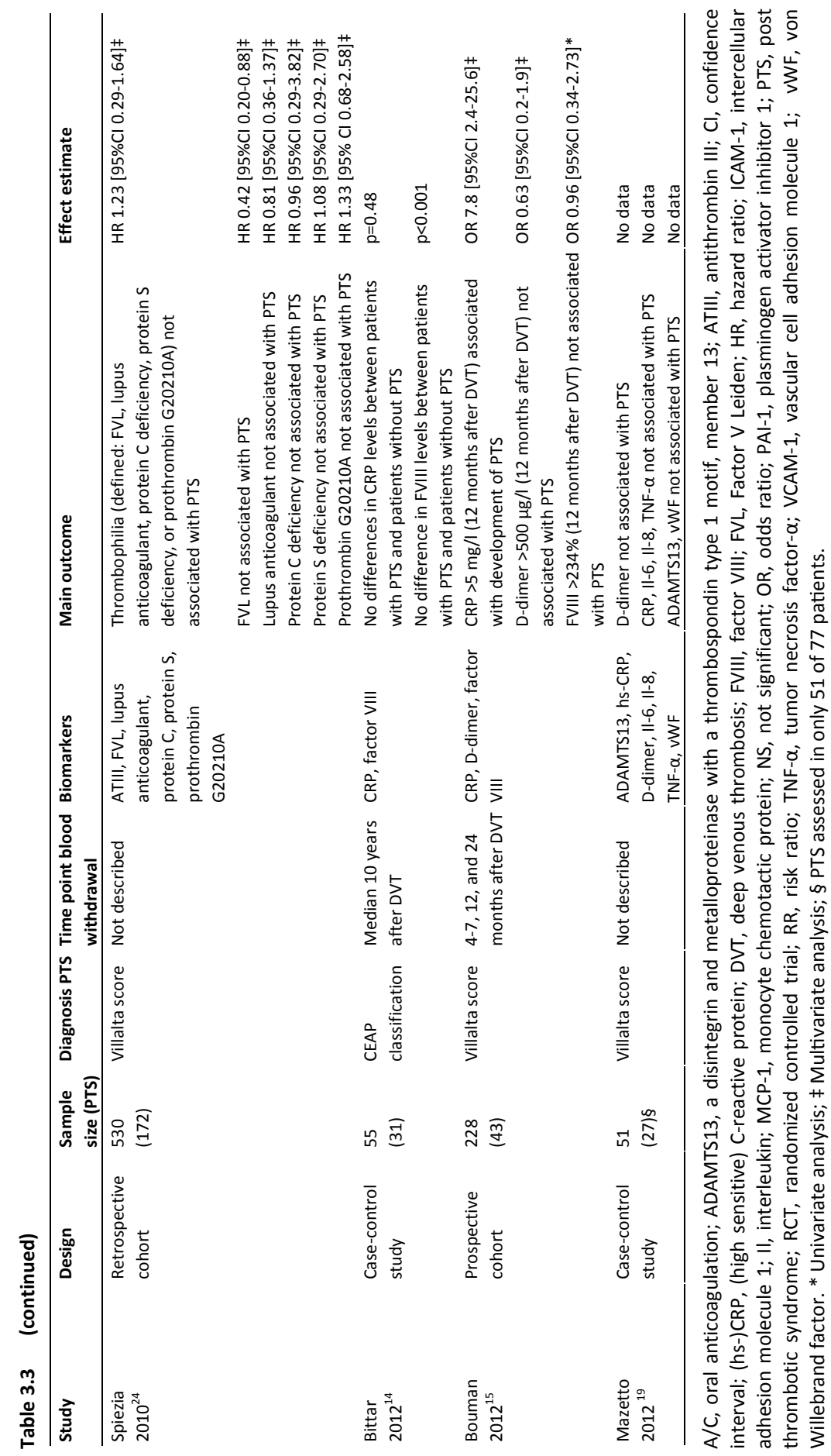




\section{Levels of D-dimer}

We found increased D-dimer $(>500 \mu \mathrm{g} / \mathrm{ml}$ ) to be significantly associated with PTS (OR 2.04 [95\% confidence interval $(\mathrm{Cl})$ 1.02-4.08] $p=0.04$.(Figure 3.2) Levels of $D$-dimer in relation to the occurrence of PTS were assessed in 4 studies. ${ }^{15,18,19,25}$ Data of three studies were eligible to be included in the meta-analysis. ${ }^{15,18,25}$ The fourth study did not find an association between increased D-dimer and PTS. This study could not be included in the meta-analysis because the data necessary to pool the results were not available nor provided by the authors on request. ${ }^{19}$ The three pooled studies match in several aspects: prospective data collection, exclusion of patients receiving oral anticoagulation $(A / C)$ from the analyses, and time of blood sampling between four to nine months after DVT. ${ }^{15,18,25}$ In one study blood was collected four months after $\mathrm{DVT}^{18}$; in another study, it was collected one month after cessation of $\mathrm{A} / \mathrm{C}$, which was either at four months or at seven months after $\mathrm{DVT}^{15}$; and in one study, it was collected three weeks after cessation of $A / C$ treatment, which was at a mean of nine months after DVT. ${ }^{25}$

\begin{tabular}{|c|c|c|c|c|c|}
\hline Stucty or Subgroup & log[Odds Ratio] & SE & Weight & $\begin{array}{l}\text { Odds Ratio } \\
\text { W, Random, } 95 \% \mathrm{Cl}\end{array}$ & $\begin{array}{l}\text { Odds Ratio } \\
\text { W, Random, 95\% Cl }\end{array}$ \\
\hline Bouman (2012) & -0.2095 & 0.7378 & $18.1 \%$ & $0.81[0.19,3.44]$ & $\longrightarrow$ \\
\hline Latella (2010) & 1.3324 & 0.4867 & $32.6 \%$ & $3.79[1.46,9.84]$ & \\
\hline Stain (2005) & 0.6419 & 0.3275 & $49.3 \%$ & $1.90[1.00,3.61]$ & \\
\hline Total $(95 \% \mathrm{Cl})$ & & & $100.0 \%$ & $2.04[1.02,4.08]$ & \\
\hline \multicolumn{6}{|c|}{ 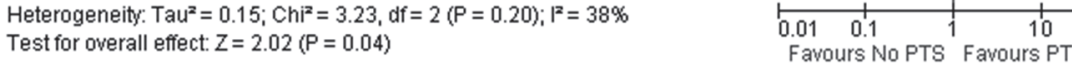 } \\
\hline
\end{tabular}

Figure 3.2 Pooled odds ratios (ORs) of D-dimer $>500 \mu \mathrm{g} / \mathrm{ml}$ in relation to post thrombotic syndrome (PTS). $\mathrm{Cl}$, confidence interval; SE, standard error.

\section{Thrombophilia}

Determinants of thrombophilia were measured in eight studies. ${ }^{14-17,20,22,24,25}$ The results were hard to pool, as thrombophilia was defined differently across studies, and not all required data could be obtained. We pooled the results of FVL and prothrombin G20210A versus PTS separately. Combining the data of Stain et al., Spiezia et al., and Kahn et al. showed that neither the presence of FVL (OR 0.98 [95\% $\mathrm{Cl}$ 0.74-1.29] $\mathrm{p}=0.88$ ) nor prothrombin G20210A (OR 0.95 [95\% Cl 0.53-1.69] $p=0.86$ ) was associated with PTS.(Figures 3.3, 3.4) (16,24,25 $^{2}$

Levels of FVIII were assessed in three studies. ${ }^{14,15,25}$ Combining the results of two studies, no significant association between increased FVIII (>234 IU/dl) and PTS was found (OR 1.78 [95\% Cl 0.88-3.57] p=0.11).(Figure 3.5) ${ }^{15,25}$ Bittar et al. found severe PTS (CEAP class 5-6) to be associated with increased levels of FVIII, when compared with patients with moderate PTS (CEAP class 3-4) or no PTS. The population of this study was highly selected; patients ten years after their first DVT, who initially presented with FVIII levels above the $90^{\text {th }}$ percentile, were included. Because this was 
such a selected group of patients and the relevant data could not be extracted, this study was not included in the meta-analysis. ${ }^{14}$ Other thrombophilic traits were measured in a few studies only. Not enough data were available to pool ORs for antithrombin deficiency, lupus anticoagulant, protein $\mathrm{C}$ deficiency, or protein $\mathrm{S}$ deficiency versus PTS.

\begin{tabular}{|c|c|c|c|c|c|c|c|}
\hline Stucty or Subgroup & log[Odds Ratio] & SE & Weight & $\begin{array}{l}\text { Odds Ratio } \\
\mathrm{N}, \text { Random, } 95 \% \mathrm{Cl}\end{array}$ & \multicolumn{3}{|c|}{$\begin{array}{c}\text { Odds Ratio } \\
\text { N, Random, } 95 \% \mathrm{Cl}\end{array}$} \\
\hline Kahn (2005) & 0.011 & 0.3154 & $20.4 \%$ & $1.01[0.54,1.88]$ & \multirow{3}{*}{\multicolumn{2}{|c|}{$\rightarrow$}} & \\
\hline Spiezia (2010) & 0.0792 & 0.2502 & $32.3 \%$ & $1.08[0.66,1.77]$ & & & \\
\hline Stain (2005) & -0.1054 & 0.2069 & $47.3 \%$ & $0.90[0.60,1.35]$ & & & \\
\hline Total $(95 \% \mathrm{Cl})$ & & & $100.0 \%$ & $0.98[0.74,1.29]$ & & & \\
\hline \multicolumn{5}{|c|}{$\begin{array}{l}\text { Heterogeneity: } \mathrm{Tau}^{2}=0.00 ; \mathrm{Chi}^{2}=0.34, \mathrm{df}=2(\mathrm{P}=0.84) ; \mathrm{I}^{2}=0 \% \\
\text { Test for overall effect: } \mathrm{Z}=0.15(\mathrm{P}=0.88)\end{array}$} & 0.01 & $0.1{ }^{1}{ }^{1} 10$ & 100 \\
\hline
\end{tabular}

Figure 3.3 Pooled odds ratios (ORs) of Factor V Leiden in relation to post thrombotic syndrome (PTS). $\mathrm{Cl}$, confidence interval; SE, standard error.

\begin{tabular}{|c|c|c|c|c|c|}
\hline Stucty or Subgroup & log[Odds Ratio] & SE & Weight & $\begin{array}{l}\text { Odds Ratio } \\
\text { N, Random, } 95 \% \mathrm{Cl}\end{array}$ & $\begin{array}{c}\text { Odds Ratio } \\
\text { N, Random, } 95 \% \mathrm{Cl}\end{array}$ \\
\hline Kahn (2005) & -0.6375 & 0.552 & $21.2 \%$ & $0.53[0.18,1.56]$ & $\longrightarrow$ \\
\hline Spiezia (2010) & 0.4134 & 0.3315 & $40.8 \%$ & $1.51[0.79,2.90]$ & \\
\hline Stain (2005) & -0.2231 & 0.3537 & $38.0 \%$ & $0.80[0.40,1.60]$ & \\
\hline Total $(95 \% \mathrm{Cl})$ & & & $100.0 \%$ & $0.95[0.53,1.69]$ & \\
\hline \multicolumn{5}{|c|}{$\begin{array}{l}\text { Heterogeneity: } \text { Tau}^{2}=0.10 ; \mathrm{Chi}^{2}=3.29, \mathrm{df}=2(P=0.19) ; \mathrm{I}^{2}=39 \% \\
\text { Test for overall effect: } Z=0.18(P=0.86)\end{array}$} & \begin{tabular}{|cccc}
0.01 & 0.1 & 1 & 10 \\
Favours No PTS Favours PTS
\end{tabular} \\
\hline
\end{tabular}

Figure 3.4 Pooled odds ratios (ORs) of prothrombin G20210A in relation to post thrombotic syndrome (PTS). Cl, confidence interval; SE, standard error.

\begin{tabular}{|c|c|c|c|c|c|c|}
\hline Stucty or Subgroup & log[Odds Ratio] & SE & Weight & $\begin{array}{l}\text { Odds Ratio } \\
\text { N, Random, } 95 \% \mathrm{Cl}\end{array}$ & $\begin{array}{l}\text { Odds Ratio } \\
\text { N, Random, 95\% Cl }\end{array}$ & \\
\hline Bouman (2012) & 0.4121 & 0.5498 & $42.0 \%$ & $1.51[0.51,4.44]$ & & \\
\hline Stain (2005) & 0.6931 & 0.4675 & $58.0 \%$ & $2.00[0.80,5.00]$ & & \\
\hline Total $(95 \% \mathrm{Cl})$ & & & $100.0 \%$ & $1.78[0.88,3.57]$ & & \\
\hline \multicolumn{5}{|c|}{$\begin{array}{l}\text { Heterogeneity: } \operatorname{Tau}^{2}=0.00 ; \mathrm{Chi}^{2}=0.15, \mathrm{df}=1(\mathrm{P}=0.70) ; \mathrm{I}^{2}=0 \% \\
\text { Test for overall effect: } Z=1.61(P=0.11)\end{array}$} & $\begin{array}{llll}0.01 & 0.1 & 1 & 10 \\
& \text { No PTS PTS } & \end{array}$ & 100 \\
\hline
\end{tabular}

Figure 3.5 Pooled odds ratios (ORs) of FVIII >234 IU/dl in relation to post thrombotic syndrome (PTS). $\mathrm{Cl}$, confidence interval; SE, standard error.

\section{Mediators of inflammation and tissue remodelling}

Mediators of inflammation and tissue remodelling were also determined in several studies.(Table 3.3) One study found increased C-reactive protein (CRP) measured twelve months after DVT to be associated with PTS. ${ }^{15}$ Three studies came across different results; increased CRP was not associated with PTS. ${ }^{14,19,21}$ In these studies, CRP was measured at the day of DVT diagnosis, ${ }^{21}$ approximately ten years after DVT, ${ }^{14}$ and at an unknown time point after DVT. ${ }^{19}$ Similarly, interleukin-6 (II-6) measured at the day of diagnosis or at an unknown time point was found not to be associated with 
PTS in two studies. ${ }^{19,21}$ However, II-6 measured at four months after diagnosis was associated with PTS in one other study. ${ }^{23}$

One study found intercellular adhesion molecule 1 (ICAM-1) to be associated with PTS. Furthermore, no differences between patients with PTS and without PTS were reported in levels of II-8, II-10, monocyte chemotactic protein 1 (MCP-1), and vascular cell adhesion molecule 1 (VCAM-1). ${ }^{19,23}$ The results for studies into markers of inflammation were not pooled, since targeted markers, time points of blood withdrawal, and cut-off values differed too much to perform a sensible meta-analysis.

\section{PTS patients versus healthy individuals}

The remaining twelve publications studied biomarkers in patients with PTS in comparison to healthy individuals that never experienced a DVT. The characteristics and results of these studies are summarized in Table 3.4.

For the majority of studies (nine) diagnosis of PTS was based on the presence of a venous ulcer in combination with a history of DVT. ${ }^{13,26-33}$ History of DVT was confirmed using additional diagnostics (Doppler, duplex, phlebography, or light reflex rheography) in four studies, ${ }^{26,31-33}$ hospital records in one study, ${ }^{13}$ and anamnestic information in two studies. ${ }^{28,29}$ Two studies did not describe whether and how history of DVT was confirmed. ${ }^{27,30}$

A history of DVT, in combination with either non-ulcerating skin changes (two studies), or signs and symptoms correlating with CEAP class 1-6 (one study), were the basis for PTS diagnosis in the other three studies. ${ }^{12,34,35}$ Two studies confirmed the history of DVT with additional diagnostics (Doppler, duplex, phlebography, or light reflex rheography), ${ }^{12,35}$ the third study left this undescribed. ${ }^{34}$

Comparing patients with post thrombotic ulcers to healthy individuals without a history of DVT, meta-analysis showed a significant association between FVL and post thrombotic ulcers (OR 11.42 [95\% Cl 6.37-20.48] p<0.00001).(Figure 3.6) I $I^{2}$ was $0 \%$. In absence of sufficient comparable data, it was not possible to perform a metaanalysis for the other thrombophilia factors or biomarkers.

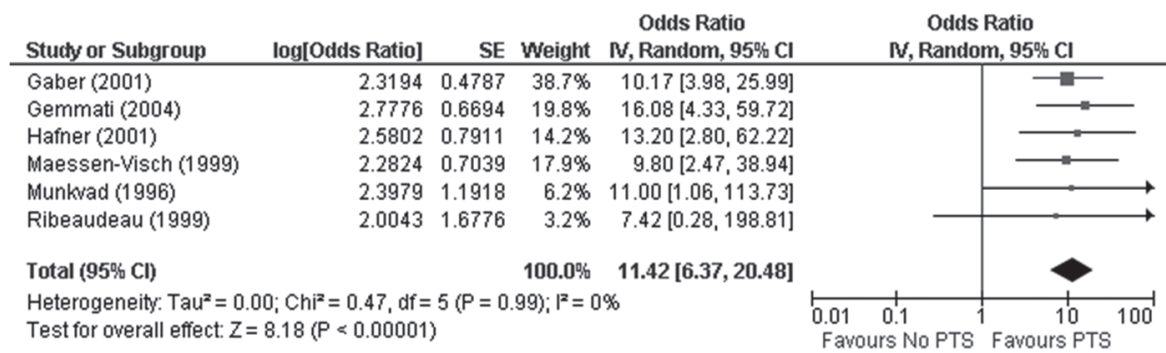

Figure 3.6 Pooled odds ratios (ORs) of Factor $\mathrm{V}$ Leiden in relation to post thrombotic ulcers. $\mathrm{Cl}$, confidence interval; SE, standard error. 


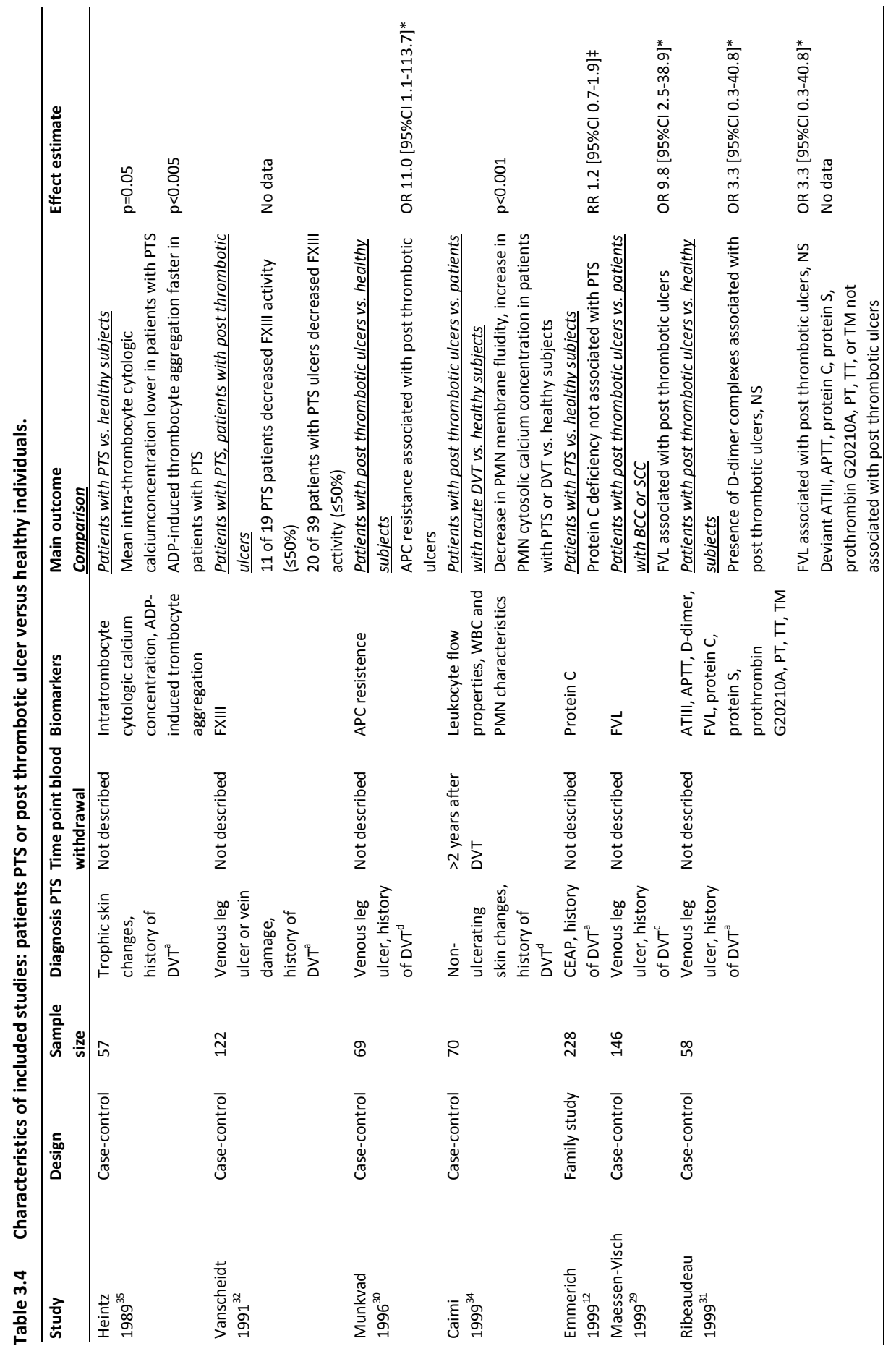




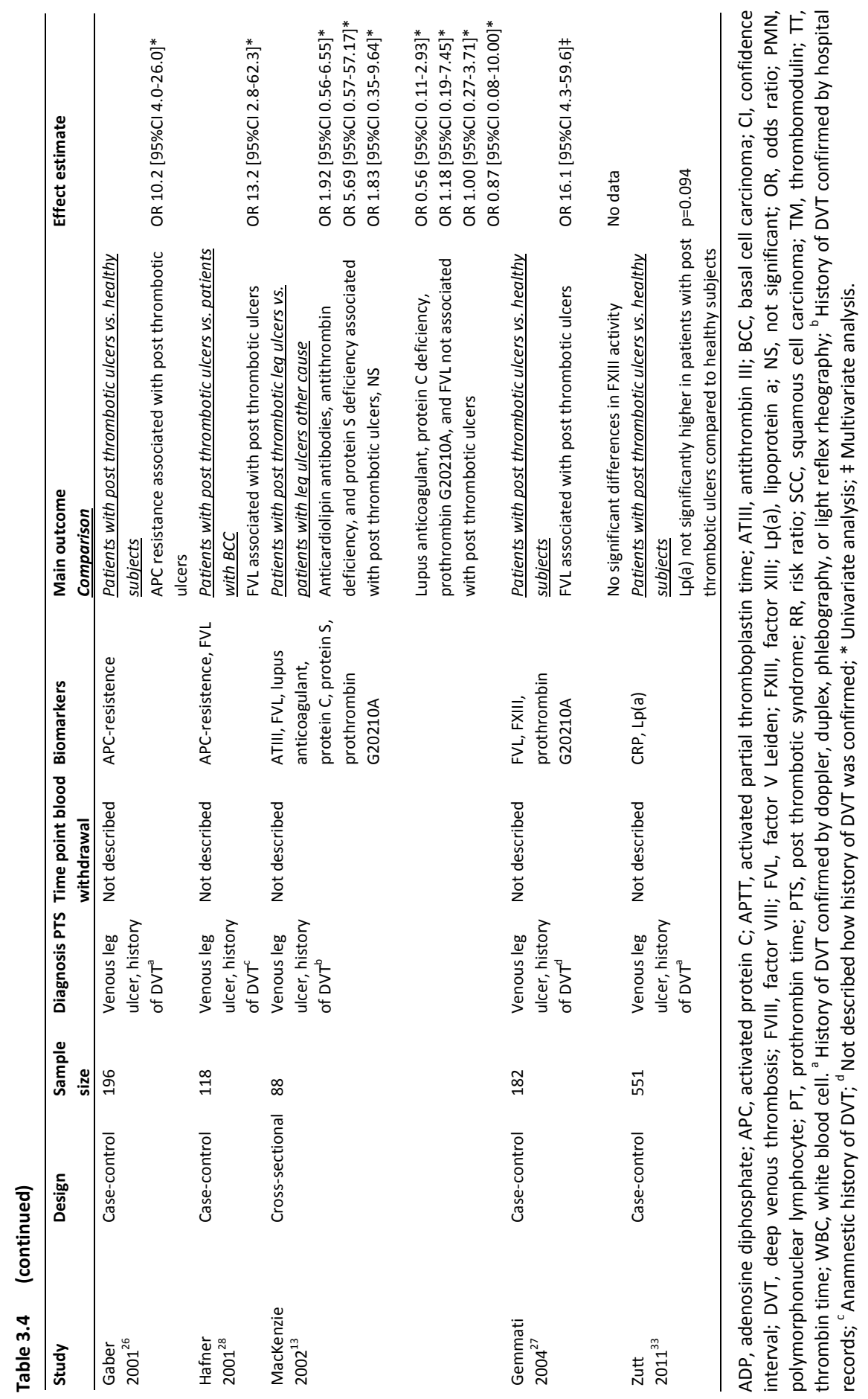




\section{Discussion}

Inherited hypercoagulability, including FVL, is not associated with PTS in populations with mainly milder forms of PTS. In contrast, FVL was found to be strongly associated with post thrombotic ulceration in patients with severe PTS compared with patients without a history of DVT. This finding may in part be a reflection of the different prevalence of FVL in patients as compared with a healthy population; FVL is much more prevalent in a population of patients that suffered from a DVT (up to 20\%) in comparison to the general population (3-5\%). ${ }^{36,37}$ Hence, the association between FVL and DVT, if patients after DVT are compared with the general population, has an OR of approximately 6.00 (4.75-8.08) (calculated using the prevalence figures mentioned above). However, we found an association between FVL and post thrombotic ulcers with an OR of 11.42. Given this high OR, a true association between post thrombotic ulcers and FVL seems credible. Our hypothesis is that FVL is associated strongest with severe PTS. Possibly, the association between FVL and PTS was not found in the studies on patients with PTS versus patients without PTS within a population after DVT, because the percentage of severe PTS is very low in these studies, $1.4 \%$ $4 \% .{ }^{16,24,25}$ Therefore the effect may have been attenuated. We hypothesize that not hypercoagulability per se, but rather impaired clot lysis may be the most important etiological factor in the development of severe PTS in the presence of FVL. A pathophysiologic explanation could be found in the fact that FVL has a dual mode of action; on the one hand FVL mutation causes a decreased susceptibility to cleavage of factor $\mathrm{Va}$ by activated protein $\mathrm{C}$, resulting in increased thrombin and fibrin generation, but also an increased induction of thrombin activatable fibrinolysis inhibitor. On the other hand, a specific effect of FVL, distinguishing it from other thrombophilic traits, is that it slows down clot lysis by abrogating the delaying effect of thrombomodulin on $\alpha(2)$-plasmin inhibitor-fibrin cross-linking, which also contributes to the impaired fibrinolysis observed in FVL carriers. $^{38}$ As a result, increased venous outflow resistance, leading to impaired microcirculation and disturbed wound healing, might be more prevalent among these patients. It, therefore, could very well be the case that impaired fibrinolysis due to FVL is a risk factor for severe PTS.

D-dimer, a marker intertwined in coagulation and fibrinolysis, was also found to be associated with PTS. This does suggest (hyper)coagulation in these patients, whereas the other results did not indicate a significant role of hypercoagulability in the etiology of PTS. It has to be elucidated further whether (hyper)coagulation is a cause of PTS or rather a consequence of other pathophysiological processes in PTS. Inflammatory processes also increase D-dimer levels. Inflammation drives thrombin and fibrin formation, generating a larger amount of fibrin to be cleaved by plasmin. Moreover, inflammatory enzymes like elastase can also yield fibrinogen and fibrin cleavage products that can be detectable in the D-dimer assay. ${ }^{39}$ Ongoing inflammation aggravates processes of tissue remodelling and consequent fibrosis, leading to stiff fibrotic vein walls, tissue deoxygenation, and impaired valve function, all probable 
causes of PTS symptoms. ${ }^{5,40}$ Only in more recent publications of the last few years markers of inflammation and tissue remodelling have been modestly studied. ${ }^{14,15,19,21,23}$ These studies on inflammatory markers and PTS were too heterogeneous to be pooled in a meta-analysis. The time point of blood withdrawal after DVT varied extensively, whereas time to event is particularly important in comparing the levels of inflammation markers between different studies, as inflammation is a transient process.

We, therefore, concur with the hypothesis that the main cause for PTS is venous hypertension, originating from poor thrombus resolution with subsequent venous outflow resistance and secondary vein wall remodelling on the one hand, and vein wall remodelling and valve destruction because of inflammatory processes during thrombus resolution on the other hand. ${ }^{5}$ Both theories on the underlying mechanism of disease include endothelial dysfunction, low grade inflammation, and vascular remodelling. Until now, however, most studies performed have been looking into hypercoagulability.

The study needed in order to strengthen our hypothesis on the involvement of FVL in post thrombotic ulceration could be performed in a case-control study design, preferably in patients with severe PTS. The markers linked to individual patient profiles such as FVL do not change over time; pathophysiologic processes therefore can be studied irrespective of time to event.

The studies needed on the elucidation of the involvement of inflammatory markers, however, should be prospective in nature because the biomarkers are transient and dependent on the activity of the processes involved. Ideally, patients after DVT should be followed and biomarkers should be measured at several time points. Standardized methods and a standard definition of PTS diagnosis should be adopted, to increase comparability. 


\section{References}

1. Prandoni P, Villalta S, Bagatella P, Rossi L, Marchiori A, Piccioli A, Bernardi E, Girolami B, Simioni P, Girolami A. The clinical course of deep-vein thrombosis. Prospective long-term follow-up of 528 symptomatic patients. Haematologica 1997;82:423-8.

2. Tick LW, Kramer MH, RosendaalFR, Faber WR, Doggen CJ. Risk factors for post-thrombotic syndrome in patients with a first deep venous thrombosis. J Thromb Haemost 2008;6:2075-81.

3. Kahn SR, Partsch H, Vedantham S, Prandoni P, Kearon C. Definition of post-thrombotic syndrome of the leg for use in clinical investigations: a recommendation for standardization. J Thromb Haemost 2009;7:879-83.

4. Henke PK, Wakefield T. Thrombus resolution and vein wall injury: dependence on chemokines and leukocytes. Thromb Res 2009; 123 Suppl 4: S72-8.

5. Phillips LJ 2nd, Sarkar R. Molecular characterization of post-thrombotic syndrome. J Vasc Surg 2007;45 Suppl A:A116-22.

6. Wakefield TW, Myers DD, Henke PK. Mechanisms of venous thrombosis and resolution. Arterioscler Thromb Vasc Biol 2008;28:387-91.

7. Ashrani AA, Heit JA. Incidence and cost burden of post-thrombotic syndrome. J Thromb Thrombolysis 2009; 28:465-76.

8. Bergqvist D, Jendteg S, Johansen L, Persson U, Odegaard K. Cost of long-term complications of deep venous thrombosis of the lower extremities: an analysis of a defined patient population in Sweden. Ann Intern Med 1997;126:454-7.

9. Caprini JA, Botteman MF, Stephens JM, Nadipelli V, Ewing MM, Brandt S, Pashos CL, Cohen AT. Economic burden of long-term complications of deep vein thrombosis after total hip replacement surgery in the United States. Value Health 2003;6:59-74.

10. Kahn S.R., A. Hirsch, I. Shrier. Effect of postthrombotic syndrome on health-related quality of life after deep venous thrombosis. Arch Intern Med 2002; 162(10): 1144-8.

11. Kahn S.R., C.E. M'Lan, D.L. Lamping, X. Kurz, A. Berard, L. Abenhaim, G. Veines Study. The influence of venous thromboembolism on quality of life and severity of chronic venous disease. J Thromb Haemost 2004; 2(12): 2146-51.

12. Emmerich J, Vossen CY, Callas PW, Demers C, Naud S, Long GL, Couture P, Rosendaal FR, Bovill EG. Chronic venous abnormalities in symptomatic and asymptomatic protein C deficiency. J Thromb Haemost 2005;3: 1428-31.

13. Mackenzie RK, Ludlam CA, Ruckley CV, Allan PL, Burns P, Bradbury WA. The prevalence of thrombophilia in patients with chronic venous leg ulceration. J Vasc Surg 2002;35:718-22.

14. Bittar LF, de Paula EV, Montalvao SA, Mello TB, Annichino-Bizzacchi JM. Severe Post-thrombotic Syndrome is Associated With Higher Levels of Factor VIII. Clin Appl Thromb Hemost 2013;19:570-3.

15. Bouman AC, Smits JJ, Ten Cate H, Ten Cate-Hoek AJ. Markers of coagulation, fibrinolysis and inflammation in relation to post-thrombotic syndrome. J Thromb Haemost 2012;10:1532-8.

16. Kahn SR, Kearon C, Julian JA, Mackinnon B, Kovacs MJ, Wells P, Crowther MA, Anderson DR, Van Nguyen P, Demers C, Solymoss S, Kassis J, Geerts W, Rodger M, Hambleton J, Ginsberg JS. Predictors of the post-thrombotic syndrome during long-term treatment of proximal deep vein thrombosis. J Thromb Haemost 2005;3:718-723.

17. Kahn SR, Shrier I, Julian JA, Ducruet T, Arsenault L, Miron MJ, Roussin A, Desmarais S, Joyal F, Kassis J, Solymoss S, Desjardins L, Lamping DL, Johri M, Ginsberg JS. Determinants and time course of the postthrombotic syndrome after acute deep venous thrombosis. Ann Intern Med 2008;149:698-707.

18. Latella J, Desmarais S, Miron MJ, Roussin A, Joyal F, Kassis J, Solymoss S, Desjardins L, Ginsberg JS, Kahn SR. Relation between D-dimer level, venous valvular reflux and the development of postthrombotic syndrome after deep vein thrombosis. J Thromb Haemost 2010;8:2169-75.

19. Mazetto BM, Orsi FL, Barnabé A, De Paula EV, Flores-Nascimento MC, Annichino-Bizzacchi JM. Increased ADAMTS13 activity in patients with venous thromboembolism. Thromb Res 2012;130:88993.

20. Prandoni $P$, Lensing AW, Prins $M H$, Frulla $M$, Marchiori A, Bernardi E, Tormene $D$, Mosena L, Pagnan A, Girolami A. Below-knee elastic compression stockings to prevent the post-thrombotic syndrome: a randomized, controlled trial. Ann Intern Med 2004;141:249-56. 
21. Roumen-Klappe EM, Janssen MC, Van Rossum J, Holewijn S, Van Bokhoven MM, Kaasjager K, Wollersheim H, Den Heijer M. Inflammation in deep vein thrombosis and the development of postthrombotic syndrome: a prospective study. J Thromb Haemost 2009;7: 582-7.

22. Schulman S, Lindmarker P, Holmstrom M, Larfars G, Carlsson A, Nicol P, Svensson E, Ljungberg B, Viering S, Nordlander S, Leijd B, Jahed K, Hjorth M, Linder O, Beckman M. Post-thrombotic syndrome, recurrence, and death 10 years after the first episode of venous thromboembolism treated with warfarin for 6 weeks or 6 months. J Thromb Haemost 2006;4:734-42.

23. Shbaklo H, Holcroft CA, Kahn SR. Levels of inflammatory markers and the development of the postthrombotic syndrome. Thromb Haemost 2009;101:505-12.

24. Spiezia L, Campello E, Giolo E, Villalta S, Prandoni P. Thrombophilia and the risk of post-thrombotic syndrome: retrospective cohort observation. J Thromb Haemost 2010; 8(1): 211-3.

25. Stain M, Schonauer V, Minar E, Bialonczyk C, Hirschl M, Weltermann A, Kyrle PA, Eichinger S. The post-thrombotic syndrome: risk factors and impact on the course of thrombotic disease. J Thromb Haemost 2005;3:2671-6.

26. Gaber Y, Siemens HJ, Schmeller W. Resistance to activated protein C due to factor $V$ Leiden mutation: high prevalence in patients with post-thrombotic leg ulcers. Br J Dermatol 2001;144:546-8.

27. Gemmati D, Tognazzo S, Serino ML, Fogato L, Carandina S, De Palma M, Izzo M, De Mattei M, Ongaro A, Scapoli GL, Caruso A, Liboni A, Zamboni P. Factor XIII V34L polymorphism modulates the risk of chronic venous leg ulcer progression and extension. Wound Repair Regen 2004;12:512-7.

28. Hafner J, Kuhne A, Schar B, Bombeli T, Hauser M, Luthi R, Hanseler E. Factor V Leiden mutation in postthrombotic and non-postthrombotic venous ulcers. Arch Dermatol 2001;137:599-603.

29. Maessen-Visch MB, Hamulyak K, Tazelaar DJ, Crombag NH, Neumann HA. The prevalence of factor V Leiden mutation in patients with leg ulcers and venous insufficiency. Arch Dermatol 1999;135:41-4.

30. Munkvad S, Jorgensen M. Resistance to activated protein $\mathrm{C}$ : a common anticoagulant deficiency in patients with venous leg ulceration. Br J Dermatol 1996; 134(2): 296-8.

31. Ribeaudeau F, Senet P, Cayuela JM, Fund X, Paul C, Robert C, Scrobohaci ML, Dubertret L. A prospective coagulation study including resistance to activated protein $\mathrm{C}$ and mutations in factors $\mathrm{V}$ and II in venous leg ulcers. Br J Dermatol 1999;141:259-63.

32. Vanscheidt W, Hasler K, Wokalek H, Niedner R, Schopf E. Factor XIII-deficiency in the blood of venous leg ulcer patients. Acta Derm Venereol 1991;71:55-7.

33. Zutt M, Kruger U, Rosenberger A, Schon MP, Neumann C, von Ahsen N, Kretschmer L. Increased Lipoprotein (a) concentrations in patients with chronic venous leg ulcers: a study on patients with or without postthrombotic syndrome. Wound Repair Regen 2011;19:168-72.

34. Caimi G, Canino B, Ferrara F, Montana M, Raimondi F, LoPresti R. Leukocyte rheology before and after chemotactic activation in some venous diseases. Eur J Vasc Endovasc Surg 1999;18:411-6.

35. Heintz B, Femers C, Maurin N, Kierdorf H, Brilon C, Wienert V. Relation between post-thrombotic syndrome, ADP-induced thrombocyte aggregation and intrathrombocyte calcium content. Klin Wochenschr 1989;67:1194-8.

36. Ridker PM, Hennekens CH, Lindpaintner K, Stampfer MJ, Eisenberg PR, Miletich JP. Mutation in the gene coding for coagulation factor $\mathrm{V}$ and the risk of myocardial infarction, stroke, and venous thrombosis in apparently healthy men. N Engl J Med 1995;332:912-7.

37. Rosendaal FR, Koster T, Vandenbroucke JP, Reitsma PH. High risk of thrombosis in patients homozygous for factor $V$ Leiden (activated protein $C$ resistance). Blood 1995;85:1504-8.

38. Koncz Z, Bagoly Z, Haramura G, Mezei ZA, Muszbek L. Thrombomodulin-dependent effect of factor V Leiden mutation on the cross-linking of alpha2-plasmin inhibitor to fibrin and its consequences on fibrinolysis. Thromb Res 2012;130:528-34.

39. Bach-Gansmo ET, Godal HC, Skjonsberg OH. Degradation of fibrinogen and cross-linked fibrin by human neutrophil elastase generates D-like fragments detected by ELISA but not latex D-dimer test. Thromb Res 1998;92:125-34.

40. Kahn SR, Ginsberg JS. Relationship between deep venous thrombosis and the postthrombotic syndrome. Arch Intern Med 2004;164:17-26. 


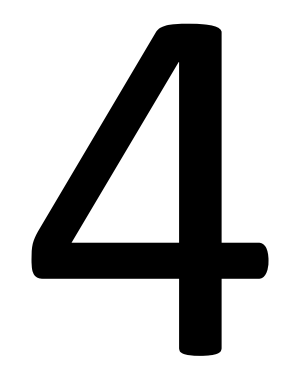

Biomarkers for post thrombotic syndrome:

a case-control study

AC Bouman, YW Cheung, HM Spronk, CG Schalkwijk, H ten Cate, M ten Wolde, AJ ten Cate-Hoek

Thrombosis Research 2014;134:369-375 


\section{Abstract}

\section{Introduction}

There is limited knowledge on the etiology of post thrombotic syndrome (PTS), although several mechanisms have been proposed. The objectives are to explore the role of different pathogenic mechanisms for PTS, through measurement of an elaborate panel of biomarkers in patients with and without PTS.

\section{Materials and methods}

Patients with a history of deep vein thrombosis (DVT) with PTS (cases) and without PTS after minimal two years follow-up (controls), were selected from the outpatient clinic of two Dutch hospitals. As a reference to the normal population healthy individuals (HI) without a history of venous thromboembolism were invited to participate. The population consisted of: 26 cases, 27 controls, and $26 \mathrm{HI}$.

A panel of predefined biomarkers was measured in venous blood.

\section{Results}

D-dimer showed a decreasing trend from cases to controls to $\mathrm{Hl} p \mathrm{p}=0.010$. Thrombin:antithrombin (TAT) complex levels were significantly higher in cases than in controls; $\mathrm{p}=0.032$, and $\mathrm{HI} ; \mathrm{p}=0.017$. Activated protein $\mathrm{C}$ (APC)-ratio was significantly lower in cases compared to controls; $\mathrm{p}=0.032$, and $\mathrm{HI} ; \mathrm{p}=0.011$. A significant trend of increasing pro thrombin activatable fibrinolysis inhibitor (proTAFI) from cases, to controls, and $\mathrm{HI} ; \mathrm{p}=0.002$ was found. There were no differences in inflammatory markers (C-reactive protein (CRP), Interleukin-6 (II6), Interleukin-8 (II-8)). Thrombomodulin (TM), tissue-plasminogen activator, and von Willebrand factor (VWF) were higher in patients compared to HI. There was a significant trend of decreasing soluble vascular cell adhesion molecule 1 (sVCAM-1), from cases, to controls, and $\mathrm{HI} ; \mathrm{p}=0.029$.

\section{Conclusions}

Patients with PTS displayed increased coagulation activity, an altered pattern of fibrinolytic marker expression, and increased endothelial activation. We found no evidence of systemic inflammation in patients with PTS at 63 months since the last DVT. 


\section{Introduction}

Post thrombotic syndrome (PTS) is a prevalent chronic complication of deep vein thrombosis (DVT) affecting $20-50 \%$ of patients within the first two years after DVT. ${ }^{1-3}$ The condition is characterized by complaints of the leg such as pain, heaviness, itching, cramps, and tingling, which may range in seriousness from mild complaints of the leg to intense pain intervening with daily activities. Signs and symptoms of PTS vary over time. ${ }^{1}$ In severe cases PTS is accompanied by chronic venous leg ulceration. ${ }^{4,5}$ PTS has a significant influence on quality of life and is associated with considerable costs. ${ }^{1,6}$

PTS is diagnosed using the Villalta scale, a scoring system developed by Prandoni and colleagues. The Villalta scale consists of five subjective complaints (heaviness, pain, cramps, itching, tingling) and six objective signs (pretibial edema, skin induration, hyperpigmentation, venous ectasia, redness, pain on calf compression), which are scored from none (zero points) to severe (three points). Furthermore, the presence of venous ulceration (yes/no) is recorded. ${ }^{7}$ The etiology of PTS is not yet entirely understood. Symptoms of PTS are thought to be the end-organ manifestation of venous hypertension, caused by several closely linked processes. ${ }^{8}$ Impaired fibrinolysis contributing to persistent (partial) obstruction of veins, increased and continued inflammation, tissue remodelling, and endothelial activation are thought to be involved in the development of PTS. ${ }^{8-11}$

Upon the occurrence of thrombosis, both thrombus and the venous wall are invaded by leukocytes that secrete growth factors, proteases, and cytokines. ${ }^{8}$ The release of proteolytic enzymes and free radicals by leukocytes contributes to damage of the venous valves, resulting in reflux of venous blood. ${ }^{12,13}$ Inflammation directs tissue remodelling, by the activation of fibroblasts and smooth muscle cells and deposition of collagen in the thrombosed venous segment, resulting in fibrosis. ${ }^{10}$

Comparable to chronic venous disease, continued activation of endothelial cells could also play a role in PTS. ${ }^{13-15}$ Attraction and adhesion of leukocytes to sustained activated endothelial cells might be a contributing factor to the chronic inflammation process, with progressive damage of vein wall and venous valves as a result. Matrix metalloproteases (MMPs) have been suggested to be involved in tissue remodelling after venous thrombosis. ${ }^{16,17}$ Several studies in mice showed that MMPs play a significant role in the remodelling processes, contributing to post thrombotic venous damage. ${ }^{18,19}$ Fibrotic vein walls become stiff and noncompliant and induce increased venous pressure. ${ }^{10}$

Thus, the available experimental data suggest a scenario of PTS pathophysiology that involves both prothrombotic and inflammatory mechanisms, linking the blood and vessel wall compartments. Clinically, however, there is very limited data on these processes. ${ }^{9,20}$ For this reason we embarked on an exploratory case-control study in patients with and without PTS to assess the potential relevance of a defined panel of biomarkers, reflecting various stages of the postulated pathophysiology of PTS. 


\section{Materials and methods}

\section{Patients and study design}

A case-control study was performed, including 60 patients with a history of objectively confirmed DVT and 30 healthy individuals ( $\mathrm{HI})$, without a history of venous thromboembolism (VTE), were invited to participate as a reference to the normal population. HI were spouse, relative, or acquaintance of patients.

Thirty patients with PTS and thirty patients without PTS were selected and recruited from the outpatient clinic of the Maastricht University Medical Centre or the Flevohospital in Almere, the Netherlands.

Patients who had developed PTS (Villalta $\geq 5$ ) were defined as cases. Patients that had not developed PTS (Villalta $\leq 4$ ), after a minimal follow-up of two years after DVT, were defined as controls. The majority of patients had visited the outpatient clinic during a period of two years after their DVT, at each visit signs and symptoms were scored according to the Villalta scale. PTS was defined as a Villalta score of $\geq 5$ on two consecutive visits, which were at least three months apart. When Villalta scores of follow-up were not present, the leg was clinically assessed and a Villalta score was taken at inclusion (six patients). Patients' legs were assessed by clinicians trained and experienced in scoring legs according to the Villalta scale.

Subjects or patients with chronic inflammatory disease (defined as any manifestation of inflammatory bowel disease or chronic rheumatic disease) or with known venous insufficiency were excluded from the study because of possible interference with the endpoints. Cases, controls, and $\mathrm{HI}$ were matched for gender, age, and BMI.

The medical ethical committee of the Maastricht University Medical Centre approved the study and all participants gave written informed consent.

\section{Measurement of biomarkers}

Venous blood was drawn from all subjects and collected in citrate $(3,2 \% \mathrm{w} / \mathrm{v})$ and EDTA polypropylene tubes for plasma (BD Vacutainer), and in clot activator (coating of micronized silica particles) containing polypropylene tubes for serum (BD Vacutainer). Citrate tubes were centrifuged for five minutes at $2500 \mathrm{~g}(3790 \mathrm{rpm}$, room temperature) and for ten minutes at $10000 \mathrm{~g}\left(11000 \mathrm{rpm}, 18^{\circ} \mathrm{C}\right)$. EDTA tubes were centrifuged for five minutes at $2500 \mathrm{~g}$ (3790 rpm, room temperature). Serum tubes were left for 30 minutes at $37^{\circ} \mathrm{C}$ and consequently centrifuged for five minutes at $2500 \mathrm{~g}$ (3790 rpm, room temperature). Plasma and serum samples were stored at $-80^{\circ} \mathrm{C}$ until analysis.

The panel of biomarkers was based on a systematic review of literature on biomarkers and PTS in humans ${ }^{20}$ and extensive review of literature on biomarkers and PTS in animal studies.

A multiplex multi-array electrochemiluminescence platform was used to measure Interleukin-8 (II-8), Interleukin-6 (II-6), Matrix metalloproteinase-9 (MMP-9), 
C-reactive protein (CRP), soluble Intercellular Adhesion Molecule 1 (sICAM-1), soluble Vascular Cell Adhesion Molecule 1 (sVCAM-1), P-selectin, and Thrombomodulin (TM) in EDTA plasma (MesoScaleDiscovery, Gaithersburg, MD, USA). ${ }^{21}$ Von Willebrand factor ( $v W F$ ) was measured in citrate plasma with a homemade enzyme-linked immunosorbent assay (ELISA) using Polyclonal Rabbit anti Human vWF (DAKO A0082, Glostrup, Denmark) as capture antibody and polyclonal Rabbit anti vWF/HRP (Zebra bioscience P0226, Enschede, the Netherlands) as detection antibody.

Single commercial ELISAs were performed for the measurement of plasminogen activator inhibitor type 1 (PAI-1) (Hyphen Biomed, Neuville-sur-oise, France), Thrombin:antithrombin complex (TAT) (Siemens, Marburg, Germany), tissueplasminogen activator (tPA) (Hyphen Biomed, Neuville-sur-oise, France), plasminalpha(2)-antiplasmin (PAP) complexes (Technoclone $\mathrm{GmbH}$, Vienna, Austria), and pro thrombin activatable fibrinolysis inhibitor (proTAFI) antigen (Hyphen Biomed, Neuville-sur-oise, France).

The activated protein C (APC-)ratio was measured with an APTT-based APC resistance assay (Instrumentation Laboratory Company, Bedford, USA). For the used LOTnumber an APC-ratio of $>2.39$ was defined as not resistant.

D-dimer was measured with the Innovance D-dimer assay (Siemens, Marburg, Germany).

\section{Statistical analyses}

SPSS 21.0 statistical software was used for all statistical analyses (SPSS Inc., Chicago, IL, USA).

Non-parametric Mann Whitney U-tests were performed to test for differences in marker levels between patients (cases and controls) and HI. Subsequently, nonparametric Kruskal-Wallis tests were performed to test for differences in marker levels between the three groups (cases, controls, HI). Post hoc Mann-Whitney U-tests were performed on significant $(p<0.05)$ Kruskal-Wallis test results. Also, trend analysis (Jonckheere-Terpstra test) was performed, to test for trends in the data. Marker levels were described as medians and interquartile ranges $\left(25^{\text {th }}\right.$ to $75^{\text {th }}$ percentile).

Additional analyses were performed to correct for possible confounders such as the use of oral anticoagulation $(A / C)$, the use of statins, the use of acetylsalicylic acid, duration of follow-up after most recent DVT, and recurrent VTE.

\section{Results}

\section{Patient characteristics}

Ninety subjects were selected, of which eleven were identified as ineligible, because of the presence of inflammatory disease or venous insufficiency. Thus, the total study 
population consisted of 79 subjects. Fifty three patients that experienced one or more episodes of DVT were included; of those, 26 patients were diagnosed with PTS (cases) and 27 patients did not have a diagnosis of PTS (controls). Furthermore, $26 \mathrm{HI}$ without a history of VTE were included. Median Villalta score (average of 1-4 measurements) was 7 (interquartile range (IQR): 6-10) for the cases and 2 (IQR: 1-3) for the controls. Among the cases, PTS was mild in twelve patients (Villalta score 5-9), moderate in ten patients (Villalta score 10-14), and severe in four patients (Villalta score $\geq 15$ ).

Thirteen cases and nine controls had a history of recurrent (two or more) VTE events. The median duration of follow-up after the most recent DVT was 63 months.

Cases, controls, and $\mathrm{HI}$ were matched for gender, age, and $\mathrm{BMI}$, and there were no significant differences between the three groups for these variables. In addition there were no significant differences between cases and controls in duration of follow-up after most recent DVT, extent and site of most recent DVT, or recurrent VTE. The most recent DVT was significantly more often provoked in patients with PTS than in patients without PTS. Baseline characteristics of the study population are shown in Table 4.1.

\section{Markers of coagulation and fibrinolysis}

Patients using A/C (15 cases, 7 controls) were excluded from the analyses of D-dimer, TAT, and APC-ratio, as these markers are affected by the use of A/C. Median levels of $\mathrm{D}$-dimer were significantly higher in patients (cases and controls) compared to $\mathrm{HI}$ $(p=0.010)$.(Table 4.2) D-dimer levels in cases and controls were not significantly different.(Table 4.3, Figure 4.1) However, a trend of decreasing D-dimer was found from cases, to controls, and $\mathrm{HI} \mathrm{p}=0.010$.

There were no significant differences between patients (cases and controls) and $\mathrm{HI}$ in TAT levels. However, there were significant differences between the three groups.(Table 4.2) Median TAT levels were significantly higher in cases compared to controls $(p=0.032)$, and $\mathrm{HI}(\mathrm{p}=0.017)$.(Table 4.3, Figure 4.1)

Two cases, 2 controls, and $1 \mathrm{HI}$ were found to be APC-resistant (defined as an APCratio of $<2.39$ ). Excluding these $A P C$-resistant patients from the analyses did not alter any of the results.

The APC-ratio was not found to be significantly different in patients (cases and controls) compared to HI.(Table 4.2) When comparing the three groups, the APC-ratio was found to be significantly lower in cases compared to controls $(p=0.032)$, and $\mathrm{HI}$ ( $p=0.011$ ).(Table 4.3, Figure 4.2)

Patients (cases and controls) had lower median levels of proTAFI as compared to $\mathrm{HI}$ $(p=0.002)$.(Table 4.2) There was a significant trend of increasing proTAFI from cases, to controls, and $\mathrm{HI}(\mathrm{p}=0.002)$. (Table 4.2)

Median levels of tPA were found to be higher in patients (cases and controls) as compared to $\mathrm{HI}$, however this difference was not significant. When comparing the three groups, this difference was only significant for controls versus $\mathrm{HI}(\mathrm{p}=0.010)$, and not for cases versus HI. Levels of tPA tended to be lower in cases than in controls, 
however this was not a significant difference.(Figure 4.2) Levels of PAI and PAP did neither differ significantly between patients (cases and controls) and $\mathrm{HI}$, nor between the three groups.(Table 4.2)

Table 4.1 Baseline characteristics.

\begin{tabular}{|c|c|c|c|}
\hline & $\begin{array}{l}\text { Cases } \\
(n=26)\end{array}$ & $\begin{array}{l}\text { Controls } \\
(n=27)\end{array}$ & $\begin{array}{l}\mathrm{HI} \\
(n=26)\end{array}$ \\
\hline \multicolumn{4}{|l|}{ Gender } \\
\hline Male & $12(46.2 \%)$ & $13(48.1 \%)$ & $12(46.2 \%)$ \\
\hline Female & $14(53.8 \%)$ & $14(51.9 \%)$ & $14(53.8 \%)$ \\
\hline \multicolumn{4}{|l|}{ Age } \\
\hline Median (IQR) & $64(47-77)$ & $63(56-75)$ & $61(58-67)$ \\
\hline \multicolumn{4}{|l|}{ BMI } \\
\hline Median (IQR) & $28(25-32)$ & $26(24-31)$ & $26(25-29)$ \\
\hline \multicolumn{4}{|l|}{ Average Villalta score* } \\
\hline Median (IQR) & $7(6-10)$ & $2(1-3)$ & $\mathrm{n} / \mathrm{a}$ \\
\hline \multicolumn{4}{|l|}{ Characteristics of most recent episode of DVT } \\
\hline Median time since DVT diagnosis (IQR) & 51 months (31-73) & 64 months (41-92) & $\mathrm{n} / \mathrm{a}$ \\
\hline Highest extent & & & $\mathrm{n} / \mathrm{a}$ \\
\hline Iliac or femoral vein & $15(57.7 \%)$ & $13(48.1 \%)$ & $\mathrm{n} / \mathrm{a}$ \\
\hline Popliteal vein & $10(38.5 \%)$ & $12(44.5 \%)$ & $\mathrm{n} / \mathrm{a}$ \\
\hline Isolated calf & $1(3.8 \%)$ & $2(7.4 \%)$ & $\mathrm{n} / \mathrm{a}$ \\
\hline \multicolumn{4}{|l|}{ Side } \\
\hline Right & $9(34.6 \%)$ & $14(51.9 \%)$ & $\mathrm{n} / \mathrm{a}$ \\
\hline Left & $17(65.4 \%)$ & $13(48.1 \%)$ & $\mathrm{n} / \mathrm{a}$ \\
\hline \multicolumn{4}{|l|}{ Provoked/Unprovoked } \\
\hline Provoked & $19(73.1 \%)$ & $8(29.6 \%)$ & $\mathrm{n} / \mathrm{a}$ \\
\hline Unprovoked & $6(23.1 \%)$ & $19(70.4 \%)$ & $\mathrm{n} / \mathrm{a}$ \\
\hline Unknown & $1(3.8 \%)$ & $0(0.0 \%)$ & $\mathrm{n} / \mathrm{a}$ \\
\hline Concurrent symptomatic pulmonary embolism & $1(3.8 \%)$ & $2(7.4 \%)$ & $\mathrm{n} / \mathrm{a}$ \\
\hline Previous DVT & $13(50.0 \%)$ & $7(25.9 \%)$ & $\mathrm{n} / \mathrm{a}$ \\
\hline Previous ipsilateral DVT & $9(34.6 \%)$ & $4(14.8 \%)$ & $\mathrm{n} / \mathrm{a}$ \\
\hline Previous PE & $0(0.0 \%)$ & $2(7.4 \%)$ & $\mathrm{n} / \mathrm{a}$ \\
\hline Distal DVT only** & $0(0.0 \%)$ & $1(3.7 \%)$ & $\mathrm{n} / \mathrm{a}$ \\
\hline \multicolumn{4}{|l|}{$\mathrm{A} / \mathrm{C}$} \\
\hline Yes & $15(57.7 \%)$ & 7 (25.9\%) & $0(0 \%)$ \\
\hline No & $11(42.3 \%)$ & $20(74.1 \%)$ & $26(100 \%)$ \\
\hline \multicolumn{4}{|l|}{ Statins } \\
\hline Yes & $9(34.6 \%)$ & $9(33.3 \%)$ & $5(19.2 \%)$ \\
\hline No & $17(65.4 \%)$ & $18(66.7 \%)$ & $21(80.8 \%)$ \\
\hline \multicolumn{4}{|l|}{ Aspirin } \\
\hline Yes & $4(15.4 \%)$ & $4(14.8 \%)$ & $5(19.2 \%)$ \\
\hline No & $22(84.6 \%)$ & $23(85.2 \%)$ & $21(80.8 \%)$ \\
\hline
\end{tabular}

$\mathrm{A} / \mathrm{C}$, oral anticoagulation; VTE, venous thromboembolism; $\mathrm{n} / \mathrm{a}$, not applicable. * Average of 1-4 measurements of Villalta score. ${ }^{* *}$ Only episode(s) of distal DVT during follow-up. 

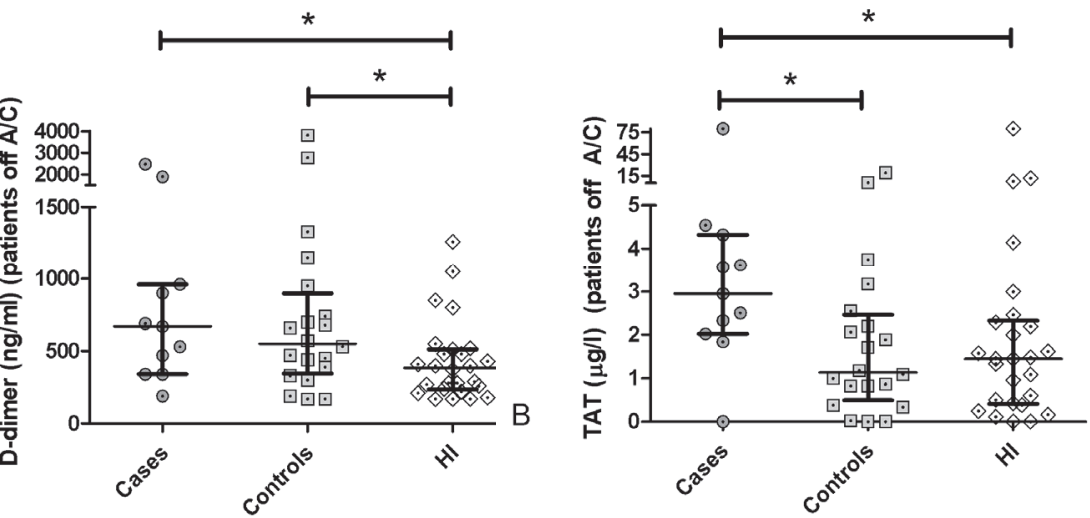

Figure 4.1 Markers of coagulation. Levels of A) D-dimer (Patients on oral anticoagulants excluded from analyses), and B) TAT (Patients on oral anticoagulants excluded from analyses). The circles, squares, and diamonds represent individual subjects. The whiskers depict the median with interquartile ranges. The dark grey circles represent the cases, the light grey squares represent the controls, and the open diamonds represent the $\mathrm{HI} .{ }^{*} \mathrm{p}<0.05$ ( $\mathrm{p}$-values of post hoc Mann Whitney U test).

Table 4.2 Biomarkers: patients (cases and controls) versus healthy individuals.

\begin{tabular}{|c|c|c|c|}
\hline Markers & $\begin{array}{l}\text { Patients (cases } \\
\text { controls) } \\
(\mathrm{n}=53) \\
\text { Median (IQR) }\end{array}$ & $\begin{array}{l}\text { and Healthy individals } \\
(\mathrm{n}=26) \\
\text { Median (IQR) }\end{array}$ & $\mathbf{p}$ \\
\hline \multicolumn{4}{|c|}{ Coagulation and fibrinolysis } \\
\hline APC-ratio* & $3.4(2.6-3.6)$ & $3.5(2.9-3.9)$ & 0.102 \\
\hline D-dimer (ng/ml)* & $570(340-950)$ & $385(235-513)$ & 0.010 \\
\hline $\mathrm{PAI}(\mathrm{ng} / \mathrm{ml})$ & $0.04(0.04-0.05)$ & $0.04(0.04-0.17)$ & 0.820 \\
\hline PAP (ng/ml) & 303.0 (267.0-371.9) & $299.2(260.7-369.4)$ & 0.574 \\
\hline proTAFI (\%) & $96.8(86.5-108.3)$ & $111.1(96.1-127.0)$ & 0.002 \\
\hline TAT $(\mu \mathrm{g} / \mathrm{l})^{*}$ & $2.0(0.8-3.6)$ & $1.4(0.4-2.3)$ & 0.279 \\
\hline $\mathrm{tPA}(\mathrm{ng} / \mathrm{ml})$ & $8.7(6.0-10.5)$ & $6.6(5.1-8.7)$ & 0.038 \\
\hline \multicolumn{4}{|l|}{ Inflammation } \\
\hline $\mathrm{CRP}(\mu \mathrm{g} / \mathrm{ml})$ & $1.8(0.9-3.4)$ & $2.9(1.0-6.0)$ & 0.356 \\
\hline II-6 (pg/ml) & $1.6(1.2-2.6)$ & $1.3(0.9-1.8)$ & 0.047 \\
\hline $\mathrm{II}-8(\mathrm{pg} / \mathrm{ml})$ & $3.1(2.3-4.3)$ & $3.2(2.5-3.8)$ & 0.703 \\
\hline \multicolumn{4}{|l|}{ Tissue remodelling } \\
\hline MMP-9 (ng/ml) & $42(32-59)$ & $38(22-51)$ & 0.150 \\
\hline \multicolumn{4}{|c|}{ Adhesion and endothelial function } \\
\hline P-selectin (ng/ml) & $39(32-53)$ & $44(36-51)$ & 0.541 \\
\hline sICAM-1 (ng/ml) & $274(243-328)$ & $271(234-313)$ & 0.735 \\
\hline sVCAM-1 (ng/ml) & $433(383-547)$ & 396 (327-479) & 0.049 \\
\hline $\mathrm{TM}(\mathrm{ng} / \mathrm{ml})$ & $4.1(3.7-5.2)$ & $3.7(3.2-4.1)$ & 0.032 \\
\hline vWF (\%) & $184(151-226)$ & 145 (89-193) & 0.003 \\
\hline
\end{tabular}

APC, activated protein C; CRP, C-reactive protein; HI, healthy individuals; II-6/8, interleukin 6/8; MMP-9, matrix metalloprotease 9; PAI-1, tissue-plasminogen activator inhibitor type 1; PAP, plasmin-alpha(2)antiplasmin complex; proTAFI, pro thrombin activatable fibrinolysis inhibitor; sICAM-1, soluble intercellular cell adhesion molecule 1; sVCAM-1, soluble vascular cell adhesion molecule 1; TAT, thrombin:antithrombin complex; TM, thrombomodulin; tPA, tissue plasminogen activator; vWF, von Willebrand factor. P-values of 
Mann Whitney $\mathrm{U}$ test. *Patients on oral anticoagulants excluded from analyses.

A

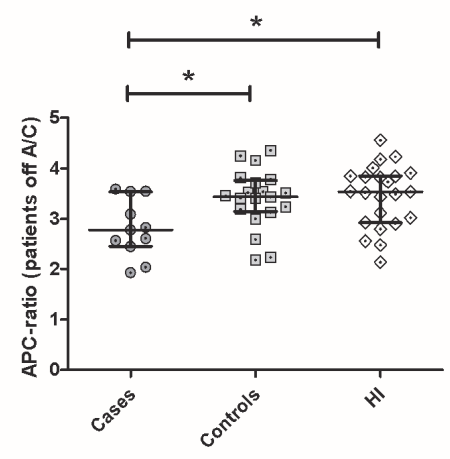

$\mathrm{B}$

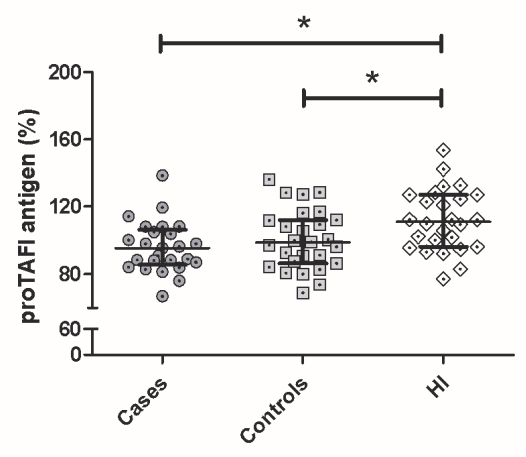

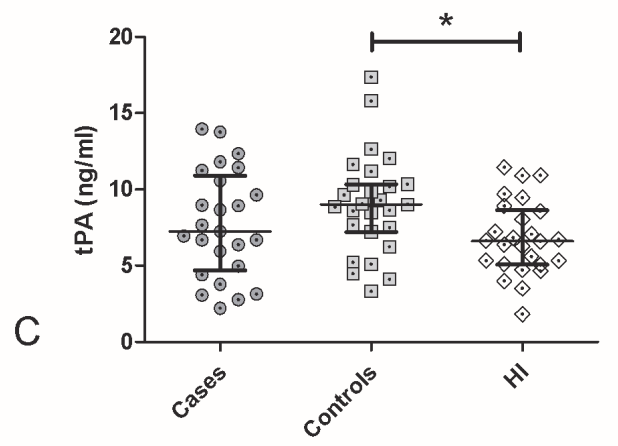

Figure 4.2 Markers of coagulation and fibrinolysis. Levels of A) APC-ratio (patients on oral anticoagulants excluded from analyses), B) proTAFI, and C) tPA. The circles, squares, and diamonds represent individual subjects. The whiskers depict the median with interquartile ranges. The dark grey circles represent the cases, the light grey squares represent the controls, and the open diamonds represent the HI. ${ }^{*} p<0.05$ ( $p$-values of post hoc Mann Whitney $U$ test).

\section{Markers of inflammation and tissue remodelling}

II-6 was significantly higher in patients (cases and controls) compared to $\mathrm{HI}$ $(p=0.047)$.(Table 4.2) However, there were no significant differences between the three groups.(Table 4.3) Furthermore, we did not find any differences between patients (cases and controls) and $\mathrm{HI}$ or between the three groups in levels of CRP, II-8, or MMP-9.(Table 4.2) However, in patients (cases and controls) who had the most recent DVT $\leq 36$ months ago, levels of MMP-9 were found to be significantly higher (56 $\mathrm{ng} / \mathrm{ml}$ [43-80]), than in patients who had the last DVT >36 months ago ( $38 \mathrm{ng} / \mathrm{ml}$ [2951]) $(p=0.007)$. When cases and controls were analysed separately, this difference over time was only significant for the cases $(53 \mathrm{ng} / \mathrm{ml}$ [45-85] versus $41 \mathrm{ng} / \mathrm{ml}$ [26-58] $\mathrm{p}=0.039$ ), and not for the controls.(Figure 4.3) 
Table 4.3 Biomarkers: cases, controls, healthy individuals.

\begin{tabular}{|c|c|c|c|c|c|c|}
\hline \multirow[t]{4}{*}{ Markers } & $\begin{array}{l}\text { Cases } \\
(\mathrm{n}=26) \\
\text { Median (IQR) }\end{array}$ & $\begin{array}{l}\text { Controls } \\
(n=27) \\
\text { Median (IQR) }\end{array}$ & $\mathbf{p}$ & $\begin{array}{l}\text { HI } \\
(n=26) \\
\text { Median (IQR) }\end{array}$ & $\mathbf{p}$ & $\mathbf{p}$ \\
\hline & & & Cases & & Cases & Controls \\
\hline & & & vs. & & vs. & vs. \\
\hline & & & Controls & & $H I$ & $H I$ \\
\hline \multicolumn{7}{|l|}{$\begin{array}{l}\text { Coagulation and } \\
\text { fibrinolysis }\end{array}$} \\
\hline APC-ratio* & $2.8(2.5-3.5)$ & $3.4(3.1-3.8)$ & 0.032 & $3.5(2.9-3.9)$ & 0.011 & 0.543 \\
\hline D-dimer $(\mathrm{ng} / \mathrm{ml})^{*}$ & $670(340-960)$ & $550(345-898)$ & 0.611 & $385(235-513)$ & 0.026 & 0.039 \\
\hline proTAFI (\%) & $95.3(85.6-106.4)$ & $98.8(86.3-112.1)$ & 0.355 & 111.1 (96.1-127.0) & 0.002 & 0.031 \\
\hline $\operatorname{TAT}(\mu \mathrm{g} / \mathrm{I})^{*}$ & $2.9(2.0-4.3)$ & $1.1(0.5-2.5)$ & 0.032 & $1.4(0.4-2.3)$ & 0.017 & 0.947 \\
\hline tPA (ng/ml) & $7.2(4.7-10.9)$ & $9.0(7.2-10.3)$ & 0.197 & $6.6(5.1-8.7)$ & 0.337 & 0.010 \\
\hline \multicolumn{7}{|l|}{ Inflammation } \\
\hline II-6 (pg/ml) & $1.6(1.1-2.8)$ & $1.7(1.2-2.0)$ & 0.735 & $1.3(0.9-1.8)$ & 0.065 & 0.111 \\
\hline \multicolumn{7}{|l|}{$\begin{array}{l}\text { Adhesion and } \\
\text { endothelial function }\end{array}$} \\
\hline sVCAM-1 (ng/ml) & 437 (409-553) & 427 (364-515) & 0.337 & 396 (327-479) & 0.033 & 0.200 \\
\hline $\mathrm{TM}$ (ng/ml) & $4.0(3.1-4.5)$ & $4.5(3.9-5.3)$ & 0.052 & $3.7(3.2-4.1)$ & 0.447 & 0.003 \\
\hline vWF (\%) & $175(146-201)$ & $197(169-234)$ & 0.100 & $145(89-193)$ & 0.051 & 0.002 \\
\hline
\end{tabular}

APC, activated protein C; CRP, C-reactive protein; HI, healthy individuals; II-6, interleukin 6; proTAFI, pro thrombin activatable fibrinolysis inhibitor; sVCAM-1, soluble vascular cell adhesion molecule 1; TAT, thrombin:antithrombin complex; TM, thrombomodulin; tPA, tissue plasminogen activator; vWF, von Willebrand factor. P-values of post hoc Mann Whitney $U$ test. *Patients on oral anticoagulants excluded from analyses.

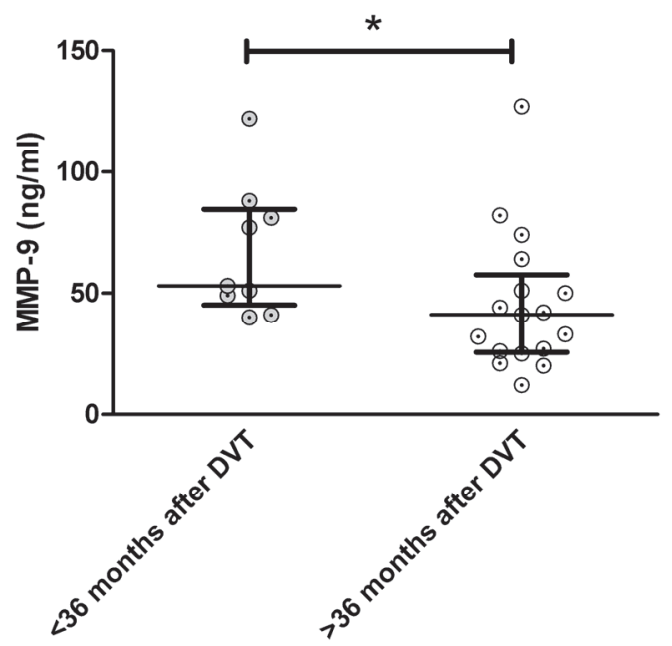

Figure 4.3 MMP-9 relative to time after most recent DVT. The circles represent individual subjects. The whiskers depict the median with interquartile ranges. The grey circles represent the cases who had the most recent DVT $\leq 36$ months ago. The open circles represent the cases who had the most recent DVT $>36$ months ago. ${ }^{*} p<0.05$ ( $p$-value of Mann Whitney $U$ test). 


\section{Markers of adhesion and endothelial function}

Median levels of sVCAM-1 were found to be significantly higher in patients (cases and controls) compared to $\mathrm{HI}(\mathrm{p}=0.049)$.(Table 4.2) There were no differences in sVCAM-1 between cases and controls, although median levels of SVCAM-1 were found to be significantly higher in cases as compared to $\mathrm{HI}(\mathrm{p}=0.033)$.(Table 4.3, Figure 4.4) In addition, a significant trend of decreasing SVCAM-1 was found: cases, controls, and $\mathrm{HI}$ $(p=0.029)$.
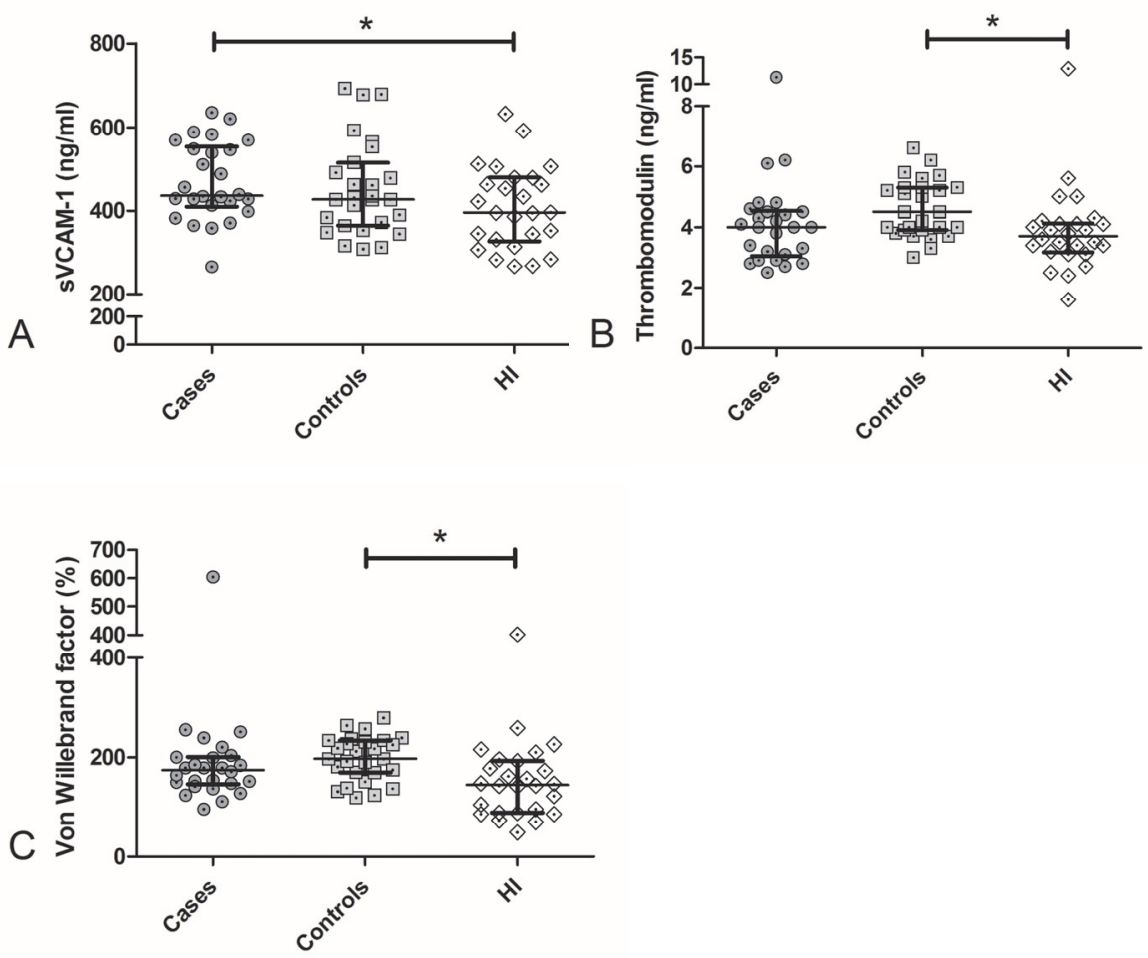

Figure 4.4 Markers of adhesion and endothelial function. Levels of A) SVCAM-1, B) Thrombomodulin, and C) von Willebrand factor. The circles, squares, and diamonds represent individual subjects. The whiskers depict the median with interquartile ranges. The dark grey circles represent the cases, the light grey squares represent the controls, and the open diamonds represent the $\mathrm{HI}$.

$* p<0.05$ ( $p$-values of post hoc Mann Whitney $U$ test).

Median levels of TM were found to be higher in patients (cases and controls) than in $\mathrm{HI}(\mathrm{p}=0.032)$. (Table 4.2) This difference was only significant for controls versus $\mathrm{HI}$ ( $p=0.003$ ), and not for cases versus HI.(Table 4.3, Figure 4.4) Levels of TM tended to be lower in cases than in controls; however this was not a significant 
difference.(Figure 4.4) A similar pattern was found for levels of vWF. Median levels of VWF were higher in patients (cases and controls) than in $\mathrm{HI}(\mathrm{p}=0.003)$.(Table 4.2) This difference was only significant for controls versus $\mathrm{HI}(p=0.002)$, and not for cases versus HI.(Table 4.3, Figure 4.4) Although levels of vWF did not differ significantly between cases and controls, levels tended to be lower in cases.

No significant differences between patients (cases and controls) and $\mathrm{HI}$ or between the three groups were found in levels of P-selectin or sICAM-1.(Table 4.2.)

MMP-9 was the only marker for which significant differences in levels were seen in relation to the duration of follow-up after most recent DVT. Furthermore, we did not find significant differences for any of the markers between patients with and patients without recurrent VTE.

Use of statins or acetylsalicylic acid did not alter the results.

\section{Discussion}

In this study we aimed to assess the association of biomarkers, selected based on a systematic literature review, with different elements of the presumed pathogenesis of PTS. A panel of blood biomarkers was measured in patients after DVT with or without PTS. The median duration of follow-up after the most recent DVT was 63 months. At this point in time, there was no indication of enhanced inflammation in patients with PTS, as levels of CRP, II-6, and II-8 were neither increased nor different. This is in contrast to previous studies that did find an association between increased levels of CRP and II-6 and PTS. ${ }^{22,23}$ However, in these studies blood sampling was performed at respectively 4 and 12 months after DVT, which, theoretically, may still reflect some residual inflammatory activity. ${ }^{22,23}$ An increased or prolonged inflammatory response could not be substantiated in patients with PTS, with a median follow up of 63 months after DVT. This could also be due to a lack of power of the present study. Patients with PTS were found to have a more pronounced coagulation activity, as suggested by higher levels of D-dimer and TAT. This is consistent with previous studies, which reported a clear association between increased levels of D-dimer and PTS. ${ }^{22,24,25}$ There were no differences in levels of PAI between the three groups. Interestingly, patients with PTS appeared to have lower levels of proTAFI. ProTAFI is a proenzyme that can be activated to TAFI by trypsin, thrombin, or plasmin. When thrombin is bound to TM, the potential to activate proTAFI is 1250 times increased. TAFI removes the C-terminal lysine residues from fibrin, resulting in a decreased rate of plasminogen activation and decreased fibrinolysis. ${ }^{18}$ As these patients have higher levels of D-dimer and TAT, thrombin levels are apparently elevated, also allowing thrombin to convert proTAFI to active TAFI, yielding lower proTAFI antigen levels. We did not perform functional fibrinolysis tests and therefore were not able to directly correlate the lower proTAFI levels to the fibrinolysis potential. 
Although APC-resistance was equally distributed over the three groups, the APC-ratio was significantly lower in cases, somewhat higher in controls, and highest in $\mathrm{HI}$. A reduced sensitivity for APC, reflected in a lower APC-ratio, increases the risk of venous thrombosis in a dose dependent manner. ${ }^{26,27}$ In addition, reduced sensitivity to activated protein $\mathrm{C}$ could also be a risk factor for PTS due to reduced fibrinolysis. ${ }^{28,29}$ In a recent review and meta-analysis on biomarkers and PTS we found FVL to be a risk factor for severe PTS, and suggested that impaired fibrinolysis due to APC-resistance could be the underlying mechanism. ${ }^{20}$ Down regulation of thrombin generation, through the APC pathway, leads to inhibition of FXIII activation and consequent $\alpha(2)$-plasmin inhibitor-fibrin cross-linking, resulting in a pro fibrinolytic effect. ${ }^{30}$ In our study, this mechanism could be hampered in the patients with PTS, as APC-ratio and consequent down regulation of thrombin generation are decreased. Although it is not known whether reduced sensitivity for APC also causes impaired fibrinolysis in a dosedependent way, one could speculate that the lower APC-ratio in patients with PTS renders a decreased fibrinolysis.

MMP-9 levels appeared to be dependent on the time passed since the most recent DVT. Only in patients with PTS, MMP-9 levels were significantly higher in those patients that had a DVT $\leq 36$ months ago, compared to those patients that experienced a DVT >36 months ago. This suggests that active tissue remodelling is present in patients with PTS, only within a certain time frame. So far, no other studies assessed the role of MMPs in relation to PTS.

We found a trend of SVCAM-1 being higher in cases compared to controls and $\mathrm{HI}$, while there were no differences in levels of sICAM-1 between the three groups. The vascular endothelium is of vital importance for homeostasis and is reactive to changes in the circulation. ${ }^{31}$ VCAM-1 and ICAM-1 are cell adhesion molecules bound to the membrane of endothelial cells and regulators of trans endothelial migration of leukocytes. These cell adhesion molecules also exist in soluble form, present in the circulation after proteolytic cleavage from the cell membrane. ${ }^{32,33}$ Soluble cell adhesion molecules are markers of endothelial activation and found to be increased in several inflammatory conditions and in chronic venous insufficiency, a condition closely related to PTS. ${ }^{13,34,35}$ Local shear stress affects the expression of adhesion molecules. In arteries, low shear stress up regulated VCAM-1 expression and down regulated ICAM-1 expression. ${ }^{36}$ Decreased shear stress in arteries, equals a level of shear stress which is still elevated for veins. ${ }^{37}$ This could explain the expression pattern of adhesion molecules found in this study.

Besides cell adhesion molecules, increased levels of TM, VWF, and TPA also reflect endothelial activation. ${ }^{31,34}$ In this study, TM, VWF, and tPA were found to be higher in patients, compared to HI. Our data suggest endothelial activation in patients after DVT as compared to $\mathrm{HI}$, either as a consequence of their hypercoagulability or because of various degrees of venous hypertension. Although SVCAM-1 is higher in patients with PTS, the tendency to lower levels of TM, VWF, and tPA in cases compared to controls, could indicate exhaustion of the endothelial cells, possibly due to long term venous 
hypertension or more severe venous hypertension. However, the evidence generated in this study only allows for speculation about the underlying pathophysiology.

Strengths of the present study are the measurement of a literature based elaborate panel of biomarkers, reflecting different elements of proposed pathogenic mechanisms of PTS, in a well-defined population of cases and controls, with a direct reference to a normal control population of comparable age and sex. Limitations are the small sample size and the blood sampling at one point in time, different for all patients with respect to their DVT, due to the cross-sectional design. Furthermore, a limitation that concerns all studies on PTS is the lack of specificity of the Villalta score as a diagnostic tool for PTS.

\section{Conclusion}

The proposed mechanisms for the etiology of PTS as described in the experimental literature: impaired fibrinolysis, increased and continued inflammation, tissue remodelling, and endothelial activation, were tested in patients making use of a selected panel of biomarkers. We found direct evidence of increased coagulant activity in patients with PTS (D-dimer and TAT) and indirect indications of impaired fibrinolysis (lower APC-ratio and proTAFI levels) associated with PTS, whereas there was no evidence for increased inflammation. We observed signs of enhanced tissue remodelling in patients with PTS, at time points earlier than 36 months after DVT and found direct evidence for endothelial activation. Based on the pattern of the biomarker levels in patients with PTS, we speculate that exhaustion of the endothelial cells develops in these patients, as a result of prolonged venous hypertension. 


\section{References}

1. Kahn SR, Shrier I, Julian JA, Ducruet T, Arsenault L, Miron MJ, Roussin A, Desmarais S, Joyal F, Kassis J, Solymoss S, Desjardins L, Lamping DL, Johri M, Ginsberg JS. Determinants and time course of the postthrombotic syndrome after acute deep venous thrombosis. Ann Intern Med 2008;149:698-707.

2. Prandoni P, Villalta S, Bagatella P, Rossi L, Marchiori A, Piccioli A, Bernardi E, Girolami B, Simioni $P$, Girolami A. The clinical course of deep-vein thrombosis. Prospective long-term follow-up of 528 symptomatic patients. Haematologica 1997;82:423-8.

3. Brandjes DP, Büller HR, Heijboer $H$, Huisman MV, de Rijk M, Jagt $H$, ten Cate JW. Randomised trial of effect of compression stockings in patients with symptomatic proximal-vein thrombosis. Lancet 1997; 349:759-62.

4. Pesavento R, Villalta S, Prandoni P. The postthrombotic syndrome. Intern Emerg Med 2010;5:185-92.

5. Prandoni $P$, Kahn SR. Post-thrombotic syndrome: prevalence, prognostication and need for progress. Br J Haematol 2009;145:286-95.

6. Bergqvist D, Jendteg S, Johansen L, Persson U, Odegaard K. Cost of long-term complications of deep venous thrombosis of the lower extremities: an analysis of a defined patient population in Sweden. Ann Intern Med 1997;126:454-7.

7. Villalta S, Bagatella P, Picolli A, Lensing A, Prins M, Prandoni P. Assessment of validity and reproducibility of a clinical scale for the post thrombotic syndrome (abstract). Haemostasis 1994: 158a.

8. Henke PK, Comerota AJ. An update on etiology, prevention, and therapy of postthrombotic syndrome. J Vasc Surg 2011;53:500-9.

9. Kahn SR. The post thrombotic syndrome. Thromb Res 2011;127 Suppl 3:S89-92.

10. Phillips LJ, 2nd, Sarkar R. Molecular characterization of post-thrombotic syndrome. J Vasc Surg 2007;45 Suppl A: A116-22.

11. Deroo S, Deatrick KB, Henke PK. The vessel wall: A forgotten player in post thrombotic syndrome. Thromb Haemost 2010;104:681-92.

12. Kahn SR. The post-thrombotic syndrome: progress and pitfalls. Br J Haematol 2006; 134(4): 357-65.

13. Saharay M, Shields DA, Georgiannos SN, Porter JB, Scurr JH, Coleridge Smith PD. Endothelial activation in patients with chronic venous disease. Eur J Vasc Endovasc Surg 1998;15:342-9.

14. Lee AJ, Lowe GD, Rumley A, Ruckley CV, Fowkes FG. Haemostatic factors and risk of varicose veins and chronic venous insufficiency: Edinburgh Vein Study. Blood Coagul Fibrinolysis 2000;11:775-81.

15. Yasim A, Kilinc M, Aral M, Oksuz H, Kabalci M, Eroglu E, Imrek S. Serum concentration of procoagulant, endothelial and oxidative stress markers in early primary varicose veins. Phlebology 2008;23:15-20.

16. Meissner MH, Wakefield TW, Ascher E, Caprini JA, Comerota AJ, Eklof B, Gillespie DL, Greenfield LJ, He AR, Henke PK, Hingorani A, Hull RD, Kessler CM, McBane RD, McLafferty R. Acute venous disease: venous thrombosis and venous trauma. J Vasc Surg 2007; 46 Suppl S: 25S-53S.

17. Wakefield TW, Myers DD, Henke PK. Mechanisms of venous thrombosis and resolution. Arterioscler Thromb Vasc Biol 2008;28:387-91.

18. Leurs J, Hendriks D. Carboxypeptidase U (TAFla): a metallocarboxypeptidase with a distinct role in haemostasis and a possible risk factor for thrombotic disease. Thromb Haemost 2005;94:471-87.

19. Deatrick KB, Obi A, Luke CE, Elfline MA, Sood V, Upchurch GR Jr, Jaffer F, Wakefield TW, Henke PK. Matrix metalloproteinase- 9 deletion is associated with decreased mid-term vein wall fibrosis in experimental stasis DVT. Thromb Res 2013;132:360-6.

20. Bouman AC, Atalay $\mathrm{S}$, ten Cate $\mathrm{H}$, ten Wolde $\mathrm{M}$, ten Cate-Hoek AJ. Biomarkers for post-thrombotic syndrome. Journal of Vascular Surgery: Venous and Lymphatic Disorders 2014;2: 79-88.

21. van Bussel BC, Ferreira I, van de Waarenburg MP, van Greevenbroek MM, van der Kallen CJ, Henry RM, Feskens EJ, Stehouwer CD, Schalkwijk CG. Multiple inflammatory biomarker detection in a prospective cohort study: a cross-validation between well-established single-biomarker techniques and an electrochemiluminescense-based multi-array platform. PLoS One 2013;8:e58576.

22. Bouman AC, Smits JJ, Ten Cate H, Ten Cate-Hoek AJ. Markers of coagulation, fibrinolysis and inflammation in relation to post-thrombotic syndrome. J Thromb Haemost 2012;10:1532-8.

23. Shbaklo H, Holcroft CA, Kahn SR. Levels of inflammatory markers and the development of the postthrombotic syndrome. Thromb Haemost 2009;101:505-12. 
24. Latella J, Desmarais S, Miron MJ, Roussin A, Joyal F, Kassis J, Solymoss S, Desjardins L, Ginsberg JS, Kahn SR. Relation between D-dimer level, venous valvular reflux and the development of postthrombotic syndrome after deep vein thrombosis. J Thromb Haemost 2010;8:2169-75.

25. Stain M, Schonauer V, Minar E, Bialonczyk C, Hirschl M, Weltermann A, Kyrle PA, Eichinger S. The postthrombotic syndrome: risk factors and impact on the course of thrombotic disease. J Thromb Haemost 2005;3:2671-6.

26. de Visser MC, Rosendaal FR, Bertina RM. A reduced sensitivity for activated protein $C$ in the absence of factor $V$ Leiden increases the risk of venous thrombosis. Blood 1999;93:1271-6.

27. Rodeghiero F, Tosetto A. Activated protein C resistance and factor $V$ Leiden mutation are independent risk factors for venous thromboembolism. Ann Intern Med 1999;130:643-50.

28. Bajzar L, Nesheim M. The effect of activated protein C on fibrinolysis in cell-free plasma can be attributed specifically to attenuation of prothrombin activation. J Biol Chem 1993;268:8608-16.

29. Sakata Y, Loskutoff DJ, Gladson CL, Hekman CM, Griffin JH. Mechanism of protein C-dependent clot lysis: role of plasminogen activator inhibitor. Blood 1986;68:1218-23.

30. Koncz Z, Bagoly Z, Haramura G, Mezei ZA, Muszbek L. Thrombomodulin-dependent effect of factor V Leiden mutation on the cross-linking of alpha2-plasmin inhibitor to fibrin and its consequences on fibrinolysis. Thromb Res 2012;130:528-34.

31. Martin FA, Murphy RP, Cummins PM. Thrombomodulin and the vascular endothelium: insights into functional, regulatory, and therapeutic aspects. Am J Physiol Heart Circ Physiol 2013;304:H1585-97.

32. Champagne B, Tremblay P, Cantin A, St Pierre Y. Proteolytic cleavage of ICAM-1 by human neutrophil elastase. J Immunol 1998;161:6398-405.

33. Hwang SJ, Ballantyne CM, Sharrett AR, Smith LS, Davis CE, Gotto AM, Jr, Boerwinkle E. Circulating adhesion molecules VCAM-1, ICAM-1, and E-selectin in carotid atherosclerosis and incident coronary heart disease cases: the Atherosclerosis Risk In Communities (ARIC) study. Circulation 1997;96:421925.

34. Deanfield JE, Halcox JP, Rabelink TJ. Endothelial function and dysfunction: testing and clinical relevance. Circulation 2007;115:1285-95.

35. Tardif JC, Heinonen T, Orloff D, Libby P. Vascular biomarkers and surrogates in cardiovascular disease. Circulation 2006;113:2936-42.

36. Walpola PL, Gotlieb Al, Cybulsky MI, Langille BL. Expression of ICAM-1 and VCAM-1 and monocyte adherence in arteries exposed to altered shear stress. Arterioscler Thromb Vasc Biol 1995;15:2-10.

37. Boisseau MR. Roles of mechanical blood forces in vascular diseases. A clinical overview. Clin Hemorheol Microcirc 2005;33:201-7. 


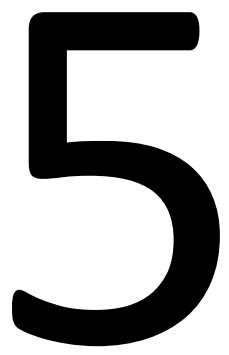

\section{Clot structure and fibrinolytic potential in patients with post thrombotic syndrome}

AC Bouman, $\mathrm{H}$ McPherson, $\mathrm{YW}$ Cheung, $\mathrm{M}$ ten Wolde, $\mathrm{H}$ ten Cate, RAS Ariëns, AJ ten Cate-Hoek

Thrombosis Research 2015;10 


\section{Abstract}

\section{Introduction}

Post thrombotic syndrome (PTS) is a chronic sequel of deep vein thrombosis (DVT). The clot structure and fibrinolytic potential in PTS is currently unknown.

\section{Objective}

To assess the fibrinolytic potential and clot structure in patients with PTS.

\section{Materials and methods}

Patients with a history of DVT were included in a case-control study: patients with PTS (cases $\mathrm{n}=30$ ) and without PTS (controls $\mathrm{n}=30$ ), and 30 apparently healthy individuals (HI) without venous thromboembolism (VTE) or venous insufficiency were enrolled. Fibrinolysis and clot structure were assessed by turbidimetric assays, permeation, and confocal microscopy. Fibrinogen was measured by Clauss and fibrinogen $\gamma^{\prime}$ by ELISA.

\section{Results}

We observed a significant trend of decreasing maximum turbidity from $\mathrm{HI}$ (median 0.52 [IQR $0.46-0.62]$ ), to controls (0.49 [IQR 0.41-0.55]), to cases (0.46 [IQR 0.39-0.49]) $p=0.020$. Fibrinogen was lower in patients (cases and controls) (3.69 g/I [IQR 3.31-4.26]) compared to HI (4.17 [IQR 3.69-4.65]) $\mathrm{p}=0.041$. Patients with recurrent VTE had lower maximum turbidity and lower permeation than patients with one episode of VTE; (0.31 [IQR 0.25-0.39] versus 0.38 [IQR $0.34-0.44] \mathrm{p}=0.008)$ and $\left(6.0 \times 10^{-9} / \mathrm{cm}^{2}\right.$ [IQR 5.1-7.9] versus $7.7 \times 10^{-9} / \mathrm{cm}^{2}$ [IQR 6.0-10.0] $\left.\mathrm{p}=0.047\right)$ respectively, at equal fibrinogen levels. There were no differences in lysis time, confocal microscopy, or fibrinogen $\gamma^{\prime}$.

\section{Conclusions}

Lower maximum turbidity, indicating a tendency towards thinner fibres and denser clots, was found in patients with PTS as well as in patients with recurrent VTE. Fibrinogen levels did not explain these differences in clot structure. The abnormal clot structure may contribute to the increased thrombotic risk profile in patients with PTS. 


\section{Introduction}

Post thrombotic syndrome (PTS) is a long-term complication of deep vein thrombosis (DVT), characterized by chronic complaints of the leg affected by DVT. Patients experience pain, heaviness, cramps, tingling, itching, and/or skin changes, and in severe cases ulceration of the leg can occur. ${ }^{1}$ PTS is a syndrome and is diagnosed based on a clinical score. ${ }^{2}$ PTS significantly reduces quality of life, and associated costs are substantial. ${ }^{3,4}$

According to current consensus, the signs and symptoms of PTS are the end organ manifestation of venous hypertension. Venous hypertension is caused by a combination of reflux of blood, due to destruction of the venous valves; and stiff fibrotic vein walls, due to processes of tissue remodelling; and venous outflow resistance, due to impaired thrombus resolution. ${ }^{5,6}$

Differences in the processes of thrombus formation and thrombus resolution between patients may therefore be associated with the occurrence of PTS. In a recent casecontrol study patients with PTS were found to have a decreased activated protein C (APC) ratio and decreased levels of zymogen thrombin activatable fibrinolysis inhibitor (proTAFI), as compared to controls. ${ }^{7}$ Based on these findings, we hypothesized that patients with PTS might have an impaired fibrinolysis, due to a decreased inhibition of thrombin generation by APC, which results in increased conversion of proTAFI to active TAFI and increased activation of Factor (F) XIII. ${ }^{7,8}$ Apart from impaired fibrinolysis, also fibrin clot structure might contribute to the development of PTS. Recent studies have shown denser fibrin clot structures with smaller pores and increased resistance to fibrinolysis in patients with DVT and other thrombotic disorders. $^{9-13}$ The role of fibrin structure in PTS is currently unknown. Therefore, the aim of the current study is to assess the fibrinolytic potential and the clot structure of patients with PTS, by means of functional fibrinolysis tests and confocal microscopy.

\section{Materials and methods}

\section{Patients and study design}

A case-control study was performed as previously described. ${ }^{7}$ In short, 60 patients with a history of objectively confirmed DVT, 30 patients with PTS and 30 patients without PTS, were recruited from the outpatient clinic of the Maastricht University Medical Centre and the Flevohospital Almere, the Netherlands. Patients who had developed PTS were defined as cases. Patients that had not developed PTS, after a minimal follow-up of 2 years after DVT, were defined as controls. PTS was defined as a Villalta score of $\geq 5$ on two consecutive visits that were at least three months apart. Most patients were followed after DVT and Villalta scores were recorded during follow-up. In case Villalta scores during follow-up were lacking ( 2 patients), diagnosis 
was based upon the Villalta score taken at the time of inclusion in this study, and in that case a single score of $\geq 5$ was defined as PTS.

As a reference to the normal population, apparently healthy individuals $(\mathrm{HI})$ without a history of venous thromboembolism (VTE) were included. For the current analyses subjects with known venous insufficiency were excluded. Cases, controls, and HI were similar in gender, age, and Body Mass Index (BMI).

This study was approved by the Medical Ethical committee of the Maastricht University Medical Centre, and all participants gave written informed consent.

\section{Blood collection and plasma preparation}

Venous blood was collected in citrate $(3,2 \% \mathrm{w} / \mathrm{v})$ and ethylenediaminetetraacetic acid (EDTA) polypropylene tubes for plasma (BD Vacutainer), and in clot activator (coating of micronized silica particles) containing polypropylene tubes for serum (BD Vacutainer). Citrate tubes were centrifuged for 5 minutes at $2500 \mathrm{~g}$ (room temperature) and for 10 minutes at $10000 \mathrm{~g}\left(18^{\circ} \mathrm{C}\right)$. EDTA tubes were centrifuged for 5 minutes at $2500 \mathrm{~g}$ (room temperature). Serum tubes were left for 30 minutes at $37^{\circ} \mathrm{C}$ and consequently centrifuged for 5 minutes at $2500 \mathrm{~g}$ (room temperature). Plasma and serum samples were stored at $-80^{\circ} \mathrm{C}$ until analysis.

\section{Laboratory analyses}

\section{Reagents}

Human Thrombin (Calbiochem, Nottingham, UK) was reconstituted in Milli-Q water and stored in aliquots at $-80^{\circ} \mathrm{C}$ until use. Recombinant tissue plasminogen activator (tPA) (Pathway Diagnostics, Dorking, UK) was dissolved in Milli-Q water and stored in aliquots at $-80^{\circ} \mathrm{C}$. Fibrinogen Alexa Fluor-488 (Life Technologies, Paisley, UK) was diluted in $0.05 \mathrm{M}$ Tris- $\mathrm{HCl}, 0.1 \mathrm{M}$ sodium chloride $(\mathrm{NaCl}), \mathrm{pH} 7.5$ (TBS) to $2.5 \mathrm{mg} / \mathrm{ml}$. Fibri-Prest, Unicalibrator, Coag Control P, Coag Control N and STA -Owren-Koller were from Diagnostica Stago S.A.S, Asnières sur Seine, France. Benzamidine, EDTA, sodium carbonate and Tween-20 were from Sigma-Aldrich, Gillingham, UK. Triethanolamine was from Acros Organics, Geel Belgium. Bovine serum albumin (BSA), calcium chloride $\left(\mathrm{CaCl}_{2}\right), \mathrm{NaCl}$, sulphuric acid and Tris- $\mathrm{HCl}$ were from Fisher Scientific, Loughborough, UK. 3,3',5,5'-Tetramethylbenzidine (TMB) Substrate was from Cell Signaling, Hertfordshire, UK. Mouse antihuman fibrinogen $\gamma^{\prime}$ (2.G2.H9) was from Santa Cruz Biotechnology, Heidelberg Germany. Horseradish peroxidise conjugated rabbit antihuman fibrinogen was from Thermo Scientific, Leicestershire, UK.

\section{Preparation of normal pooled plasma for fibrinogen assays}

Blood samples were collected from free-flowing blood from the antecubital vein without the use of a tourniquet. ${ }^{14}$ Samples were collected on $0.1 \mathrm{~mol} / \mathrm{l}$ sodium citrate 
(9 parts blood per 1 part citrate), then centrifuged at $2400 \mathrm{~g}$ for 20 minutes to separate platelet-poor plasma. Plasma samples from $n=23$ healthy volunteers (staff and students in the laboratory) were pooled and used as standard normal pooled plasma in fibrinogen $\gamma^{\prime}$ assays. The pooled plasma was aliquoted, snap-frozen in liquid nitrogen and stored at $-80^{\circ} \mathrm{C}$. Collection of plasma samples for the normal pool was approved by the local Ethics Committee (HSLTLM/12/045) and informed consent was obtained prior to blood sampling.

\section{Turbidity and fibrinolysis}

Polymerization of plasma samples was studied by turbidity on low binding microtiter well plates (Greiner Bio-One Ltd, Stonehouse, UK) using a Spectra Max plus 384 microtiter plate reader (Molecular Devices, Sunnyvale, CA, USA). ${ }^{14}$ Plasma samples were diluted 1:6 in TBS and the reaction was initiated by addition of $\mathrm{CaCl}_{2}$ (3.33 $\mathrm{mM})$ and thrombin $(0.1 \mathrm{U} / \mathrm{ml}$, final concentrations). The plate was read every 12 seconds at $340 \mathrm{~nm}$ for $1 \mathrm{hr}$ at $37^{\circ} \mathrm{C}$. For fibrinolysis measurements, tPA $(41.5 \mathrm{ng} / \mathrm{ml}$ final concentration) was added to the plasma and TBS mixture before activation. The plate was read every 12 seconds at $340 \mathrm{~nm}$ for 3 hours at $37^{\circ} \mathrm{C}$. Both turbidity and fibrinolysis plasma samples were run in triplicate.

\section{Fibrin pore structure}

Average pore size of the fibrin clot (Darcy constant or Ks) was established by permeation studies. ${ }^{15}$ Permeation measures the flow rate of buffer through a fibrin clot under constant pressure. Plasma samples are mixed with $\mathrm{CaCl}_{2}(16 \mathrm{mM}$ final concentration) and thrombin ( $1 \mathrm{U} / \mathrm{ml}$ final concentration) which were prepared in TBS and incubated in a moist chamber at room temperature for 2 hours. The fibrin clot was washed with TBS for 1 hour and 30 minutes, before droplets were collected and weighed every 30 minutes for 2 hours. The permeation constant was determined by $K s=(Q \times L X \eta) /(T \times A X P)$, expressed in $\mathrm{cm}^{2}$, where $Q=$ volume of liquid $\left(\mathrm{cm}^{3}\right)$, $\mathrm{L}=$ clot length $(\mathrm{cm}), \eta=$ viscosity $\left(\mathrm{N} \mathrm{s} / \mathrm{m}^{2}\right), T=$ time (seconds),$A=$ cross- sectional area $\left(\mathrm{cm}^{2}\right)$, and $\mathrm{P}=$ pressure $\operatorname{drop}\left(\mathrm{N} / \mathrm{m}^{2}\right)$. The Ks is a measure of the average pore-size of the fibrin network.

\section{Confocal microscopy}

Plasma samples, $\mathrm{CaCl}_{2}(5 \mathrm{mM})$ and $5 \%$ AlexaFluor488 fibrinogen were diluted in TBS. ${ }^{16}$ Once thrombin $(0.1 \mathrm{U} / \mathrm{ml}$ final concentration) was added, the samples were briefly mixed and inserted in to a micro chamber ( $\mu$-slide VI 0.4, Ibidi, Glasgow, UK), clots were left to form in the dark in a moist atmosphere for 1 hour and then stored at $4^{\circ} \mathrm{C}$ overnight and analysed the following morning. Clots were observed with $63 \mathrm{x}$ oil immersion objective on a LSM510 Upright confocal microscopy system (Zeiss, Jena, Germany). Optical z stacks were acquired every $2 \mu \mathrm{m}$ over $20 \mu \mathrm{m}$ and then transformed by maximum projection into one image per scanned clot area. Three 
random fields were viewed per clot. Fibre density was obtained by an in-house designed macro (in Image J, Wayne Rasband, NIH) that analyses the number of fibres per area in the clot.

\section{Fibrinogen levels}

Fibrinogen levels were assessed via Fibri-prest automate assay (Diagnostica Stago S.A.S) on a Start 4 coagulometer (Diagnostica Stago S.A.S). ${ }^{17}$ Briefly, an independently moving ball-bearing was inserted into each cuvette. The patient plasma was diluted, added to the cuvette and heated to $37^{\circ} \mathrm{C}$. Clotting was initiated with the addition of fibri-prest automate containing thrombin resulting in clotting of the patient plasma. The clotting time (seconds) was measured from the addition of fibri-prest automate to the time taken for the ball bearing to stop moving independently. The amount of fibrinogen was calculated by the clotting time (seconds), which was measured from the addition of fibri-prest automate to the time taken for the ball bearing to stop moving independently.

\section{Fibrinogen $\gamma^{\prime}$ concentration}

Fibrinogen $\gamma^{\prime}$ concentration was determined through enzyme-linked immunosorbent assay (ELISA). ${ }^{18} \mathrm{~A}$ maxisorp nunc-immuno microtiter plate (Nunc, Leicestershire, UK) was coated with $2 \mu \mathrm{g} / \mathrm{ml}$ of mouse monoclonal anti-human fibrinogen $\gamma^{\prime}$ antibody in $50 \mathrm{mM}$ sodium carbonate $\mathrm{pH} 9.6$ and incubated overnight at $4^{\circ} \mathrm{C}$. The following day the plate was washed with washing buffer $(50 \mathrm{mM}$ triethanolamine, $100 \mathrm{mM} \mathrm{NaCl}$ and $10 \mathrm{mM}$ EDTA) then blocked with $1 \%$ BSA, $50 \mathrm{mM}$ triethanolamine, $100 \mathrm{mM} \mathrm{NaCl}$, $10 \mathrm{mM}$ EDTA and $0.1 \%$ tween-20 at $\mathrm{pH}$ 7.5, and incubated at room temperature for 1 hour on a microtitre plate shaker at $400 \mathrm{rpm}$. Plasma was diluted 1:1600 and 1:3200 in dilution buffer (50 mM triethanolamine, $100 \mathrm{mM} \mathrm{NaCl}, 10 \mathrm{mM}$ EDTA, $0.1 \%$ tween20 and $10 \mathrm{mM}$ benzamidine at $\mathrm{pH}$ 7.5). Normal pooled plasma with a known concentration of fibrinogen $\gamma^{\prime}$ (calibrated against purified $\gamma^{\prime}$ fibrinogen) was used as a standard and prepared in dilution buffer. Horseradish peroxidise conjugated rabbit antihuman fibrinogen was prepared as secondary antibody in dilution buffer and used at 1:20 000. The plate was developed with TMB substrate. The reaction was stopped with $4 \mathrm{M} \mathrm{H}_{2} \mathrm{SO}_{4}$ and the plate was read at $450 \mathrm{~nm}$ with a Thermo Scientific Multiskan Go plate reader. The plate was washed with washing buffer between each step, and for all steps the plate was incubated at room temperature for 1 hour on a shaker unless otherwise stated. Levels were expressed in $\mu \mathrm{g} / \mathrm{ml}$ calculated from the standard curve of normal pooled plasma with known $\gamma^{\prime}$ concentration.

\section{Statistical analyses}

SPSS 21.0 software was used for statistical analyses (SPSS Inc., Chicago, IL, USA). Non-parametric Mann Whitney U-tests were performed to test for differences in test results between patients (cases and controls) and $\mathrm{HI}$, and between patients with a 
history of recurrent VTE and patients with only one episode of VTE. Non-parametric Kruskal-Wallis tests were performed to test for differences in test results between the three groups (cases, controls, $\mathrm{HI}$ ). Mann-Whitney $\mathrm{U}$ tests were performed to test for differences between cases and controls, cases and $\mathrm{HI}$, and controls and $\mathrm{HI}$.

Trend analysis (Jonckheere-Terpstra test) was performed, to test for trends in the data.

Correlation between variables was assessed by Spearman's correlation coefficient.

Test results were described as medians and interquartile ranges (25th to 75th percentile). For all analyses, statistical significance was set as a two-sided p-value of $<0.05$.

\section{Results}

After exclusion of subjects with venous insufficiency $(n=1)$, and subjects of whom no blood samples were left for the laboratory analyses $(n=15)$, the total study population for the current analyses consisted of a total of 74 subjects, 24 cases, 28 controls, and $22 \mathrm{HI}$. For the baseline characteristics of the study population, see Table 5.1. Cases, controls, and $\mathrm{HI}$ were similar for gender, age, and BMI.

Twenty-one patients (cases and controls) had a history of recurrent VTE. Of these 21 patients, 11 developed PTS (cases) and 10 did not develop PTS (controls). A total of 31 patients had only one episode of VTE, of these 31 patients, 13 patients developed PTS (cases) and 18 did not develop PTS (controls).

\section{Turbidity, permeation, and fibrinogen}

\section{Turbidimetric clotting assay}

Maximum turbidity was not different between cases and controls. However, there was a significant trend of decreasing maximum turbidity from $\mathrm{HI}$ (median 0.52 [interquartile range (IQR) $0.46-0.62$ ]), to controls (0.49 [IQR 0.41-0.55]), to cases (0.46 [IQR 0.39-0.49]) $p=0.020$.(Figure $5.1 \mathrm{~A}$ ) The difference in maximum turbidity was most pronounced between $\mathrm{HI}$ (0.52 [IQR 0.46-0.62]) and patients (cases and controls) (0.47 [IQR 0.40-0.53]) $p=0.038$. (Figure 5.2A)

There were no significant differences in duration of the lag phase between patients (cases and controls) and $\mathrm{HI}$, nor between the three groups.(Table 5.2) 
Table 5.1 Baseline characteristics.

\begin{tabular}{|c|c|c|c|}
\hline & Cases $(n=24)$ & Controls $(n=28)$ & $\mathrm{HI}(\mathrm{n}=22)$ \\
\hline \multicolumn{4}{|l|}{ Gender } \\
\hline Male & $12(50 \%)$ & $12(43 \%)$ & $11(50 \%)$ \\
\hline Female & $12(50 \%)$ & $16(57 \%)$ & $11(50 \%)$ \\
\hline \multicolumn{4}{|l|}{ Age } \\
\hline Median (IQR) & $66(49-76)$ & $69(58-78)$ & $63(54-69)$ \\
\hline \multicolumn{4}{|l|}{ BMI } \\
\hline Median (IQR) & $28(25-33)$ & $25(24-31)$ & $26(25-30)$ \\
\hline \multicolumn{4}{|l|}{ Average Villalta* } \\
\hline Median (IQR) & $7(6-8)$ & $2(1-3)$ & $\mathrm{n} / \mathrm{a}$ \\
\hline \multicolumn{4}{|l|}{ Severity PTS** } \\
\hline Mild & $12(50 \%)$ & $\mathrm{n} / \mathrm{a}$ & $\mathrm{n} / \mathrm{a}$ \\
\hline Moderate & $8(33 \%)$ & $\mathrm{n} / \mathrm{a}$ & $\mathrm{n} / \mathrm{a}$ \\
\hline Severe & $4(17 \%)$ & $\mathrm{n} / \mathrm{a}$ & $\mathrm{n} / \mathrm{a}$ \\
\hline \multicolumn{4}{|l|}{ Characteristics most recent DVT } \\
\hline $\begin{array}{l}\text { Median time between DVT and blood } \\
\text { withdrawal for study (IQR) }\end{array}$ & $\begin{array}{l}55 \text { months } \\
(35-78)\end{array}$ & $\begin{array}{l}64 \text { months } \\
(41-91)\end{array}$ & $\mathrm{n} / \mathrm{a}$ \\
\hline \multicolumn{4}{|l|}{ Highest extent } \\
\hline Iliac or femoral & $13(54 \%)$ & $14(50 \%)$ & $\mathrm{n} / \mathrm{a}$ \\
\hline Popliteal & $11(46 \%)$ & $13(46 \%)$ & $\mathrm{n} / \mathrm{a}$ \\
\hline Isolated calf & $0(0 \%)$ & $1(4 \%)$ & $\mathrm{n} / \mathrm{a}$ \\
\hline \multicolumn{4}{|l|}{ Side } \\
\hline Left & $13(54 \%)$ & $15(54 \%)$ & $\mathrm{n} / \mathrm{a}$ \\
\hline Right & $11(46 \%)$ & $13(46 \%)$ & $\mathrm{n} / \mathrm{a}$ \\
\hline \multicolumn{4}{|l|}{ Provoked/unprovoked } \\
\hline Provoked & $6(25 \%)$ & $6(21 \%)$ & $\mathrm{n} / \mathrm{a}$ \\
\hline Unprovoked & $18(75 \%)$ & $22(79 \%)$ & $\mathrm{n} / \mathrm{a}$ \\
\hline Concurrent symptomatic PE & $0(0 \%)$ & $2(7 \%)$ & $\mathrm{n} / \mathrm{a}$ \\
\hline Previous DVT & $10(42 \%)$ & $8(29 \%)$ & $\mathrm{n} / \mathrm{a}$ \\
\hline Previous ipsilateral DVT & 7 (29\%) & $6(21 \%)$ & $\mathrm{n} / \mathrm{a}$ \\
\hline Previous PE & $0(0 \%)$ & $2(7 \%)$ & $\mathrm{n} / \mathrm{a}$ \\
\hline Distal DVT only*** & $0(0 \%)$ & $1(4 \%)$ & $\mathrm{n} / \mathrm{a}$ \\
\hline \multicolumn{4}{|l|}{$\mathrm{A} / \mathrm{C}$} \\
\hline Yes & $11(46 \%)$ & $7(25 \%)$ & $2(9 \%)$ \\
\hline No & $13(54 \%)$ & $21(75 \%)$ & $20(91 \%)$ \\
\hline
\end{tabular}

$\mathrm{A} / \mathrm{C}$, oral anticoagulants; DVT, deep vein thrombosis, $\mathrm{PE}$, pulmonary embolism. *Average of 1-4 measurements of Villalta score; ${ }^{* *}$ Based on highest Villalta score during follow-up; ***Only episodes of distal DVT during follow-up

\section{Turbidimetric lysis assay}

In agreement with the turbidimetric clotting assay, maximum turbidity in the turbidimetric lysis assay was higher in $\mathrm{HI}(0.41$ [IQR 0.33-0.53]) compared to patients (cases and controls) (0.36 [IQR 0.30-0.43]) $\mathrm{p}=0.046$.(Figure 5.2B) There was also a trend of decreasing maximum turbidity form $\mathrm{HI}$ (0.41 [IQR 0.33-0.53]), to controls (0.37 [IQR 0.29-0.44]), to cases (0.36 [IQR 0.30-0.43]), $p=0.057$.(Figure 5.1B) Furthermore, both maximum turbidity and turbidity at $50 \%$ lysis were significantly lower in patients with a history of recurrent VTE compared to patients with only one 
episode of VTE; (0.31 [IQR 0.25-0.39] versus 0.38 [IQR 0.34-0.44] $\mathrm{p}=0.008)$ and $(0.15$ [IQR 0.13-0.20] versus 0.20 [IQR 0.17-0.23] $\mathrm{p}=0.007$ ) respectively.(Figure 5.3A, 5.3B) There were no differences in the time taken for total lysis or $50 \%$ lysis between patients (cases and controls) and $\mathrm{HI}$, nor between the three groups.(Table 5.2)

Both maximum turbidity and turbidity at $50 \%$ lysis were significantly lower in patients on $A / C$ compared to patients who do not use $A / C$; (0.30 [IQR 0.26-0.39] versus 0.38 [IQR $0.33-0.44] \mathrm{p}=0.010$ ) and (0.15 [IQR $0.13-0.19$ ] versus 0.20 [IQR $0.16-0.22$ ] $p=0.006)$, respectively.

A

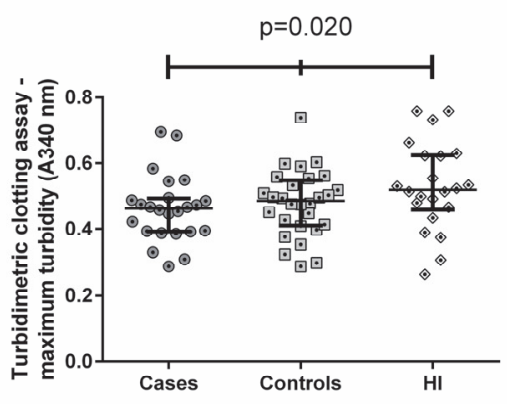

B

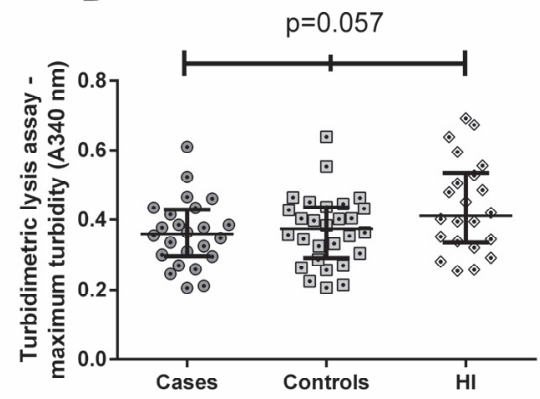

Figure 5.1 Maximum turbidity: cases, controls, HI. A) Turbidimetric clotting assay. Cases, controls, HI. pvalue of Jonckheere-Terpstra test. B) Turbidimetric lysis assay. Cases, controls, HI. p-value of Jonckheere-Terpstra test.

\section{Permeation}

Clot permeation, a measure of average clot pore-size, was not significantly different between the three groups, nor between patients (cases and controls) and $\mathrm{HI}$. (Table 5.2) Patients with a history of recurrent VTE had a significant lower permeation $\left(6.0 \times 10^{-9} / \mathrm{cm}^{2}\right.$ [IQR 5.1-7.9]), indicating a reduced pore-size, compared to patients with only one episode of VTE $\left(7.7 \times 10^{-9} / \mathrm{cm}^{2}\right.$ [IQR 6.0-10.0]) $\mathrm{p}=0.047$.(Figure 5.3C) Patients on $\mathrm{A} / \mathrm{C}$ had a significant lower permeation $\left(5.7 \times 10^{-9} / \mathrm{cm}^{2}\right.$ [IQR 4.1-6.6]), compared to patients who do not use $A / C\left(7.9 \times 10^{-9} / \mathrm{cm}^{2}\right.$ [IQR 6.1-10.0]) $p=0.003$. 

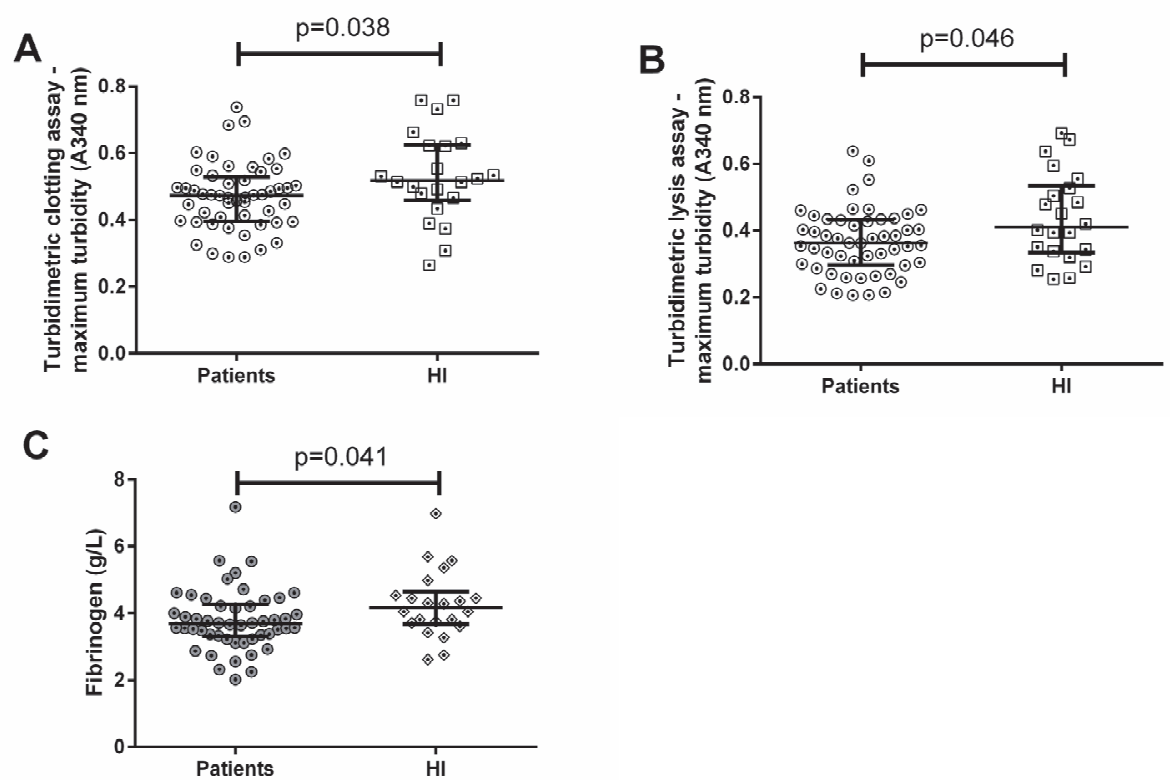

Figure 5.2 Maximum turbidity and fibrinogen: patients versus HI. A) Maximum turbidity in turbidimetric clotting assay. Patients (cases and controls) versus HI. p-value of Mann-Whitney $\mathrm{U}$ test. B) Maximum turbidity in turbidimetric lysis assay. Patients (cases and controls) versus HI. p-value of Mann-Whitney U test. C) Fibrinogen. Patients (cases and controls) versus HI. pvalue of Mann-Whitney $U$ test.

\section{Fibrinogen and fibrinogen $\gamma$}

Median levels of fibrinogen were found to be significantly higher in $\mathrm{HI}$ (4.17 g/l [IQR 3.69-4.65]) compared to patients (cases and controls) (3.69 g/I [IQR 3.31-4.26]) $\mathrm{p}=0.041$. (Figure $5.2 \mathrm{C}$ ) However, in contrast to maximum turbidity, there was no significant trend of decreasing fibrinogen from $\mathrm{HI}$, to controls, to cases. In all subjects, fibrinogen showed a positive correlation with maximum turbidity in the turbidimetric clotting assay $(\rho=0.76 p<0.001)$, with maximum turbidity $(\rho=0.57 p<0.001)$ and with turbidity at $50 \%$ lysis $(\rho=0.58 p<0.001)$ in the turbidimetric lysis assay.

Neither levels of fibrinogen $\gamma^{\prime}$, nor the percentage of fibrinogen $\gamma^{\prime}$ (of total fibrinogen) were significantly different between the three groups, nor between patients (cases and controls) and HI.(Table 5.2)

Overall, patients (cases and controls) using oral anticoagulants $(A / C)$ were found to have increased levels of fibrinogen $(p=0.021)$. 

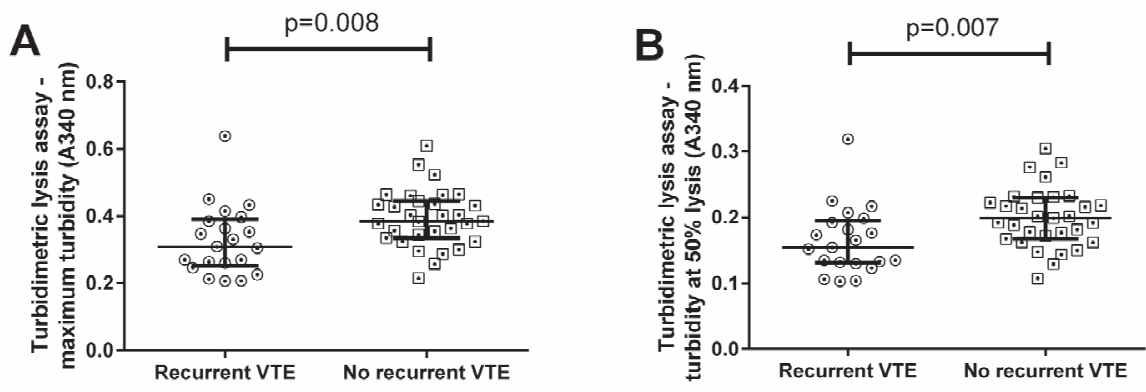

C

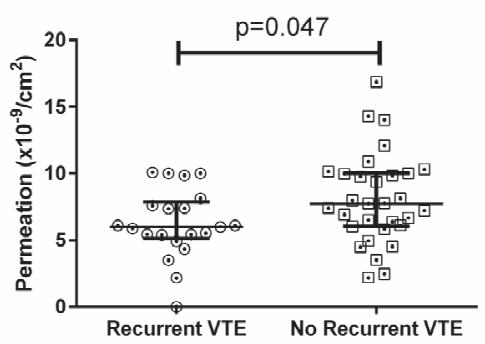

Figure 5.3 Turbidimetric lysis assay and Permeation - Influence of recurrent VTE. Patients with a history of recurrent VTE versus patients with one episode of VTE. A) Maximum turbidity. pvalue of Mann-Whitney $U$ test. B) Turbidity at $50 \%$ lysis. p-value of Mann-Whitney $U$ test. C) Permeation. p-value of Mann-Whitney $U$ test.

\section{Confocal microscopy}

There were no differences in number of fibres per area between patients (cases and controls) and HI. Median number of fibres per area were 428 [IQR 285-555]) in cases, 354 [IQR 258-538]) in controls, and 402 [IQR 259-475]) in HI.(Table 5.2) 


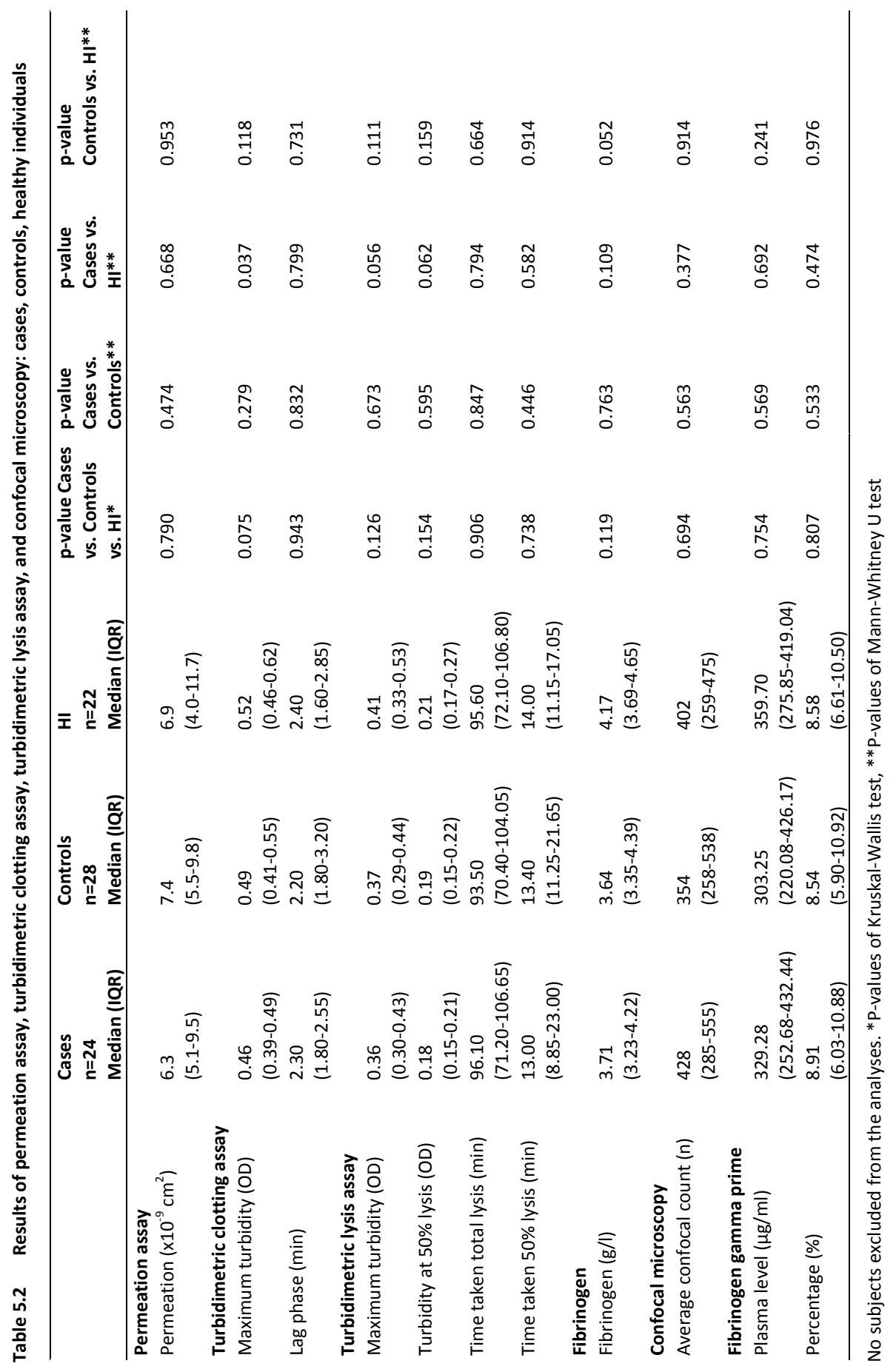




\section{Discussion}

In this study we aimed to assess the clot structure and the fibrinolytic potential in patients with PTS. We found lower maximum turbidity indicating a tendency towards a denser clot structure with thinner fibres in the patients with PTS. Fibrinogen is a major determinant of clot density, but the lower maximum turbidity in the patients with PTS cannot be attributed to lower fibrinogen levels. There was a trend of lower maximum turbidity in cases compared to controls, while the fibrinogen levels did not differ between cases and controls. Turbidity results indicated a denser clot structure in patients with PTS, this finding could however not be confirmed by confocal microscopy. Denser clots composed of thinner fibres tend to be more difficult to lyse, because of a decrease in TPA and plasmin binding sites, and an increased resistance of thin fibres to plasmin digestion. ${ }^{19} \mathrm{~A}$ denser clot structure therefore likely predisposes to PTS as it may lead to poor recanalization, with consequent outflow resistance, and venous hypertension. Whilst in this study we found no differences in clot lysis time between patients with and without PTS, differences in clot lysis present under in vivo conditions, including the effects of local tPA concentrations and flow, could be masked by the excess of tPA added in our turbidity assay.

Only one previous study assessed clot structure in patients after VTE. Patients with a history of VTE were found to have a clot structure with smaller pores and thicker fibres, as indicated by a higher maximum turbidity and lower permeation, compared to healthy controls. ${ }^{20}$ In contrast to our study, two previous studies reported higher fibrinogen levels in patients with a history of VTE compared to healthy controls ${ }^{21,22}$, albeit that this was only significant in the study by Koster et al. ${ }^{22}$ As a whole, fibrinogen levels in our study were higher on average (fibrinogen level $\geq 4 \mathrm{~g} / \mathrm{l}$ in $34 \%$ of patients and $59 \%$ of $\mathrm{HI}$ ) than fibrinogen levels in the study by Koster et al. (fibrinogen level $\geq 4 \mathrm{~g} / \mathrm{l}$ in $21 \%$ of patients and $12 \%$ of healthy controls). ${ }^{22}$ This is probably a consequence of a higher age in our study population (median age 66, 69, 63 years) as compared to the study by Koster et al. (mean age 44 years) ${ }^{22}$, since fibrinogen levels increase with age. ${ }^{23}$ However, this does not explain the lower fibrinogen levels in the patients (cases and controls) relative to the HI. We speculate that fibrinogen levels are lower in the patients due to consumption of fibrinogen. We have previously shown that the patients in this study have a hypercoagulable profile, as apparent by their higher D-dimer and TAT levels. ${ }^{7}$ Increased thrombin generation may lead to increased conversion of fibrinogen to fibrin, thereby increasing fibrin turnover and yielding lower fibrinogen levels. It is unlikely that the higher fibrinogen levels in the $\mathrm{HI}$ are caused by an acute phase reaction, as there were no differences in CRP levels between patients and $\mathrm{HI}^{7}$

A previous study showed that reduced levels of fibrinogen $\gamma^{\prime}$ are associated with an increased risk of venous thrombosis. ${ }^{18}$ In our study there were no differences in fibrinogen $\gamma^{\prime}$ between the patients and $\mathrm{HI}$, probably due to the limited sample size. 
Patients with recurrent VTE were found to have a denser clot structure with smaller pores and thinner fibres, at equal levels of fibrinogen, compared to patients with only one episode of VTE. It appears intuitive that patients predisposed to recurrent VTE are characterized by denser clots with smaller pores. However, to our knowledge, this has not been shown before. Our data suggest that fibrin pore-size may be a biomarker to understand why some patients develop recurrent episodes of VTE. In addition, patients with recurrent (ipsilateral) DVT are also at increased risk of developing PTS. ${ }^{1,24}$ Thus, denser clots might predispose to PTS in itself, but also via recurrent DVT. However, more data are needed to substantiate these findings.

We did not correct the results of the turbidimetric and permeation assays for the use of $A / C$, as clotting was initiated by thrombin in these assays, largely bypassing the coagulation pathway intrinsic to the plasma itself. It has been previously shown that $\mathrm{A} / \mathrm{C}$ (vitamin $\mathrm{K}$ antagonists) do not influence the fibrin network in thrombin initiated assays. ${ }^{25}$ Although thrombin generation is impaired by $A / C$, this is overcome by the excess of thrombin added to initiate clotting. ${ }^{25}$

Our study has several limitations and strengths. We hypothesized that patients with PTS might have impaired fibrinolysis acting through TAFI and increased activation of FXIII. We chose to perform a functional lysis assay instead of measurement of TAFI and FXIII activity levels, however the fibrinolytic potential may have been better investigated under more suitable test conditions, taking into account flow and local variations in TPA concentrations. Moreover, the population studied had a limited sample size largely composed of patients with mild PTS, with a median Villalta of 7 and only 4 patients with severe PTS. The strength of this study is that this was the first study to assess the clot properties and fibrinolysis in patients with PTS. We studied a well-defined population and additionally used $\mathrm{HI}$ as a reference to the normal population.

In conclusion, we found differences in clot structure in patients with PTS, which differentiated these patients from patients with DVT without PTS. The observed differences in clot structure might contribute to the development of PTS, as abnormal clot structure may contribute to a prothrombotic environment. Patients with a tendency towards a denser clot structure might also be at risk for recurrent VTE, which itself is a risk factor for PTS. 


\section{References}

1. Kahn SR, Shrier I, Julian JA, Ducruet T, Arsenault L, Miron MJ, Roussin A, Desmarais S, Joyal F, Kassis J, Solymoss S, Desjardins L, Lamping DL, Johri M, Ginsberg JS. Determinants and time course of the postthrombotic syndrome after acute deep venous thrombosis. Ann Intern Med 2008;149:698-707.

2. Kahn SR, PartschH, Vedantham S, Prandoni P, Kearon C. Definition of post-thrombotic syndrome of the leg for use in clinical investigations: a recommendation for standardization. J Thromb Haemost 2009;7:879-83.

3. Kahn SR, Shbaklo H, Lamping DL, Holcroft CA, Shrier I, Miron MJ, Roussin A, Desmarais S, Joyal F, Kassis J, Solymoss S, Desjardins L, Johri M, Ginsberg JS. Determinants of health-related quality of life during the 2 years following deep vein thrombosis. J Thromb Haemost 2008;6:1105-12.

4. MacDougall DA, Feliu AL, Boccuzzi SJ, Lin J. Economic burden of deep-vein thrombosis, pulmonary embolism, and post-thrombotic syndrome. Am J Health Syst Pharm 2006;63(20 Suppl 6):S5-15.

5. Henke PK, Comerota AJ. An update on etiology, prevention, and therapy of postthrombotic syndrome. J Vasc Surg 2011;53:500-9.

6. Phillips LJ 2nd, Sarkar R. Molecular characterization of post-thrombotic syndrome. J Vasc Surg 2007;45 Suppl A:A116-22.

7. Bouman A.C., Y.W. Cheung, H.M. Spronk, C.G. Schalkwijk, H. ten Cate, M. ten Wolde, A.J. ten CateHoek. Biomarkers for post thrombotic syndrome: a case-control study. Thromb Res 2014;134:369-75.

8. Koncz Z, Bagoly Z, Haramura G, Mezei ZA, MuszbekL. Thrombomodulin-dependent effect of factor V Leiden mutation on the cross-linking of alpha2-plasmin inhibitor to fibrin and its consequences on fibrinolysis. Thromb Res 2012;130:528-34.

9. Ariens RA. Fibrin(ogen) and thrombotic disease. J Thromb Haemost 2013;11 Suppl 1:294-305.

10. Krzek M, Ciesla-Dul M, Zabczyk M, Undas A. Fibrin clot properties in women heterozygous for factor $\mathrm{V}$ Leiden mutation: effects of oral contraceptives. Thromb Res 2012;130:e216-21.

11. Marsh JJ, Chiles PG, Liang NC, Morris TA. Chronic thromboembolic pulmonary hypertensionassociated dysfibrinogenemias exhibit disorganized fibrin structure. Thromb Res 2013;132:729-34.

12. Martinez MR, Cuker A, Mills AM, Crichlow A, Lightfoot RT, Chernysh IN, Nagaswami C, Weisel JW, Ischiropoulos $\mathrm{H}$. Enhanced lysis and accelerated establishment of viscoelastic properties of fibrin clots are associated with pulmonary embolism. Am J Physiol Lung Cell Mol Physiol 2014;306: L397-404.

13. Undas A, Plicner D, Stepien E, Drwila R, Sadowski J. Altered fibrin clot structure in patients with advanced coronary artery disease: a role of C-reactive protein, lipoprotein(a) and homocysteine. J Thromb Haemost 2007; 5:1988-90.

14. Bridge KI, Macrae F, Bailey MA, Johnson A, Philippou H, Scott DJ, Arismall io RRA. The alpha-2antiplasmin Arg407Lys polymorphism is associated with Abdominal Aortic Aneurysm. Thromb Res 2014; 134:723-8.

15. Ariens RA, Philippou H, Nagaswami C, Weisel JW, Lane DA, GrantPJ. The factor XIII V34L polymorphism accelerates thrombin activation of factor XIII and affects cross-linked fibrin structure. Blood 2000; 96: 988-95.

16. Duval C, Allan P, Connell SD, Ridger VC, Philippou H, Ariens RA. Roles of fibrin alpha- and gammachain specific cross-linking by FXIIla in fibrin structure and function. Thromb Haemost 2014;111:84250.

17. Macrae FL, Evans HL, Bridge KI, Johnson A, Scott DJ, Ariens RA. Common FXIII and fibrinogen polymorphisms in abdominal aortic aneurysms. PLoS One 2014; 9(11): e112407.

18. Uitte de Willige S, de Visser MC, Houwing-Duistermaat JJ, Rosendaal FR, Vos HL, BertinaRM. Genetic variation in the fibrinogen gamma gene increases the risk for deep venous thrombosis by reducing plasma fibrinogen gamma' levels. Blood 2005;106:4176-83.

19. Gabriel DA, Muga K, Boothroyd EM. The effect of fibrin structure on fibrinolysis. J Biol Chem 1992; 267: 24259-63.

20. Undas A, Zawilska K, Ciesla-Dul M, Lehmann-Kopydlowska A, Skubiszak A, Ciepluch K, Tracz W. Altered fibrin clot structure/function in patients with idiopathic venous thromboembolism and in their relatives. Blood 2009;114:4272-8. 
21. Austin H, Hooper WC, Lally C, Dilley A, EllingsenD, Wideman C, Wenger NK, Rawlins P, Silva V, Evatt B. Venous thrombosis in relation to fibrinogen and factor VII genes among African-Americans. J Clin Epidemiol 2000;53:997-1001.

22. Koster T, Rosendaal FR, Reitsma PH, van der Velden PA, Briet E, Vandenbroucke JP. Factor VII and fibrinogen levels as risk factors for venous thrombosis. A case-control study of plasma levels and DNA polymorphisms--the Leiden Thrombophilia Study (LETS). Thromb Haemost 1994;71:719-22.

23. Drenos F, Miller GJ, Humphries SE. Increase of plasma fibrinogen levels and variability with age in a sample of middle aged healthy men. Ann Hum Genet 2007;71:43-53.

24. Prandoni $P$, Lensing AW, Cogo A, Cuppini S, Villalta S, Carta M, Cattelan AM, Polistena P, Bernardi E, Prins $\mathrm{MH}$. The long-term clinical course of acute deep venous thrombosis. Ann Intern Med 1996;125: 1-7.

25. Ząbczyk M, Blombäck M, Majewski J, Karkowski G, Wallen HN, Undas A, He S. Assays of fibrin network properties altered by VKAs in atrial fibrillation - importance of using an appropriate coagulation trigger. Thromb Haemost 2014; 113:851-61. 


\section{Part II}

Personalized management of post thrombotic

syndrome 


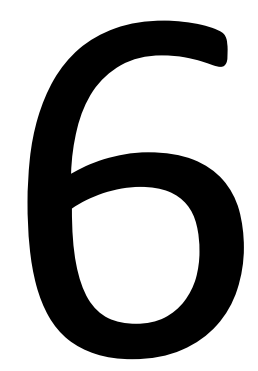

Timing and duration of compression therapy after deep vein thrombosis 


\section{Abstract}

After deep vein thrombosis (DVT) $20-50 \%$ of patients develop post thrombotic syndrome (PTS). Up till now, there is no effective treatment for PTS and prevention is therefore of major importance. Compression therapy after DVT, with elastic compression stockings (ECS), is the only available preventive measure for PTS. However, the usefulness, timing, and duration of compression therapy are matters of debate. The effect of early compression on the long-term development of PTS is still unclear as studies performed so far have conflicting outcomes. The effectiveness of ECS therapy initiated in the sub-acute phase was assessed in three large randomized controlled trials. Kahn et al. could not reproduce the large risk reduction found in the trials by Brandjes and Prandoni et al. Also for the optimal duration of ECS therapy, a certain conclusion has yet to be drawn. Therefore identification of patients who most likely will benefit from ECS therapy as well as the optimal ECS treatment strategy remain subjects for further study. 


\section{Introduction}

After deep vein thrombosis (DVT) $20-50 \%$ of patients develop post thrombotic syndrome (PTS). PTS is characterized by chronic complaints of the leg affected by the DVT. Patients experience heaviness, pain, cramps, itching, and in severe cases venous ulceration of the leg may occur. ${ }^{1-4}$

PTS reduces quality of life significantly and is associated with considerable costs. ${ }^{1,5}$ Up till now, there is no effective treatment for PTS and prevention is therefore of major importance. Compression therapy after DVT, with elastic compression stockings (ECS), is the only available preventive measure for PTS. However, the usefulness, timing, and duration of compression therapy are matters of debate. In this review we summarize and appraise current literature on this subject.

\section{Pathogenic substrate for compression therapy}

The precise etiology of PTS is not entirely understood. The signs and symptoms of PTS are thought to be the clinical manifestation of venous hypertension. Both the presence and the resolution of the thrombus initiate various pathogenic mechanisms. In the acute phase of DVT the thrombus itself, inflammatory cells, and enzymes involved in thrombus resolution damage the venous valves, resulting in valvular reflux. In the sub-acute phase, secondary vein wall remodelling and fibrosis take place, making the vein wall stiff and non-compliant. ${ }^{6-8}$ Thrombus resolution is often incomplete, as residual vein thrombosis is present in $50 \%$ of legs three years after DVT. ${ }^{9}$ Residual thrombosis increases venous outflow resistance. Valvular reflux, noncompliant vein walls, and increased outflow resistance increase blood pressure in the veins. $^{6-8}$ The increased venous pressure is transmitted to the capillaries, which dilate and start leaking plasma, proteins, and erythrocytes, leading to edema and skin changes. Microcirculation and blood supply to the muscles of the lower limb become impaired, eventually leading to the characteristic complaints of PTS and in severe cases instigating venous ulceration. ${ }^{8}$ The use of compression therapy for the prevention of PTS is derived from compression practice in primary venous insufficiency. In patients with primary venous insufficiency, compression therapy was found to have several beneficial effects on venous haemodynamics. ECS therapy reduces ambulatory venous pressure and venous reflux, and improves calf muscle pump function. ${ }^{10-11}$ ECS therapy was shown to improve the venous ejection fraction. The venous ejection fraction is a quantification of the venous pumping function, which is the ejection volume divided by the total venous volume. ${ }^{12}$ Furthermore, external compression on the leg reduces the diameter of the vein, thereby accelerating blood flow and improving oxygen supply to the skin. ${ }^{13}$ Since the end manifestations of primary and secondary venous insufficiency are similar, it seems likely that elastic compression therapy will have beneficial effects on PTS as well. It is however not clear 
whether and how elastic compression therapy can prevent PTS. Adequate flow is an important component of thrombus resolution as shown in animal experimental studies and therefore enhancing the venous ejection fraction may be the pivotal function of ECS therapy for the prevention of PTS. ${ }^{14}$

\section{Early compression}

A large prospective cohort study following patients after DVT showed that early (one month after DVT) severe post thrombotic manifestations are strong predictors of PTS at two years, whereas most patients with no or mild PTS one month after DVT had no or mild PTS after two years. ${ }^{1}$

Only three randomized controlled trials assessed the effect of immediate compression therapy in the acute phase after DVT on the development of PTS.

Partsch et al. compared early compression either with (1) compression bandages (Unna boot) or with (2) compression stockings and early mobilisation, to (3) bed rest without compression therapy. Forty-five patients were equally distributed over the three treatment groups. In the compression groups $(1+2)$ pain was already significantly reduced at day two compared to day zero. This reduction in pain was not reached until day five in the bed rest group (3). In the compression groups leg circumference at day nine was significantly lower, compared to the bed rest group. ${ }^{15}$ After the initial nine days all patients were prescribed elastic compression stockings for two years. Thirty-seven of these 45 patients were reinvestigated after two years. In the compression groups 8 of 26 patients (30.7\%) had developed PTS (at cut-off $>5$ for the diagnosis of PTS), compared to 9 of 11 (82\%) in the bed rest group (RR 0.37; $95 \% \mathrm{Cl} 0.27-0.72, \mathrm{p}<0.01)$. The stocking was worn for up to the time of follow-up by 13 of $26(50 \%)$ patients in the compression groups and in 8 of $11(73 \%)$ patients in the bed rest group. ${ }^{16}$

Arpaia et al. looked specifically into the effect of immediate compression on vein recanalization. Seventy-three patients were randomized to either early compression with class II ECS $(n=36)$ or start of compression with class II ECS after 14 days $(n=37)$. Complete vein segment recanalization was significantly more often reported in the early compression group ( 28 of 34 (82\%) patients) compared to the control group (18 of $30(60 \%)$ patients), yielding an odds ratio (OR) of 0.27 (95\% $\mathrm{Cl} 0.07-0.89$ ). Popliteal vein diameter at day 14 and day 90 of follow-up was significantly lower in the early compression group ( $p=0.035 ; p=0.014)$, as was the popliteal patency score at day 14 $(p=0.0047)$. However, none of the patients had symptoms of PTS at day 90 of followup and there were no differences in leg circumference between the two groups. ${ }^{17}$

Roumen-Klappe et al. studied immediate compression bandaging in the acute phase after DVT. Sixty-nine patients were randomized to either immediate multilayer compression bandaging $(n=34)$ or no bandaging $(n=35)$. Improvement of clinical 
symptoms and decrease of leg circumference was significantly better and faster in the bandage group in the first 7-30 days.

However, after one year the incidence of PTS was equal in both groups, according to both the CEAP classification; $39 \%$ versus $42 \%$ (RR $0.91,95 \% \mathrm{Cl} 0.50-1.66$ ) and the Villalta score; $29 \%$ versus $33 \%$ (RR $0.87,95 \% \mathrm{Cl} 0.41-1.8$ ). In addition, there were no significant differences in venous outflow resistance, thrombosis score, or reflux between the two groups. ${ }^{18}$

\section{Effectiveness and duration of ECS therapy}

After the acute phase, when the acute edema has been resorbed, nowadays it is common practice to prescribe ECS for a period of 24 months to prevent PTS. This is mainly based on the results of two randomized controlled trials performed by Brandjes et al. in 1997 and Prandoni et al. in 2004. In both trials patients after DVT were randomized to either 24 months ECS or no ECS. ${ }^{19,20}$ In the study by Brandjes et al. in the stocking group $(n=96) 19$ patients developed mild to moderate PTS and 11 patients developed severe PTS. In the other group ( $n=98) 46$ patients developed mild to moderate PTS and 23 patients developed severe PTS. These differences are highly significant: $p<0.001$. In the stocking group, 89 of the $96(93 \%)$ patients reported to wear their stocking always or more than $80 \%$ of time. ${ }^{19}$ Prandoni et al. found a 24-month cumulative PTS incidence of $24,5 \%(95 \% \mathrm{Cl} 15,6-33,4)$ in the ECS group $(n=90)$ and $49,1 \%(95 \% \mathrm{Cl} 38,7-59,4)$ in the no ECS group ( $n=90)$. This amounts to a hazard ratio $(\mathrm{HR})$ of $0.49(95 \% \mathrm{Cl}$ 0.29-0.84) after correction for baseline characteristics. Seventy-eight of the 90 patients $(87 \%)$ in the stocking group wore the stocking at least $80 \%$ of daytime during the two-year period. ${ }^{20}$

Very recently, the results of a large placebo controlled trial have been published. Eight hundred and six patients were randomized to either active ECS $(n=410)$ or placebo ECS $(n=396)$. No differences between active ECS and placebo ECS could be demonstrated in terms of PTS prevention. Cumulative PTS incidence (from 6 to 24 months follow-up) rated according to the Ginsberg score was $14,2 \%$ in the active ECS group and $12,7 \%$ in the placebo ECS group, generating a non-significant HR of 1,13 (95\% Cl 0.73-1.76). Compliance to ECS was equal in both groups, at the 24 month visit 378 patients $(69,1 \%)$ still wore the stocking of whom 304 patients $(55,6 \%)$ wore the stocking three days or more per week. ${ }^{21}$

The timing and especially the optimal duration of compression therapy after DVT have not been addressed in these three studies. A few studies did assess timing and duration of therapy. Ginsberg et al. showed that active ECS, applied one year after the event of DVT in patients without symptoms of PTS but with confirmed venous valvular incompetence by plethysmography or duplex, did not significantly reduce the incidence of PTS compared to placebo ECS. In the active ECS group $(n=24)$ no patients 
developed symptoms of PTS during follow-up, in the placebo ECS group $(n=23)$ one patient developed symptoms of PTS during follow-up $(p=0.49) .{ }^{22}$

Only one study so far investigated whether prolonged duration of ECS therapy after six months is superior to only six months ECS therapy. In this study by Aschwanden et al. patients were randomized six months after the event of DVT to either prolonged ECS therapy ( $n=84)$ or discontinuation of ECS therapy $(n=85)$. The occurrence of post thrombotic skin changes was not significantly different between the two groups. Eleven patients in the prolonged ECS group versus 17 patients in the other group developed post thrombotic skin changes (HR 0.60 (95\% Cl 0.28-1.28); $p=0.19$ ). However, a sub analysis showed that women did benefit significantly from prolonged ECS therapy (HR $0.11(95 \% \mathrm{Cl} 0.02-0.91)$. Non-adherence, defined as wearing the stocking $<4$ days a week, was reported in $8,4 \%$ of follow-up visits ( $11 \%$ in men, $3.6 \%$ in women). ${ }^{23}$ Ten Cate-Hoek et al. performed a management study, in which duration of ECS therapy was tailored based on the patients' individual signs and symptoms of PTS. In a cohort of 125 patients, the cumulative PTS incidence at the two-year follow-up was $21.1 \%$ (95\% Cl 13.51-28.69). Fifty percent of patients did not need ECS therapy for as long as 24 months, while the overall incidence of PTS was comparable to the published incidences after 24 months ECS therapy. ${ }^{24} \mathrm{~A}$ randomized controlled trial comparing individually tailored duration of ECS therapy to standard duration of 24 months ECS therapy is currently underway.(NCT01429714)

\section{Discussion}

Compression therapy has been shown to have beneficial effects on the venous circulation in the setting of primary venous insufficiency. ${ }^{10-12}$ This may explain its presumed benefit after DVT both for the reduction of symptoms as well as for the prevention of PTS. Although the rationale behind compression therapy is very intuitive, we do not know what patients will benefit most and what the optimal timing of onset and subsequent duration of compression therapy following DVT should be.

According to the limited evidence available, compression therapy in the acute phase after DVT reduces pain and swelling. Yet, the effect of early compression on the long term development of PTS is still unclear as studies performed so far have conflicting outcomes. ${ }^{15-18}$ The studies performed all had limited sample sizes and used different definitions for PTS; therefore a sufficiently large study is needed to assess the effect of early compression on PTS development in order to provide us with a definitive answer. Besides the clear benefits for the patient's wellbeing such as reduction of pain and edema, it may be prudent to start ECS therapy, with its perceived benefit of restoring the venous ejection fraction and counteracting the exudation of venous fluids, as soon as possible after the DVT. As early severe post thrombotic complaints have been shown to be a strong predictor for PTS later on. ${ }^{1}$ The effectiveness of ECS therapy initiated in the sub-acute phase was assessed in three large randomized 
controlled trials. The $50 \%$ risk reduction of ECS therapy found in the trials by Brandjes et al. and Prandoni et al. is in stark contrast to the lack of effectiveness found in the trial by Kahn et al. ${ }^{19-21}$ At least part of the beneficial effect of ECS is thought to be accountable to the open label design of the first two trials. Subjective complaints form a large part (about half) of the diagnosis of PTS, and therefore the true effect of the stocking can be overestimated due to an imagined benefit. However, it seems unlikely that such a substantial reduction in PTS incidence can be dismissed as a placebo effect. If an average placebo effect of $20 \%$ were to be assumed, a risk reduction of $30 \%$ would still be expected to remain. A more likely explanation for the apparent lack of effectiveness in the study by Kahn et al. therefore can be found in the reduced compliance to ECS therapy. At the 24 months follow up visit $55.6 \%$ of patients did wear the stocking three days or more per week. In contrast, Brandjes et al. reported that $93 \%$ of patients did wear their stocking always or more than $80 \%$ of time. Moreover, Prandoni et al. reported that $87 \%$ of patients wore the stocking at least $80 \%$ of daytime during the two-year period, thus, showing much higher compliance rates. ${ }^{19-21}$ It is therefore likely that suboptimal compliance in the active ECS group could have undermined the effectiveness of ECS therapy in the study by Kahn et al.

As for the optimal duration of ECS therapy, a certain conclusion has yet to be drawn. Only one study assessed whether six months of ECS therapy was inferior to prolonged treatment of ECS and did not find a difference. ${ }^{23}$ To optimize treatment duration tailoring of ECS therapy based on the patients' individual signs and symptoms may be a promising strategy. ${ }^{24}$ On the other hand, there are also patients who do not develop PTS even without any ECS therapy at all. As shown by the study of Ginsberg et al. where start of ECS therapy as late as one year after the event of DVT in patients without complaints did not influence the onset of PTS. ${ }^{22}$ Therefore identification of patients who most likely will benefit from ECS therapy as well as the optimal ECS treatment strategy remain subjects for further study.

In conclusion, PTS is a long-term chronic and debilitating complication of DVT of the leg. Counteracting increased pressure in the venous vasculature is the rationale for ECS therapy after DVT. The function of ECS therapy for the prevention of PTS is not yet fully understood; enhancing the venous ejection fraction may be a pivotal factor. For the practical application it is still undecided what the optimal timing of onset and subsequent duration of compression therapy following DVT should be, and in addition it is uncertain how patients who are likely to benefit most from ECS therapy can be identified. 


\section{References}

1. Kahn SR, Shrier I, Julian JA, Ducruet T, Arsenault L, Miron MJ, Roussin A, Desmarais S, Joyal F, Kassis J, Solymoss S, Desjardins L, Lamping DL, Johri M, Ginsberg JS. Determinants and time course of the postthrombotic syndrome after acute deep venous thrombosis. Ann Intern Med 2008;149:698-707.

2. Pesavento R, Villalta S, Prandoni P. The postthrombotic syndrome. Intern Emerg Med 2010;5:185-92.

3. Prandoni $P$, Kahn SR. Post-thrombotic syndrome: prevalence, prognostication and need for progress. Br J Haematol 2009;145:286-95.

4. Prandoni P, Lensing AW, Cogo A, Cuppini S, Villalta S, Carta M, Cattelan AM, Polistena P, Bernardi E, Prins $\mathrm{MH}$. The long-term clinical course of acute deep venous thrombosis. Ann Intern Med 1996;125: 1-7.

5. Bergqvist D, Jendteg S, Johansen L, Persson U, Odegaard K. Cost of long-term complications of deep venous thrombosis of the lower extremities: an analysis of a defined patient population in Sweden. Ann Intern Med 1997;126:454-7.

6. Deroo S, Deatrick KB, Henke PK. The vessel wall: A forgotten player in post thrombotic syndrome. Thromb Haemost 2010;104:681-92.

7. Henke PK, Wakefield T. Thrombus resolution and vein wall injury: dependence on chemokines and leukocytes. Thromb Res 2009;123 Suppl 4:S72-8.

8. Phillips LJ 2nd, Sarkar R. Molecular characterization of post-thrombotic syndrome. J Vasc Surg 2007;45 Suppl A:A116-22.

9. Markel A. Meissner M, Manzo RA, Bergelin RO, Strandness DE Jr. Deep venous thrombosis: rate of spontaneous lysis and thrombus extension. Int Angiol 2003;22:376-82.

10. Horner J, Fernandes J, Fernandes E, Nicolaides AN. Value of graduated compression stockings in deep venous insufficiency. Br Med J 1980;280:820-1.

11. Ibegbuna V, Delis KT, Nicolaides AN, Aina O. Effect of elastic compression stockings on venous hemodynamics during walking. J Vasc Surg 2003;37:420-5.

12. Mosti G, Partsch H. Compression stockings with a negative pressure gradient have a more pronounced effect on venous pumping function than graduated elastic compression stockings. Eur J Vasc Endovasc Surg 2011;42:261-6.

13. Klyscz T, Galler S, Steins A, Zuder D, Rassner G, Junger M. The effect of compression therapy on the microcirculation of the skin in patients with chronic venous insufficiency (CVI). Hautarzt 1997;48: 806-11.

14. Cooley BC, Chen CY, Hess R, Schmeling G. Incomplete resolution of deep vein thrombosis under reduced flow conditions. Thromb Res 2013;131:55-8.

15. Partsch $\mathrm{H}$, Blattler $\mathrm{W}$. Compression and walking versus bed rest in the treatment of proximal deep venous thrombosis with low molecular weight heparin. J Vasc Surg 2000;32:861-9.

16. Partsch $\mathrm{H}$, Kaulich $\mathrm{M}$, Mayer $\mathrm{W}$. Immediate mobilisation in acute vein thrombosis reduces postthrombotic syndrome. Int Angiol 2004;23:206-12.

17. Arpaia G, Cimminiello C, Mastrogiacomo O, de Gaudenzi E. Efficacy of elastic compression stockings used early or after resolution of the edema on recanalization after deep venous thrombosis: the COM.PRE Trial. Blood Coagul Fibrinolysis 2007;18:131-7.

18. Roumen-Klappe EM, den Heijer M, van Rossum J, Wollersheim H, van der Vleuten $C$, Thien $\mathrm{T}$, Janssen MC. Multilayer compression bandaging in the acute phase of deep-vein thrombosis has no effect on the development of the post-thrombotic syndrome. J Thromb Thrombolysis 2009;27:400-5.

19. Brandjes DP, Buller HR, Heijboer H, Huisman MV, de Rijk M, Jagt H, ten Cate JW. Randomised trial of effect of compression stockings in patients with symptomatic proximal-vein thrombosis. Lancet 1997; 349:759-62.

20. Prandoni $P$, Lensing AW, Prins $M H$, Frulla $M$, Marchiori $A$, Bernardi $E$, Tormene $D$, Mosena $L$, Pagnan A, Girolami A. Below-knee elastic compression stockings to prevent the post-thrombotic syndrome: a randomized, controlled trial. Ann Intern Med 2004;141:249-56. 
21. Kahn SR, Shapiro S, Wells PS, Rodger MA, Kovacs MJ, Anderson DR, Tagalakis V, Houweling $A H$, Ducruet T, Holcroft C, Johri M, Solymoss S, Miron MJ, Yeo E, Smith R, Schulman S, Kassis J, Kearon C, Chagnon I, Wong T, Demers C, Hanmiah R, Kaatz S, Selby R, Rathbun S, Desmarais S, Opatrny L, Ortel TL, Ginsberg JS; SOX trial investigators. Compression stockings to prevent post-thrombotic syndrome: a randomised placebo-controlled trial. Lancet 2014;383:880-8.

22. Ginsberg JS, Hirsh J, Julian J, Vander LaandeVries M, Magier D, MacKinnon B, Gent M. Prevention and treatment of postphlebitic syndrome: results of a 3-part study. Arch Intern Med 2001;161:2105-9.

23. Aschwanden M, Jeanneret C, Koller MT, Thalhammer C, Bucher HC, Jaeger KC. Effect of prolonged treatment with compression stockings to prevent post-thrombotic sequelae: a randomized controlled trial. J Vasc Surg 2008;47:1015-21.

24. Ten Cate-Hoek AJ, Ten Cate H, Tordoir J, Hamulyak K, Prins MH. Individually tailored duration of elastic compression therapy in relation to incidence of the postthrombotic syndrome. J Vasc Surg 2010;52:132-8. 


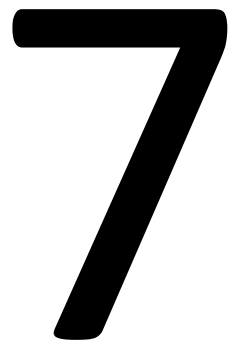

The IDEAL DVT study, individualized duration elastic compression therapy against long-term duration of therapy for the prevention of post thrombotic syndrome: protocol of a randomized controlled trial 


\section{Abstract}

\section{Introduction}

Post thrombotic syndrome (PTS) is a serious complication of deep vein thrombosis (DVT) of the leg that affects $20-50 \%$ of patients. Once a patient experiences PTS there is no treatment that effectively reduces the debilitating complaints. Two randomized controlled trials showed that elastic compression stocking (ECS) therapy after DVT for 24 months can reduce the incidence of PTS by $50 \%$. However, it is unclear whether all patients benefit to the same extent from ECS therapy or what the optimal duration of therapy for individual patients should be. ECS therapy is costly, inconvenient, demanding and sometimes even debilitating. Tailoring therapy to individual needs could save substantial costs. The objective of the IDEAL DVT study, therefore, is to evaluate whether tailoring the duration of ECS therapy on signs and symptoms of the individual patient is a safe and effective method to prevent PTS, compared to standard ECS therapy.

\section{Methods and analysis}

A multicentre, single-blinded, allocation concealed, randomized, non-inferiority trial. A total of 864 consecutive patients with acute objectively documented proximal DVT of the leg are randomized to either standard duration of 24 months or tailored duration of ECS therapy following an initial therapeutic period of 6 months. Signs and symptoms of PTS are recorded at regular clinic visits. Furthermore, quality of life, costs, patient preferences, and compliance are measured. The primary outcome is the proportion of patients with PTS at 24 months.

\section{Ethics and dissemination}

Based on current knowledge the standard application of ECS therapy is questioned. The IDEAL DVT study will address the central questions that remain unanswered: Which individual patients do benefit from ECS therapy and what is the optimal individual treatment duration? Primary ethics approval was received from the Maastricht University Medical Centre.

\section{Results}

Results of the study will be disseminated via peer-reviewed publications and presentations at scientific conferences. 


\section{Background}

After deep vein thrombosis (DVT) $20-50 \%$ of patients develop post thrombotic syndrome (PTS). PTS is a chronic condition characterized by leg complaints such as pain, heaviness, cramps, aching, tingling, and leg signs due to venous insufficiency, evolving in severe cases to venous ulceration of the leg that was affected by the DVT. ${ }^{1-}$

${ }^{5}$ PTS is a serious affliction, with substantial impact on quality of life and costs. ${ }^{2,6}$ Because an effective therapy is lacking, prevention of PTS is of major importance.

Until now, elastic compression stocking (ECS) therapy after DVT has been the mainstay of PTS prevention. The evidence sustaining the value of ECS therapy following acute DVT is derived from two randomized clinical trials, which showed that incidences of PTS were reduced by approximately 50\%, with application of ECS therapy for 24 months. ${ }^{7,8}$ However, based on these trials it is still undecided whether all patients benefit to the same extent from ECS therapy or what the optimal duration of ECS therapy for individual patients should be. We have previously assessed the safety of shortened duration of ECS therapy based on individual patient clinical scores in a management study of 125 patients, and we have shown that tailoring the duration of ECS therapy based on the signs and symptoms of the individual patient after an initial treatment period of six months, is a safe strategy to prevent PTS. We found that $50 \%$ of our patients did not need ECS therapy for as long as two years, while the overall incidence of PTS was $21.1 \%$ [ $95 \%$ confidence interval $(\mathrm{CI}) 13.5-28.7] .{ }^{9}$ This incidence is comparable to published incidences after 24 months of ECS therapy. ${ }^{7,8}$ While this was a prospective management cohort study with an open character and therefore prone to bias, the results of this study need to be confirmed by an adequately powered randomized controlled trial.

There have been other studies that highlighted different aspects of ECS therapy. ECS therapy may not be indicated for all patients as shown by a study that assessed whether ECS therapy initiated one year after the event of DVT would lower the incidence of PTS in patients without complaints but with reflux on duplex testing. No significant benefit of ECS therapy at this late time of onset was found. The incidence of PTS was low in both groups. ${ }^{10}$ One study so far assessed whether prolonged duration of ECS therapy was superior to 6 months of ECS therapy following an event of proximal DVT. In this study no significant difference in the incidence of PTS according to the Clinical-Etiology-Anatomy-Pathophysiology (CEAP) classification was observed between the two treatment groups. ${ }^{11}$

The proposed IDEAL (individually tailored elastic compression against (=versus) longterm therapy) DVT study is a non-inferiority trial and aims to demonstrate that the assessed alternative therapy based on ECS for six months followed by individually prolonged ECS therapy based on Villalta scores is non-inferior to the comparator ECS therapy for a standard duration of 24 months. In addition, we are interested in studying the cost-effectiveness of individual tailoring of the duration of ECS therapy 
via a cost-utility analysis (CUA) and we want to retrieve information on the patient's motivations for compliance or non-compliance to therapy. Because compliance to therapy is one of the most important prerequisites for successful ECS therapy, a discrete choice experiment (DCE) will be performed in which patient preferences towards ECS therapy will be assessed, in order to reveal the main obstacles for compliance to therapy. For this purpose, a DCE questionnaire will be send to a subset of the population (300 patients) at approximately three months after DVT.

The results of a recently published placebo-controlled trial performed by Kahn et al. refuted the routine wearing of ECS after DVT altogether. ${ }^{12}$ This study showed no treatment effect at all from ECS therapy in contrast to the large treatment effects found in previous non-placebo-controlled trials. ${ }^{7,8}$ The unexpected lack of effectiveness cannot be dismissed solely as a placebo effect. The compliance to ECS therapy, a major determinant of effectiveness, was $55.6 \%$ after 24 months. This was less in comparison to the previous trials by Brandjes et al. and Prandoni et al., where compliance was up to $90 \% .^{7,8,12}$ Although a per protocol analysis of the patients reporting regular stocking use yielded the same outcome, this sub analysis may not be adequately powered to dismiss lack of compliance as an important determinant of non-effectiveness.

Based on current knowledge, it is therefore understood that the standard application of ECS therapy is questioned. Especially the benefit to individual patients and the optimal duration of ECS therapy were never studied properly and as a result it is unclear which individual patients require therapy and for how long. The IDEAL DVT study aims to address these topics. In addition quality of life, patient preference towards ECS therapy, compliance to therapy, as well as cost-effectiveness of ECS therapy will be assessed.

The primary outcome of the IDEAL DVT study will be PTS at 24 months after the event. The secondary outcomes will be: (1) health related quality of life (HRQOL), measured by questionnaires (Short Form (SF)-36, ${ }^{13}$ EuroQOL (EQ)-5D, ${ }^{14}$ Dutch translated VeinesQol, $^{15}(2)$ costs, $^{16}$ (3) recurrent thrombosis, according to criteria as published ${ }^{17}$ and assessed by objective tests, (4) venous thromboembolism (VTE)-related death during follow-up, assessed by an independent and blinded adjudication committee, (5) patient preferences, assessed with a DCE. ${ }^{18}$

\section{The scope of the problem in the Netherlands}

In the Netherlands, each year around 25,000 patients experience a new event of DVT. To prevent PTS, the common practice is to prescribe custom fitted ECS therapy for two years for all patients. ${ }^{19,20}$ ECS therapy is costly, demanding, and sometimes even debilitating. Elderly patients can often not apply the ECS by themselves but need help from family or they even need home care visits (7.5\%). ${ }^{21-23}$ Total annual costs of ECS therapy roughly amounts to $€ 2.5$ million for stockings $(25,000$ patients $x € 100)$ and $€ 21$ million for home care $(7.5 \%$ x 25,000 patients $x 500$ visits $x € 20) .{ }^{21-23}$ Moreover, 
the majority of patients do not experience any post thrombotic complaints. ${ }^{10}$ In the Netherlands, over $€ 10$ million each year could be saved if ECS treatment could be individualized.

\section{Methods and design}

A multicentre, single-blinded, allocation concealed, randomized, non-inferiority trial comparing individually tailored duration of ECS therapy (intervention) with standard duration of 24 months ECS therapy (control), for the prevention of PTS. Randomization will guarantee a balanced distribution of patients within each patient group. Stratification will be performed on centre and potentially confounding effects such as age, sex, and body mass index (BMI). The study will be a multicenter study in order to get a good representation of patients and to achieve sufficient patient numbers. The primary outcome will be PTS at 24 months after the event; the observers will be blinded to the allocated treatment arm. The allocation will be concealed from study personnel involved in assessing the leg symptoms and rating the PTS scores. Both randomization and allocation concealment are used as strategies against bias. The study is not double blinded; no inactive stockings will be used in the comparator group. The use of sham stockings will very likely interfere with the quality of life and will complicate the assessment of perceived differences between groups. Patients will be followed for the entire study duration; incidence of recurrent DVT and VTE-related death during the follow-up period will be documented.

\section{Patients and treatment}

Consecutive, consenting adults with an acute objectively documented proximal DVT of the leg, adequately treated with anticoagulant treatment and initial compression therapy according to a prespecified protocol are included in the study. Patients are included and randomized in the IDEAL DVT study within 2-6 weeks after DVT.

Exclusion criteria are:

- Previous DVT in the affected leg. Patients with a previous ipsilateral DVT might already have developed PTS after the first DVT.

- Recurrent DVT in the six months following inclusion, as it cannot be justified to advise these patients to discontinue ECS therapy six months after DVT.

- Pre-existent venous insufficiency (skin signs C3-C6 on CEAP score or requiring ECS therapy). Pre-existent venous insufficiency increases the risk of developing PTS and the majority of patients with venous insufficiency already chronically wear ECSs. In addition, venous insufficiency is closely related to PTS and is therefore difficult to differentiate from PTS. 
- Contraindication for ECS therapy, such as intermittent claudication or clinical signs of leg ischemia or asymptomatic arterial insufficiency (a pulse deficit or bruit at sites of narrowing at physical examination).

- Active thrombolysis, as thrombolysis reduces the risk of PTS.

- Limited life expectancy (<6 months), as the follow-up period is two years.

Patients are recruited from twelve hospitals in the Netherlands and two hospitals in Italy.

There is a prespecified protocol for the management of DVT in all participating centres.

In the initial acute phase after DVT, until the acute oedema has disappeared, one of three strategies will be applied. The leg is either bandaged with short stretch bandages to a compression of $30-40 \mathrm{mmHg}$, worn day and night and redressed twice per week; or a bandage stocking with $35 \mathrm{mmHg}$ compression is prescribed (Mediven Struva $35^{\circ}$, Medi, Breda, the Netherlands), worn day and night; or no initial compression therapy is applied, according to the prespecified strategy of the hospital protocol. After the initial phase, a custom-fitted, flat-knitted, knee length graduated ECS class III (ankle pressure $40 \mathrm{mmHg}$ ) is prescribed for all patients. The same brand and type (Mediven 550) of compression stocking is prescribed to all patients in all participating centres. Compression therapy with the ECS is started immediately after the initial phase, so there is no period without compression in between, with exception of the patients who do not receive compression in the initial phase. Patients receive two new stockings every year. Patients are advised to wear the stockings during the daytime.

\section{Procedures}

After obtaining written informed consent, randomization is performed centrally at the coordinating study centre, the Maastricht University Medical centre. Patients are included and randomized within 2-6 weeks after diagnosis of DVT. Patients are randomized to one of the two treatment arms.(Figure 7.1) A web-based randomization programme (TENALEA (Trans European Network for Clinical Trials Services)) is used that executes blocked randomization with stratification on centrelevel and on possible confounding patient characteristics such as age, sex, and BMI $\left(<26 \mathrm{~kg} / \mathrm{m}^{2}\right.$ to $\left.\geq 26 \mathrm{~kg} / \mathrm{m}^{2}\right)$. Permuted blocks of randomly varying size are used to maintain balance of numbers in each treatment group and to ensure allocation concealment.

Information on allocation is only accessible to the study personnel at the coordinating study centre in Maastricht, patients will receive information about their allocation via the coordinating study centre. The allocation will be concealed from study personnel involved in assessing the leg symptoms and rating the PTS scores. Patients are not blinded by the use of sham stockings, because they may influence quality of life, complicating the assessment of perceived differences between groups. Patients are 
asked not to reveal their treatment allocation to their own physician, and not to wear the ECS at the day of their outpatient clinic visits.

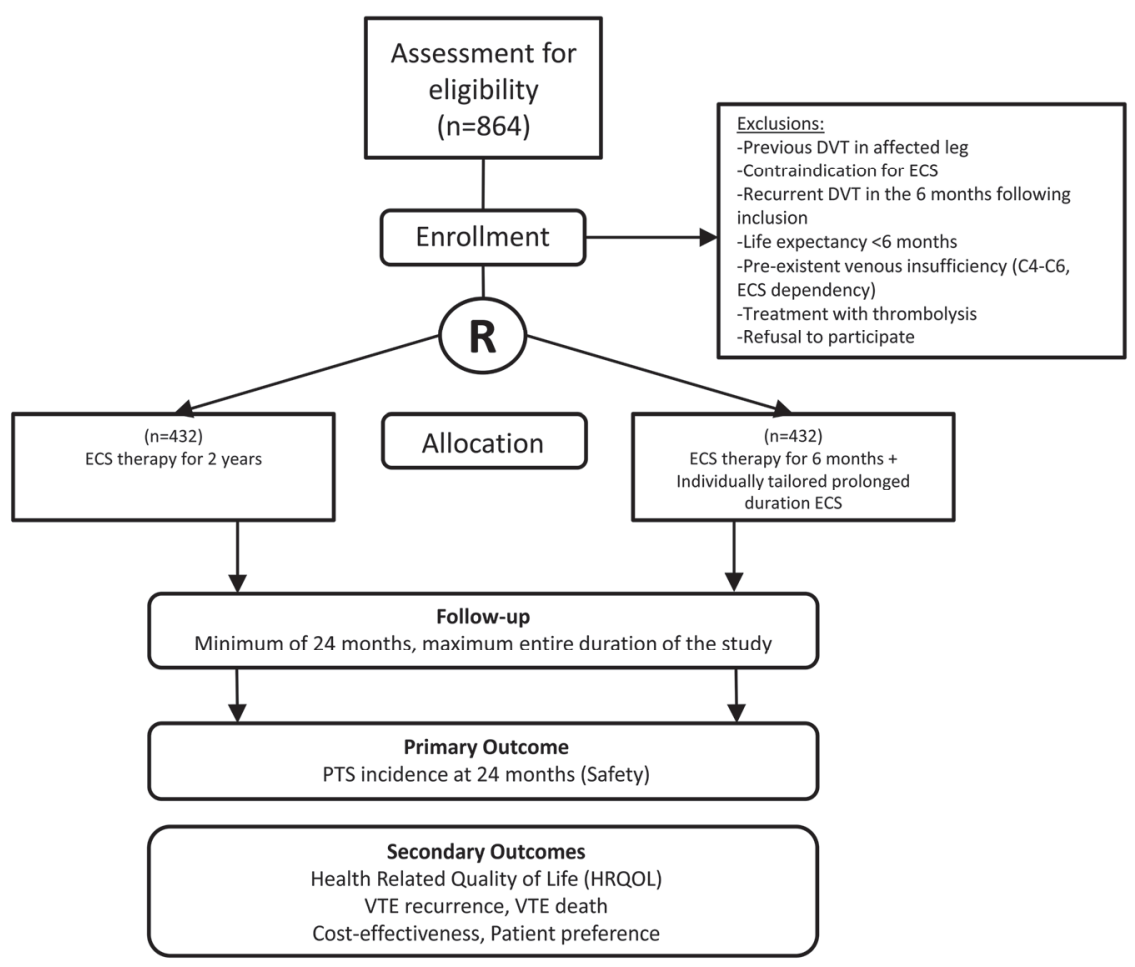

Figure 7.1 Study flow diagram.

All patients are advised to wear the ECS during the first 6 months after DVT. In the control group, all patients are instructed to wear the elastic compression stocking daily for a total duration of two years. In the Intervention group, duration of ECS therapy is individually tailored based on Villalta scores. ${ }^{24}$ After the first six months, therefore, there are three scenarios:

1. The Villalta score at both the three-month and six-month follow-up visit is $\leq 4$, in which case the patient is advised to discontinue ECS therapy.

2. The Villalta score at the three-month follow-up visit is $\geq 5$ and at the six-month follow-up visit is $\leq 4$. The patient is advised to continue the ECS therapy for another six months. If the Villalta score at the twelve-month follow-up visit is $\leq 4$, the patient is allowed to discontinue the ECS therapy.

3. The Villalta score is $\geq 5$ at both the three-month and six-month follow-up visit. The patient is advised to continue the ECS therapy for a total duration of 24 months.(Figure 7.2) 


\section{Inclusion}

0 months

3 months

24 months

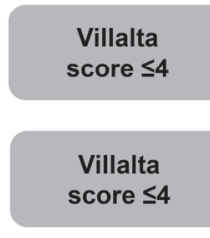

$=$

Stop ECS

12 months

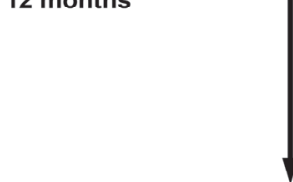

(1)
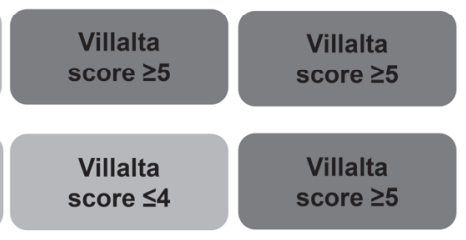

Villalta

score $\geq 5$

$=$

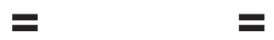

Continue ECS Continue ECS
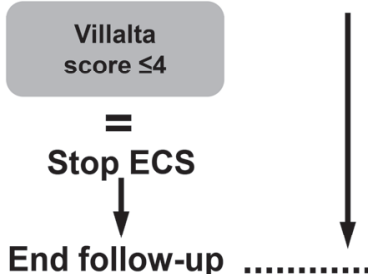

Figure 7.2 Algorithm individually tailored elastic compression stocking (ECS) therapy.

Using this algorithm the duration of ECS therapy is individually tailored to each patient. The decision on the duration of ECS therapy in patients in the intervention group is made centrally at the coordinating study centre, as the information on treatment allocation is available only there. The patient is informed about the decisions on the (dis) continuation of the ECS therapy by the coordinating centre.

When a patient develops symptoms and signs of PTS after discontinuation of ECS therapy, a predefined protocol is followed. If necessary, ECS treatment will be reinstated.

\section{Follow-up}

All patients are followed for 24 months after DVT. During these 24 months they visit the outpatient clinic four times: at 3, 6, 12, and 24 months after the DVT. At each follow-up visit the signs of PTS will be recorded and scored by the study nurse or the treating physician using the objective part of the Villalta clinical scale for PTS. ${ }^{24}$ In case of intermittent leg complaints or signs or symptoms suspected to be recurrent VTE, patients are instructed to visit their treating physician. Study documentation will be filled out and adverse events will be recorded. The CCMO (central committee humanrelated research) will be notified in case of serious adverse events or death.

The patient is asked to fill out five questionnaires: at baseline, and 3,6, 12, and 24 months later. All questionnaires will be offered as a web-based application; each patient will have a unique personal entry code. For patients who are not able or 
willing to use the electronic questionnaires, a paper version will be available. The first questionnaire is filled out shortly after inclusion (4-6 weeks after DVT) and the subsequent questionnaires are filled out the day before each follow-up visit. All questionnaires contain the subjective part of the Villalta clinical scale for PTS, ${ }^{24}$ questions on ECS compliance, a cost questionnaire, ${ }^{16}$ and three HRQOL questionnaires: the Dutch translated Veines-Qol, ${ }^{15}$ the SF-36, ${ }^{13}$ and the EQ-5D. ${ }^{14}$ In a subset of the study population patient preferences regarding elastic compression therapy will be analysed by conducting a DCE. For this purpose, a DCE questionnaire will be send to a subset of the population at approximately 3 months after DVT.

Compliance to ECS therapy is monitored in two ways. Each questionnaire contains a question on compliance to the advised version of ECS therapy. Because compliance and adherence to therapy is of crucial importance the number of contact moments for the assessment of compliance with ECS therapy will be increased by adding telephone contacts to the regular clinical visits. Study-supporting staff will make computerassisted random telephone calls during the entire follow-up period to the patients in the group with the two-year ECS intervention as well as to patients in the group with individualized ECS therapy. The telephone calls will be made randomly to create a surprise effect (patients are off guard) and to allow for a distribution of contacts over the entire study period. Per patient 3 extra contact moments will be created. A standard questionnaire will be used to assess compliance and to address reasons for non-compliance. Crossover to another therapy arm will be discussed and discouraged.

\section{Outcomes}

The primary outcome is the proportion of patients with PTS at the end of follow-up, 24 months after DVT. PTS is defined as a Villalta score of $\geq 5$ at two consecutive visits that are at least three months apart. The time point of the second Villalta score of $\geq 5$ will be considered the time point of PTS diagnosis. Although the consensus is to diagnose PTS at the six-month visit or later based on one single Villalta score of $\geq 5,{ }^{25}$ we modelled this study after the preceding management study in which two consecutive Villalta scores of $\geq 5$ were needed for the diagnosis PTS. We observed that a proportion of patients (about 12\%) had fluctuating Villalta scores beyond six months after the acute event of DVT. ${ }^{9}$ Assigning the diagnosis based on one single score of $\geq 5$ would therefore lead to misclassification and overestimation of the PTS incidence. The Villalta scores at six months will be available; therefore, the proportion of patients with PTS according to the consensus scoring method will also be presented.

\section{Secondary outcomes include:}

(1) HRQOL, measured by questionnaires (SF-36, ${ }^{13}$ EQ-5D, ${ }^{14}$ Dutch translated VeinesQol $^{15}$ ); (2) costs; ${ }^{16}$ (3) recurrent thrombosis, according to criteria as published ${ }^{17}$ and assessed by objective tests; (4) VTE-related death during follow-up, assessed by an 
independent and blinded adjudication committee; (5) patient preferences, assessed with a DCE. ${ }^{18}$

Since both effects on costs as well as generic HRQOL are to be expected, the method of economic evaluation is a CUA. The analysis will be from a societal perspective. The primary effect parameter is generic $\mathrm{HRQOL}$, measured in quality-adjusted life years (QALYS). We will perform two analyses: a trial based CUA with a time horizon of two years (identical to the duration of follow-up in the clinical study), and a model-based CUA with a lifelong time horizon. For the latter, we will follow the guidelines of good modelling. ${ }^{26}$ We will be able to adapt a Markov model for diagnostic strategies in DVT, which was developed by our group earlier. ${ }^{27}$ Costs in the economic analyses include direct health care costs (medical costs for prevention, diagnostics, therapy, rehabilitation, and care), direct non-health care costs (travel costs), and indirect costs (productivity loss). Utilities will be calculated from the responses on the EQ-5D and SF-36 classification systems using the available multi-attribute utility functions. ${ }^{28,29}$ Incremental cost-utility ratios will be calculated, and non-parametric bootstrap analyses will be used to quantify the uncertainty surrounding the cost-utility ratio of the trial-based analysis. Sensitivity analyses and subgroup analyses will be performed to assess the impact of variation in parameters and heterogeneity of the patient population.

ECS therapy has several disadvantages for the patients (stockings are uncomfortable, ugly, and difficult to put on and take off), while duration and effectiveness are uncertain. A DCE will be conducted to assess the patient preferences regarding ECS therapy, providing insight to the trade-offs patients make between characteristics of the therapy when deciding to wear the stocking or not. Duration of ECS therapy is one of the characteristics. Data will be analysed using multinomial logit models and mixed logit models.(Nlogit, Econometric Software)

\section{Sample size calculation}

The proposed study is a non-inferiority trial and aims to demonstrate that the assessed alternative therapy based on ECS for six months followed by individually prolonged ECS therapy based on Villalta scores is not worse than the comparator ECS therapy for a standard duration of 24 months, by more than the prespecified amount of $7.5 \%$ (the non-inferiority margin). The published incidence of PTS following two years of ECS lies between 20 and 30\% (Prandoni et al. 24.5\% [95\% Cl 15.6-33.4], Brandjes et al. $20 \%[95 \% \mathrm{Cl} 12.4-29.2])^{7,8}$ As it is statistically impossible to demonstrate equivalence (prove the $\mathrm{HO}$ of no difference), Blackwelder proposed a one-sided significance test to reject the null hypothesis by a clinically acceptable amount. $^{30}$ If we allow a difference of $7.5 \%$ in the outcome PTS between the group with ECS for two years and the group with the alternative therapy, $70 \%$ of the effect will be preserved. This proportion of loss in efficacy is customarily accepted in 
controlled randomized clinical trials. At a one sided significance level of 0.05 and a power of $80 \%$, with a ratio of 1 , a total of 847 patients is needed to provide sufficient patients for an adequately powered trial. ${ }^{30,31}$ Loss to follow-up of patients is expected to be less than $2 \%$ since the intervention does not have an invasive nature. Therefore, a total of 864 patients are needed (432 patients per treatment arm).

\section{Statistical analysis}

Descriptive statistics of the total population and of the two treatment groups separately will be computed to provide baseline characteristics of the patients in both treatment arms.

For the primary outcome PTS, univariate analysis of all proportions will be performed with logistic regression (chi-squared) analysis. Kaplan-Meier method will be used to calculate the cumulative incidences of PTS, adjusted for centre to compare incidence rates between the two treatment arms. Patients who die or are lost to follow-up will be censored at their last visit. Analysis of variance (ANOVA) will be applied to assess changes over time, by comparing different outcome measures at the different time points of follow-up.

Hazard ratio's (HRs) and 95\% Cl for both treatment arms will be calculated using Cox regression models. HRs will be stratified for centre and adjusted for age, sex, BMI, clinical presentation of DVT, and extent of the index DVT.

\section{Interim analysis (safety)}

A prespecified safety analysis will be performed when $50 \%$ of the participants have completed the two-year follow-up. The analysis will be performed by the coordinating centre, and supervised by the principal investigators. The safety analysis will be performed to assess significant enhanced risk of PTS or excess morbidity/mortality in the intervention arm of the study population. Fisher's exact test will be performed to compare incidence of PTS at a significance level of 0.05 (two sided). The study can be stopped in case of significant excess morbidity/mortality in the alternative treatment arm.

\section{Ethical considerations}

All patients are extensively informed about the study, and written informed consent is obtained from all participating patients.

The IDEAL DVT study started including patients on 11 March 2011 and inclusion is currently on-going. Recruitment is expected to be terminated in January 2015. As the follow-up is two years, the results are expected within three years, in January 2017. 


\section{Discussion}

Based on current knowledge the standard application of ECS therapy after DVT is questioned. The definitive answer on the usefulness of ECS therapy for the prevention of PTS is not yet provided. Therefore the need for the IDEAL DVT study remains unchanged. The benefit to individual patients and the optimal duration of ECS therapy were never studied properly and as a result it is unclear which individual patients require therapy and for how long. The IDEAL DVT study will address the central questions that remain unanswered: Which individual patients benefit from ECS therapy and what is the optimal individual treatment duration? The study that we plan to perform is not only innovative, for the first time individual tailoring of duration of ECS therapy will be investigated, but it will provide unique additional knowledge on the safety, effectiveness, and cost-effectiveness of this approach as well. 


\section{References}

1. www.rijksoverheid.nl.

2. Kahn SR, Shrier I, Julian JA, Ducruet T, Arsenault L, Miron MJ, Roussin A, Desmarais S, Joyal F, Kassis J, Solymoss S, Desjardins L, Lamping DL, Johri M, Ginsberg JS. Determinants and time course of the postthrombotic syndrome after acute deep venous thrombosis. Ann Intern Med 2008;149:698-707.

3. Pesavento R, Villalta S, Prandoni P. The postthrombotic syndrome. Intern Emerg Med 2010;5:185-92.

4. Prandoni P, Kahn SR. Post-thrombotic syndrome: prevalence, prognostication and need for progress. Br J Haematol 2009;145:286-95.

5. Prandoni $P$, Villalta S, Bagatella P, Rossi L, Marchiori A, Piccioli A, Bernardi E, Girolami B, Simioni $P$, Girolami A. The clinical course of deep-vein thrombosis. Prospective long-term follow-up of 528 symptomatic patients. Haematologica 1997;82:423-8.

6. Bergqvist D, Jendteg S, Johansen L, Persson U, Odegaard K. Cost of long-term complications of deep venous thrombosis of the lower extremities: an analysis of a defined patient population in Sweden. Ann Intern Med 1997;126:454-7.

7. Brandjes DP, Buller HR, Heijboer $H$, Huisman MV, de Rijk M, Jagt $H$, ten Cate JW. Randomised trial of effect of compression stockings in patients with symptomatic proximal-vein thrombosis. Lancet 1997; 349:759-62.

8. Prandoni $P$, Lensing AW, Prins MH, Frulla M, Marchiori A, Bernardi E, Tormene D, Mosena L, Pagnan A, Girolami A. Below-knee elastic compression stockings to prevent the post-thrombotic syndrome: a randomized, controlled trial. Ann Intern Med 2004;141:249-56.

9. Ten Cate-Hoek AJ, Ten Cate H, Tordoir J, Hamulyak K, Prins MH. Individually tailored duration of elastic compression therapy in relation to incidence of the postthrombotic syndrome. J Vasc Surg 2010;52: 132-8.

10. Ginsberg JS, Hirsh J, Julian J, Vander Laan deVries M, Magier D, MacKinnon B, Gent M. Prevention and treatment of postphlebitic syndrome: results of a 3-part study. Arch Intern Med 2001;161:2105-9.

11. Aschwanden M, Jeanneret C, Koller MT, Thalhammer C, Bucher HC, Jaeger KA. Effect of prolonged treatment with compression stockings to prevent post-thrombotic sequelae: a randomized controlled trial. J Vasc Surg 2008;47:1015-21.

12. Kahn SR, Shapiro S, Wells PS, Rodger MA, Kovacs MJ, Anderson DR, Tagalakis V, Houweling AH, Ducruet T, Holcroft C, Johri M, Solymoss S, Miron MJ, Yeo E, Smith R, Schulman S, Kassis J, Kearon C, Chagnon I, Wong T, Demers C, Hanmiah R, Kaatz S, Selby R, Rathbun S, Desmarais S, Opatrny L, Ortel $\mathrm{TL}$, Ginsberg JS; SOX trial investigators. Compression stockings to prevent post-thrombotic syndrome: a randomised placebo-controlled trial. Lancet 2014; 383:880-8.

13. Aaronson NK, Muller M, Cohen PD, Essink-Bot ML, Fekkes M, Sanderman R, Sprangers MA, te Velde A, Verrips E. Translation, validation, and norming of the Dutch language version of the SF-36 Health Survey in community and chronic disease populations. J Clin Epidemiol 1998;51:1055-68.

14. Brooks R. EuroQol: the current state of play. Health Policy 1996;37:53-72.

15. Kahn SR1, Lamping DL, Ducruet T, Arsenault L, Miron MJ, Roussin A, Desmarais S, Joyal F, Kassis J, Solymoss S, Desjardins L, Johri M, Shrier I. VEINES-QOL/Sym questionnaire was a reliable and valid disease-specific quality of life measure for deep venous thrombosis. J Clin Epidemiol 2006;59: 1049-56.

16. Brouwer W. Handleiding voor het gebruik van PRODISQ versie 2.1 (PROductivity and DISease Questionnaire). Een modulaire vragenlijst over de relatie tussen ziekte en productiviteitskosten. Toepasbaar bij economische evaluaties van gezondheidszorgprogramma's voor patiënten en werknemers. Rotterdam/Maastricht 2004

17. Prandoni $P$, Lensing AW, Bernardi E, Villalta S, Bagatella P, Girolami A. The diagnostic value of compression ultrasonography in patients with suspected recurrent deep vein thrombosis. Thromb Haemost 2002;88:402-6.

18. Lancaster K. A new approach to consumer theory. J Polit Econ 1966(74):132-57.

19. СВO. СВO Richtlijn Diagnostiek, preventie en behandeling van veneuze trombo-embolie en secundaire preventie van arteriele trombose, ed. K.v.d.G. CBO. 2008, Utrecht: Kwaliteitsinstituut voor de Gezondheidszorg CBO. 
20. Hirsh J, Guyatt G, Albers GW, Harrington R, Schünemann HJ, American College of Chest Physician. Antithrombotic and thrombolytic therapy: American College of Chest Physicians Evidence-Based Clinical Practice Guidelines (8th Edition). Chest 2008;133(6 Suppl): 110S-112S

21. Blattler W. Aspects of cost effectiveness in therapy of acute leg/pelvic vein thrombosis. Wien Med Wochenschr 1999;149:61-5.

22. Gelderblom GJ, Hagedoorn-Meuwissen EAV. Kousen uittrekhulpmiddel Easy-Lever. Een onderzoek naar bruikbaarheid, effecten en belemmeringen, in opdracht van ZonMw. 2005(juni).

23. Raju S, Hollis K, Neglen P. Use of compression stockings in chronic venous disease: patient compliance and efficacy. Ann Vasc Surg 2007;21:790-5.

24. Villalta S, Bagatella P, Picolli A, Lensing A, Prins M, Prandoni P. Assessment of validity and reproducibility of a clinical scale for the post thrombotic syndrome (abstract). Haemostasis 1994(24): 158 a.

25. Kahn SR, Partsch H, Vedantham S, Prandoni P, Kearon C. Definition of post-thrombotic syndrome of the leg for use in clinical investigations: a recommendation for standardization. J Thromb Haemost 2009; 7:879-83.

26. Weinstein MC, O'Brien B, Hornberger J, Jackson J, Johannesson M, McCabe C, Luce BR. Principles of good practice for decision analytic modeling in health-care evaluation: report of the ISPOR Task Force on Good Research Practices--Modeling Studies. Value Health 2003;6:9-17.

27. Ten Cate-Hoek AJ, Toll DB, Büller HR, Hoes AW, Moons KG, Oudega R, Stoffers HE, van der Velde EF, van Weert HC, Prins $\mathrm{MH}$, Joore MA. Cost-effectiveness of ruling out deep venous thrombosis in primary care versus care as usual. J Thromb Haemost 2009;7:2042-9.

28. Brazier J, Roberts J, Deverill M. The estimation of a preference-based measure of health from the SF36. J Health Econ 2002;21:271-92.

29. Dolan P. Modeling valuations for EuroQol health states. Med Care 1997;35:1095-108.

30. Blackwelder W.C. "Proving the null hypothesis" in clinical trials. Control Clin Trials 1982;3:345-53.

31. Laster LL, Johnson MF. Non-inferiority trials: the 'at least as good as' criterion. Stat Med 2003;22: $187-200$ 


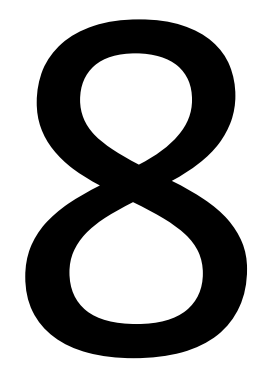

Sample size estimation for non-inferiority trials: Frequentist approach versus decision theory approach

AC Bouman, AJ ten Cate-Hoek, BLT Ramaekers, MA Joore PLoS One 2015;10:1-14 


\section{Abstract}

\section{Background}

Non-inferiority trials are performed when the main therapeutic effect of the new therapy is expected to be not unacceptably worse than that of the standard therapy, and the new therapy is expected to have advantages over the standard therapy in costs or other (health) consequences. These advantages however are not included in the classic frequentist approach of sample size calculation for non-inferiority trials. In contrast, the decision theory approach of sample size calculation does include these factors. The objective of this study is to compare the conceptual and practical aspects of the frequentist approach and decision theory approach of sample size calculation for non-inferiority trials, thereby demonstrating that the decision theory approach is more appropriate for sample size calculation of non-inferiority trials.

\section{Methods}

The frequentist approach and decision theory approach of sample size calculation for noninferiority trials are compared and applied to a case of a non-inferiority trial on individually tailored duration of elastic compression stocking therapy compared to two years elastic compression stocking therapy for the prevention of post thrombotic syndrome after deep vein thrombosis.

\section{Results}

The two approaches differ substantially in conceptual background, analytical approach, and input requirements. The sample size calculated according to the frequentist approach yielded 788 patients, using a power of $80 \%$ and a one-sided significance level of $5 \%$. The decision theory approach indicated that the optimal sample size was 500 patients, with a net value of $€ 92$ million.

\section{Conclusions}

This study demonstrates and explains the differences between the classic frequentist approach and the decision theory approach of sample size calculation for non-inferiority trials. We argue that the decision theory approach of sample size estimation is most suitable for sample size calculation of non-inferiority trials. 


\section{Introduction}

Non-inferiority trials that evaluate whether a new therapy is not inferior to the standard therapy, are becoming more common in the last two decades. ${ }^{1,2}$ An important reason for conducting a non-inferiority trial is when a new therapy is expected to have advantages over the standard therapy, other than the main therapeutic effect. ${ }^{3}$ For example, the new therapy is expected to save costs or lead to less side effects or complications. In the traditional frequentist approach of sample size calculation for non-inferiority trials, the costs and health consequences, beyond the main therapeutic effect, are not taken into consideration. ${ }^{4}$ In this paper we argue and illustrate, using an exemplifying case study, that decision theory may provide a more comprehensive, and hence more appropriate, approach to sample size calculation for non-inferiority trials.

As described in literature by Schumi et al. and Laster et al. non-inferiority trials aim to show that the new therapy is 'not unacceptably worse' or 'at least as good as' the standard therapy, with respect to the main therapeutic outcome. ${ }^{3,5}$ It is not possible to prove equivalence of two therapies, as the null hypothesis of no difference is impossible to prove. ${ }^{6}$ Blackwelder developed a one-sided significance test to assess whether the loss of therapeutic efficacy of the new therapy compared to the standard therapy is not more than a prespecified clinically accepted amount.(Figure 8.1, panel A) This prespecified maximal accepted loss of therapeutic effect is called the noninferiority margin $(\delta) .{ }^{6}$ If the loss of therapeutic effect of the new therapy compared to the standard therapy does not exceed the non-inferiority margin, the new therapy is considered non-inferior to the standard therapy. ${ }^{3}$ The sample size of a noninferiority trial is calculated based on the non-inferiority margin, the intended power, and the significance level. ${ }^{4,6}$ Conceptually, it is calculated what sample size is needed to prove, with statistical significance and a certain power, that the loss of therapeutic effect of the new therapy compared to the standard therapy is not larger than what is deemed maximally acceptable. An accepted difference in main therapeutic effect, the non-inferiority margin, is introduced in order to enable testing for statistical significance. Although guidelines exist on the choice of the non-inferiority margin, the choice of the margin remains arbitrary. $3,7,8$

Another approach of sample size calculation finds its origin in decision theory. In health care decision making two distinct but related decisions are made: whether or not to adopt a new therapy, and whether or not to do further research to obtain additional information. ${ }^{9}$ In these decisions not only the main therapeutic effect, but also costs and other health consequences (such as complications, side effects and the quality of life impact associated with these health outcomes) are taken into account. The health outcomes are usually summarized in quality adjusted life years (QALYs). The expected costs and QALYs of each therapy are expressed in net monetary benefits (NMB). The therapy with the highest expected NMB should be adopted. Uncertainty surrounding the expected NMB can result in wrongful decisions and, thus, benefits 
forgone. Obtaining additional information can reduce uncertainty, increasing the probability of making the right decision on adoption of the new therapy. ${ }^{10}$ The maximum value that can be ascribed to the additional information (i.e. value of information) can be compared to the costs of acquiring additional information, for example trial costs. This information can be used to estimate the optimal sample size of a trial (expected value of sampling information; EVSI). ${ }^{9}$ The costs of acquiring additional information can be subtracted from the EVSI to obtain the value of a trial (i.e. expected net benefit of sampling; ENBS). Hence, the EVSI and ENBS analyses can be performed to determine the optimal sample size. Conceptually, it is calculated at what sample size the difference between the costs of acquiring additional information and the value of the additional information is maximum. ${ }^{11-14}$ Several studies applied the decision theory approach to a health care decision problem. ${ }^{15-23}$ These studies all focused on superiority trials. In our opinion, the decision theory approach of sample size estimation will be even more valuable for non-inferiority trials, because in the decision theory approach not only the main therapeutic effect, but also costs and other health consequences are taken into account. In non-inferiority trials, it often is the latter in which the new therapy is supposed to make a difference, as the main therapeutic effect is expected to be at least as good as or not unacceptably worse.

The aim of this study is to demonstrate that the decision theory approach of sample size calculation is more appropriate for non-inferiority trials than the frequentist approach of sample size calculation. To this end, the conceptual as well as the practical aspects of both approaches are compared and both approaches are applied to a case. Furthermore, we aim to initiate discussion on this topic of sample size calculation for clinical trials, because there is need for innovation.

\section{Formula Box 1:}

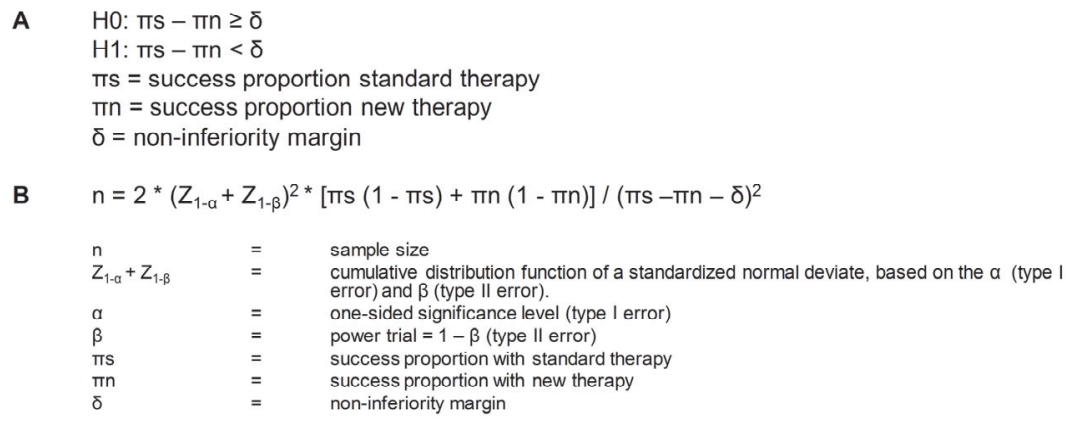

Figure 8.1 Formula Box 1. 


\section{Materials and methods}

\section{Frequentist approach}

The sample size needed to prove non-inferiority of a new therapy was calculated using the formula shown in Figure 8.1, panel B. The non-inferiority margin, success proportion of the standard therapy and the new therapy, and the intended significance level $(\alpha)$ and power $(1-\beta)$ of the trial were specified, subsequently the sample size was calculated. ${ }^{4,6}$

\section{Decision theory approach}

Health economic decision modeling can be used to assess the relevant effects and costs of a new therapy against its comparator over time. Whether or not to adopt a new therapy depends on the health effects and the costs of the new therapy. A health care decision model can be used to estimate the costs and health effects of the therapy alternatives $j$, given uncertain parameters represented as vector $\theta$.(Figure 8.2, panel $A)^{24}$ Every value of the uncertain parameters $\theta$, gives different $\operatorname{costs}(C(j, \theta))$ and health outcomes $(H(j, \theta))$. The expected NMB is the difference in health outcomes of the different therapy alternatives times the threshold (amount of money society is willing to pay for additional health outcomes $\lambda$ ), minus the difference in costs.(Figure 8.2, panel B) The therapy with the highest NMB, is the therapy of choice $\left(j^{*}\right)$. Obtaining new information can reduce the uncertainty on some or all uncertain parameters $\theta_{\text {new }}$. When perfect information would be available (no uncertainty) on all parameters, the right decision would always be made and the therapy with the highest NMB would always be chosen. Thus, the value of having perfect information on $\theta_{\text {new, }}$ is the amount of money that could be saved if the therapy with the highest NMB is always chosen. This is called the expected value of perfect information per patient (EVPI).(Figure 8.2, panel C) ${ }^{10}$ The number of patients that is affected by the decision to adopt the new therapy over the lifetime of the new therapy is called the effective population, represented as $\mathrm{p}$. The effective population is used to calculate the EVPI for the whole population involved.(Figure 8.2, panel D) Further research usually cannot address all uncertainty as studies obtain information on only one or a few uncertain parameters. Therefore, it is useful to calculate the expected value of perfect information on a certain parameter or a certain group of parameters $\left(\theta_{\text {new }}=\right.$ $(\phi, \psi))$, the expected value of perfect parameter information (EVPPI).(Figure 8.2, panel $E$ and $F$ ) Studies will have to be performed to obtain additional information, represented as $X$, on a parameter or a group of parameters. After obtaining additional information $X$ on parameters $\theta$, the posterior probability distribution of $\theta$ will have smaller confidence intervals. The more the reduction in uncertainty is, the higher the value of the additional information. It is possible to calculate the expected value of information for different samples sizes of a study. This is called the expected value of sampling information (EVSI).(Figure 8.2, panel $\mathrm{G}$ and $\mathrm{H})^{10}$ Performing studies costs 
money: $C(X)$. Therefore, the net gain of obtaining additional information is the expected value of sampling information minus the costs made. This is called the expected net benefit of sampling (ENBS).(Figure 8.2, panel I) ${ }^{12}$

To estimate the optimal sample size according to the decision theory approach, a health economic decision model was build and EVSI analyses were performed. For different sample sizes, possible trial results were simulated multiple times, using Monte Carlo simulation. According to Bayesian methods, model parameters were updated with the simulated trial results, and an updated EVPI per patient was calculated. To calculate the updated population EVPI, the sample size of the trial was subtracted from the effective population, because the patients participating in the trial do not benefit from the additional information obtained in the trial. The EVSI is the prior population EVPI (before update with simulated trial results) minus the updated population EVPI. The EVSI was calculated for different sample sizes. ${ }^{9}$ Costs of the trial were defined and subsequently the ENBS was calculated to assess for which sample size the net gain was optimal. Sensitivity analyses were performed to explore the effect of changes in the size of the effective population on the EVSI and ENBS results.

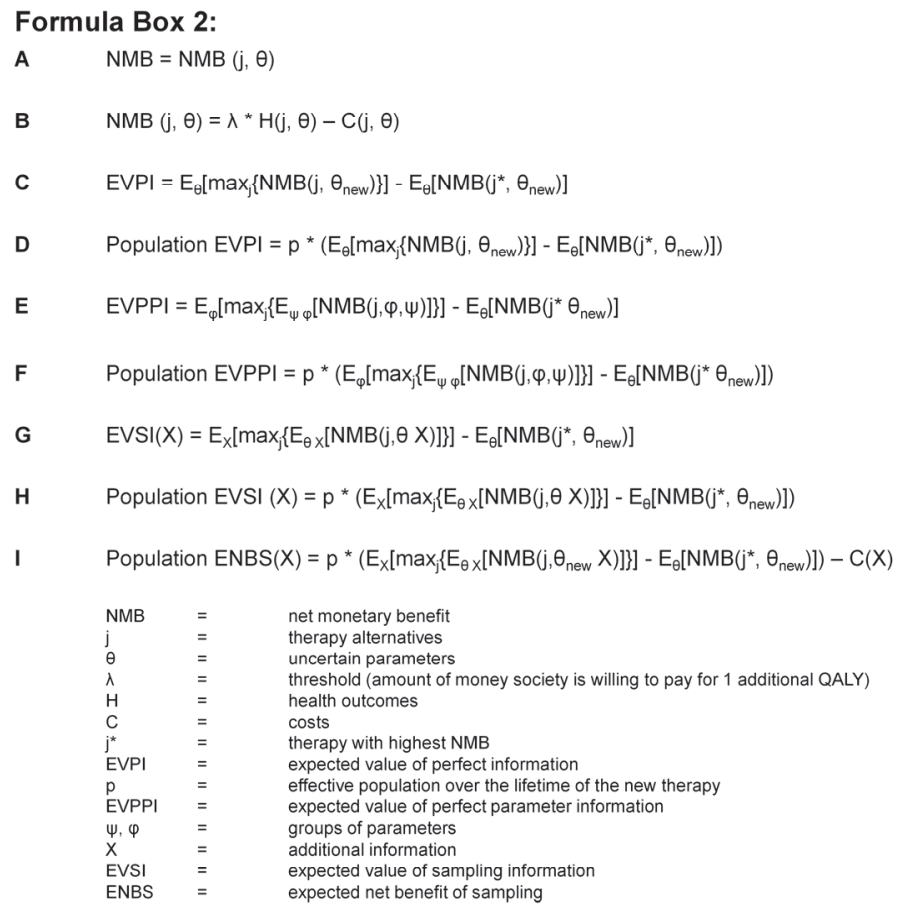

Figure 8.2 Formula Box 2. 
In Table 8.1 the most essential differences between the frequentist approach and the decision theory approach of sample size calculation for non-inferiority trials are described.

\section{Case description}

Twenty to fifty percent of the patients who suffer from a DVT of the leg, develop PTS. ${ }^{25,26}$ Patients with PTS have complaints of the leg that was affected by the DVT; for example pain, heaviness, cramps, tingling, itching, and in severe cases ulceration of the leg. ${ }^{25,26}$ Patients with mild to moderate PTS report a quality of life that is lower than contemporaries with arthritis, chronic lung disease, hearing impairment, or diabetes. Patients with severe PTS report a quality of life that is comparable to patients with angina, cancer, or congestive heart failure. ${ }^{27}$ The healthcare costs of PTS were found to be $\$ 7000$ per patient per year, in a retrospective study in the USA on administrative claim data of patients after DVT. ${ }^{28}$ There is no effective treatment for PTS, and prevention remains the cornerstone for disease management. Two large randomized controlled trials (RCT) showed a relative risk reduction in PTS of approximately $50 \%$ when patients wore elastic compression stockings (ECS) for a period of two years after DVT. ${ }^{25,26}$ ECS are not very costly, roughly $€ 100$ per patient per year. However, the incidence of DVT is substantial. Every year, 25,000 patients develop PTS in the Netherlands, ${ }^{29}$ and around $7.5 \%{ }^{30}$ of the patients need home care to apply and take off the stockings ( $€ 10,000$ per patient per year ${ }^{31}$ ). As a result, in the Netherlands the total annual impact on the health care budget amounts to approximately $€ 23.5$ million. Besides the cost issue, compliance is a major problem of ECS therapy. Patients do not wear the stocking because it is warm, itching, and pinching. Elderly patients are restricted in their freedom of movement because they have to wait at home until the nurse arrives to apply or take off their stocking. In the end, more than $50 \%$ of patients do not develop PTS. ${ }^{32}$ A new strategy of ECS therapy is to tailor the duration of therapy on the signs and symptoms of PTS of the individual patient, after the first six months of therapy. In a management study including 125 patients, this approach was safe and effective, as the incidence of PTS was comparable to the PTS incidence in the active arm of the two previous RCTs. ${ }^{33}$ In addition, approximately $50 \%$ of patients could safely take off the stocking after six months. ${ }^{33}$ This strategy appears to be safe and potentially cost saving. However, to confirm the results of the management study, a randomized non-inferiority trial should be performed to assess whether individually tailored ECS therapy is not inferior to two years ECS therapy, in preventing PTS. ${ }^{34}$ 


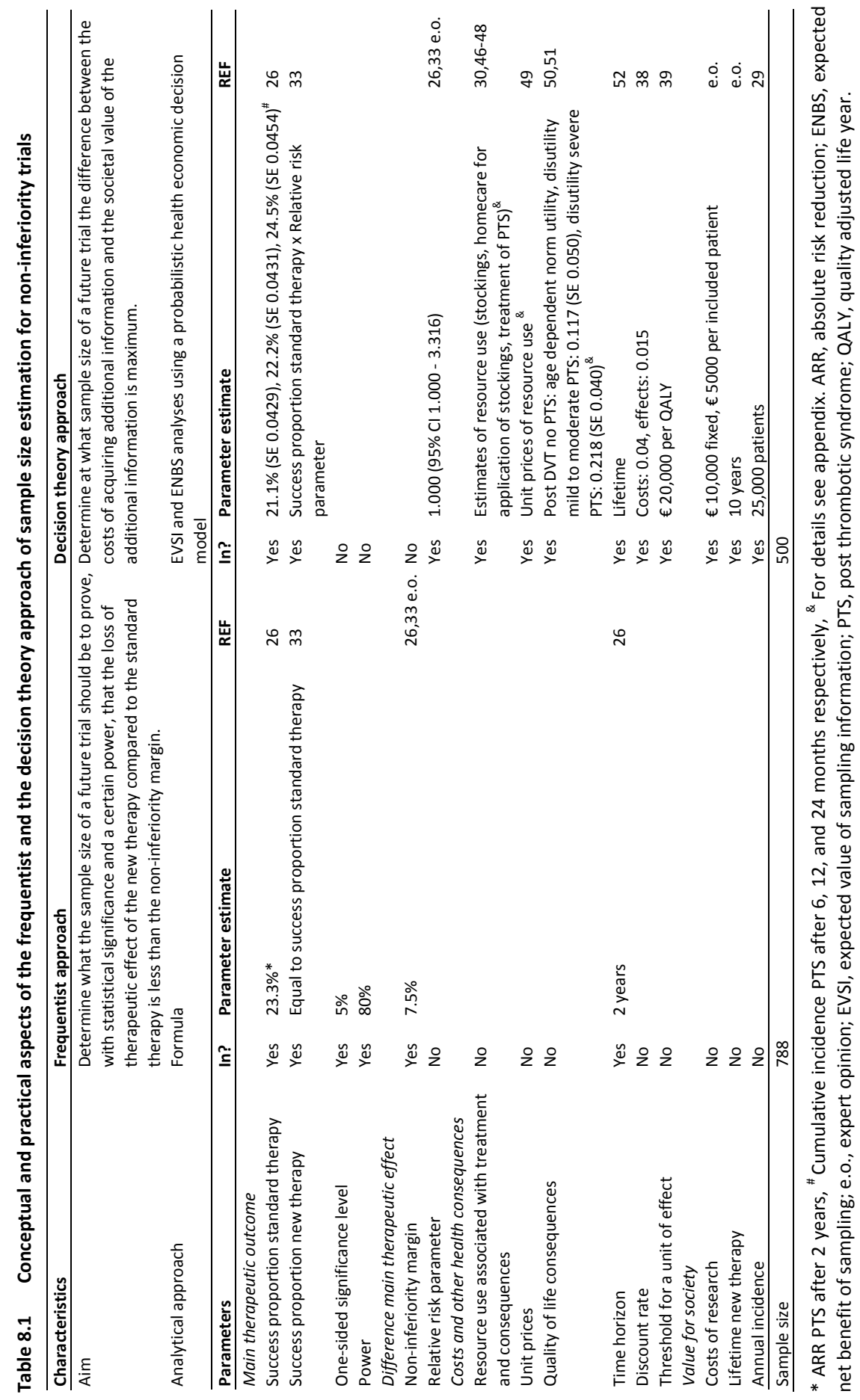




\section{Results}

\section{Frequentist approach}

The non-inferiority margin was based on the proportion of therapeutic effect of the active control that should be retained. ${ }^{8}$ In this case the active control was two years ECS therapy. The therapeutic effect of the active control was derived from an RCT comparing two years ECS therapy versus no ECS therapy, for the prevention of PTS, performed by Prandoni et al. This study found an absolute risk reduction of $23.3 \%$ of PTS at two years after DVT. ${ }^{26}$ The non-inferiority margin was set at 7,5\% in order for individually tailored ECS therapy (the new therapy) to preserve approximately $70 \%$ of the therapeutic effect of the active control. It is customarily accepted in noninferiority trials to preserve at least $50-70 \%$ of the therapeutic effect of the active control. $^{35-37}$ Based on the management study, it was hypothesized that individually tailored ECS therapy would have an equal success proportion as two years ECS therapy. ${ }^{33}$ At a one- sided significance level of $5 \%$ and a power of $80 \%$, a sample size of 788 needed to test the hypothesis was calculated.(Figure 8.3, Table 8.1)

Calculations Box 1:

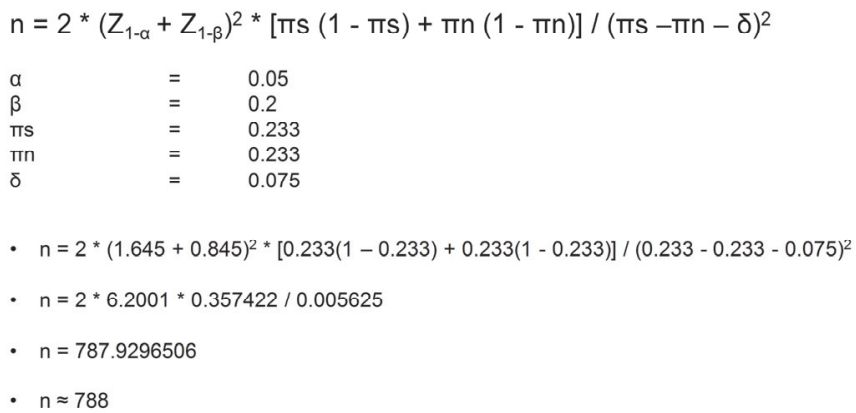

Figure 8.3 Calculations Box 1.

\section{Decision theory approach}

A probabilistic state transition health economic decision model was developed to assess the lifetime costs and health consequences (the main therapeutic effect, complications, side effects, and the quality of life impact associated with these health outcomes) of individually tailored ECS therapy versus two years ECS therapy in patients after DVT. The decision model consisted of four health states: No PTS, Mild to moderate PTS, Severe PTS, and Death. The difference between the two therapies was modeled by taking into account the differential impact on the probability of developing PTS, the costs of ECS therapy (for stockings and home care for stocking 
application), and the disutility of ECS therapy. Cycle length was six months for the first two cycles, and one year for the cycles thereafter. Cohort simulation was used to evaluate the decision model. Future costs and effects were discounted using a discount rate of $4 \%$ for costs and $1.5 \%$ for (quality adjusted) life years, in concordance with Dutch guidelines. ${ }^{38}$

In the decision model, PTS incidence was hypothesized to be equal for both therapies. This assumption was based on the management study. ${ }^{33}$ The transition probabilities for developing PTS in the two years after DVT were derived from the RCT by Prandoni et al. for both therapies. ${ }^{26}$

A relative risk (RR) parameter was incorporated in the decision model to represent the uncertainty of the development of PTS with individually tailored ECS therapy. A log normal distribution, with a mean of 1.000 and $95 \%$ confidence intervals $(\mathrm{Cl})$ ranging between 1.000 and 3.316 (the standard error of the $L N(R R)$ is 0.612 ) is used. The RR parameter is multiplied with the probabilities of developing PTS after six months with individually tailored ECS therapy. The upper limit of the $95 \% \mathrm{Cl}$ corresponds with a 7.5\% increase in the two year PTS incidence, representing the expected maximal increase in PTS incidence with individually tailored ECS therapy. Values of the parameter below 1 are rounded up to 1 , because we assume that individually tailored ECS therapy does not lead to a decrease in PTS incidence. The RR parameter is based on the same evidence as the non-inferiority margin of the frequentist approach. However, it represents the uncertainty of developing PTS with individually tailored ECS therapy, which is conceptually different from the non-inferiority margin. The decision model was built in Microsoft Excel 2010.(For more details on the decision model construction, see the Appendix 8.1.)

EVPI and EVPPI were calculated for an effective population of 25,000 patients, the yearly incidence of DVT in the Netherlands, ${ }^{29}$ and a lifetime of individually tailored ECS therapy of ten years. The threshold was set at $€ 20,000$ per QALY. ${ }^{39}$ The EVSI of a noninferiority trial comparing individually tailored ECS therapy with two years ECS therapy for the prevention of PTS was calculated for different sample sizes $(n=25, n=100$, $n=400, n=500, n=700, n=1000, n=1500, n=5000)$. The model parameters concerning the development of PTS with both individually tailored ECS therapy and two years ECS therapy, and the relative risk parameter were updated with the simulated trial results. Two hundred possible trial results were simulated using Monte Carlo simulation with 1000 iterations. For the trial we assumed a fixed cost of $€ 10,000$ and a variable cost of $€ 5000$ per included patient.

Based on current evidence the total expected lifetime costs were $€ 14,400(95 \% \mathrm{Cl}$ $5,700-28,100)$ for two years ECS therapy and $€ 14,300$ (95\% Cl 5,500-28,100) for individually tailored ECS therapy. The lifetime health outcomes yielded $12.50(95 \% \mathrm{Cl}$ 11.70-13.29) QALY and 12.49 (95\% Cl 11.63-13.30) QALY, respectively. The differences in health outcomes and costs are small according to these analyses. Since there is a large amount of uncertainty it is worthwhile to perform a trial. The uncertainty surrounding the cost-effectiveness of individually tailored ECS therapy 
versus two years ECS therapy resulted in an EVPI of $€ 600$ per patient, and the population EVPI was found to be $€ 122$ million.(Figure 8.4 ) The partial EVPI was highest for the uncertainty of the parameters concerning the incidence of PTS when applying individually tailored ECS therapy, EVPPI of $€ 117$ million.(Figure 8.4) The EVSI increased with an increasing sample size. However, from a sample size of 500 patients the EVSI was found to remain stable around $€ 94.5$ million.(Figure 8.4) The optimal sample size was found to be 500 patients (Table 8.1), as the ENBS reached its maximum (€ 92 million) for 500 patients.(Figure 8.4) The sensitivity analysis revealed that the optimal sample size remained to be 500 patients for effective populations of 10,000 and 40,000 , with ENBS of $€ 35.5$ million and $€ 150$ million, respectively.

A

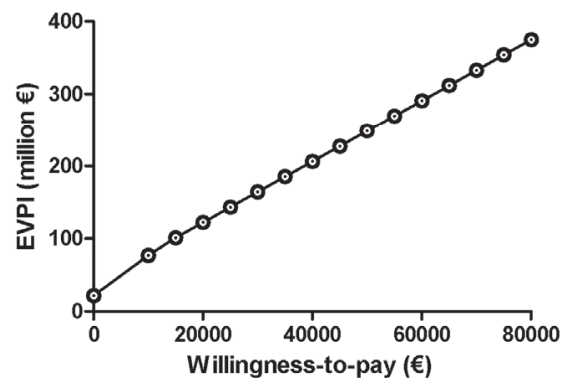

C
B

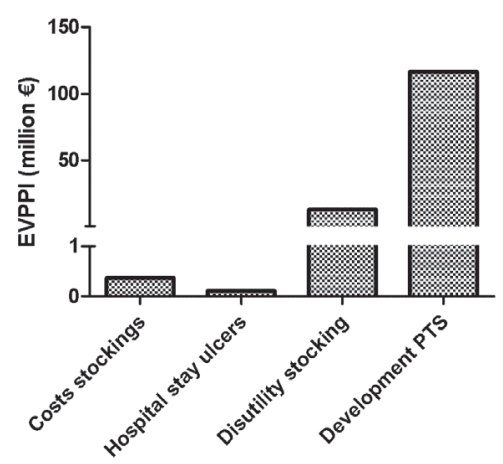

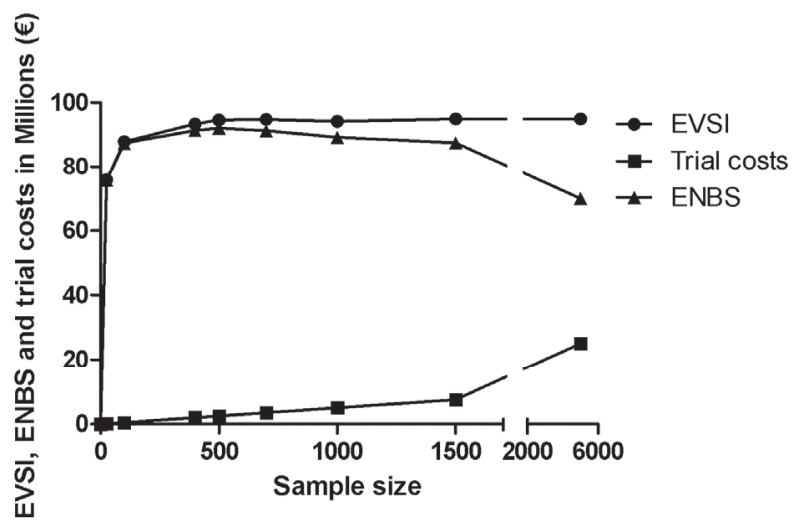

Figure 8.4 Results Value of information analyses. A)EVPI, B)EVPPI, C)EVSI and ENBS. 


\section{Discussion}

The aim of this study was to compare the conceptual and practical aspects of the frequentist approach and decision theory approach of sample size calculation for noninferiority trials, thereby demonstrating that the decision theory approach is more appropriate for sample size calculation of non-inferiority trials. The approaches differ with respect to conceptual background, analytical approach, and input requirements. The application to the case revealed that the sample size of a non-inferiority trial comparing individually tailored ECS therapy with two years ECS therapy for the prevention of PTS after DVT was 788 patients according to the frequentist approach and 500 patients according to the decision theory approach.

With regard to the conceptual background, the two approaches take a distinctly different point of view. While according to the frequentist approach the sample size that is necessary to prove non-inferiority with statistical significance is calculated, in the decision theory approach it is calculated for what sample size value of information is optimal. A number of differences in analytical approach and input requirements result from this difference in conceptual background.

There are several differences in the analytical approach. Firstly, there is a difference in the type of statistics employed to analyse the trial data. As the sample size calculation according to the frequentist approach is based on frequentist statistics; after completion of the trial the data will be analysed using frequentist statistics. In the decision theory approach a probabilistic health economic decision model is used for the sample size calculation, and consequently after completion of the trial the data will need to be analysed with a probabilistic health economic decision model. Although outcomes in health economic decision modelling are mainly composite outcomes, it is also possible to derive singular outcomes, such as the main therapeutic effect, from the analyses. Furthermore, it is also possible to exclude costs from the analyses of composite outcomes. ${ }^{40}$ However, analyses of composite outcomes including all relevant parameters are usually more informative. Secondly, the two approaches include the (difference in) main therapeutic effect between the two therapies in a different manner. In the frequentist approach, a pre-specified maximal accepted therapeutic effect loss is introduced to enable statistical testing. In the decision theory approach, a parameter indicating the uncertainty on the difference in main therapeutic outcome between the two therapies is applied. In our opinion, the method used in the decision theory approach is the better way of taking into account the expected difference in main therapeutic effect. Rather than a fixed difference, an estimate with assigned distribution is used, which yields a more accurate reflection of the uncertainty associated with the difference in main therapeutic outcome between the two therapies. Thirdly, the approaches deal differently with the uncertainty present. The frequentist approach includes the point estimate of the main therapeutic outcome, and uncertainty is reflected by the one-sided significance level and power. In order to reflect uncertainty in the decision theory approach, distributions are 
assigned to all estimates of the parameter to model the main therapeutic outcome. We feel estimates with accompanying distributions give a more genuine representation of the uncertainty, as they describe the boundaries within which the true value lies based on all current evidence.

Input requirements differ distinctively between the two approaches. Firstly, costs and health consequences, other than the main therapeutic effect, are typically not included in the frequentist approach of sample size calculation. Consequently, the frequentist sample size of non-inferiority trials can be underpowered to show a difference in the costs and other health consequences. In the decision theory approach of sample size calculation these costs and other health consequences are taken into account. Secondly, aspects of patient preferences are included in the decision theory approach of sample size calculation by inclusion of quality of life consequences associated with health states and therapies. ${ }^{41}$ It is increasingly advocated to incorporate patient preferences in clinical guidelines and healthcare policy decisions. ${ }^{41,42}$ In the frequentist approach of sample size estimation, aspects of patient preferences can only be included to the extent that this is reflected in the main therapeutic outcome. Therefore, only if a patient reported outcome (for example generic quality of life) is the main therapeutic outcome measure, patient preferences are involved. However, most clinical trials have clinical effect estimates (survival, recurrence) as the main therapeutic outcome.

Thirdly, the value of research for society is incorporated in the decision theory approach and not in the frequentist approach. Performing a clinical trial is a large investment of, usually, limited public financial resources. Researchers are obliged to use these financial resources sensibly, by prioritizing research activities and designing clinical trials conscientiously. The decision theory approach of sample size calculation is based on the economic principles of resource allocation, and therefore forms a framework of decision making based on the costs and consequences of all factors and consequences involved. Moreover, it appears unethical to expose patients to randomization in a clinical trial that has not clearly assessed its future value for society a priori.

The decision theory approach of sample size calculation is far from implemented regularly in clinical research. The frequentist approach remains the most used and therefore most accepted method of sample size calculation for non-inferiority trials. A true paradigm shift is needed to allow for the universal implementation of the decision theory approach. The reality is that scientists today are condemned to participate in competitive grant writing rounds and are judged by citation rates and impact factors, and are thereby chained to adhere to what is most accepted, in order to get their work funded or published. This hampers innovation and progress.

Besides a change in mind-set, some more practical issues demand attention before universal implementation of the decision theory approach can occur. The presumed lack of acceptability of the decision theory approach may result from a number of factors. Firstly, a probabilistic health economic decision model needs to be developed 
and comprehensive analyses need to be performed for the sample size calculation according to the decision theory approach. This is far more time-consuming than the frequentist sample size calculation. However, the time used to consult the existing literature to estimate all model parameters (i.e. treatment effects, costs of treatment, health consequences, trial costs) and their distributions seems an appropriate investment in the planning of, often very costly, RCTs. Moreover, the decision model built can be used for (cost-effectiveness) analyses at a later stage. Secondly, the technical quality of the model, as well as the appropriateness of the model structure, data sources, assumptions, and uncertainty incorporated in the model, influence the validity of the model, and hence the sample size calculation. ${ }^{43}$ It is crucial that the decision model is transparent and thoroughly validated. For a thorough validation of the model, several forms of validation should be addressed. 1) Face validity: clinical experts in the field should judge whether the model structure, data sources, problem formulation, and results fit in with the current science and evidence. 2) Internal validity: the mathematical calculations and consistency of the model should be checked and assessed, by i.e. elaborate verifications and sensitivity analyses. 3) Crossvalidation: whenever possible the model should be compared to other models which are designed to answer the same question. 4\&5) External validation and predictive validity: if feasible the results of the model should be compared to real-world data, for example the results of a clinical trial. ${ }^{43}$ The field made efforts to harmonize the methods used in cost-effectiveness modelling by making guidelines for validation. ${ }^{43,44}$ Of course, assumptions regarding for instance the non-inferiority margin, also influence the sample size estimation in the frequentist approach. However, as the decision theory approach uses much more inputs, the validity may be more easily violated, if only in perception. If so-called reference models for distinct disease areas would become freely available to researchers, this could eliminate these drawbacks. Finally, a disadvantage of the decision theory approach is that it is necessary to define a threshold: the maximum amount society is willing to pay for additional health outcomes, usually expressed in QALYs. Such a threshold is much-debated, and defining this threshold is not straightforward. ${ }^{45}$ It does however assist transparent health care policy decision making.

Despite these practical drawbacks, we argue that for non-inferiority trials the decision theory approach of sample size estimation is more appropriate than the classic frequentist approach, and we hope to initiate discussion on this important topic. 


\section{References}

1. Julious SA, Owen RJ. A comparison of methods for sample size estimation for non-inferiority studies with binary outcomes. Stat Methods Med Res 2011;20:595-612.

2. Soonawala D, Middelburg RA, Egger M, Vandenbroucke JP, Dekkers OM. Efficacy of experimental treatments compared with standard treatments in non-inferiority trials: a meta-analysis of randomized controlled trials. Int J Epidemiol 2010;39:1567-81.

3. Schumi J, Wittes JT. Through the looking glass: understanding non-inferiority. Trials 2011;12:106.

4. Laster LL, Johnson MF, Kotler ML. Non-inferiority trials: the 'at least as good as' criterion with dichotomous data. Stat Med 2006;25:1115-30.

5. Laster LL, Johnson MF. Non-inferiority trials: the 'at least as good as' criterion. Stat Med 2003;22: 187-200.

6. Blackwelder WC. "Proving the null hypothesis" in clinical trials. Control Clin Trials 1982;3:345-53.

7. Committee for Medicinal Products for Human Use (CHMP) guideline on the choice of the noninferiority margin. Stat Med 2006;25:1628-38.

8. Rothmann MD, Tsou HH. On non-inferiority analysis based on delta-method confidence intervals. J Biopharm Stat 2003;13:565-83.

9. Eckermann S, Willan AR. Expected value of information and decision making in HTA. Health Econ 2007; 16:195-209.

10. Briggs A CK, Sculpher M. Efficient research design., in Decision Modelling for Health Economic Evaluation, O.U. Press, Editor. 2006: Oxford.

11. Ades AE, Lu G, Claxton K. Expected value of sample information calculations in medical decision modeling. Med Decis Making 2004;24:207-27.

12. Claxton K, Posnett J. An economic approach to clinical trial design and research priority-setting. Health Econ 1996;5:513-24.

13. Detsky AS. Using economic analysis to determine the resource consequences of choices made in planning clinical trials. J Chronic Dis 1985;38:753-65.

14. Lindley DV. The choice of sample size. Statistician 1997(46):129-138.

15. Groot Koerkamp B, Nikken JJ, Oei EH, Stijnen T, Ginai AZ, Hunink MG. Value of information analysis used to determine the necessity of additional research: MR imaging in acute knee trauma as an example. Radiology 2008;246:420-5.

16. Grutters JP, Abrams KR, de Ruysscher D, Pijls-Johannesma M, Peters HJ, Beutner E, Lambin P, Joore MA. When to wait for more evidence? Real options analysis in proton therapy. Oncologist 2011;16:1752-61.

17. Kent S, Briggs A, Eckermann S, Berry C. Are value of information methods ready for prime time? An application to alternative treatment strategies for NSTEMI patients. Int J Technol Assess Health Care 2013;29:435-42.

18. Koerkamp BG, Spronk S, Stijnen T, Hunink MG. Value of information analyses of economic randomized controlled trials: the treatment of intermittent claudication. Value Health 2010;13:24250.

19. McKenna C, Claxton K. Addressing adoption and research design decisions simultaneously: the role of value of sample information analysis. Med Decis Making 2011;31:853-65.

20. Retel VP, Grutters JP, van Harten WH, Joore MA. Value of research and value of development in early assessments of new medical technologies. Value Health 2013;16:720-8.

21. Thariani R, Henry NL, Ramsey SD, Blough DK, Barlow B, Gralow JR, Veenstra DL. Is a comparative clinical trial for breast cancer tumor markers to monitor disease recurrence warranted? A value of information analysis. J Comp Eff Res 2013;2:325-34.

22. Welton NJ, Madan J, Ades AE. Are head-to-head trials of biologics needed? The role of value of information methods in arthritis research. Rheumatology (Oxford) 2011;50 Suppl 4:iv19-25.

23. Willan AR. Clinical decision making and the expected value of information. Clin Trials 2007;4:279-85.

24. Buxton MJ. Economic evaluation and decision making in the UK. Pharmacoeconomics 2006;24:113342. 
25. Brandjes DP, Buller HR, Heijboer $H$, Huisman MV, de Rijk M, Jagt $H$, ten Cate JW. Randomised trial of effect of compression stockings in patients with symptomatic proximal-vein thrombosis. Lancet 1997;349:759-62.

26. Prandoni $\mathrm{P}$, Lensing $\mathrm{AW}$, Prins $\mathrm{MH}$, Frulla $\mathrm{M}$, Marchiori $\mathrm{A}$, Bernardi $\mathrm{E}$, Tormene $\mathrm{D}$, Mosena $\mathrm{L}$, Pagnan A, Girolami A. Below-knee elastic compression stockings to prevent the post-thrombotic syndrome: a randomized, controlled trial. Ann Intern Med 2004;141:249-56.

27. Kahn SR, Shbaklo H, Lamping DL, Holcroft CA, Shrier I, Miron MJ, Roussin A, Desmarais S, Joyal F, Kassis J, Solymoss S, Desjardins L, Johri M, Ginsberg JS. Determinants of health-related quality of life during the 2 years following deep vein thrombosis. J Thromb Haemost 2008;6:1105-12.

28. MacDougall DA, Feliu AL, Boccuzzi SJ, Lin J. Economic burden of deep-vein thrombosis, pulmonary embolism, and post-thrombotic syndrome. Am J Health Syst Pharm 2006;63(20 Suppl 6):S5-15.

29. Naess IA, Christiansen SC, Romundstad P, Cannegieter SC, Rosendaal FR, Hammerstrom J. Incidence and mortality of venous thrombosis: a population-based study. J Thromb Haemost 2007;5:692-9.

30. Gelderblom G.J., E.A.V. Hagedoorn-Meuwissen. Kousen uittrekhulpmiddel Easy-Lever. Een onderzoek naar bruikbaarheid, effecten en belemmeringen, in opdracht van ZonMw. 2005(juni).

31. Blattler W. Aspects of cost effectiveness in therapy of acute leg/pelvic vein thrombosis. Wien Med Wochenschr 1999;149:61-5.

32. Kahn SR, Shrier I, Julian JA, Ducruet T, Arsenault L, Miron MJ, Roussin A, Desmarais S, Joyal F, Kassis J, Solymoss S, Desjardins L, Lamping DL, Johri M, Ginsberg JS. Determinants and time course of the postthrombotic syndrome after acute deep venous thrombosis. Ann Intern Med 2008;149:698-707.

33. Ten Cate-Hoek AJ, Ten Cate H, Tordoir J, Hamulyak K, Prins MH. Individually tailored duration of elastic compression therapy in relation to incidence of the postthrombotic syndrome. J Vasc Surg 2010; 52:132-8.

34. Ten Cate-Hoek AJ, Bouman AC, Joore MA, Prins M, Ten Cate H. The IDEAL DVT study, individualised duration elastic compression therapy against long-term duration of therapy for the prevention of post-thrombotic syndrome: protocol of a randomised controlled trial. BMJ Open 2014;4:e005265.

35. Buller HR, Cohen AT, Davidson B, Decousus H, Gallus AS, Gent M, Pillion G, Piovella F, Prins MH, Raskob GE. Idraparinux versus standard therapy for venous thromboembolic disease. N Engl J Med 2007;357: 1094-104.

36. Buller HR, Gallus AS, Pillion G, Prins MH, Raskob GE. Enoxaparin followed by once-weekly idrabiotaparinux versus enoxaparin plus warfarin for patients with acute symptomatic pulmonary embolism: a randomised, double-blind, double-dummy, non-inferiority trial. Lancet 2012;379:123-9.

37. Schulman S, Kearon C, Kakkar AK, Schellong S, Eriksson H, Baanstra D, Kvamme AM, Friedman J, Mismetti P, Goldhaber SZ. Extended use of dabigatran, warfarin, or placebo in venous thromboembolism. N Engl J Med 2013;368:709-18.

38. Oostenbrink JB, Koopmanschap MA, Rutten FF. Standardisation of costs: the Dutch Manual for Costing in economic evaluations. Pharmacoeconomics 2002;20:443-54.

39. Casparie AF, van Hout BA, Simoons ML. Guidelines and costs. Ned Tijdschr Geneeskd 1998;142:20757.

40. Claxton K, Griffin S, Koffijberg H, McKenna C. Expected health benefits of additional evidence: Principles, methods and applications. CHE Research Paper 83, 2013.

41. Krahn M, Naglie G. The next step in guideline development: incorporating patient preferences. Jama 2008;300:436-8.

42. Boivin A, Currie K, Fervers B, Gracia J, James M, Marshall C, Sakala C, Sanger S, Strid J, Thomas V, van der Weijden T, Grol R, Burgers J. Patient and public involvement in clinical guidelines: international experiences and future perspectives. Qual Saf Health Care 2010;19:e22.

43. Eddy DM, Hollingworth W, Caro JJ, Tsevat J, McDonald KM, Wong JB. Model transparency and validation: a report of the ISPOR-SMDM Modeling Good Research Practices Task Force--7. Value Health 2012;15:843-50.

44. Briggs AH, Weinstein MC, Fenwick EA, Karnon J, Sculpher MJ, Paltiel AD. Model parameter estimation and uncertainty: a report of the ISPOR-SMDM Modeling Good Research Practices Task Force--6. Value Health 2012;15:835-42.

45. Smith RD, Richardson J. Can we estimate the 'social' value of a QALY? Four core issues to resolve. Health Policy 2005;74:77-84. 
46. Caprini JA, Botteman MF, Stephens JM, Nadipelli V, Ewing MM, Brandt S, Pashos CL, Cohen AT. Economic burden of long-term complications of deep vein thrombosis after total hip replacement surgery in the United States. Value Health 2003;6:59-74.

47. Ramacciotti E, Gomes M, de Aguiar ET, Caiafa JS, de Moura LK, Araujo GR, Truzzi A, Dietrich-Neto F. A cost analysis of the treatment of patients with post-thrombotic syndrome in Brazil. Thromb Res 2006; 118:699-704.

48. Ten Cate-Hoek AJ, Toll DB, Buller HR, Hoes AW, Moons KG, Oudega R, Stoffers HR, van der Velde EF, van Weert HC, Prins $\mathrm{MH}$, Joore MA. Cost-effectiveness of ruling out deep venous thrombosis in primary care versus care as usual. J Thromb Haemost 2009;7:2042-9.

49. College voor zorgverzekeringen. Handleiding voor kostenonderzoek, in Methoden en standaard kostprijzen voor economische evaluaties in de gezondheidszorg 2004.

50. Kind P, Hardman G, Macran S. UK Population Norms for EQ-5D Discussion paper 172. Centre for Health Economics The University of York 1999.

51. Sullivan PW, Slejko JF, Sculpher MJ, Ghushchyan V. Catalogue of EQ-5D scores for the United Kingdom. Med Decis Making 2011;31:800-4.

52. Roberts $M$, Russell LB, Paltiel AD, Chambers M, McEwan P, Krahn M. Conceptualizing a model: a report of the ISPOR-SMDM Modeling Good Research Practices Task Force--2. Value Health 2012;15:804-11. 


\section{Appendix 8.1 supporting information}

\section{Model description}

A probabilistic state transition health economic decision model was developed to assess the lifetime consequences on costs and quality adjusted life years (QALYS) of the two therapies: individually tailored ECS therapy; and two years ECS therapy, after DVT. Patients after a first proximal DVT of the leg are included in the decision model. The decision model consists of four mutually exclusive health states. Cohort simulation was used to evaluate the decision model: each cycle a hypothetical cohort of patients moves between the health states according to a set of transition probabilities. Cycle length is six months for the first two cycles, and one year for the cycles thereafter. The time horizon of the decision model is lifelong, because PTS is a chronic condition.

The decision model was built and analyzed in Microsoft Excel 2010.

\section{Model construction}

\section{Health states}

The decision model consists of four mutually exclusive health states: No PTS, Mild to moderate PTS, Severe PTS, and Death. States 1-3 are based on the diagnosis of PTS using the Villalta score, a scoring scale used to diagnose and rate post thrombotic complaints and signs, developed by Prandoni and colleagues. ${ }^{1}$ PTS is diagnosed if the Villalta score is $\geq 5$ on two consecutive visits that are at least three months apart or a venous ulcer is present. PTS is classified as mild to moderate if the Villalta score is 514 , and severe if the Villalta score is $\geq 15$ or a venous ulcer is present. ${ }^{2}$ The final 'absorbing' state is 'death' or all-cause mortality.

\section{Strategies}

In the decision model two strategies are compared: (1) individually tailored ECS therapy, after the first 6 months duration of ECS therapy is based on the signs and symptoms of the individual patient and (2) two years ECS therapy, all patients are advised to wear the elastic compression stocking for a standard duration of two years after DVT. The difference between the two strategies was modeled by taking into account the differential impact on the probability of developing PTS, the costs of ECS (for stocking and home care for stocking application), and the disutility of ECS therapy. 


\section{Model assumptions}

The following assumptions were adopted in this health economic decision model:

- After two years no additional patients develop PTS, since only very few patients develop PTS beyond two years after DVT. ${ }^{1}$

- PTS incidence is equal in both strategies. This assumption is based on a management study in which individually tailored ECS therapy was applied in 125 patients after DVT, and appeared to generate a comparable PTS incidence as the active arm (two years ECS therapy) of previous RCTs. ${ }^{3}$

- All patients without PTS (both strategies) stop ECS therapy at two years after DVT, if they have not stopped ECS therapy yet.

- All patients with PTS (mild to moderate or severe) continue ECS therapy for the rest of their lives.

\section{Transition probabilities}

The transition probabilities for the development of PTS for each cycle were derived from an RCT by Prandoni et al., in which two years ECS therapy was compared to no ECS therapy. The 6-month, 12-month, and 24-month probability to develop PTS was extracted from this study. ${ }^{1}$ PTS incidence was assumed to be equal for individually tailored ECS therapy and two years ECS therapy, based on a management study on individually tailored ECS therapy. ${ }^{3}$ A relative risk (RR) parameter was incorporated in the decision model to represent the uncertainty of the development of PTS with individually tailored ECS therapy. A log normal distribution, with a mean of 1.000 and 95\% confidence intervals $(\mathrm{Cl})$ ranging between 1.000 and 3.316 (the standard error of the $L N(R R)$ is 0.612 ) is used. The RR parameter is multiplied with the probabilities of developing PTS after six months with individually tailored ECS therapy. The upper limit of the $95 \% \mathrm{Cl}$ corresponds with a $7.5 \%$ increase in the two year PTS incidence, representing the expected maximal increase in PTS incidence with individually tailored ECS therapy. Values of the parameter below 1 are rounded up to 1 , because we assume that individually tailored ECS therapy does not lead to a decrease in PTS incidence. For individually tailored ECS therapy, the transition probabilities for taking off the stocking and compliance of ECS therapy after six and after twelve months were derived from the results of the management study. ${ }^{3}$ For two years ECS therapy, the transition probabilities concerning compliance of ECS therapy in the two years after DVT were derived from the RCT by Prandoni et al. ${ }^{1}$

\section{Health effects}

Health-related quality of life in the form of utility scores were used as an outcome of the decision model. Utility scores provide a single index value for health status, ranging from 0 (death) to 1 (perfect health). Utility scores for the different health states were derived from literature. Patients who do not develop PTS were assumed to have an equal utility as the general population. Therefore, for the health state No 
PTS the utility was derived from age-specific EuroQol 5D (EQ-5D) utilities from the general population. ${ }^{4}$ Since no data were available on utility scores for mild to moderate and severe PTS specifically, we used utilities of conditions which are very similar to PTS. Patients with mild to moderate PTS were assumed to have a utility comparable to patients with varicose veins of the lower extremity. Patients with severe PTS were assumed to have a utility comparable to patients with a chronic ulcer of the skin. The utilities of varicose veins of the lower extremity and chronic ulcer of the skin were derived from a catalogue of EQ5D utilities from the United Kingdom. ${ }^{5}$

Since most patients experience ECS therapy as unpleasant, because stockings are itchy; warm; pinching; and difficult to apply, a disutility was assigned to ECS therapy in case PTS was not present. In literature no data were present to substantiate this disutility of ECS therapy, and therefore it was based on expert opinion.

\section{Costs}

A healthcare perspective was used. All costs were reported in Euros and price indices were used to convert the costs to the 2013 price level. As far as possible, costs were based on the Dutch manual for cost research. ${ }^{6}$ Costs of PTS were derived from literature, expert opinion, and the previously published AMUSE model. ${ }^{7-10}$

\section{Model analysis}

Distributions were assigned to the input parameters and probabilistic sensitivity analysis with 5,000 iterations was used to generate expected outcomes. Future costs and effects were discounted using a discount rate of $4 \%$ for costs and $1.5 \%$ for (quality adjusted) life years, according to Dutch guidelines. ${ }^{11}$ For both therapies (individually tailored ECS therapy and two years ECS therapy) a model was built. Total costs and QALYs were calculated for each model. Cost-effectiveness acceptability curves were calculated, for different thresholds.

Value of information analyses were performed: expected value of perfect information (EVPI) and expected value of perfect parameter information (EVPPI), for an effective population of 25,000 patients, the total yearly incidence of DVT in the Netherlands, ${ }^{12}$ over a lifetime of individually tailored ECS therapy of ten years. A threshold of $€$ 20,000 per QALY was used.

Furthermore, the optimal sample size of a future trial was evaluated, using the expected value of sampling information (EVSI) analysis and expected net benefit of sampling (ENBS). For different sample sizes ( $n=25, n=100, n=400, n=500, n=700$, $n=1000, n=1500, n=5000$ ), 200 possible trial results were simulated, using Monte Carlo simulation with 1000 iterations. Model parameters concerning the development of PTS and the relative risk parameter were updated with the simulated trial results. Subsequently the resulting EVPI per patient based on the simulated trial results was calculated. To calculate the updated population EVPI, the sample size of the trial was subtracted from the effective population, because the patients participating in the 
trial do not benefit from the additional information obtained in the trial. The EVSI is the prior EVPI (before update with simulated trial results) minus the new EVPI. Per sample size the 200 EVSI results are averaged, to obtain the mean EVSI of that sample size. For the trial we assumed a fixed cost of $€ 10,000$ and a variable cost of $€ 5000$ per included patient. The ENBS was calculated by subtracting the trial costs from the EVSI. Sensitivity analyses were performed to explore the effect of changes in the size of the effective population on the EVSI and ENBS results.

Table Appendix $1 \quad$ Input parameters model.

\begin{tabular}{|c|c|c|c|c|}
\hline Parameter & Mean & SE & Distribution & Ref \\
\hline \multicolumn{5}{|l|}{ Transition probabilities } \\
\hline Probability Mild to moderate PTS after 6 months & 0.176 & 0.046 & Beta & 1 \\
\hline Probability Mild to moderate PTS after 12 months & 0.036 & 0.047 & Beta & 1 \\
\hline Probability Mild to moderate PTS after 24 months & 0.033 & 0.045 & Beta & 1 \\
\hline Probability Severe PTS after 6 months & 0.035 & 0.018 & Beta & 1 \\
\hline Probability Severe PTS after 12 months & 0.000 & & & 1 \\
\hline Probability Severe PTS after 24 months & 0.000 & & & 1 \\
\hline Uncertainty of probability PTS & 1.000 & $0.612^{*}$ & Log normal & 1,3 e.o. \\
\hline Probability stocking off 0-6 months - individually tailored ECS & 0.197 & 0.035 & Beta & 3 \\
\hline Probability stocking off 6-12 months - individually tailored ECS & 0.488 & 0.046 & Beta & 3 \\
\hline Probability stocking off $12-24$ months - individually tailored ECS & 0.485 & 0.051 & Beta & 3 \\
\hline Compliance ECS therapy $0-6$ months - 2 years ECS & 0.018 & 0.007 & Beta & 1 \\
\hline Compliance ECS therapy 6-12 months - 2 years ECS & 0.035 & 0.014 & Beta & 1 \\
\hline Compliance ECS therapy off $12-24$ months - 2 years ECS & 0.070 & 0.027 & Beta & 1 \\
\hline \multicolumn{5}{|l|}{ Quality of life consequences } \\
\hline No PTS & \multicolumn{3}{|c|}{ Age-dependent norm utility post DVT } & 4 \\
\hline Disutility - stocking & 0.052 & & Uniform & e.o. \\
\hline Mild to moderate PTS - disutility & 0.117 & 0.050 & Beta & 5 \\
\hline Severe PTS - disutility & 0.218 & 0.040 & Beta & 5 \\
\hline \multicolumn{5}{|l|}{ Costs of treatment and costs of consequences } \\
\hline Costs stockings per year** & $€ 572$ & & & 7,9 \\
\hline Costs Mild to moderate PTS 1 st 6 months & $€ 273$ & & & $7,8,10,13$ \\
\hline Costs Mild to moderate PTS 2nd 6 months & $€ 183$ & & & $7,8,10,13$ \\
\hline Costs Mild to moderate PTS 2nd year on & $€ 183$ & & & $7,8,10,13$ \\
\hline Costs Severe PTS 1st 6 months & $€ 11,98$ & & & $7,8,10,13$ \\
\hline Costs Severe PTS 2nd 6 months & $€ 11,88$ & & & $7,8,10,13$ \\
\hline Costs Severe PTS 2nd year on & $€ 23,60$ & & & $7,8,10,13$ \\
\hline
\end{tabular}

* Standard error of LN(RR). ${ }^{* *}$ Homecare for application of stockings included for those patients who need that. DVT, deep vein thrombosis; ECS, elastic compression stocking; PTS, post thrombotic syndrome; QALY, quality adjusted life year. 


\section{References}

1. Prandoni P, Lensing AW, Prins MH, Frulla M, Marchiori A, Bernardi E, Tormene D, Mosena L, Pagnan A Girolami A. Below-knee elastic compression stockings to prevent the post-thrombotic syndrome: a randomized, controlled trial. Ann Intern Med 2004;141:249-56.

2. Kahn SR, Partsch H, Vedantham S, Prandoni P, Kearon C. Definition of post-thrombotic syndrome of the leg for use in clinical investigations: a recommendation for standardization. J Thromb Haemost 2009;7:879-83.

3. Ten Cate-Hoek AJ, Ten Cate H, Tordoir J, Hamulyak K, Prins MH. Individually tailored duration of elastic compression therapy in relation to incidence of the postthrombotic syndrome. J Vasc Surg 2010; 52:132-8.

4. Kind P, Hardman G, Macran S. UK Population Norms for EQ-5D Discussion paper 172. Centre for Health Economics The University of York 1999.

5. Sullivan PW, Slejko JF, Sculpher MJ, Ghushchyan V. Catalogue of EQ-5D scores for the United Kingdom. Med Decis Making 2011;31:800-4.

6. Oostenbrink JB, Bouwmans CAM, Koopmanschap MA, Rutten FF. Handleiding voor kostenonderzoek in Methoden en standaard kostprijzen voor economische evaluaties in de gezondheidszorg. 2004, Instituut voor Medical Technology Assessment, Erasmus MC in opdracht van College voor zorgverzekeringen: Diemen.

7. Ten Cate-Hoek AJ, Toll DB, Buller HR, Hoes AW, Moons KG, Oudega R, Stoffers HE, van der Velde EF, van Weert $\mathrm{HC}$, Prins $\mathrm{MH}$, Joore MA. Cost-effectiveness of ruling out deep venous thrombosis in primary care versus care as usual. J Thromb Haemost 2009;7:2042-9.

8. Caprini JA, Botteman MF, Stephens JM, Nadipelli V, Ewing MM, Brandt S, Pashos CL, Cohen AT. Economic burden of long-term complications of deep vein thrombosis after total hip replacement surgery in the United States. Value Health 2003; 6:59-74.

9. Gelderblom GJ, Hagedoorn-Meuwissen EAV. Kousen uittrekhulpmiddel Easy-Lever. Een onderzoek naar bruikbaarheid, effecten en belemmeringen, in opdracht van ZonMw. 2005(juni).

10. Ramacciotti E, Gomes M, de Aguiar ET, Caiafa JS, de Moura LK, Araujo GR, Truzzi A, Dietrich-Neto F. A cost analysis of the treatment of patients with post-thrombotic syndrome in Brazil. Thromb Res 2006;118:699-704.

11. Oostenbrink JB, Koopmanschap MA, Rutten FF. Standardisation of costs: the Dutch Manual for Costing in economic evaluations. Pharmacoeconomics 2002;20:443-54.

12. Naess IA, Christiansen SC, Romundstad P, Cannegieter SC, Rosendaal FR, Hammerstrom J. Incidence and mortality of venous thrombosis: a population-based study. J Thromb Haemost 2007;5: 692-9.

13. College voor zorgverzekeringen. Handleiding voor kostenonderzoek, in Methoden en standaard kostprijzen voor economische evaluaties in de gezondheidszorg 2004. 


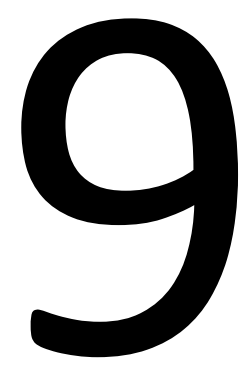

Eliciting patients' preferences for elastic compression stocking therapy in patients after deep vein thrombosis: a potential for improving compliance

AC Bouman, AJ ten Cate-Hoek, CD Dirksen, MA Joore Journal of Thrombosis and Haemostasis; accepted for publication in Nov. 2015 


\section{Abstract}

\section{Background}

Elastic compression stocking (ECS) therapy is used for prevention of post thrombotic syndrome (PTS) after deep vein thrombosis (DVT). Current evidence on its effectiveness is conflicting. Compliance, a major determinant of effectiveness of ECS therapy, remained largely ignored in former studies.

\section{Objective}

Gain insight into preferences regarding ECS therapy in patients after DVT.

\section{Methods}

A discrete choice experiment was conducted in patients three months after DVT enrolled in the IDEAL DVT study, a randomized controlled trial comparing two years ECS therapy to individually tailored duration of ECS therapy for the prevention of PTS. Nine unlabelled, forced choice sets of two hypothetical types of ECS were presented to each patient. Choice data were analysed with multinomial logit models.

\section{Results}

The respondent sample consisted of $81 \%$ (300/369) of invited patients. The most important determinants of preference were PTS risk reduction and putting on the ECS. Patients were willing to increase therapy duration with one year if this increases the PTS risk reduction with $10 \%$. Patients accepted an increase in PTS risk of $29 \%$, if they are able to put on the ECS themselves. Preferences were heterogeneous with respect to education level.

\section{Conclusion}

Risk reduction of PTS and the ability to put on the ECS without help are the most important characteristics of ECS therapy. In the medical office, physicians should pay considerable attention to patient education on PTS. In addition, patients should be supported in their ability to put on/take off the ECS independently. These rather simple interventions could improve compliance. 


\section{Introduction}

Post thrombotic syndrome (PTS) is a long-term complication of deep vein thrombosis (DVT), that occurs in $20-50 \%$ of patients, and is characterized by: debilitating complaints of the leg; oedema; skin changes; and in severe cases chronic ulceration of the leg. ${ }^{1}$ PTS is diagnosed with the Villalta scale, a scoring system consisting of subjective complaints and objective signs. ${ }^{2,3}$ Elastic compression stocking (ECS) therapy is the cornerstone of prevention of PTS after DVT of the leg. ${ }^{4,5}$ Two randomized controlled trials (RCT) demonstrated that ECS therapy for a duration of two years reduced the absolute risk of PTS with $23-39 \% .{ }^{4,5}$ However, a recent placebocontrolled trial did not find a difference in PTS incidence between active ECS and placebo ECS. ${ }^{6}$ Compliance with ECS therapy was suboptimal in the latter trial, with only $55.6 \%$ of patients wearing ECS for three or more days per week after two years. ${ }^{6}$ This contrasts the far higher compliance, up to $90 \%$ of patients reported to wear the ECS more than $80 \%$ of time during the two-year study period, of the two earlier 'positive' RCTs. ${ }^{4,5}$ Compliance may be a major determinant of effectiveness of ECS therapy. Therefore, making efforts to improve compliance to ECS therapy is worthwhile.

Patient compliance is a generic issue that affects treatment success for different disease entities and for different patient populations. ${ }^{7,8}$ In patients after DVT, compliance to ECS therapy is a trade-off between potential benefits and burden of the therapy. ECS therapy may reduce the risk of developing PTS. Over $50 \%$ of patients do not experience any complaints of the leg in the sub-acute phase after DVT. For these patients the risk of developing PTS might be hard to imagine or understand. Still, they have to endure an unpleasant therapy to decrease this risk. The ECS is tight, warm, and considered unfashionable. In addition, it is difficult to apply and take off the ECS. A subset of patients will therefore need home care to assist in the use of the ECS. ${ }^{9}$ These twice-daily home care visits involve an intrusion of patients' privacy and confine them to home while waiting for the home care worker to arrive. These might all be underlying reasons for lack of compliance to ECS therapy. In order to improve compliance, it should be assessed which factors are the main drives of (non) compliance in this particular group of patients, and how patients make trade-offs between perceived benefits and burden of ECS therapy.

To our knowledge, only two studies assessed reasons for (non) compliance to ECS therapy in patients after DVT so far. In the first study, short telephone interviews were conducted with 150 patients after DVT. All patients were asked whether ECS therapy was prescribed to them, and, if yes, how often they wore the ECS and which reasons they had for not wearing the ECS. The two most frequently reported reasons for nonregular use of ECS was difficulty in putting on the ECS and discomfort of the ECS. ${ }^{10}$ In the second study, 13 patients after DVT were asked to indicate whether they agreed or disagreed with some predefined statements on (among other things) barriers to prevent ECS use. Patients mentioned that difficulty of application of the ECS $(n=8)$, 
discomfort of the ECS $(n=4)$, and appearance of the ECS $(n=4)$ prevented them from being compliant. ${ }^{11}$

These two studies only asked a limited number of patients for reasons of not being compliant to ECS therapy. In the current study we take the issue of compliance to ECS therapy a step further, by investigating the trade-offs patients make between perceived benefits and burden of ECS therapy using discrete choice modelling.

A discrete choice experiment (DCE) is an attribute-based survey method that is based on the assumption that a healthcare intervention can be described by its characteristics (attributes) and accompanying levels. Each attribute (for example duration of therapy) has two or more levels (for example six or twelve months duration). In a DCE, series of choice sets are presented to individuals. Each choice set represents a choice between two or more alternative healthcare interventions with different combinations of attribute levels. It is assumed that respondents choose the alternative that gives them the highest personal satisfaction (utility), based on the levels of the attributes. Analysis of the resulting choice data gives information on the relative importance of the different attributes to individuals and the trade-offs individuals make between attributes. ${ }^{12}$

The aim of this study is to investigate what characteristics of ECS therapy in patients after DVT affect their preferences, and which trade-offs patients make between perceived benefits and burden of ECS therapy. In addition, we assess heterogeneity of preferences within this patient population.

The ultimate goal is to use the results of this study to improve compliance to ECS therapy in patients after DVT.

\section{Patients and methods}

\section{Establishing attributes and levels}

In a DCE, it is crucial to include all attributes that may influence the preferences of the majority of respondents, in order to get valid results. Therefore, a careful selection of attributes is essential. ${ }^{13}$ We performed semi-structured, in-depth interviews with six patients who had one or more episodes of DVT and were experience experts in ECS therapy. Several themes were elaborately discussed with all patients: how they experienced ECS therapy, advantages and disadvantages of ECS therapy, applying and taking off the ECS, compliance to ECS therapy, and costs of ECS therapy. The interviews were used to identify attributes potentially important for ECS therapy. After discussions with experts in the field, eight final attributes were selected. We grouped the attributes in benefits or burdens of therapy: 1 . PTS risk reduction (benefit), 2. reduction in current complaints (benefit), 3. comfort of wearing (burden), 4. appearance of the ECS (burden), 5. putting on the ECS (burden) 6. duration of ECS 
therapy (burden), 7. costs (burden), 8. ease of washing of the ECS (burden). The levels of the attributes were based on literature and expert opinion., ${ }^{4,5,15}$ Table 9.1 gives an overview of the attributes and levels.

Table 9.1 Attributes and levels

\begin{tabular}{|c|c|}
\hline Attributes & Levels \\
\hline \multicolumn{2}{|l|}{ Benefits of therapy } \\
\hline \multirow[t]{3}{*}{ PTS risk reduction } & Risk reduction of $20 \%$ \\
\hline & Risk reduction of $35 \%$ \\
\hline & Risk reduction of $50 \%$ \\
\hline \multirow[t]{2}{*}{ Reduction in current complaints } & Slight decrease in current complaints \\
\hline & Strong decrease in current complaints \\
\hline \multicolumn{2}{|l|}{ Burdens of therapy } \\
\hline \multirow[t]{2}{*}{ Comfort of wearing } & Warm and squeezing \\
\hline & Breathing and not squeezing \\
\hline \multirow[t]{2}{*}{ Appearance of the ECS } & Thick material and skin coloured \\
\hline & Thin material and colour of choice \\
\hline \multirow[t]{2}{*}{ Putting on the ECS } & Help needed \\
\hline & Independently \\
\hline \multirow[t]{3}{*}{ Duration of ECS therapy } & 6 months \\
\hline & 15 months \\
\hline & 24 months \\
\hline \multirow[t]{3}{*}{ Costs } & $€ 0$,- per ECS and helping aid slide \\
\hline & $€ 75$,- per ECS and helping aid slide \\
\hline & $€ 150$,- per ECS and helping aid slide \\
\hline \multirow[t]{2}{*}{ Ease of washing the ECS } & Hand washed, dries slowly \\
\hline & Machine washed, dries quickly \\
\hline
\end{tabular}

\section{Experimental design}

Ngene 1.1.1 software (Choicemetrics) was used to construct the choice sets according to a Bayesian efficient, unlabelled, forced-choice design. An efficient design maximizes the amount of information that can be obtained from the choice data, and increases the precision of the estimated effects of interest. ${ }^{12,16}$ Results of a pilot DCE in 64 subjects were used as a priori information for the utility functions of the design. ${ }^{17}$ The design was forced-choice, meaning that there was no opt-out option. The Bayesian efficient design yielded 18 choice sets, which were divided into two versions (version $A$ and $B$ ) using blocking, to reduce the number of choice sets per respondent. Versions $A$ and $B$ were equally distributed over the patients of the two treatment arms. Figure 9.1 shows an example of a choice set. 


\begin{tabular}{|c|c|c|}
\hline & ECS A & ECS B \\
\hline $\begin{array}{l}\text { Risk reduction } \\
\text { PTS }\end{array}$ & $35 \%$ & $35 \%$ \\
\hline $\begin{array}{l}\text { Reduction in } \\
\text { current } \\
\text { complaints }\end{array}$ & Slight decrease & Strong decrease \\
\hline $\begin{array}{l}\text { Comfort of } \\
\text { wearing }\end{array}$ & $\begin{array}{l}\text { Warm and } \\
\text { squeezing }\end{array}$ & $\begin{array}{l}\text { Breathing and } \\
\text { not squeezing }\end{array}$ \\
\hline Putting on & Independently & Help needed \\
\hline Appearance & $\begin{array}{l}\text { Thick material } \\
\text { and skin coloured }\end{array}$ & $\begin{array}{l}\text { Thin material } \\
\text { and colour of } \\
\text { choice }\end{array}$ \\
\hline $\begin{array}{l}\text { Duration of } \\
\text { therapy }\end{array}$ & 15 months & 15 months \\
\hline Costs & $€ 75$,- & $€ 0,-$ \\
\hline Washing & $\begin{array}{l}\text { Hand washed, } \\
\text { dries slowly }\end{array}$ & $\begin{array}{l}\text { Machine } \\
\text { washed, } \\
\text { dries quickly }\end{array}$ \\
\hline
\end{tabular}

Figure 9.1 Structure of choice set presented to patients.

\section{Questionnaire}

The questionnaire consisted of a brief introduction on the goal of the study. The questioning method was explained using a simple household example of a choice set of two coffee-makers. Subsequently, some information on PTS was given, followed by a detailed description of the attributes and levels. Nine choice sets were presented to each patient. Apart from the choice sets, patients were asked to rank the attributes in order of importance. The questionnaire ended with questions on the availability of a person (spouse, roommate, acquaintance) to help with putting on and taking off the stocking on a daily basis and the net household income. Other background information on the patients was retrieved via other questionnaires within the study. 


\section{Patients and data collection}

This DCE was executed in a subset of the study population of the IDEAL DVT study (NCT01429714). This is a randomized controlled non-inferiority trial in which a standard duration of two years ECS therapy (control, two years ECS therapy) is compared with individually tailored duration of ECS therapy (intervention, six months ECS therapy and thereafter therapy duration tailored on individual symptoms and signs) for the prevention of PTS in patients after DVT. The medical ethical committee of the Maastricht University Medical Centre approved this study, and all patients gave written informed consent. Consecutive patients with proximal DVT are being included in the IDEAL DVT study. ${ }^{18}$ In September 2013 the DCE survey was implemented in the study. Data were collected between September 2013 and May 2015. The questionnaires were sent between three and six months after DVT diagnosis. This time frame during follow-up was chosen, because duration of ECS therapy only started to differ between the patients of the two treatment arms as from six months after DVT. The questionnaire was sent to all patients by mail. Patients were asked to complete the questionnaire at home and send it back in a postage-paid envelope. Data collection was stopped as soon as 300 completed questionnaires were received. We did not perform an a priori power calculation to assess the amount of patients needed for the DCE.

\section{Data analysis}

Data were analysed with Nlogit 5.0 software (Economic Software Inc.). Multinomial logit (MNL) models were estimated to assess the influence of attribute levels on patients' preferences. These models describe the relation between personal satisfaction (utility) and the attributes. The overall level of personal satisfaction (utility $\mathrm{U})$ that is associated with a healthcare intervention (i) is determined by the different attributes and unobserved influences $(\varepsilon)^{12}$ :

$U_{i}=\beta_{1 i} \times$ PTS risk reduction $+\beta_{2 i} \times$ Reduction in current complaints $+\beta_{3 i} \times$ Comfort of wearing $+\beta_{4 i} \times$ Putting on the ECS $+\beta_{5 i} \times$ Appearance of the $E C S+\beta_{6 i} \times D$

In this model, the parameter estimates $\left(\beta_{1 i}-\beta_{8 i}\right)$ represent the size of the effect of a change in attribute level on the total level of personal satisfaction (utility). When a parameter estimate is statistically significant, a change in the level of the corresponding attribute has a significant influence on the personal satisfaction (utility), and thus on patients' preferences. The sign of the parameter estimate (+ or -) indicates whether a higher level of the attribute increases or decreases the personal satisfaction (utility). We did not include an alternative-specific constant, as this was an unlabelled DCE. ${ }^{12}$ The internal validity of the model was assessed by comparison of the sign of the parameter estimates to prior expectations. We expected that patients would prefer a higher level of PTS risk reduction, reduction in current complaints, a 
higher comfort of wearing, being able to put on the ECS independently, a nicer appearance, and being able to wash the ECS in a machine (positive sign of parameter estimate); and a shorter duration of ECS therapy, and lower costs (negative sign of parameter estimate).

The relative importance of significant attributes was assessed by calculating the partial level of personal satisfaction (parameter estimate multiplied by the range of the accompanying attribute levels), and dividing this by the total level of personal satisfaction (utility). ${ }^{19}$ Furthermore, willingness to trade efficacy of treatment or duration of therapy for a higher level of other attributes was calculated.

Mixed logit models were used to assess the presence of (unexplained) preference heterogeneity. In mixed logit models, parameter estimates are randomly drawn from a distribution multiple times. The results of these random draws are averaged to calculate estimates and standard deviations of the random parameter. If the parameter estimate for the derived standard deviation is statistically significant, this indicates that dispersion around the mean is statistically different from zero suggesting that there might be subgroups within the population that have different preferences on that particular attribute. ${ }^{12}$ Preference heterogeneity was assessed for all attributes using 1000 Halton draws from a normal distribution.

In case of preference heterogeneity of an attribute, we searched for an explanation of the heterogeneity by trying to identify subgroups with different preferences. Interaction terms of the particular attribute with socio-demographic characteristics were included in the main MNL model (Table 9.2). We additionally tested hypotheses based interactions between attributes and socio-demographic characteristics (see Appendix 9.1), as well as interactions between attributes and study treatment arm (intervention or control). All significant interactions were included in the main MNL model. Subsequently, non-significant interactions were removed from the model. This was repeated several times, to assess which interactions had the largest influence on patients' preferences.

\section{Results}

\section{Respondent characteristics}

The response rate was $81 \%$; of the 369 questionnaires that were send out 300 were completed and returned. Versions $A$ and $B$ were equally distributed over the 300 patients: of the 141 patients in the control treatment arm 73 patients (52\%) had version $A$ and 68 patients (48\%) had version $B$; and of the 159 patients in the intervention treatment arm 82 patients (52\%) had version $A$ and 77 patients $(48 \%)$ version B. Table 9.2 gives an overview of the baseline characteristics of the respondent sample. 
Table 9.2 Baseline characteristics.

\begin{tabular}{|c|c|c|c|c|}
\hline Characteristic & & $\begin{array}{l}\text { Total } \\
\text { population } \\
(n=300)\end{array}$ & $\begin{array}{l}\text { Intervention } \\
(n=159)\end{array}$ & $\begin{array}{l}\text { Control } \\
(n=141)\end{array}$ \\
\hline \multirow[t]{2}{*}{ Gender } & Male & $184(61 \%)$ & $96(60 \%)$ & $88(62 \%)$ \\
\hline & Female & $116(39 \%)$ & $63(40 \%)$ & $53(38 \%)$ \\
\hline Age (years) & Mean (SD) & $59(13)$ & $60(12)$ & $58(14)$ \\
\hline \multirow{6}{*}{ Educational level } & No education & $1(0.3 \%)$ & $0(0 \%)$ & $1(0.7 \%)$ \\
\hline & Primary education & $14(4.7 \%)$ & $10(6.3 \%)$ & $4(2.8 \%)$ \\
\hline & Secondary education & $115(38.4 \%)$ & $63(39.6 \%)$ & $52(36.9 \%)$ \\
\hline & $\begin{array}{l}\text { Secondary vocational } \\
\text { education }\end{array}$ & $52(17.3 \%)$ & $29(18.2 \%)$ & $23(16.3 \%)$ \\
\hline & Higher education & $82(27.3 \%)$ & $43(27.1 \%)$ & $39(27.7 \%)$ \\
\hline & Missing & $36(12.0 \%)$ & $14(8.8 \%)$ & $22(15.6 \%)$ \\
\hline Net family month income* & Mean (SD) & $€ 2728$ (1431) & $€ 2761$ (1615) & $€ 2693$ (1215) \\
\hline \multirow{4}{*}{$\begin{array}{l}\text { Help (spouse, roommate, } \\
\text { acquaintance) available on } \\
\text { daily basis for putting on } \\
\text { ECS }\end{array}$} & Yes & $203(68 \%)$ & 102 (64\%) & $101(72 \%)$ \\
\hline & & & & \\
\hline & No & $92(30 \%)$ & $54(34 \%)$ & $38(27 \%)$ \\
\hline & Missing & $5(2 \%)$ & $3(2 \%)$ & $2(1 \%)$ \\
\hline \multirow[t]{3}{*}{ Villalta score at 3 months } & Total score (range) & $4.2(0-18)$ & $4.1(0-17)$ & $4.2(0-18)$ \\
\hline & Subjective score (range) & $2.6(0-13)$ & $2.5(0-11)$ & $2.6(0-13)$ \\
\hline & Objective score (range) & $1.6(0-9)$ & $1.6(0-9)$ & $1.6(0-8)$ \\
\hline \multirow{3}{*}{$\begin{array}{l}\text { Compliance ECS therapy at } \\
3 \text { months }\end{array}$} & Compliant & $279(93 \%)$ & $146(92 \%)$ & $133(94 \%)$ \\
\hline & Not compliant $\%$ & $10(3 \%)$ & $6(3 \%)$ & $4(3 \%)$ \\
\hline & Unknown & $11(4 \%)$ & $7(5 \%)$ & $4(3 \%)$ \\
\hline
\end{tabular}

* Missing for 121 patients, ${ }^{\$}$ Patients report to wear the ECS every day or almost every day, ${ }^{\%}$ Patients report to wear the ECS sometimes, rarely, or never.

\section{Main effects model}

Table 9.3 presents the results of the main effects MNL model, including the relative importance of the significant attributes. The signs of the parameter estimates were in line with our prior expectations.

Significant determinants of preference were: PTS risk reduction $(0.039$ [95\% confidence interval (Cl) 0.032-0.046]), putting on the ECS (1.121 [95\% Cl 0.947-1.295]), duration of ECS therapy $(-0.034[95 \% \mathrm{Cl}-0.041--0.027])$, reduction in current complaints $(0.527$ [ $95 \% \mathrm{Cl} 0.390-0.664])$, comfort of wearing $(0.479$ [95\% Cl 0.314 $0.643])$, and ease of washing of the ECS $(0.178$ [95\% Cl 0.082-0.273]). Costs and appearance of the ECS did not significantly influence preference.

Patients were willing to increase therapy duration with one year for an additional PTS risk reduction of $10 \%$. Patients accepted an increase in PTS risk of $29 \%$, if they could put on the ECS independently. 
Table 9.3 Main effects MNL model and relative importance.

\begin{tabular}{lllll}
\hline Attributes & $\begin{array}{l}\text { Parameter } \\
\text { estimate }\end{array}$ & $\begin{array}{l}\text { 95\% confidence } \\
\text { interval }\end{array}$ & p-value & $\begin{array}{l}\text { Relative } \\
\text { importance* }\end{array}$ \\
\hline PTS risk reduction & 0.039 & $0.032-0.046$ & 0.000 & $29 \%$ \\
Putting on the ECS & 1.121 & $0.947-1.295$ & 0.000 & $27 \%$ \\
Duration of ECS therapy & -0.034 & $-0.041--0.027$ & 0.000 & $15 \%$ \\
Reduction in current complaints & 0.527 & $0.390-0.664$ & 0.000 & $13 \%$ \\
Comfort of wearing & 0.479 & $0.314-0.643$ & 0.000 & $12 \%$ \\
Ease of washing the ECS & 0.178 & $0.082-0.273$ & 0.000 & $4 \%$ \\
Appearance of the ECS & 0.023 & $-0.081-0.126$ & 0.669 & - \\
Costs & -0.002 & $-0.004-0.000$ & 0.107 & - \\
\hline Log likelihood function & -1499.38 & & & \\
\hline
\end{tabular}

*Only significant attributes are included in the calculation of the relative importance

\section{Preference heterogeneity and interactions}

Significant preference heterogeneity was only found to exist for the attribute PTS risk reduction. Interactions between PTS risk reduction and socio-demographic characteristics (Table 9.2) were tested to determine the cause of the heterogeneity.

\section{Interactions between PTS risk reduction and socio-demographic characteristics}

There was a significant interaction between PTS risk reduction and level of education (0.005 [95\% $\mathrm{Cl} 0.002-0.007])$. Patients with a higher level of education attached a higher value to the PTS risk reduction attribute. An increase in PTS risk reduction increases the total personal satisfaction (total utility) with $9 \%$ in patients with primary education, whereas this increase is $15 \%$ in patients with higher education. There was a significant interaction between PTS risk reduction and the objective Villalta score (physician assessed signs) at the time of the 3-month visit $(0.004$ [95\% Cl 0.001 0.007]). Patients with a higher objective Villalta score also attached a higher value to PTS risk reduction. In patients with an objective Villalta score of 5 (for example: moderate pretibial edema, moderate venous ectasia, and mild hyperpigmentation), an increase in PTS risk reduction increases the total personal satisfaction (total utility) with $16 \%$. In patients with an objective Villalta score of 0 (no objective signs of PTS), the total personal satisfaction (total utility) increases with only $12 \%$.

\section{Interactions based on hypotheses}

In addition some hypothesis based interactions were tested.(see Appendix 9.1) Three additional significant interactions were found. First, reduction in current complaints significantly interacted with the subjective Villalta score (patient reported symptoms) at the time of the 3-month visit $(0.052$ [95\% Cl 0.018-0.086]). Patients with a higher subjective Villalta score (more subjective complaints), more strongly preferred an ECS with a higher reduction in current complaints. For patients with a subjective Villalta score of 5 (for example: moderate pain, moderate cramps, and mild pruritus of the 
affected leg), a reduction in current complaints increases the total personal satisfaction (total utility) with $18 \%$, as opposed to an increase of $11 \%$ for patients with a subjective Villalta score of 0 (no subjective complaints of PTS). Second, patients for whom no help (spouse, roommate, acquaintance) was available on a daily basis to put on and take off the ECS, more strongly preferred an ECS that could be put on independently $(-0.496[95 \% \mathrm{Cl}-0.733-0.258])$. The total personal satisfaction (total utility) increased with $42 \%$ when the ECS could be put on independently, in patients for whom no help is available compared to a $34 \%$ increase in patients for whom help is available. Third, patients with a higher Euroqol 5D score at the time of the 3-month visit, preferred an ECS that could be put on independently more strongly $(0.952$ [95\% $\mathrm{Cl} 0.431-1.474])$. The Euroqol $5 \mathrm{D}$ is a generic health-related quality of life instrument. ${ }^{20}$ In Table 9.4 the model with interactions is presented.

There were no significant interactions between study treatment allocation and any of the attributes.

Table 9.4 MNL model with interactions.

\begin{tabular}{|c|c|c|c|}
\hline & $\begin{array}{l}\text { Parameter } \\
\text { estimate }\end{array}$ & $\begin{array}{l}95 \% \text { confidence } \\
\text { interval }\end{array}$ & $p$-value \\
\hline \multicolumn{4}{|l|}{ Attributes } \\
\hline PTS risk reduction & 0.014 & $0.001-0.026$ & 0.031 \\
\hline Putting on the ECS & 0.700 & $0.179-1.222$ & 0.009 \\
\hline Duration of ECS therapy & -0.036 & $-0.044--0.028$ & 0.000 \\
\hline Reduction in current complaints & 0.391 & $0.213-0.570$ & 0.000 \\
\hline Comfort of wearing & 0.475 & $0.288-0.662$ & 0.000 \\
\hline Ease of washing the ECS & 0.199 & $0.091-0.308$ & 0.000 \\
\hline Appearance of the ECS & 0.031 & $-0.086-0.147$ & 0.607 \\
\hline Costs & -0.002 & $-0.004-0.000$ & 0.109 \\
\hline \multicolumn{4}{|l|}{ Interaction terms } \\
\hline $\begin{array}{l}\text { PTS risk reduction } \mathrm{x} \\
\text { Education level }\end{array}$ & 0.005 & $0.002-0.007$ & 0.000 \\
\hline \multicolumn{3}{|c|}{ Help available on daily basis for putting on } & 0.000 \\
\hline \multicolumn{3}{|c|}{ Subjective Villalta score at 3 months } & 0.003 \\
\hline $\begin{array}{l}\text { PTS risk reduction } x \\
\text { Objective Villalta score at } 3 \text { mon }\end{array}$ & 0.004 & $0.001-0.007$ & 0.003 \\
\hline \multicolumn{4}{|l|}{ Euroqol 5D at 3 months } \\
\hline Log likelihood function & -1179.58 & & \\
\hline
\end{tabular}

\section{Discussion}

The aim of this study was to investigate what characteristics of ECS therapy affect preferences in patients after DVT, and which trade-offs patients make between perceived benefits and burden of ECS therapy. PTS risk reduction was the most 
important determinant of preference, followed by the ability to put on the ECS themselves (autonomy), and duration of ECS therapy.

Patients with a higher level of education had an even stronger preference for an ECS with a higher PTS risk reduction, as compared to patients with a lower level of education. It is known that patients with a higher level of education display more positive health behaviour (i.e. no smoking, less consumption of alcohol, and more physical activity) than patients with a lower level of education, in part due to more knowledge on the benefit of healthy behaviour. ${ }^{21,22}$ This highlights the importance of a careful and thorough explanation of the disease that is being prevented by the therapy, in this case PTS. In the medical office physicians could benefit from this knowledge and use it to tailor counselling based on the individual patient's needs. Another major determinant of preference was the ability to put on the ECS independently. Patients who indicated there was no help (spouse, roommate, acquaintance) available on a daily basis to put on and take off the ECS, valued the ability to put on the ECS independently higher, than patients who indicated there was other help available. There are several put-on aids on the market, that have been tested to effectively allow patients to put on or take off the ECS without help. ${ }^{9,23,24}$ In the Netherlands these put-on aids are not reimbursed and therefore not commonly used. Meanwhile home care for the application of ECS, which is far more expensive, is being reimbursed. Efforts should be made to make the most effective put-on aids (economically) available to patients. Enabling patient independence could increase compliance in these patients and at the same time induce cost savings.

Patients were also found to have a preference for a shorter duration of ECS therapy, and were willing to trade PTS risk reduction for a shorter therapy duration. Even though patients already knew to which treatment duration they were allocated at the time of the survey, preferences did not differ between the study treatment arms. Whether a shorter duration of ECS therapy provides the same benefits for the prevention of PTS still needs to be established. The final results of the IDEAL DVT study will have to be awaited to ensure the safety of individually tailored duration of ECS therapy and its eventual effect on compliance on the long term. ${ }^{18}$

The fact that ECS are reimbursed in the Netherlands might be the reason that costs did not have an influence on patients' preferences. Although patients were asked to imagine that they had to pay the ECS themselves, this hypothetical situation might have been difficult to take into account while completing the DCE questionnaires. Another explanation may be that the chosen levels for the cost attribute were considered too low to evoke meaningful trade-offs between this attribute and the others.

Some limitations of this study ought to be taken into account. First, the attribute risk reduction of PTS might not have been completely clear to all patients. Possibly, visual aids, like a graphic presentation of the risk reduction, could have increased patients' understanding and thereby increased the validity of our results. Second, this DCE was performed in a Dutch population. Because of cultural differences and differences in 
reimbursement policies of ECS therapy, not all results might be directly applicable to other countries. Third, the short time frame between the acute event of DVT and the DCE questionnaire (3-6 months) might have influenced our results. At three to six months after DVT diagnosis the amount of patients with residual complaints and signs of the leg is expected to be larger than at later points in time. This might influence patients' preferences.

Strengths of this study are that a large patient population of 300 patients was studied, enabling the assessment of interactions within a large dataset. In addition, the questionnaire yielded a very high respondent rate of $81 \%$, therefore ensuring a representative sample of the population studied. The attributes and levels, were carefully selected and elaborate pilot testing of the questionnaire in more than 60 subjects was performed. Therefore, we are confident that the most important factors that influence preferences regarding ECS therapy were included in the DCE.

Up till now, the importance of compliance for successful ECS therapy in patients after DVT has been underestimated. This patient preference study provides important insights into the considerations patients make regarding the different aspects of ECS therapy. PTS risk reduction and the ability to put on the ECS independently, were the most valued characteristics of ECS therapy for the patients in this study. Patients are willing to accept the discomfort and costs associated with ECS to reduce their risk of developing PTS in the future. However, patients were significantly willing to sacrifice risk reduction in order to have autonomy (the ability to put on the ECS themselves). Moreover, preferences were heterogeneous with respect to education level. These results stress the importance of individually tailored patient information that addresses all aspects patients regard as important. 


\section{References}

1. Prandoni P, Lensing AW, Cogo A, Cuppini S, Villalta S, Carta M, Cattelan AM, Polistena P, Bernardi E, Prins $\mathrm{MH}$. The long-term clinical course of acute deep venous thrombosis. Ann Intern Med 1996; 125: 1-7.

2. Kahn S.R., H. Partsch, S. Vedantham, P. Prandoni, C. Kearon. Definition of post-thrombotic syndrome of the leg for use in clinical investigations: a recommendation for standardization. J Thromb Haemost 2009;7:879-83.

3. Villalta S., P. Bagatella, A. Picolli, A. Lensing, M. Prins, P. Prandoni. Assessment of validity and reproducibility of a clinical scale for the post thrombotic syndrome (abstract). Haemostasis 1994: 158 .

4. Brandjes D.P., H.R. Buller, H. Heijboer, M.V. Huisman, M. de Rijk, H. Jagt, J.W. ten Cate. Randomised trial of effect of compression stockings in patients with symptomatic proximal-vein thrombosis. Lancet 1997;349:759-62.

5. Prandoni P., A.W. Lensing, M.H. Prins, M. Frulla, A. Marchiori, E. Bernardi, D. Tormene, L. Mosena, A. Pagnan, A. Girolami. Below-knee elastic compression stockings to prevent the post-thrombotic syndrome: a randomized, controlled trial. Ann Intern Med 2004;141:249-56.

6. Kahn S.R., S. Shapiro, P.S. Wells, M.A. Rodger, M.J. Kovacs, D.R. Anderson, V. Tagalakis, A.H. Houweling, T. Ducruet, C. Holcroft, M. Johri, S. Solymoss, M.J. Miron, E. Yeo, R. Smith, S. Schulman, J. Kassis, C. Kearon, I. Chagnon, T. Wong, C. Demers, R. Hanmiah, S. Kaatz, R. Selby, S. Rathbun, S. Desmarais, L. Opatrny, T.L. Ortel, J.S. Ginsberg. Compression stockings to prevent post-thrombotic syndrome: a randomised placebo-controlled trial. Lancet 2014;383:880-8.

7. Mills E.J., R. Lester, N. Ford. Promoting long term adherence to antiretroviral treatment. BMJ 2012; 344:e4173.

8. Selak V., C.R. Elley, C. Bullen, S. Crengle, A. Wadham, N. Rafter, V. Parag, M. Harwood, R.N. Doughty, B. Arroll, R.J. Milne, D. Bramley, L. Bryant, R. Jackson, A. Rodgers. Effect of fixed dose combination treatment on adherence and risk factor control among patients at high risk of cardiovascular disease: randomised controlled trial in primary care. BMJ 2014;348:g3318.

9. Gelderblom G.J., E.A.V. Hagedoorn-Meuwissen. Kousen uittrekhulpmiddel Easy-Lever. Een onderzoek naar bruikbaarheid, effecten en belemmeringen, in opdracht van ZonMw. 2005(juni).

10. Roche-Nagle G., F. Ward, M. Barry. Current prescribing patterns of elastic compression stockings postdeep venous thrombosis. Phlebology 2010;25:72-8.

11. Carolyn C. Post-thrombotic syndrome patient education based on the health belief model: selfreported intention to comply with recommendations. J Wound Ostomy Continence Nurs 2011;38: 648-54.

12. Hensher D.A., J.M. Rose, W.H. Greene. Applied choice analysis A Primer. 2005, Camebridge: Camebridge University Press.

13. Lancsar E., J. Louviere. Conducting discrete choice experiments to inform healthcare decision making: a user's guide. Pharmacoeconomics 2008;26:661-77.

14. Oostenbrink J.B., C.A.M. Bouwmans, M.A. Koopmanschap, F.F. Rutten. Handleiding voor kostenonderzoek in Methoden en standaard kostprijzen voor economische evaluaties in de gezondheidszorg. 2004, Instituut voor Medical Technology Assessment, Erasmus MC in opdracht van College voor zorgverzekeringen: Diemen.

15. Ten Cate-Hoek A.J., H. Ten Cate, J. Tordoir, K. Hamulyak, M.H. Prins. Individually tailored duration of elastic compression therapy in relation to incidence of the postthrombotic syndrome. J Vasc Surg 2010; 52:132-8.

16. Reed Johnson F., E. Lancsar, D. Marshall, V. Kilambi, A. Muhlbacher, D.A. Regier, B.W. Bresnahan, B. Kanninen, J.F. Bridges. Constructing experimental designs for discrete-choice experiments: report of the ISPOR Conjoint Analysis Experimental Design Good Research Practices Task Force. Value Health 2013;16:3-13.

17. Bliemer M.C.J., J.M. Rose, S. Hess. Approximation of bayesian efficiency in experimental choice designs. Journal of Choice Modelling 2008;1:98-126. 
18. Ten Cate-Hoek A.J., A.C. Bouman, M.A. Joore, M. Prins, H. Ten Cate. The IDEAL DVT study, individualised duration elastic compression therapy against long-term duration of therapy for the prevention of post-thrombotic syndrome: protocol of a randomised controlled trial. BMJ Open 2014

19. Malhotra N.K., D.F. Birks. Marketing research: an applied approach. 2007: Pearson Education Limited.

20. Brooks R. EuroQol: the current state of play. Health Policy 1996;37: 53-72.

21. Mechanic D., P.D. Cleary. Factors associated with the maintenance of positive health behavior. Prev Med 1980;9:805-14.

22. Winkleby M.A., D.E. Jatulis, E. Frank, S.P. Fortmann. Socioeconomic status and health: how education, income, and occupation contribute to risk factors for cardiovascular disease. Am J Public Health 1992; 82:816-20.

23. Dilks A., J. Green, S. Brown. The use and benefits of compression stocking aids. Nurs Times 2005;101: 32-4.

24. Sippel K., B. Seifert, J. Hafner. Donning devices (foot slips and frames) enable elderly people with severe chronic venous insufficiency to put on compression stockings. Eur J Vasc Endovasc Surg 2015;49:221-9. 


\section{Appendix 9.1}

Hypotheses for interactions between attributes and socio-demographic characteristics:

1. Woman more strongly prefer an ECS which can be machine washed and dries quickly.

2. Patients with a lower income more strongly prefer an ECS with lower costs.

3. Patients randomized to the control arm of the study (2 years ECS therapy) more strongly prefer an ECS with a shorter therapy duration.

4. Woman more strongly prefer an ECS with a nice appearance.

5. Patients for whom no help (spouse, roommate, acquaintance) is available on a daily basis to put on and take off the ECS, more strongly prefer an ECS that can be put on independently.

6. Younger patients more strongly prefer an ECS that they can put on independently.

7. Patients that do not receive home care to apply and take of the ECS, more strongly prefer an ECS that can be put on independently.

8. Patients with a higher EuroqoL 5D score more strongly prefer an ECS that can be put on independently.

9. Patients with a higher subjective Villalta score more strongly prefer an ECS that reduces the current complaints. 
Part III

Discussion 


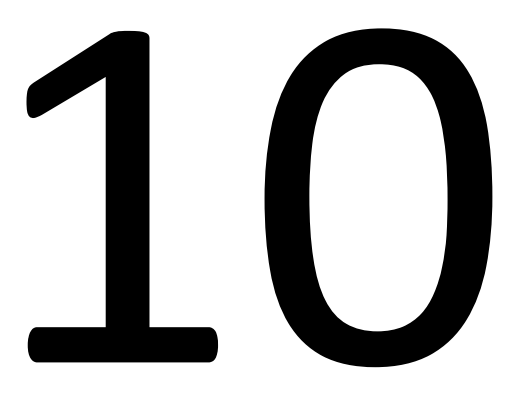

Summary and general discussion 
Chapter 10

10 
The objective of this thesis was to explore aspects of pathophysiology and personalized management of post thrombotic syndrome (PTS). In this chapter the main findings of this thesis are summarized and discussed.

\section{Pathophysiology of PTS}

In chapter 2 the relation between PTS and D-dimer, factor (F) VIII, and C-reactive protein (CRP) was investigated over time in a prospective cohort study of consecutive patients after deep vein thrombosis (DVT). All patients were followed for two years after DVT and levels of D-dimer, FVIII, and CRP were measured at three time points during follow-up (4-7, 12, and 24 months after DVT). Both D-dimer and CRP were found to be significantly higher in patients with PTS as compared to patients without PTS at twelve months after DVT. Furthermore, CRP above a cut-off of $5 \mathrm{mg} / \mathrm{l}$ at twelve months after DVT remained significantly associated with PTS, after adjustment for confounders in a multivariate logistic regression model. These findings may indicate the presence of increased inflammation in the sub-acute phase after DVT in patients with PTS, as compared to patients without PTS, either as a cause or a consequence of PTS.

In chapter 3 a systematic review and meta-analysis of the literature on biomarkers and PTS in human is presented. Pooling of three prospective cohort studies revealed a strong association between increased D-dimer levels and PTS. Increased D-dimer levels might be a reflection of hypercoagulability, which could be a causal factor in the development of PTS. However, increased D-dimer levels might also be a consequence of PTS. Markers of inflammation in relation to PTS are investigated in several studies. The studies into markers of inflammation show conflicting results: in some studies an association between inflammatory markers and PTS was found, in other studies this association was not observed. Therefore, the role of increased inflammation in the pathophysiology of PTS could neither be established nor refuted based on these results. A significant association between factor $V$ Leiden (FVL) and post thrombotic ulceration was found, after pooling of six studies that compared patients with post thrombotic ulceration to healthy controls without a history of DVT. FVL is more prevalent in DVT patients, than in subjects without a history of DVT. However, the strength of the association (OR 11.42) exceeded the expected difference in prevalence between the two populations, suggesting the existence of an actual positive association between FVL and post thrombotic ulceration. A possible explanation could be that FVL causes activated protein $C$ (APC) resistance, yielding increased thrombin generation and thus hypercoagulability. ${ }^{1}$ Additionally, in plasma of patients with $\mathrm{FVL}$, clot lysis time was previously found to be prolonged as compared to clot lysis time in wild type FV plasma, due to increased TAFI activation and increased factor (F) XIIla mediated cross-linking of $\alpha(2)$-plasmin inhibitor ( $\alpha 2-\mathrm{PI})$ to fibrin, ${ }^{2}$ resulting in a decreased rate of plasminogen activation and decreased fibrinolysis. ${ }^{2,3}$ This 
mechanism has not been described for other thrombophilic traits (i.e. prothrombin mutation, protein $\mathrm{C}$ or $\mathrm{S}$ deficiency). Associations between other thrombophilic traits and post thrombotic ulceration have not been established so far. Based on the association between FVL and post thrombotic ulceration, we presumed that not only increased thrombin generation might contribute to the development of (severe) PTS, but also impaired fibrinolysis.

The results of a case-control study are presented in chapter 4 . In this study, a panel of biomarkers identified by the systematic review presented in chapter 3 , was measured in patients after DVT who developed PTS, and compared to patients after DVT without PTS, and healthy individuals without a history of venous thromboembolism (VTE). Once more, we found indications of hypercoagulability in patients with PTS suggested by increased D-dimer levels and increased levels of thrombin:antithrombin (TAT) complexes. Furthermore, patients with PTS had a lower APC-ratio and lower proTAFI levels, than patients without PTS. A lower APC-ratio indicates increased resistance to APC, ${ }^{4,5}$ and might also impair fibrinolysis via TAFI and FXIII. ${ }^{2,6}$ As TAT complexes were higher in patients with PTS, we hypothesize that this indicates an increased conversion of proTAFI to TAFI by thrombin, yielding lower proTAFI levels. There were no differences in markers of inflammation between patients with and without PTS. This may be due to the time point of blood withdrawal, which was quite some time after DVT (median of 63 months); at that time point most inflammatory responses might already have subsided, even in the patients with PTS. We found elevated markers of endothelial activation (soluble Vascular Cell Adhesion Molecule 1 (VCAM-1), thrombomodulin (TM), von Willebrand factor (VWF), and tissueplasminogen activator (tPA)) in patients with DVT as compared to healthy individuals. These differences were subtle between the patients with and without PTS, most markers of endothelial activation tended to be lower in the patients with PTS. One possible explanation for this could be the relative exhaustion of endothelial cells as a result of chronic venous hypertension in patients with PTS. However, this hypothesis needs to be investigated.

Based on the results of both the systematic review and the case-control study we concluded that there are indications of ongoing thrombin generation either based on hypercoagulability or on on-going inflammation and endothelial perturbation in patients with PTS. We hypothesized that an impaired fibrinolysis and differences in clot structure might contribute to the development of PTS. This hypothesis was tested in chapter 5. Several functional fibrinolysis tests and confocal microscopy of the clots were performed in the subjects of the previous case-control study. Contrary to our expectations, no difference in the fibrinolytic potential was observed in the ex-vivo laboratory setting; there were no differences in clot lysis time between the patients with and without PTS. We did however find a lower maximum turbidity in patients with PTS, which could be an indication of a denser clot structure. A denser clot structure may cause a prothrombotic environment, via impaired clot lysis. ${ }^{7}$ Possibly, a denser clot structure may also induce a prothrombotic environment via interactions 
with cells and changes in elasticity. ${ }^{8,9}$ So far, solid evidence to support these hypotheses is lacking. The observed differences in clot structure might contribute to the development of PTS.

The collective objective of the studies described above was to further elucidate the pathophysiology of PTS, and to explore which etiologic entities should be investigated further. Taking all our findings into account, what progress was made in the elucidation of this complex and rather unexplored syndrome? A consistent finding in all studies was the hypercoagulable profile in patients with PTS. Studies into other etiologic entities such as inflammation, tissue remodelling, endothelial (dys) function, and fibrinolysis did not yield unequivocal results. Common denominators are small differences between patients with and without PTS and inconsistencies in findings between studies.

Patients with PTS form a very heterogeneous group. Some patients only have subjective complaints, with no or very mild objective signs. Meanwhile, other patients show objective signs, with no or very mild subjective complaints. In addition, there are patients with both subjective complaints and objective signs. On top of that, the severity of complaints and signs also differs between patients to a great extent. Nonetheless, according to current diagnostic methods this heterogeneous assembly of patients is considered one group and all patients are defined as having PTS. This begs the question whether this is in fact one group, and whether our current diagnostic methods are adequate. Diagnosis of PTS is based on the Villalta score; ${ }^{10}$ Villalta scores tend to fluctuate in a proportion of patients over time. ${ }^{11}$ In addition, the subjective complaints of the Villalta score are not very specific, and some patients do not have any objective signs. Therefore, current diagnostic methods may probably cause misclassification of patients to a certain extent. This may hamper progress in the research on the pathophysiology of PTS.

In spite of these drawbacks, the results of the studies described in part I of this thesis did yield valuable information, especially for guiding focus of future research. Fibrinolysis should be investigated further, with different assays that monitor fibrinolysis in conditions more similar to the in vivo situation. Processes of inflammation, tissue remodelling, and endothelial function should also be investigated further. As these are time-dependent processes, prospective cohort studies should be performed, in which patients are followed for some years after DVT, and biomarkers are measured at different points in time. Studies should include a substantial amount of patients, in order to have enough patients with PTS to be able to differentiate between patients with only subjective complaints or only objective signs, and between differences in PTS severity. However, such studies are time-consuming and costly and might therefore not be feasible. 


\section{Personalized management of PTS}

In chapter 6 the literature on compression therapy for the prevention of PTS was summarized.

The evidence regarding compression therapy in the acute phase after DVT is limited. The studies performed so far were small, but showed a consistent therapeutic effect of reduction in pain and swelling of the leg by inelastic compression therapy. However, these studies were not conclusive on the effectiveness of this early intervention for the prevention of PTS. ${ }^{12-15}$ The earlier established effectiveness of long-term elastic compression stocking (ECS) therapy for the prevention of PTS ${ }^{16,17}$ was questioned by a recently published trial. ${ }^{18}$ This study compared active ECS with placebo ECS in about 800 patients after DVT. No difference in PTS incidence was found between the active and placebo ECS group. ${ }^{18}$ The impact of ECS therapy on the amelioration of early leg symptoms in patients after DVT was called into question. ${ }^{19}$ Although the SOX trial was a placebo-controlled randomized trial with a large patient number and hence graded as high quality evidence, there are some important drawbacks for adopting the results of the SOX trial and abandoning ECS therapy after DVT altogether. First, compliance to ECS therapy was substantially lower in the SOX trial compared to the previous studies that showed a beneficial effect of ECS. ${ }^{16-18}$ In the studies of Brandjes et al. and Prandoni et al. 93\% and $87 \%$ of patients respectively, wore the ECS at least $80 \%$ of daytime during the two-year study period. ${ }^{16,17}$ In the study by Kahn et al., after two years, 378 patients $(69,1 \%)$ still wore the stocking of whom only 304 patients $(55,6 \%)$ wore the stocking three days or more per week. ${ }^{18}$ Second, the diagnostic methods differed between the studies, which decreases comparability and might also partly explain differences in results. Prandoni et al. uses the Villalta score to diagnose PTS, and PTS is defined as a Villalta score of $\geq 5$ on two consecutive visits that were at least three months apart. ${ }^{17}$ In the study by Brandjes et al. PTS is diagnosed using the Brandjes scale, a scoring system that is very much comparable to the first version of the Villalta scale, and diagnosis of PTS was made at six months after DVT. ${ }^{10,16}$ In the SOX trial, PTS was diagnosed using the Ginsberg criteria for the primary outcome. As a secondary outcome, diagnosis of PTS was established using the Villalta scale; PTS was defined as a single Villalta score of $\geq 5$. These two diagnostic methods yielded very different PTS incidences: $14.2 \%$ (active ECS) versus $12.7 \%$ (placebo ECS) using the Ginsberg criteria, and 52.6\% (active ECS) versus $52.3 \%$ (placebo ECS) using the Villalta scale. ${ }^{18}$

In conclusion, evidence is conflicting. So far, all studies presumed 'one size fits all' regarding ECS therapy in patients after DVT. As mentioned before, the group of patients with PTS is quite heterogeneous, and prevention of PTS should therefore take the existing differences between individuals into account. Individualized management might be the way forward. Results of a management study performed by ten CateHoek et al. suggested that duration of ECS therapy can be tailored individually without increasing PTS incidence. ${ }^{11}$ Chapter 7 is the protocol of the IDEAL DVT study, a 
randomized controlled non-inferiority trial comparing two years ECS therapy with individually tailored duration of ECS therapy. The population consists of consecutive, consenting adults with an acute objectively documented proximal DVT of the leg. Patients with a previous DVT in the affected leg, recurrent DVT in the six months following inclusion, pre-existent venous insufficiency, contraindication for ECS therapy, active thrombolysis, or limited life expectancy ( $<6$ months) are excluded. The patients are randomized to either individually tailored duration of ECS therapy or a standard duration of two years ECS therapy. Individually tailored duration of ECS therapy literally tailors the duration of ECS therapy on the symptoms and signs of PTS of the individual patient. In practice, this means that duration of ECS therapy can be six months up to two years, depending on the individual symptoms and signs of the patient at three, six, and twelve months after DVT. The primary outcome is the proportion of patients with PTS at 24 months after DVT. In order to prove with a statistical significance level of 0.05 and a power of $80 \%$ that the loss of therapeutic effect of individually tailored duration of ECS therapy compared to standard two years ECS therapy is not larger than the non-inferiority margin of 7.5\%, a sample size of 864 patients is needed. A loss to follow-up of $2 \%$ is taken into account. The secondary outcomes are health related quality of life, costs, recurrent thrombosis, VTE-related death during follow-up, and patient preferences. A trial-based and model-based costutility analysis will be performed to evaluate the cost-effectiveness of individually tailored duration of ECS therapy. The estimated sample size of 864 patients was reached in the beginning of July 2015 and the results of this study are expected by the end of 2017.

The results of the IDEAL DVT study will have to be awaited in order to confirm that individually tailored duration of ECS therapy is not inferior to two years ECS therapy, and that the expected advantages for patient and society are realised.

In chapter $\mathbf{8}$ we compared the frequentist approach of sample size estimation to the decision theory approach of sample size estimation and applied both approaches to the case of a non-inferiority trial on individually tailored duration of ECS therapy. Noninferiority trials evaluate whether a new therapy is not inferior to the standard therapy. The main reason for conducting a non-inferiority trial is when a new therapy is expected to have advantages over the standard therapy other than the main therapeutic effect, such as patient satisfaction and cost savings. Non-inferiority trials that evaluate both effectiveness and costs-effectiveness are becoming increasingly important to inform decision makers on implementing new therapies. However, the frequentist approach of sample size estimation falls short for such trials. The frequentist approach estimates the sample size that is necessary to prove noninferiority with statistical significance, using the expected success proportion of standard and new therapy, the intended power and significance level, and the noninferiority margin. ${ }^{20,21}$ The decision theory approach on the other hand estimates for what sample size value of information is optimal, using value of information analyses 
in a health economic decision model. ${ }^{22-25}$ Based on the comparison of these two approaches, we concluded that decision theory is more appropriate for sample size calculation of non-inferiority trials. The decision theory approach includes both cost and health consequences besides the main therapeutic effect, could include aspects of patient preferences, and takes the value of research for society into account. There are some practical issues that hinder the implementation of the decision theory approach, such as the need to build a health economic decision model and laborious complex analyses. Furthermore, there is some theoretical and methodological concern on implementing the decision theory approach of sample size estimation. One concern is that introducing more factors into the sample size calculation, also introduces more uncertainty, thereby potentially violating the validity of the sample size estimation. This implies that ignoring relevant factors decreases uncertainty, which appears unintuitive at the least. Another concern of the decision theory approach of sample size estimation might be that it is subject to manipulation because of the inclusion of more factors. However, transparency and thorough validation of the health economic decision model should prevent this.

Compliance and adherence may be major determinants of effectiveness of ECS therapy. In chapter 9 , the results of a discrete choice experiment (DCE) performed in 300 patients included in the IDEAL DVT study are presented. The objective of using this specific methodology of analysing choice behaviour was threefold. First, to investigate what characteristics of ECS therapy affect the preferences of patients after DVT. Second, to asses which trade-offs patients make between perceived benefits and burden of ECS therapy and third, to explore heterogeneity of preferences within the patient population.

We found that the magnitude of reduction in PTS risk the ECS generates, is the most important characteristic of ECS therapy to patients. Furthermore, patients with a higher level of education, preferred an ECS with a higher PTS risk reduction more strongly than patients with a lower level of education. These insights can be used in tailored counselling to help to improve compliance to therapy. Physicians should take time to explain what PTS is and how ECS therapy might reduce the risk of PTS, while taking into account individual preferences and beliefs. Evidence regarding the effectiveness of ECS therapy after DVT is conflicting and as a result some physicians may express doubts regarding the effectiveness of ECS therapy. Based on the result of the DCE, it can be anticipated that when the physician expresses doubts on the effectiveness of ECS therapy, the attractiveness of the therapy decreases and the odds of the patient being compliant is likely to decrease substantially.

The ability to put on and take off the ECS independently was the second most important determinant of preference. Patients were willing to trade effectiveness of therapy (PTS risk reduction), to be able to put on and take off the ECS independently. Put-on aids are tools that can be used to put on and take off the ECS. ${ }^{26-28}$ Put-on aids might help a subset of patients in gaining or keeping the ability to put on and take off 
the ECS independently. Currently, put-on aids for ECS are not reimbursed in the Netherlands; such reimbursement could increase compliance to ECS therapy and reduce costs of homecare.

Although ECS therapy does not bring any clinical harm, it is perceived as an unpleasant therapy by the majority of patients, and thereby it does cause 'well-being' harm. These factors should all be taken into consideration. Physicians are educated to judge the available evidence, assess the benefits and harms of the therapy, and base their advice to the patient thereupon. Additionally, physicians should pay attention to the perspective of the patient and his or her perception of risk reduction, burden of therapy, and autonomy. Together, patient and physician should come to the optimal treatment by 'shared decision making'.

\section{Future prospects}

In order to efficiently study the pathophysiological processes involved in the onset of PTS as described in this thesis, one of the most important additional areas for future research concerns the diagnostic strategy of PTS. Diagnosis of PTS is currently based on clinical scores combining symptoms and clinical signs, since PTS is a syndrome and there is no gold standard diagnostic test. ${ }^{10,29-31}$ Current diagnostic methods probably cause misclassification of patients to a certain extent, which hampers research into both pathophysiology and management of PTS. Possibly, the diagnostic accuracy may be improved by changing current definition and cut-off values of the Villalta score. However, a change in diagnostic methods cannot be tested against a gold standard, and therefore it is difficult to determine whether a change indeed leads to a more correct classification of patients.

Lacking a gold standard, the next best option is to correlate PTS to relevant health outcomes. During the development of the Villalta scale, the degree of interference with daily life was used to define the cut-offs for the Villalta score. ${ }^{10}$ Furthermore, several studies assessed the impact of PTS on quality of life, and reported a good correlation between the Villalta score and the disease-specific quality of life at up to two years after DVT. ${ }^{32-37}$ Disease-specific quality of life was only correlated to the presence or absence of PTS in most studies. ${ }^{32,34-36} \mathrm{~A}$ distinction between mild to moderate PTS and severe PTS was made in one study. ${ }^{33}$ So far, only one study compared (disease-specific) quality of life in patients with mild PTS to patients with no PTS. The total population consisted of 133 patients after DVT, of which $51.6 \%$ developed PTS based on a single Villalta score of $\geq 5$. At twelve months after DVT, both mild PTS $(n=38)$, and moderate to severe PTS $(n=25)$ significantly reduced (diseasespecific) quality of life, as compared to population norms. ${ }^{37}$ In future studies, it would be interesting to correlate (disease-specific) quality of life to subgroups of patients with only subjective complaints or only objective signs. In addition, as PTS is considered a chronic condition, its impact on quality of life should be present lifelong. 
It would be worthwhile to investigate whether quality of life of patients diagnosed with PTS using current diagnostic methods is still affected beyond two years after DVT. Results of such studies might give some indications on whether the current diagnostic criteria are adequate, and - if not - what changes ought to be made. It should also be assessed whether diagnosis can be made according to the current scientific and standardization committee consensus of the international society on thrombosis and haemostatis, which is based upon a single Villalta score of $\geq 5,{ }^{29}$ or whether two consecutive scores of $\geq 5$ are needed to make an accurate diagnosis. Further development of imaging tools, such as MRV, might help to substantiate diagnostics of PTS with a more objective tool.

As of yet, no definite recommendations can be made regarding the role of ECS therapy in the management of PTS. The results of the on-going IDEAL DVT study should be carefully assessed, in order to determine the role of individually tailored duration of ECS therapy.

Since patients with PTS form a heterogeneous group, personalized management might be the way forward, also for other options of PTS management, such as catheter-directed thrombolysis ${ }^{38}$ or pharmacotherapy. However, evidence of on-going studies on catheter-directed thrombolysis (CAVA study and ATTRACT trial) and future studies on pharmacotherapy is needed to substantiate such recommendations. Future trials, especially non-inferiority trials, should adopt the decision theory approach to estimate the required sample size.

Whatever the management strategy will be, attention for the patient-perspective is of utter importance. Compliance and adherence determines the success of most therapies and possibly influences research to a great extent. Future studies on PTS management should evaluate patient preferences, in order to assess which factors are important to patients, and how these factors influence compliance and adherence. These factors can be incorporated in counselling and shared decision making. 


\section{References}

1. Rosing J, Hemker HC, Tans G. Molecular biology and pathophysiology of APC resistance: current insights and clinical implications. Semin Thromb Hemost 1998;24:329-35.

2. Koncz Z, Bagoly Z, Haramura G, Mezei ZA, Muszbek L. Thrombomodulin-dependent effect of factor V Leiden mutation on the cross-linking of alpha2-plasmin inhibitor to fibrin and its consequences on fibrinolysis. Thromb Res 2012;130:528-34.

3. Leurs J, Hendriks D. Carboxypeptidase U (TAFla): a metallocarboxypeptidase with a distinct role in haemostasis and a possible risk factor for thrombotic disease. Thromb Haemost 2005;94:471-87.

4. de Visser MC, Rosendaal FR, Bertina RM. A reduced sensitivity for activated protein $C$ in the absence of factor V Leiden increases the risk of venous thrombosis. Blood 1999;93:1271-6.

5. Rodeghiero F, Tosetto A. Activated protein $C$ resistance and factor $V$ Leiden mutation are independent risk factors for venous thromboembolism. Ann Intern Med 1999;130:643-50.

6. Bajzar L, Kalafatis M, Simioni P, Tracy PB. An antifibrinolytic mechanism describing the prothrombotic effect associated with factor VLeiden. J Biol Chem 1996;271:22949-52.

7. Gabriel DA, Muga K, Boothroyd EM. The effect of fibrin structure on fibrinolysis. J Biol Chem 1992; 267:24259-63.

8. Laurens N, Koolwijk P, de Maat MP. Fibrin structure and wound healing. J Thromb Haemost 2006;4: 932-9.

9. Undas A. Fibrin clot properties and their modulation in thrombotic disorders. Thromb Haemost 2014; 112:32-42.

10. Villalta S, Bagatella P, Picolli A, Lensing A, Prins M, Prandoni P. Assessment of validity and reproducibility of a clinical scale for the post thrombotic syndrome (abstract). Haemostasis 1994(24): 158a.

11. Ten Cate-Hoek AJ, Ten Cate H, Tordoir J, Hamulyak K, Prins MH. Individually tailored duration of elastic compression therapy in relation to incidence of the postthrombotic syndrome. J Vasc Surg 2010;52: 132-8.

12. Arpaia G, Cimminiello C, Mastrogiacomo O, de Gaudenzi E. Efficacy of elastic compression stockings used early or after resolution of the edema on recanalization after deep venous thrombosis: the COM.PRE Trial. Blood Coagul Fibrinolysis 2007;18:131-7.

13. Partsch $\mathrm{H}$, Blattler $\mathrm{W}$. Compression and walking versus bed rest in the treatment of proximal deep venous thrombosis with low molecular weight heparin. J Vasc Surg 2000;32:861-9.

14. Partsch $\mathrm{H}$, Kaulich $\mathrm{M}$, Mayer W. Immediate mobilisation in acute vein thrombosis reduces postthrombotic syndrome. Int Angiol 2004;23:206-12.

15. Roumen-Klappe EM, den Heijer M, van Rossum J, Wollersheim H, van der Vleuten C, Thien $T$, Janssen MC. Multilayer compression bandaging in the acute phase of deep-vein thrombosis has no effect on the development of the post-thrombotic syndrome. J Thromb Thrombolysis 2009;27:400-5.

16. Brandjes DP, Buller HR, Heijboer $\mathrm{H}$, Huisman MV, de Rijk M, Jagt $\mathrm{H}$, ten Cate JW. Randomised trial of effect of compression stockings in patients with symptomatic proximal-vein thrombosis. Lancet 1997; 349:759-62.

17. Prandoni $P$, Lensing AW, Prins $M H$, Frulla $M$, Marchiori $A$, Bernardi $E$, Tormene $D$, Mosena $L$, Pagnan A, Girolami A. Below-knee elastic compression stockings to prevent the post-thrombotic syndrome: a randomized, controlled trial. Ann Intern Med 2004;141:249-56.

18. Kahn SR, Shapiro S, Wells PS, Rodger MA, Kovacs MJ, Anderson DR, Tagalakis V, Houweling $A H$ Ducruet T, Holcroft C, Johri M, Solymoss S, Miron MJ, Yeo E, Smith R, Schulman S, Kassis J, Kearon C, Chagnon I, Wong T, Demers C, Hanmiah R, Kaatz S, Selby R, Rathbun S, Desmarais S, Opatrny L, Ortel $\mathrm{TL}$, Ginsberg JS. Compression stockings to prevent post-thrombotic syndrome: a randomised placebocontrolled trial. Lancet 2014;383:880-8.

19. Kahn SR, Comerota AJ, Cushman M, Evans NS, Ginsberg JS, Goldenberg NA, Gupta DK, Prandoni P, Vedantham S, Walsh ME, Weitz JI. The postthrombotic syndrome: evidence-based prevention, diagnosis, and treatment strategies: a scientific statement from the American Heart Association. Circulation 2014; 130:1636-61.

20. Blackwelder WC. "Proving the null hypothesis" in clinical trials. Control Clin Trials 1982;3:345-53. 
21. Laster LL, Johnson MF, Kotler ML. Non-inferiority trials: the 'at least as good as' criterion with dichotomous data. Stat Med 2006;25:1115-30.

22. Ades $A E$, Lu G, Claxton $K$. Expected value of sample information calculations in medical decision modeling. Med Decis Making 2004;24:207-27.

23. Claxton K, Posnett J. An economic approach to clinical trial design and research priority-setting. Health Econ 1996;5:513-24.

24. Detsky AS. Using economic analysis to determine the resource consequences of choices made in planning clinical trials. J Chronic Dis 1985;38:753-65.

25. Briggs A CK, Sculpher M. Efficient research design., in Decision Modelling for Health Economic Evaluation, O.U. Press, Editor. 2006: Oxford.

26 Dilks A, Green J, Brown S. The use and benefits of compression stocking aids. Nurs Times 2005;101: 32-4.

27. Gelderblom G.J., E.A.V. Hagedoorn-Meuwissen. Kousen uittrekhulpmiddel Easy-Lever. Een onderzoek naar bruikbaarheid, effecten en belemmeringen, in opdracht van ZonMw. 2005(juni).

28. Sippel K, Seifert B, Hafner J. Donning devices (foot slips and frames) enable elderly people with severe chronic venous insufficiency to put on compression stockings. Eur J Vasc Endovasc Surg 2015;49:2219.

29. Kahn SR, Partsch H, Vedantham S, Prandoni P, Kearon C. Definition of post-thrombotic syndrome of the leg for use in clinical investigations: a recommendation for standardization. J Thromb Haemost 2009; 7: 879-83.

30. Prandoni P. The Diagnostic and Therapeutic Management of Deep-Vein Thrombosis and its Sequelae, in Department of Internal medicine. 1992, University of Amsterdam: Amsterdam.

31. Prandoni P, Lensing AW, Cogo A, Cuppini S, Villalta S, Carta M, Cattelan AM, Polistena P, Bernardi E, Prins $\mathrm{MH}$. The long-term clinical course of acute deep venous thrombosis. Ann Intern Med 1996;125: 1-7.

32. Kahn SR, Desmarais S, Ducruet T, Arsenault L, Ginsberg JS. Comparison of the Villalta and Ginsberg clinical scales to diagnose the post-thrombotic syndrome: correlation with patient-reported disease burden and venous valvular reflux. J Thromb Haemost 2006;4:907-8.

33. Kahn SR, Hirsch A, Shrier I. Effect of postthrombotic syndrome on health-related quality of life after deep venous thrombosis. Arch Intern Med 2002;162:1144-8.

34. Kahn SR, Lamping DL, Ducruet T, Arsenault L, Miron MJ, Roussin A, Desmarais S, Joyal F, Kassis J, Solymoss S, Desjardins L, Johri M, Shrier I. VEINES-QOL/Sym questionnaire was a reliable and valid disease-specific quality of life measure for deep venous thrombosis. J Clin Epidemiol 2006;59:104956.

35. Kahn SR, Shbaklo H, Lamping DL, Holcroft CA, Shrier I, Miron MJ, Roussin A, Desmarais S, Joyal F, Kassis J, Solymoss S, Desjardins L, Johri M, Ginsberg JS. Determinants of health-related quality of life during the 2 years following deep vein thrombosis. J Thromb Haemost 2008;6:1105-12.

36. van Korlaar IM, Vossen CY, Rosendaal FR, Bovill EG, Cushman M, Naud S, Kaptein AA. The impact of venous thrombosis on quality of life. Thromb Res 2004;114:11-8.

37. Roberts LN, Patel RK, Donaldson N, Bonner L, Arya R. Post-thrombotic syndrome is an independent determinant of health-related quality of life following both first proximal and distal deep vein thrombosis. Haematologica 2014;99:e41-3.

38. Watson L, Broderick C, Armon MP. Thrombolysis for acute deep vein thrombosis. Cochrane Database Syst Rev 2014;1:CD002783. 


\section{Part IV}

Addendum 
Samenvatting 
Diep veneuze trombose (DVT) van het been, in de volksmond ook wel een 'trombosebeen' genoemd, wordt veroorzaakt door een bloedstolsel in één of meerdere van de diepe aderen (venen) van het been. DVT komt voor bij 1 tot 2 per 1000 personen per jaar. Een DVT kan leiden tot een longembolie, een ernstige en potentieel dodelijke complicatie, waarbij er sprake is van een bloedstolsel in de slagaderen die het bloed naar de longen voeren. Als gevolg van een DVT kan op lange termijn post trombotisch syndroom (PTS) ontstaan. PTS is een chronische complicatie die optreedt bij $20 \%$ tot $50 \%$ van de patiënten na DVT. Patiënten met PTS houden klachten aan het been dat was aangedaan door de DVT. Zij hebben bijvoorbeeld last van een zwaar gevoel van het been, pijn, krampen, jeuk of tintelingen. Bij activiteiten zoals staan of lopen worden deze klachten over het algemeen erger. De klachten nemen af in rust. In ernstige gevallen (ongeveer 5\%) kunnen er wonden (ulcera) ontstaan aan het been; deze ulcera genezen vaak zeer moeilijk.

Men denkt dat de klachten en symptomen van PTS ontstaan door een verhoogde druk in de venen (veneuze hypertensie). Mogelijk leiden verschillende processen, in gang gezet door de initiële trombose, tot veneuze hypertensie:

1) Doordat het bloedstolsel niet volledig wordt opgelost en een deel van de vene (blijvend) blokkeert, neemt de weerstand in de vene, en daardoor de veneuze druk, toe.

2) Veneuze kleppen zorgen ervoor dat het veneuze bloed niet terugstroomt. Veneuze kleppen gaan kapot doordat ze betrokken worden in het proces van trombosering en worden aangetast door beschadigende stoffen die vrijkomen bij het oplossen van het stolsel. Door beschadiging van de kleppen wordt de terugstroom van het veneuze bloed minder goed voorkomen en stijgt de veneuze druk.

3) Ontstekingsreacties die optreden bij het oplossen van het stolsel kunnen leiden tot verlittekening van de vaatwand, waardoor deze stijver wordt en de veneuze druk toeneemt.

Hoe PTS precies ontstaat is echter nog onbekend. Ook is het niet duidelijk waarom na een DVT sommige patiënten wel en anderen geen PTS ontwikkelen.

$\mathrm{Er}$ is geen effectieve behandeling voor PTS en daarom is het van groot belang PTS te voorkomen. Patiënten wordt geadviseerd gedurende twee jaar een therapeutische elastische compressiekous (steunkous) te dragen, ter voorkoming van PTS. Vanwege tegenstrijdige resultaten van studies blijft de effectiviteit van de therapeutische elastische compressiekous een punt van discussie. Daarnaast is het de vraag of een gelijke behandeling voor elke patiënt gewenst is, of dat bijvoorbeeld de draagduur van de therapeutische elastische compressietherapie zou moeten worden gepersonaliseerd.

In dit proefschrift worden aspecten die belangrijk zijn bij het ontstaan van PTS (pathofysiologie) en aspecten van gepersonaliseerde behandeling van PTS verkend. Het proefschrift bestaat uit twee delen. Het eerste deel heeft betrekking op de pathofysiologie en het tweede deel op gepersonaliseerde behandeling. Voorafgaand 
aan deze twee delen wordt in hoofdstuk 1 het ziektebeeld PTS verder uitgediept. Er wordt ingegaan op de diagnostiek, het ontstaan, de behandeling en de preventie van PTS.

In hoofdstuk 2 wordt de relatie tussen PTS en verschillende biomarkers onderzocht. Een biomarker is een stof die een aanwijzing geeft voor het bestaan van een bepaalde ziekte, als de concentratie in het bloed (of in een ander compartiment) verhoogd of verlaagd is. In een prospectieve cohort studie werden patiënten na een DVT gedurende twee jaar gevolgd. Op drie momenten (4-7, 12, en 24 maanden na DVT) werd het bloedgehalte van D-dimeer (een afbraakproduct van bloedstolsels), factor (F) VIII (een stollingsfactor) en C-reactief proteïne (CRP, een acute fase-eiwit waarvan het bloedgehalte toeneemt bij ontsteking) gemeten. Zowel D-dimeer als CRP, gemeten 12 maanden na DVT, bleken significant hoger te zijn in het bloed van patiënten met PTS, dan in het bloed van patiënten zonder PTS. Een CRP gehalte hoger dan $5 \mathrm{mg} / \mathrm{l}$, gemeten 12 maanden na DVT, bleef geassocieerd met PTS na correctie voor beïnvloedende factoren (confounders) in een multivariaat logistisch regressie model. Deze bevindingen suggereren dat patiënten met PTS in de subacute fase na een DVT een toegenomen ontstekingsreactie hebben, in vergelijking met patiënten zonder PTS. Dit kan zowel een oorzaak als een gevolg van PTS zijn.

Hoofdstuk 3 is een systematische review en meta-analyse over biomarkers in relatie tot PTS. Op systematische wijze werd alle beschikbare wetenschappelijke literatuur over biomarkers in relatie tot PTS gezocht, beoordeeld en samengevat. Het poolen of samennemen van de resultaten van drie prospectieve cohort studies in een metaanalyse liet een sterke relatie zien tussen een verhoogd D-dimeer gehalte in het bloed en PTS. Een verhoogd D-dimeer gehalte in het bloed kan een reflectie zijn van verhoogde stolbaarheid. Deze verhoogde stolbaarheid kan een oorzaak zijn van het ontwikkelen van PTS. Echter, het verhoogde D-dimeer gehalte in het bloed kan ook een consequentie zijn van PTS, bijvoorbeeld door ontstekingsreacties die een verhoogd D-dimeergehalte induceren. Verschillende studies onderzochten de relatie tussen PTS en biomarkers van ontsteking. Deze studies hadden tegenstrijdige resultaten: sommige studies lieten een relatie tussen PTS en biomarkers van ontsteking zien, andere studies niet. Deze studies verschilden zodanig van elkaar dat we de resultaten niet konden samennemen in een meta-analyse. De exacte rol van ontsteking in de pathofysiologie van PTS kon daarom niet duidelijk worden bewezen of verworpen op basis van de huidige literatuur.

We vonden echter wel een sterke associatie tussen Factor $V$ Leiden (FVL) en post trombotische ulcera. FVL is een genetisch bepaalde afwijking van stollingsfactor $V$. Geactiveerd proteïne C (APC), een remmer van de stolling, kan het geactiveerde stollingsfactor $\mathrm{V}$ minder goed remmen in patiënten met $\mathrm{FVL}$, waardoor deze patiënten een verhoogde stolbaarheid van het bloed en een verhoogd risico op het ontwikkelen van veneuze trombose hebben. Bij het samennemen van de resultaten van zes studies vonden we een sterke associatie tussen FVL en post trombotische ulcera; dit zou kunnen betekenen dat het hebben van FVL predisponeert tot het krijgen van post 
trombotische ulcera. Mogelijk komt dit door de verhoogde stolbaarheid in patiënten met FVL. Daarnaast liet onderzoek enkele jaren geleden zien dat de afbraak van het stolsel (fibrinolyse) ook minder snel verloopt in bloed van patiënten met FVL. Wellicht spelen zowel een verhoogde stolbaarheid als een verminderde fibrinolyse een rol bij de ontwikkeling van post trombotische ulcera.

Hoofdstuk 4 beschrijft de resultaten van een case-control studie. In deze studie werden drie groepen met elkaar vergeleken: patiënten na een DVT die PTS hadden ontwikkeld, patiënten na een DVT die geen PTS hadden ontwikkeld en gezonde controles die nooit een veneuze trombose hadden doorgemaakt. In het bloed van al deze patiënten werd een panel van biomarkers gemeten. In deze studie werden wederom aanwijzingen gevonden voor een verhoogde stolbaarheid van het bloed van patiënten met PTS. Zij hadden een verhoogd D-dimeer gehalte en trombine:antitrombine (TAT) complex gehalte in hun bloed, in vergelijking met patiënten zonder PTS. Trombine is een belangrijke stollingsfactor die zorgt voor de omzetting van fibrinogeen in fibrine. Fibrine is de bouwsteen voor de uiteindelijke bloedstolsels. Antitrombine is een remmer van (onder andere) trombine; het bindt en inactiveert trombine direct. Een verhoogd TAT complex gehalte in het bloed is dus een maat voor toegenomen vorming van trombine (en inactivatie door antitrombine) en een actieve bloedstolling.

Ook vonden we een lager proTAFI (voorloper van actief TAFI) gehalte en een lagere APC-ratio bij patiënten met PTS. Bij een lagere APC-ratio worden de stollingsfactoren $V$ en VIII minder effectief geremd. Daarnaast hebben patiënten met een lagere APCratio mogelijk ook een afgenomen fibrinolyse. Het lagere proTAFI gehalte in het bloed van de patiënten met PTS wordt mogelijk veroorzaakt door een verhoogde omzetting van proTAFI naar actief TAFI. Actief TAFI remt de fibrinolyse.

In deze studie vonden we geen verschillen in ontstekingsmarkers tussen patiënten met en zonder PTS. Dit komt mogelijk doordat het moment van bloedafname voor de studie redelijk lang na het optreden van de DVT (mediaan 63 maanden) lag; op dat moment zijn de meeste ontstekingsreacties waarschijnlijk al uitgedoofd.

De binnenste laag van de bloedvatwand wordt gevormd door endotheelcellen. Biomarkers van endotheelactivatie waren hoger in het bloed van patiënten die een DVT hadden doorgemaakt dan in het bloed van gezonde controles. Binnen de groep patiënten met PTS waren de meeste biomarkers van endotheelactivatie juist lager in vergelijking met de groep patiënten zonder PTS. Deze verschillen waren echter subtiel en niet significant.

Op basis van de resultaten van zowel hoofdstuk 3 als hoofdstuk 4 werd de hypothese gevormd dat een verminderde fibrinolyse en verschillen in de structuur van het bloedstolsel mogelijk een rol zouden kunnen spelen bij het ontstaan van PTS. Deze hypothese wordt onderzocht in hoofdstuk 5. In de onderzoekspopulatie van de casecontrol studie werden verschillende functionele fibrinolysetesten uitgevoerd en werd de structuur van de bloedstolsels onderzocht. We vonden geen verschillen in snelheid van de fibrinolyse tussen de patiënten met en zonder PTS. Dit kan echter liggen aan 
het feit dat de fibrinolyse kunstmatig met een overmaat van tPA (een enzym dat een belangrijke rol speelt in de fibrinolyse) werd gestimuleerd. Wel vonden we een lagere maximale turbiditeit van stolsels van patiënten met PTS, wat een aanwijzing kan zijn voor een meer compacte structuur van het stolsel. Een stolsel met een meer compacte structuur is minder goed af te breken. Mogelijk kan een meer compacte stolselstructuur ook leiden tot een pro trombotische omgeving door interacties met cellen en veranderingen in elasticiteit. Echter, hiervoor ontbreekt nog het benodigde bewijs. De afwijkende stolselstructuur draagt mogelijk bij aan het ontstaan van PTS.

In hoofdstuk 6 wordt de literatuur over compressie therapie ter preventie van PTS samengevat. In Nederland wordt in de acute fase na een DVT over het algemeen nietelastische compressietherapie toegepast, door middel van zwachtelen of een verbandkous. Deze compressie zorgt voor een snelle afname van de zwelling van het been in de eerste weken na de DVT, alvorens een therapeutische elastische compressiekous wordt aangemeten. In hoeverre compressie in de acute fase bijdraagt aan de preventie van PTS is onbekend. In de weinige kleine onderzoeken die hiernaar zijn gedaan werd op de korte termijn een afname gezien in zowel pijn als zwelling van het been. Er werd geen effect op het optreden van PTS gevonden.

$\mathrm{Na}$ de acute fase wordt een therapeutische elastische compressiekous aangemeten. Twee grote studies, waarvan de resultaten in 1997 respectievelijk 2004 werden gepubliceerd, hebben laten zien dat het risico op PTS aanzienlijk afneemt als gedurende twee jaar na een DVT een therapeutische elastische compressiekous wordt gedragen, ten opzichte van het niet dragen van een therapeutische elastische compressiekous. Een recente studie uit Canada vond geen verschil in het optreden van PTS, bij patiënten die twee jaar een therapeutische elastische compressiekous droegen vergeleken met patiënten die twee jaar een placebo kous droegen. $\mathrm{Er}$ is echter het één en ander op deze Canadese studie af te dingen. De therapietrouw in deze studie was bijvoorbeeld veel lager dan in de eerdere twee studies, waardoor de effectiviteit van de therapeutische elastische compressiekous minder goed kan worden beoordeeld. Immers, als de therapeutische elastische compressiekous niet of nauwelijks wordt gedragen, is de effectiviteit waarschijnlijk lager, en daardoor mogelijk vergelijkbaar met de placebo kous. De boeken zijn dus nog niet gesloten over het effect van het gebruik van de therapeutische elastische compressiekous ter preventie van PTS.

Mogelijk is het niet nodig dat alle patiënten de therapeutische elastische compressiekous voor een totale duur van twee jaar dragen. In een prospectieve management cohort studie werd eerder een strategie onderzocht waarin de draagduur van de therapeutische elastische compressiekous werd geïndividualiseerd op basis van de klachten en symptomen van de individuele patiënt. In de groep patiënten die op basis van een klinische score de kous korter droeg, werd geen verhoogd risico op PTS gevonden, terwijl ongeveer $50 \%$ van de patiënten de kous minder dan twee jaar hoefde te dragen. Er zou veel geld kunnen worden bespaard 
met de toepassing van deze nieuwe strategie. De kosten op jaarbasis (in Nederland) van de therapeutische elastische compressiekousen ( $€ 2,5$ miljoen) en met name de kosten voor thuiszorg (€ 21 miljoen) zijn aanzienlijk, ondanks dat slechts een deel (ongeveer $7.5 \%$ ) van de patiënten thuiszorg nodig heeft voor het aan- en uittrekken van de kous. Een gerandomiseerde studie is nodig om de veiligheid van deze behandelstrategie aan te tonen. Hoofdstuk $\mathbf{7}$ is het protocol van de IDEAL DVT studie, een gerandomiseerde, non-inferioriteit studie waarin geïndividualiseerde draagduur van therapeutische elastische compressiekousen wordt vergeleken met een standaard draagduur van twee jaar bij patiënten na een eerste DVT. De primaire uitkomstmaat van deze studie is het optreden van PTS 24 maanden na de DVT. Als secundaire uitkomstmaten wordt er onder andere gekeken naar kwaliteit van leven, kosten en kosteneffectiviteit. Voor deze studie is een steekproefgrootte van 864 patiënten nodig. De inclusie werd in juli 2015 afgerond (865 patiënten) en de eindresultaten van deze studie worden eind 2017 verwacht.

In hoofdstuk 8 worden twee methodes om de steekproefgrootte van een noninferioriteit studie te bepalen met elkaar vergeleken. Een non-inferioriteit studie is een studie waarin wordt onderzocht of het therapeutische effect van de nieuwe behandeling niet inferieur is aan de huidige behandeling. Dergelijke studies worden vaak gedaan wanneer verwacht wordt dat een nieuwe behandeling hetzelfde therapeutische effect heeft, maar andere voordelen biedt ten opzichte van de huidige behandeling. De nieuwe behandeling is bijvoorbeeld goedkoper of heeft minder bijwerkingen.

We vergeleken de frequentistische benadering en de beslissingstheorie benadering om een steekproefgrootte te bepalen. Bij de frequentistische benadering wordt de steekproefgrootte berekend die nodig is om met een bepaalde statistische power en een bepaalde mate van statistische significantie aan te tonen dat het verlies in primaire therapeutische effectiviteit van de nieuwe behandeling ten opzichte van de huidige behandeling niet groter is dan wat maximaal acceptabel wordt geacht. De nulhypothese is in dit geval dat het verlies in primaire therapeutische effectiviteit van de nieuwe behandeling vergeleken met de huidige behandeling groter is dan wat maximaal acceptabel wordt geacht. Hoe groter de statistische power, des te groter is de kans dat deze nulhypothese op basis van de onderzoeksresultaten wordt verworpen, indien deze in werkelijkheid onwaar is. Hoe groter de statistische significantie, des te groter is de kans dat de nulhypothese op basis van de onderzoeksresultaten niet wordt verworpen, indien deze in werkelijkheid waar is. Bij de beslissingstheorie benadering wordt de steekproefgrootte bepaald waarbij het verschil tussen de kosten van het verkrijgen van meer informatie (door het doen van een studie met een bepaalde steekproefgrootte) en de waarde van de aanvullende informatie uit de studie in besluitvorming (grotere kans op een juiste beslissing) maximaal is. We concludeerden dat de beslissingstheorie benadering te prefereren valt voor het bepalen van de steekproefgrootte van een non-inferioriteit studie. Bij de beslissingstheorie benadering worden in de waarde bepaling naast het primaire 
therapeutische effect ook andere zaken meegenomen, zoals kosten, kwaliteit van leven en overleving. In non-inferioriteit studies zijn het juist deze zaken waarin de nieuwe behandeling het verschil kan maken ten opzichte van de huidige behandeling. Het is daarom van belang om deze aspecten ook in de bepaling van de steekproefgrootte mee te nemen. De frequentistische benadering is echter vooralsnog de meest toegepaste methode ten gevolge van praktische obstakels en theoretische en methodologische bezwaren die de implementatie van de beslissingstheorie benadering bemoeilijken.

Naar alle waarschijnlijkheid is therapietrouw één van de belangrijkste determinanten van effectiviteit van therapeutische elastische compressietherapie. In hoofdstuk $\mathbf{g}$ worden de resultaten van een discreet keuze experiment gepresenteerd, uitgevoerd bij 300 patiënten die deelnemen aan de IDEAL DVT studie. Een discreet keuze experiment is een methodiek waarmee keuzegedrag kan worden geanalyseerd. Deze analyse techniek, die oorspronkelijk uit de consumentenleer komt, wordt gebruikt om patiënt preferenties in de gezondheidszorg te onderzoeken. Bij een discreet keuze experiment wordt een aantal keuze scenario's aan patiënten voorgelegd, waarbij ze moeten kiezen tussen twee of meer gezondheidsinterventies. Wij lieten de patiënten kiezen tussen twee hypothetische soorten therapeutische elastische compressiekousen. In de keuze scenario's worden de gezondheidsinterventies beschreven aan de hand van kenmerken, attributen genoemd. Twee voorbeelden van attributen in het geval van de therapeutische elastische compressiekous zijn prijs en draagcomfort. Alle attributen hebben één of meerdere niveaus; de prijs kan bijvoorbeeld $€ 80$,- of $€ 100$,zijn. In elk keuze scenario wisselen de niveaus van de attributen. Bij de discreet keuze experiment analyse methodiek wordt verondersteld dat patiënten steeds de gezondheidsinterventie kiezen, die hen de hoogste mate van persoonlijke voldoening geeft. Door de keuzedata te analyseren, kan worden uitgezocht door welke attributen de keuze voor de ene of de andere gezondheidsinterventie het sterkst wordt bepaald. In deze studie vonden patiënten de mate waarin de therapeutische elastische compressiekous hun risico op PTS vermindert, het belangrijkste attribuut. Patiënten waren zelfs bereid een langere draagduur te accepteren, indien dit hun risico op PTS verder zou verlagen. Daarnaast was het kunnen aan- en uittrekken van de therapeutische elastische compressiekous zonder hulp het op één na belangrijkste attribuut voor de patiënten in deze studie. Patiënten die geen partner, huisgenoot of kennis hadden die op dagelijkse basis beschikbaar zou kunnen zijn voor het aan- en uittrekken van de therapeutische elastische compressiekous, hechtten zelfs nog meer waarde aan het zelf kunnen aan- en uittrekken van de kous en zijn bereid om daarvoor een hoger risico op PTS te riskeren. Deze bevindingen kunnen worden gebruikt om de therapietrouw van therapeutische elastische compressietherapie te verbeteren. Het is belangrijk dat artsen goed uitleggen wat PTS is en hoe het dragen van de therapeutische elastische compressiekous het risico op PTS kan verlagen. Daarnaast is het van belang om patiënten zoveel mogelijk te helpen hun autonomie te behouden. Hierbij kan men denken aan het vergoeden van hulpmiddelen voor het 
aan- en uittrekken van de kous. Dit zou mogelijk ook kosten voor thuiszorg kunnen besparen. Naast een gedegen en begrijpelijke uitleg is het belangrijk om in de spreekkamer alle aspecten van de behandeling te bespreken die voor de patiënt een rol kunnen spelen.

In hoofdstuk 10 worden de resultaten van dit proefschrift besproken en bediscussieerd. Tevens worden in dit hoofdstuk aanbevelingen gedaan voor toekomstig onderzoek. In toekomstig onderzoek naar de pathofysiologie van PTS zou de fibrinolyse bij patiënten met PTS verder moeten worden uitgediept onder omstandigheden die zoveel mogelijk overeenkomen met de werkelijke situatie in het menselijk lichaam. Daarnaast zou de rol van andere pathofysiologische processen bij PTS verder moeten worden bestudeerd. Dergelijke onderzoeken zouden in grote groepen patiënten moeten worden gedaan, die gedurende langere tijd na hun DVT worden gevolgd.

Patiënten met PTS vormen een heterogene groep, waarbij subjectieve klachten en objectieve symptomen alsook de ernst van klachten en symptomen sterk wisselt van patiënt tot patiënt. Mogelijk dat de huidige diagnostische methoden hierdoor tekort schieten en zorgen voor misclassificatie van patiënten. Dit belemmert onderzoek naar PTS. Het zou daarom zeer waardevol zijn om de diagnostiek van PTS te verbeteren.

Op basis van de resultaten van dit proefschrift kunnen geen aanbevelingen worden gedaan over de effectiviteit van de therapeutische elastische compressiekous in de preventie van de PTS. De resultaten van de IDEAL DVT studie zullen ons leren welke rol geïndividualiseerde draagduur van de therapeutische elastische compressiekous kan spelen in de preventie van PTS.

Aangezien therapietrouw een zeer belangrijk aspect is bij de effectiviteit van de meeste behandelingen, is het belangrijk om in behandelstudies ook patiënt preferenties te onderzoeken. Dit kan helpen om te achterhalen welke factoren van belang zijn voor patiënten en hoe deze factoren therapietrouw beïnvloeden. Deze factoren kunnen en moeten worden meegenomen in de gezamenlijke besluitvorming van patiënt en arts. 
Valorization 
Deep vein thrombosis (DVT) of the leg occurs in 1 to 2 per 1000 persons per year. ${ }^{1-3}$ After DVT, twenty to fifty percent of patients develop post thrombotic syndrome (PTS). ${ }^{4,5}$ PTS has a significant influence on quality of life of patients. ${ }^{6}$ In addition, costs of PTS, both healthcare costs and costs due to productivity loss, are substantial. ${ }^{7}$

This thesis is separated in two parts: pathophysiology and personalized management of PTS. Therefore, the valorization of the results will also be described in two parts.

In the first part of this thesis the pathophysiology of PTS is studied. Various biomarkers and laboratory measurements were studied in patients with PTS. Biomarkers can be used for diagnostic and prognostic purposes. Biomarkers could contribute to identifying those patients at risk of PTS. Biomarkers together with clinical risk factors could potentially be translated into a risk prediction score, which can be used to individualize management strategies.

In addition, research into the pathophysiology of disease contributes to the understanding of the disease, and may contribute to the development of new therapies. New therapies can potentially decrease the incidence of PTS and decrease the disease burden of PTS.

The results of the studies described in this thesis have added new findings to the existing body of evidence, and although it did not result in the concrete development of new therapies or risk prediction tools yet, this data can be the basis for further study on both subjects. More research is therefore needed. Future studies on the pathophysiology of PTS should include substantial numbers of patients and follow-up of these patients for longer periods of time.

The second part of this thesis is about personalized management of PTS. Currently all patients are advised to wear elastic compression stockings (ECS) for a total period of two years after DVT, to prevent PTS. Probably, not all patients will need ECS therapy for two years, and a shorter duration of therapy might be safe in a subset of patients. ${ }^{8}$ Individually tailored duration of ECS therapy is a promising new therapeutic strategy that might save substantial costs and increase patients' well-being. In the Netherlands, individually tailored duration of ECS therapy could induce cost savings of over $€ 10$ million each year. In addition, individually tailored ECS therapy might contribute to patients' well-being, as ECS therapy is considered very unpleasant by most patients.

In this thesis we compared two methods of sample size estimation for non-inferiority trials: the frequentist approach and the decision theory approach. In the decision theory approach both effects and costs are taken into account, and aspects of patient preferences can also be included. In addition, the value of research for society is taken into account in the decision theory approach, as the potential cost savings of a new therapy are compared to the costs of performing the trial. Therefore, the decision theory approach of sample size estimation might be a tool to prioritize research activities, in order to invest these financial resources wisely. Based on the findings of 
this thesis we recommend grant providers to demand the inclusion of a sample size estimation according to the decision theory approach in applications of grants for non-inferiority trials. Such implementation does need a more widespread knowledge and knowhow of the decision theory approach and decision modelling, not only for scientists that write the grant applications, but also for the experts that judge the grant applications. Besides knowhow, it would require early modelling; asking researchers to develop decision models in advance to grant applications. The development of open source reference models for distinct disease areas might help to overcome this issue.

A successful clinical trial does not always lead to an improvement in management of disease. The eventual success of management of disease depends, among other factors, on patient behaviour, as compliance and adherence to therapy determines effectiveness of therapies to a large extent. In this thesis, we studied the characteristics of ECS therapy that affect the preferences of patients after DVT and the trade-offs patients make between perceived benefits and burden of ECS therapy. PTS risk reduction was the most important determinant of preference, followed by the ability to put on and take off the ECS independently. These insights can be used by physicians to tailor counselling to improve compliance to therapy. Furthermore, based on this study we can make the recommendation that put-on aids for ECS should be made (economically) available to patients. These put-on aids can enable patients to keep their highly valued independence, which could increase compliance. In addition, costs of home care could be reduced. In general, assessment of patients' preferences should be included, when studying management of disease in clinical trials. Involving patients might increase success of clinical trials and contribute to the eventual implementation of new therapies. 


\section{References}

1. Anderson FA Jr, Wheeler HB, Goldberg RJ, Hosmer DW, Patwardhan NA, Jovanovic B, Forcier A, Dalen JE. A population-based perspective of the hospital incidence and case-fatality rates of deep vein thrombosis and pulmonary embolism. The Worcester DVT Study. Arch Intern Med 1991;151: 933-8.

2. Cogo A, Lensing AW, Prandoni $P$, Hirsh J. Distribution of thrombosis in patients with symptomatic deep vein thrombosis. Implications for simplifying the diagnostic process with compression ultrasound. Arch Intern Med 1993;153:2777-80.

3. Nordstrom M, Lindblad B, Bergqvist D, Kjellstrom T. A prospective study of the incidence of deep-vein thrombosis within a defined urban population. J Intern Med 1992;232:155-60.

4. Brandjes DP, Buller HR, Heijboer H, Huisman MV, de Rijk M, Jagt H, ten Cate JW. Randomised trial of effect of compression stockings in patients with symptomatic proximal-vein thrombosis. Lancet 1997; 349:759-62.

5. Prandoni $P$, Lensing AW, Prins $M H$, Frulla $M$, Marchiori A, Bernardi $E$, Tormene $D$, Mosena L, Pagnan A, Girolami A. Below-knee elastic compression stockings to prevent the post-thrombotic syndrome: a randomized, controlled trial. Ann Intern Med 2004;141:249-56.

6. Kahn SR, Shbaklo H, Lamping DL, Holcroft CA, Shrier I, Miron MJ, Roussin A, Desmarais S, Joyal F, Kassis J, Solymoss S, Desjardins L, Johri M, Ginsberg JS. Determinants of health-related quality of life during the 2 years following deep vein thrombosis. J Thromb Haemost 2008;6:1105-12.

7. Ashrani AA, Heit JA. Incidence and cost burden of post-thrombotic syndrome. J Thromb Thrombolysis 2009;28:465-76.

8. Ten Cate-Hoek AJ, Ten Cate H, Tordoir J, Hamulyak K, Prins MH. Individually tailored duration of elastic compression therapy in relation to incidence of the postthrombotic syndrome. J Vasc Surg 2010;52:132-8. 
Curriculum Vitae 


\section{Curriculum vitae}

Annemieke Clementine Bouman was born on April 4th 1987 in Schiedam, the Netherlands. She attended secondary education at Scholengemeenschap Spieringshoek and received her gymnasium degree in 2005, graduating cum laude. Subsequently, she studied Medicine at Maastricht University and obtained her Master's degree in 2011. From 2011 until 2015 she worked on her PhD thesis about post thrombotic syndrome. During this period, she also worked as a physician in the thrombosis outpatient clinic and the thrombosis service of the Maastricht University Medical Centre.

Currently, she works as a resident at the department of geriatrics of the Amphia hospital in Breda. 
List of publications 


\section{List of publications}

\section{Published papers}

Bouman AC, Smits JJ, ten Cate H, ten Cate-Hoek AJ. Markers of coagulation, fibrinolysis and inflammation in relation to post-thrombotic syndrome. Journal of Thrombosis and Haemostasis. 2012;10(8):1532-8.

van der Meijden PE, Bouman AC, Feijge MA, van Oerle R, Spronk HM, Hamulyák K, ten Cate-Hoek AJ, ten Cate $\mathrm{H}$, Heemskerk JW. Platelet dysfunction in thrombosis patients treated with vitamin $K$ antagonists and recurrent bleeding. PLoS One. 2013;8(5):e64112.

Bouman AC, Atalay S, ten Cate $\mathrm{H}$, ten Wolde M, ten Cate-Hoek AJ. Biomarkers for post-thrombotic syndrome. Journal of Vascular Surgery: Venous and Lymphatic Disorders 2014;2(1):79-88.

Bouman AC, Cheung YW, Spronk HM, Schalkwijk CG, ten Cate $\mathrm{H}$, ten Wolde $\mathrm{M}$, ten Cate-Hoek AJ. Biomarkers for post thrombotic syndrome: a case-control study. Thrombosis Research. 2014;134(2):369-75.

Bouman AC, ten Cate-Hoek AJ. Timing and duration of compression therapy after deep vein thrombosis. Phlebology. 2014;29(1 suppl):78-82.

ten Cate-Hoek AJ, Bouman AC, Joore MA, Prins $M$, ten Cate $H$, IDEAL DVT trial investigators. The IDEAL DVT study, individualised duration elastic compression therapy against long-term duration of therapy for the prevention of post-thrombotic syndrome: protocol of a randomised controlled trial. BMJ Open. 2014;4(9):e005265.

Bouman AC, ten Cate-Hoek AJ, Ramaekers BL, Joore MA. Sample Size Estimation for Non-Inferiority Trials: Frequentist Approach versus Decision Theory Approach. PLoS One. 2015;10(6):e0130531.

ten Cate-Hoek AJ, Weitz JI, Gailani D, Meijer K, Philippou H, Bouman AC, Whitney Cheung Y, van Mens TE, Govers-Riemslag JW, Vries M, Bleker S, Biedermann JS, Stoof SC, Buller HR. Theme 3: Non-invasive management of (recurrent) venous thromboembolism (VTE) and post thrombotic syndrome (PTS). Thrombosis Research. 2015;136 Suppl 1:S13-8.

Bouman AC, McPherson $\mathrm{H}$, Cheung $\mathrm{YW}$, ten Wolde $\mathrm{M}$, ten Cate $\mathrm{H}$, Ariëns RA, ten CateHoek AJ. Clot structure and fibrinolytic potential in patients with post thrombotic syndrome. Thrombosis Research. 2015 Nov. 
AC Bouman, AJ ten Cate-Hoek, CD Dirksen, MA Joore. Eliciting patients' preferences for elastic compression stocking therapy in patients after deep vein thrombosis: a potential for improving compliance. Journal of Thrombosis and Haemostasis. Accepted for publication 2015 Nov.

\section{Oral and poster presentations}

Bouman AC, Smits JJ, Ten Cate H, Ten Cate-Hoek AJ. Markers of coagulation, fibrinolysis and inflammation in relation to post-thrombotic syndrome. Nederlandse vereniging voor Trombose en Hemostase (NVTH) symposium, Koudekerke, the Netherlands 2012 (oral presentation)

Bouman AC, Smits JJ, Ten Cate H, Ten Cate-Hoek AJ. Markers of coagulation, fibrinolysis and inflammation in relation to post-thrombotic syndrome. Scientific and Standardization Committe (SSC) meeting, Liverpool, UK, 2012 (poster presentation)

Bouman AC, Atalay S, ten Cate $\mathrm{H}$, ten Wolde M, ten Cate-Hoek AJ. Biomarkers for post-thrombotic syndrome. International Society on Thrombosis and Haemostasis (ISTH) congress, Amsterdam, the Netherlands, 2013 (poster presentation)

Bouman AC, Cheung YW, Spronk HM, Schalkwijk CG, ten Cate $\mathrm{H}$, ten Wolde $\mathrm{M}$, ten Cate-Hoek AJ. Biomarkers for post thrombotic syndrome: a case-control study. ISTH congress, Amsterdam, the Netherlands, 2013 (poster presentation)

Bouman AC, ten Cate-Hoek AJ, ten Cate H, Joore MA. Individually tailored elastic compression therapy for the prevention of post thrombotic syndrome: Assessing the value of further research. International Society for Pharmacoeconomics and Outcomes Research (ISPOR) congress Dublin, Ireland, 2013 (poster presentation)

Bouman AC, McPherson $\mathrm{H}$, Cheung YW, ten Wolde $\mathrm{M}$, ten Cate $\mathrm{H}$, Ariëns RA, ten CateHoek AJ. Clot structure and fibrinolytic potential in patients with post thrombotic syndrome. ISTH congress, Toronto, Canada 2015 (poster presentation)

Bouman AC, ten Cate-Hoek AJ, Dirksen CD, Joore MA for the IDEAL investigators Eliciting patients' preferences for elastic compression stocking therapy in patients after deep vein thrombosis: a potential for improving compliance. ISTH congress, Toronto, Canada 2015 (poster presentation)

\section{Awards}

Award of Excellence - NVTH, NVTH symposium, Koudekerke, the Netherlands (April 2012)

Young investigator award - ISTH, SSC meeting, Liverpool, UK (July 2012) 
Dankwoord 


\section{Dankwoord}

Zonder de hulp en steun van velen, op zowel professioneel als persoonlijk vlak, zou dit proefschrift niet tot stand zijn gekomen. Ik wil daarom iedereen bedanken die op welke wijze dan ook een bijdrage heeft geleverd! Een heel aantal mensen wil ik echter graag met naam en toenaam vermelden.

Professor dr. ten Cate, beste Hugo, dank voor de kans om als zesdejaars geneeskundestudent een onderzoeksstage (WESP) te mogen doen in jouw onderzoeksgroep. In een aantal maanden heb ik kennis mogen maken met de verschillende facetten van het doen van onderzoek en dit heeft mijn enthousiasme voor het onderzoek aangewakkerd. Dankjewel voor de mogelijkheden die je me vervolgens tijdens mijn promotietijd hebt geboden om naast het onderzoek ook poli te doen en te werken als doseerarts bij de trombosedienst. Deze waardevolle ervaringen kan ik meenemen in mijn verdere carrière. Dank voor jouw bijdrage in je rol als promotor en supervisor. Ik kon altijd aankloppen met vragen en dan nam jij altijd rustig de tijd om naar mijn vraag te luisteren en advies te geven. Jouw rust en vriendelijkheid zijn uniek en heb ik de afgelopen jaren enorm gewaardeerd.

Dr. ten Cate-Hoek, beste Arina, dank voor de mogelijkheid om als promovendus te komen werken aan de IDEAL studie. Ik heb het als een voorrecht ervaren om mee te mogen werken aan dit interessante en gevarieerde project, dat jouw geesteskind is en dat jij samen met velen vanaf de grond hebt opgebouwd. Dankjewel voor de tijd en aandacht die je als copromotor altijd hebt genomen om me te begeleiden. Slechts bij grote uitzondering kon ons wekelijkse overleg niet doorgaan en altijd nam je ruim de tijd om de lopende zaken te bespreken en mijn vragen te beantwoorden. Ook kreeg ik van jou binnen de kortste keren duidelijke feedback op de stukken die ik je toestuurde. Ik heb heel veel van je geleerd en jouw inzet voor mijn promotietraject heeft er mede voor gezorgd dat ik mijn proefschrift binnen vier jaar af heb kunnen krijgen. Dankjewel voor alle kansen die je me in de afgelopen vier jaar hebt geboden: alle congressen die ik heb mogen bezoeken en de verschillende cursussen die ik heb kunnen volgen. Dankjewel voor het vertrouwen dat je in me hebt gesteld voor het runnen van de IDEAL studie, dat na vier jaar ook een beetje mijn kindje is geworden. Naast het werk had je ook altijd een warme belangstelling voor mijn privé leven en op de verschillende tripjes in binnen- en buitenland hebben we heel wat afgekletst. Ik wens jou en Hugo alle goeds toe, en weet zeker dat jouw enthousiasme en inzet de afronding van de IDEAL studie tot een groot succes zullen maken.

Dr. Joore, beste Manuela, dankjewel voor de mogelijkheid die jij me hebt geboden om als arts een blik in de keuken te werpen van de health technology assessment, waarbij ik twee dagen per week deel mocht uitmaken van de ontzettend gezellige afdeling Kemta. Zoals ik in stelling 7 poneer, denk ik dat het voor iedere arts waardevol is om 
iets over gezondheidseconomie te leren. Dankjewel voor jouw waardevolle bijdrage als copromotor in de begeleiding van mijn promotietraject. De duidelijke manier waarop jij dingen uitlegt, waarbij je vaak in jouw karakteristieke handschrift een mooi overzicht maakt, heeft mij veel geleerd, evenals de zeer gestructureerde manier van denken die jij toepast. Dank voor jouw humor en nuchtere kijk op zaken.

Graag wil ik ook de leden van de beoordelingscommissie bedanken, dr. Essers, professor Huisman, professor Meijer, professor Steijlen, onder de bezielende leiding van professor Boonen, dank voor het lezen en beoordelen van mijn proefschrift.

Gedurende de afgelopen vier jaar ben ik bij de uitvoering van de IDEAL studie geholpen door drie onderzoeksassistentes, die mij veel werk uit handen hebben genomen. Marianne Nelis, beste Marianne, dank voor de ontzettend fijne samenwerking, waarbij ik altijd kon rekenen op jouw onverminderde inzet, punctualiteit en warmte. Het was een feestje om met jou samen te werken! Annemieke Lindl, beste Annemieke, dank voor jouw hulp en efficiëntie. Roos van Gorp, beste Roos, dankjewel voor jouw hulp tijdens de laatste maanden van mijn promotietraject, waarbij jij me al snel enorm ontlastte, zodat ik mij kon focussen op het afronden van mijn proefschrift.

Michelle Balink, beste Michelle, dank voor jouw hulp op de vrijdagen in het afgelopen jaar.

Ook wil ik alle artsen en onderzoeksassistenten van de verschillende ziekenhuizen die meedoen aan de IDEAL studie bedanken. Saskia Middeldorp, Whitney Cheung, Mandy Lauw, Selma Atalay, Michiel Cuppens, Marije ten Wolde, Simone van den Heiligenberg, Karina Meijer, Saskia Walstra, Lidwine Tick, Martin Nijziel, Marleen Bax, Sandra Silvis, Sanne van Wissen, Wim Terpstra, Yvette Henstra, Judith Westra, Edith Klappe, Mirian Janssen, Hans-Martin Otten, Olga Ternede, Guy Mostard, Asiong Jie, Catherine Combee, Alex Patty, Erik Serné, Herman Hofstee en Marlène van de Poel, dank voor de fijne samenwerking de afgelopen jaren! I would also like to thank the Italian participators of the IDEAL study from Padua and Treviso. Paolo Prandoni, Valentina Valdevetto and Sabina Villalta, thank you for the cooperation, thanks for the warm welcome when we visited Padua. Grazie!

In de afgelopen vier jaar heb ik mogen samenwerken met verschillende co-auteurs, die allen op verschillende manieren hebben bijgedragen aan de artikelen zoals ze nu in dit boekje staan. In chronologie van de hoofdstukken: Jacqueline Smits, Selma Atalay, Marije ten Wolde, Whitney Cheung, Henri Spronk, Casper Schalkwijk, Helen McPherson, Robert Ariëns, Martin Prins, Bram Ramaekers, Carmen Dirksen. Dank voor jullie hulp! Jacqueline, dankjewel voor jouw hulp en enthousiasme tijdens de maanden dat je als student-assistent betrokken was bij het onderzoek. Marije, dankjewel voor jouw begeleiding en enthousiasme bij de review en case-control 
studie. Whitney, bedankt voor de goede en gezellige samenwerking de afgelopen jaren. Heel veel succes bij het afronden van jouw proefschrift! Henri, dank voor jouw input en altijd kritische vragen. Helen, thanks for all the labour you did in the lab, and thanks for the cooperation on the article on clot structure. Robert Ariëns, dankjewel voor jouw hulp bij het artikel over stolselstructuur, dank dat je ervoor zorgde dat alle samples in jouw lab konden worden doorgemeten en dank voor jouw adviezen.

Bram, dank voor jouw hulp bij het modelleren en uitvoeren van ingewikkelde EVSI analyses. Met vragen kon ik bij jou terecht en altijd had je een antwoord. Dank voor jouw gezelligheid als kamergenoot bij Kemta!

Professor Dirksen, beste Carmen, dank voor jouw begeleiding en hulp bij het uitvoeren van de patiënt preferentie studie. Dank voor de tijd die je hebt genomen om de modellen in Ngene te maken en te helpen met de analyses in Nlogit. Dank voor je kritische blik bij het proces van het schrijven van hoofdstuk 9.

Ook wil ik graag alle patiënten en deelnemers van de verschillende onderzoeken bedanken. Zonder patiënten geen klinisch onderzoek; de participatie en bereidwilligheid tot het doneren van enkele buisjes bloed, het invullen van (lange) vragenlijsten en het geven van interviews zijn onmisbaar. Oneindig veel dank hiervoor!

Graag wil ik alle medewerkers van de vakgroep biochemie bedanken voor de goede sfeer op de afdeling en de praktische hulp. Professor Hackeng, beste Tilman, jou wil ik in het bijzonder bedanken voor jouw rol als voorzitter van de vakgroep biochemie.

Trees, dankjewel voor jouw hulp bij het versturen van alle brieven aan de Minderbroerdersberg. Lidewij, dank voor je hulp bij allerhande praktische zaken. Bedankt voor gezellige kletspraatjes en serieuzere gesprekken.

Collega's en oud-collega's van het Laboratory for Clinical Thrombosis and Haemostasis, dank voor jullie hulp, dank voor de gezelligheid! Patricia, Diane en Stefanie, dank voor het doormeten van vele samples. René, dankjewel voor jouw praktische adviezen en hulp. Paola, bedankt voor jouw begeleiding bij mijn eerste stapjes in het onderzoek tijdens mijn WESP stage. Bedankt ook voor de gezelligheid zowel binnen als buiten kantoortijd.

Collega's en oud-collega's van Kemta, dank voor jullie hulp, dank voor de gezelligheid! Brigitte, dank dat ik altijd bij jou binnen mocht lopen voor vragen over (onder andere) de DCE. Irene, dankjewel voor jouw praktische hulp bij allerhande zaken.

Zowel bij de biochemie als bij Kemta heb ik het geluk gehad steeds een kamer te mogen delen met gelijkgestemden met wie ik 'promotie lief en leed' kon delen. Bram, Denise, Geert-Jan, Iris, Jana, Jelle, Jill, Joke, Minka, Mirjam, Pieter, Rachel, Sanne en Suzanne. Dank voor de gezellige tijd, dank ook voor jullie luisterend oor. 
Minka, dankjewel dat je mij bij wil staan als paranimf. Dankjewel voor jouw hulp bij het organiseren van deze dag. Je bent rustig en slim, en weet in je onderzoek snel tot de kern van de zaak te komen. Ik weet daarom zeker dat het met jouw proefschrift helemaal goed komt!

Tijdens de afgelopen vier jaar heb ik als doseerarts bij de trombosedienst gewerkt. Ik wil alle medewerkers van de trombosedienst bedanken voor de ontzettend fijne tijd! Beste Jolanda en Loes, bedankt voor de fijne samenwerking, ik heb ervan genoten! Dr. Hamulyák, beste Karly, dank voor het overleg over doseren en patiënt gerelateerde zaken.

Tiny, dankjewel voor jouw onmisbare hulp bij het opmaken van mijn proefschrift.

Ik mag mij gelukkig prijzen met lieve vriendinnen die zorgen voor de benodigde afleiding. Vanaf het eerste uur: Maaike (van Paridon) en mijn nichtje Lotje; vriendinnen van de middelbare school en daarvoor: Hannah, Jiska, Lisenka, Maaike (de Kruik), Marieke en Yukari; mijn vriendinnen van JC Harrie: Berb, Eva, Inge, Maud, Prisca en Saar; alle meiden van Candor en Vulptur en in het bijzonder Annelieke, Carlijn, Hanneke, Irene, Jilde, Josee, Marija, Renée en Sandra. Dank voor jullie vriendschap!

Jilde, dankzij jou heb ik de liefde van mijn leven ontmoet, daar zal ik je altijd dankbaar voor zijn!

$\mathrm{Nu}$ dit boekje af is heb ik binnenkort weer meer tijd om met jullie allemaal af te spreken en bij te kletsen!

Familie en familievrienden, dank voor jullie interesse en steun in de afgelopen jaren.

Lieve Johan en Lieneke, dank voor de warmte waarmee jullie mij als schoondochter in jullie gezin hebben opgenomen. Ik voel me altijd enorm welkom en het is een voorrecht jullie schoondochter te mogen zijn. Dank voor jullie oprechte interesse in mijn onderzoek en de vele gesprekken over werk en heel veel meer.

Lieve Arne en Willemijn, ondanks de grote afstand tussen Zwolle en Maastricht (inmiddels Breda) staan jullie altijd klaar om te helpen bij klussen, verhuizingen, winterbanden en fietsmontages. Dank voor al jullie hulp, maar ook dank voor de gezellige etentjes, fietsweekendjes en wintersportvakanties.

Dear Arie and Eileen, unfortunately the distance between New York and the Netherlands is too far to see each other more often. However, this makes me cherish the moments together even more! Lieve Arie, mijn grote broer, dankjewel voor jouw hulp bij het ontwerpen en maken van de voorkant van dit proefschrift, daardoor zijn jij en Eileen er toch een beetje bij vandaag. 
Lieve Maria, al van jongs af aan bewonder ik jou, mijn grote zus. Ik ben daarom ook heel blij dat jij me vandaag bij wil staan als paranimf. Dankjewel voor jouw steun in goede en slechte tijden, dankjewel voor de gesprekken over de telefoon of tijdens weekendjes in het zuiden of noorden van het land.

Lieve Jan, mijn grote kleine broertje. Dankjewel voor jouw humor en gezelligheid en de levendige discussies die jij aan tafel aanwakkert.

Lieve papa en mama, dank voor jullie onvoorwaardelijke steun en liefde. Jullie hebben mij het vertrouwen gegeven dat ik veel meer kan dan ik zelf denk en daar ben ik jullie dankbaar voor. Ik hou van jullie!

Lieve Niek, zonder jou had ik hier nu zeker niet gestaan. Dankjewel voor jouw onvoorwaardelijke liefde en steun! Jij droogt mijn tranen als ik het even niet meer zie zitten en staat me altijd bij met raad en daad. Dankjewel voor het lezen en nakijken van artikelen, voor het bekijken van presentaties, voor alle lekkere maaltijden en natuurlijk voor de heerlijke tijd die we samen doorbrengen. Dankjewel voor wie je bent! Mijn lief, ik hou oneindig veel van jou!

Annemieke 
